\title{
The role of phospholipases in atherosclerosis
}

Citation for published version (APA):

Ghesquiere, S. A. I. (2006). The role of phospholipases in atherosclerosis. [Doctoral Thesis, Maastricht University]. Universitaire Pers Maastricht. https://doi.org/10.26481/dis.20060607sg

Document status and date:

Published: 01/01/2006

DOI:

$10.26481 /$ dis.20060607sg

Document Version:

Publisher's PDF, also known as Version of record

\section{Please check the document version of this publication:}

- A submitted manuscript is the version of the article upon submission and before peer-review. There can be important differences between the submitted version and the official published version of record.

People interested in the research are advised to contact the author for the final version of the publication, or visit the DOI to the publisher's website.

- The final author version and the galley proof are versions of the publication after peer review.

- The final published version features the final layout of the paper including the volume, issue and page numbers.

Link to publication

\footnotetext{
General rights rights.

- You may freely distribute the URL identifying the publication in the public portal. please follow below link for the End User Agreement:

www.umlib.nl/taverne-license

Take down policy

If you believe that this document breaches copyright please contact us at:

repository@maastrichtuniversity.nl

providing details and we will investigate your claim.
}

Copyright and moral rights for the publications made accessible in the public portal are retained by the authors and/or other copyright owners and it is a condition of accessing publications that users recognise and abide by the legal requirements associated with these

- Users may download and print one copy of any publication from the public portal for the purpose of private study or research.

- You may not further distribute the material or use it for any profit-making activity or commercial gain

If the publication is distributed under the terms of Article $25 \mathrm{fa}$ of the Dutch Copyright Act, indicated by the "Taverne" license above, 


\section{The role of phospholipases in atherosclerosis}


The studies presented in this thesis were performed at the Department of Molecular Genetics, Cardiovascular Research Institute Maastricht, Maastricht University (CARIM), The Netherlands

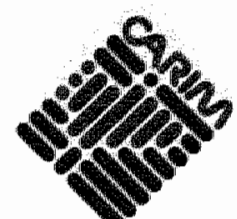

(c) Stijn A. I. Ghesquiere, Maastricht 2006

ISBN-10: 90-5278-530-9

ISBN-13: 978-90-5278-530-1

Datawyse / Universitaire Pers Maastricht 


\section{The role of phospholipases in atherosclerosis}

\section{Proefschrift}

Ter verkrijging van de graad van doctor aan de Universiteit Maastricht, op gezag van de Rector Magnificus, Prof. Mr. G.P.M.F. Mols, volgens het besluit van het College van Decanen, in het openbaar te verdedigen op woensdag 7 juni 2006 om 14.00 uur

door

Stijn Albert Irena Ghesquiere

Geboren te Leiden op 29 september 1973

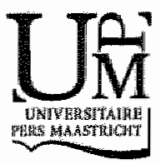




\section{Promotor:}

Prof. dr. M. H. Hofker

\section{Co-Promotor:}

Dr. M. P. J. de Winther

\section{Beoordelingscommissie:}

Prof, dr W. A. Buurman (voorzitter)

Prof dr. Berit Johansen

Prof. dr. G. Kraal

Dr. C. P. M. Reutelingsperger

Prof. dr. A. M. W. J. Schols

The studies presented in this thesis were supported by the Dutch Organization for Scientific Research (NWO 902-26-194). Printing of this thesis was financially supported by the Dr. Ir. van de Laar Stichting, Heerlen and Hope Farms / abdiets, Woerden. 


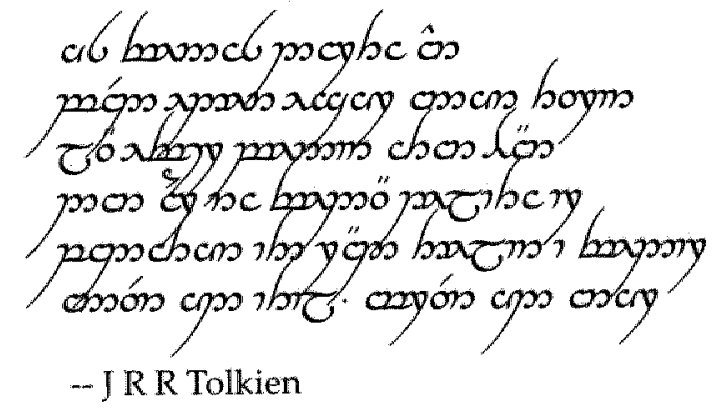





\section{Content}

Chapter 1

General introduction

Chapter 2

The role of phospholipases $A_{2}$ in lipid modification and atherosclerosis

Chapter 3

Macrophage specific overexpression of group IIA sPLA increases atherosclerosis and enhances collagen deposition

Chapter 4

75

Secretory Phospholipase $\mathrm{A}_{2}$ group $X$ expression mediates foam cell formation and inhibits lipopolysaccharide induced activation of murine macrophages.

Chapter 5

Phospholipase group $X$ overexpression induces fatal

pulmonary inflammation and protein accumulation in mice.

Chapter 6

Phospholipase expression in different stages of human atherosclerotic lesions.

Chapter 7

General discussion

Summary

Samenvatting

Dankwoord / Acknowledgements

Curriculum vitae 



\section{Chapter 1}

\section{General introduction}




\section{History}

Atherosclerosis is progressive disease, which is characterized by thickening and loss of elasticity of the arterial walls. The underlying initiating biological mechanism is the accumulation of low-density lipoprotein (LDL) in the arterial wall. This triggers an inflammatory reaction, followed by lesion formation and eventually a whole myriad of processes takes place, leading to the development of a complicated disease. While atherosclerosis is often considered a 'modern' disease as a result of our life style and feeding habits, a short introduction through the discovery of atherosclerosis teaches us that it is in fact not a "new' disease.

Throughout a large part of history, atherosclerosis was not recognized as a life threatening disease. Pathological complications seldom develop before the fourth decade of life, an age seldom exceeded $(1,2)$, which made atherosclerosis a rather rare disease. However, a better control of infectious diseases over the last century resulted in increased life expectancy. In combination with changes in dietary habits, this resulted in an increased prevalence of cardiovascullar failures. At a certain point, atherosclerosis became epidemic in western societies and developed into a major cause of death. However, atherosclerosis is not a recent phenomenon. Atherosclerotic lesions have been discovered in 3500-year-old Egyptian mummies (3). In the antiquity, Hippokrates ( $460-377$ b.c.) mentions sudden death, probably caused by myocardial infarction (4). Erasistratos ( -300 b.c.) described claudication intermittent, a condition originating in peripheral artery disease. Despite all this, understanding of the origin, the pathology and its importance in the circulatory system was very limited.

The centuries between the ancient Greeks and the late medieval times are marked by absence of new discoveries. No significant progression was made in the scientific understanding until the onset of the Renaissance. At that time, more attention

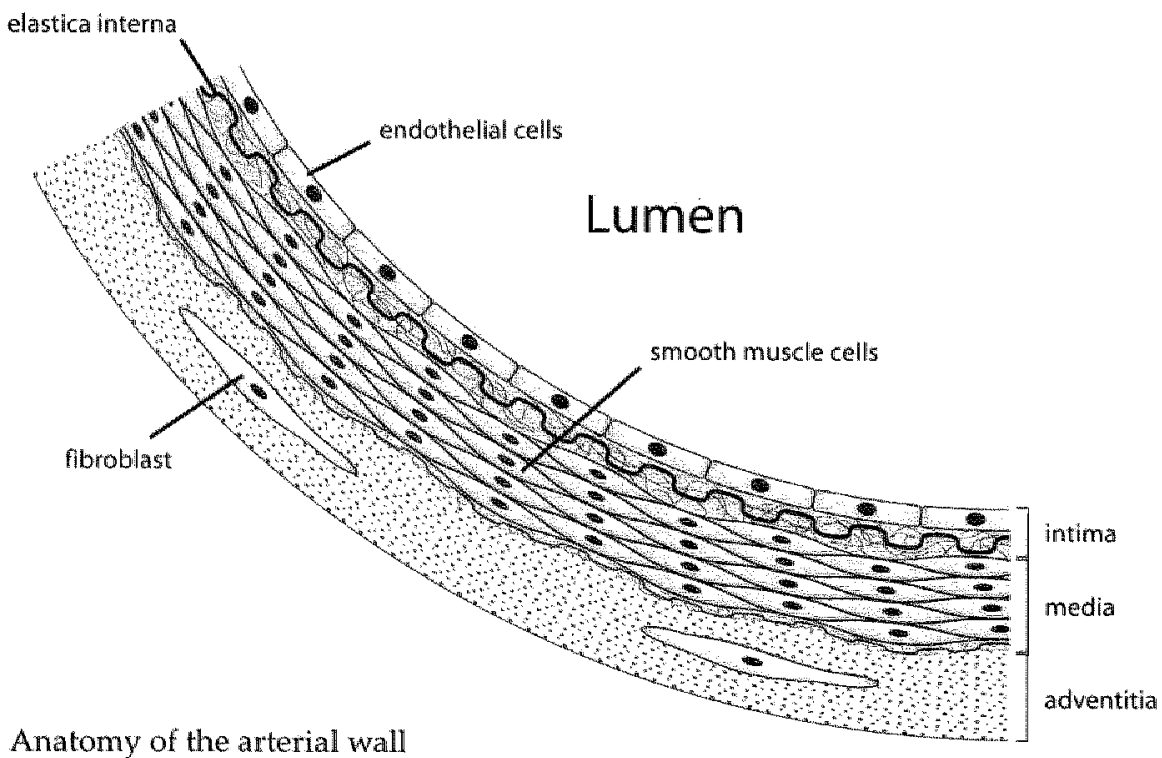

Fig. 1. Anatomy of the arteriall wall 
was given to the anatomy of the human body, and this quickly led to new insights. In 1575, Fallopius described the degeneration of vessels to bones in his "Lectiones de partibus similaribus humani corporis' (5). In fact he discovered arterial calcification, a feature of advanced atherosclerotic lesions. Understanding of the circulatory system in those days was rather limited. Most attention was given to the venous system, as the arterial system shrinks when blood pressure drops after death. This changed when William Harvey described the mechanism of blood circulation with arterial and venous vessels in 1628 (6). Interestingly $y_{r}$ he mentions the presence of thrombi in the vessel walls of the arterial system, a feature of severe atherosclerosis.

In the 18th century, discoveries in the field of the vascular system gained pace. Morgagni (1761) observed calcifications in coronary arteries (7). In 1774, Albrecht van Haller found calcified lesions in an abdominal aorta (8). Towards the end of the century, chest pain was connected to coronary sclerosis by Parry (1799) (9) and Jenner (1799) (10), although the exact cause of pain wasn't discovered until 1880, when Potain explained angina pectoris as result of myocardial ischemia, due to reduction in blood flow to the heart muscles.

In the 19th century, focus shifted from anatomical observations to the etiology of atherosclerosis. Already in 1852, Virchow (11) postulated atherosclerosis as an inflammation of the vessel walls. The connection with food composition was made in the early decades of the 20th century. It was observed that rabbits fed on meat and eggs developed atherosclerosis $(12,13)$. Protein was considered the food component causing atherosclerosis. In 1913, Anitschkow established the connection with cholesterol (14). Moreover, he described cholesterol loaden cells as main component of the lesions. He described what we now refer to as 'foam cells'.

For a large part during history, the formation of atherosclerosis was considered an inevitable result of wear and tear in the circulatory system. The 'tubes' were simply worn out when aging sets in. It was not until the last decades of the 20th century that arteries were not regarded as merely rigid, non-active structures, but as dynamic, living tissue. "The response to injury" hypothesis, formulated by Ross and Glomset in $1976(15,16)$, marked the start of a new era in atherosclerosis research and understanding. Elevated levels of blood cholesterol had been associated with heart attacks (17) since the early seventies, but the mechanism that transported cholesterol into the vessel walls and its relation to plaque formation was not known. This changed once the function of low-density lipoprotein (LDL) in the lipid transport was discovered by Brown and Goldstein (18). LDL turned out to be responsible for cholesterol and cholesteryl ester transport in the body, and the link between LDL and atherosclerosis was quickly made. Although LDL is capable to accumulate in the vessel wall (19), it was known that the native LDL did not trigger macrophage foam cell formation and inflammation associated with atherosclerosis (20). LDL oxidation and enzymatic modifications render the particles pro-atherogenic $(21,22)$. Amongst the most potent enzymes capable to modify LDL are the phospholipases, which have been shown in atherosclerotic lesions and inflammatory diseases $(23,24)$.

Today, the development of atherosclerosis is considered a complex process, influenced by numerous factors and based on interaction between vessel wall and 
Dumen. Attention for atherosclerosis and its etiology increased, and this is reflected in the increasing number of publications. The annual number of articles published on atherosclerosis doubles every decade (25).

\section{Anatomy of an artery}

Basic knowledge of the structure and biology of the normal artery is essential for the understanding of the development and progression of atherosclerosis. Normal arteries have three distinct layers. At the inside there is the tunica intima. At birth, the tunica intima is a rather thin layer. At the lumen side it consists of an endothelial monolayer. Directly below is a collagen $\mathrm{V}$ and laminin rich layer, containing the internal elastic lamina. This lamina or layer consists of elastic fibers and functions as a barrier for cells and macromolecules between the intima and the underlying media (26).

The endothelium is in close contact with the blood and has many functions. It is a selective barrier between blood and tissues. The endothelial cells are closely interconnected with tight junctional complexes. At points in the circulation with inregular heamodynamics, like in artery branches and curvatures, the endothelial layer is less structured and more permeable. These sites are more prone to develop atherosclerosis (27). The intima is a biological active tissue that plays a role in inflammation, blood flow regulation, vascular modelling and thrombus formation. During adulthood, the intima becomes more complex in structure. Smooth muscles cells become part of the intima and different types of collagen (I and III) are

\section{Lumen}

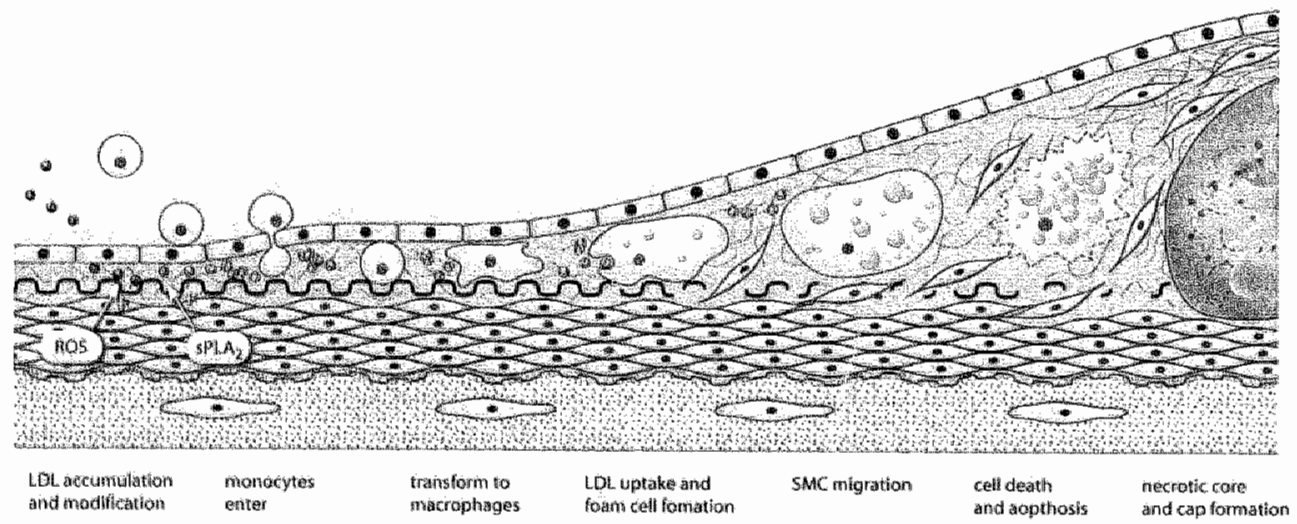

Fig. 2. Onset and development of atherosclerosis

LDL accumulated in the vessel wall and becomes modified by reactive oxygen species (ROS), phospholipases and other processes. Monocytes enter the vessel wall and differentiate into macrophages. Continuous uptake of modified LDL leads to foam cell formation and inflammatory processes induce smooth muscle cell migration to form a stabilizing fibrous cap. Finally, cell death leads to the development of a necrotic core and progression into an advanced plaque. 
deposited. This results in diffuse intimal thickening in many human arteries when aging. The tunica media lies in between the intima and the adventitia. This layer is rich in smooth muscle cells, embed ded between elastin-rich extracellular matrix components. Arteries undergo large pressure changes during systole and diastole. The elasticity of the media is essential to buffer these pressure fluctuations. Arteries close to the heart have a thick, well-organized media, compared to the thinner media of less pressurized arteries. Below the tunica media, at the outside of the vessel lays the tunica adventitia. This layer with loosely arranged collagen fibrils, contains relatively few cells. However often ignored in studies, the adventitia is important as supportive tissue. In large arteries, the adventitia contains small arteries (vasa vasorum) that provide oxygen and nutrients for the artery.

\section{Development of atherosclerosis}

Accumulation of low-density lipoprotein (LDL) particles in the intima of the vessel wall is one of the earliest events marking the development of an atherosclerotic lesion (28). In the initial phase, LDL diffuses passively through the endothelial layer and enters the intima were it can accumulate (19). Once entrapped, various processes change the properties of the LDL particles. In the first place, LDL particles tend to attach to extracellular matrix components. This induces conformational changes, leading to aggregation and prolonged retention time $(29,30)$. Once bound to the extracellular matrix, LDL is susceptible to oxidation and enzymatic modifications (21, 30-32). Many of these modifications are pro-atherogenic (33). Initial LDL oxidation is promoted by reactive oxygen species released by nitric oxide metabolism (34). During the course of atherosclerosis, various enzymes produced by inflammatory cells induce further oxidation. Myeloperoxidase (35), 15-lipoxygenase (36) and NADPH oxidase (37) are the most important enzymes capable to induce LDL oxidation. Sphingomyelinase enzymatically modifies sphingomyelin, an abundant phospholipid in the membrane of LDL particles. The phosphorylcholine moieties are removed from the ceramide backbone. As result, the increased ceramide content induces LDL aggregation (38) and prolonging retention time in the vessel wall. Once entrapped, the $L_{i} D L$ is continuously modified.

The secreted phospholipases $\mathrm{A}_{2}$ (sPLA $\mathrm{s}_{2}$ ) are very potent modifiers of LDL particles in the vessel wall. SPL $\mathrm{A}_{2}$ consist of a large group of related enzymes, from which several are present in atherosclerotic lesions. Phospholipases hydrolyse phospholipids and release free fatty acid (FEA) and lysophospholipids (lysoPL) (39). One of the released FFA is arachidonic acid (AA), providing a substrate for the production of a whole range of prostaglandins, leukotrienes and thromboxanes (40-42). Many of these molecules modulate inflammation and thus affect the course of atherosclerotic plaque formation. LysoPLs have various inflammation mediating functions that can affect lesion progression (43). Not only does phospholipase activity release inflammatory modulators, it also degrades and depletes the phospholipid content of $L D L$, thus inducing conformational changes, again promoting aggregation and enhancing retention in the vessel walls (28),

LDL modification and degradation in the vessel wall initiates an inflammatory response. Monocytes are amongst the first inflammatory cells attracted. Endothe 


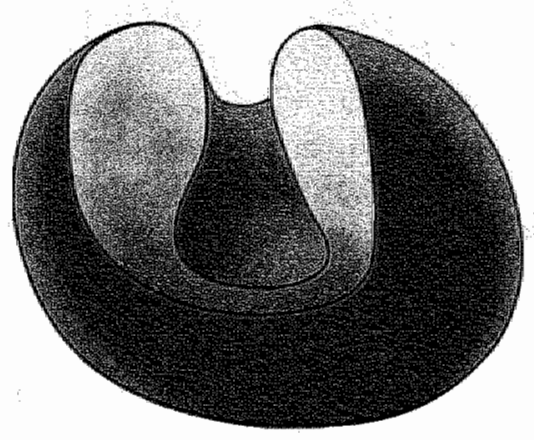

Fig. 3. Phospholipase $\mathrm{A}_{2}$ structure

The enzymatic active cavity of the phospholipase $A_{2}$ molecule is surrounded by an interfacial-binding surface (IBS). The IBS contains cationic, aromatic and aliphatic residues and determines the substrate preference. Differences between phospholipases mainly depend on the ability to bind to the substrate and the properties of the enzymatic cavity. In the active site, $\mathrm{Ca}^{+*}$, a water molecule and. a His-Asp dyad participate in the actual enzymatic activity: the hydrolysis of the sn-2 ester of a phospholipid. route using the scavenger receptors, SR-A and CD36, that has no feedback mechanism, resulting in continuous ingestion and transgression into lipid loaden foam cells (20). With increasing numbers of monocytes entering and transforming into macrophages and foam cells, thickening of the vessel wall begins and a so-called 'fatty streak' is formed. These fatty streaks further evolve into complex atherosclerotic plaques. Under the influence of inflammatory mediators and oxidized LDL, the macrophages secrete chemoattractant molecules, like platelet-derived growth factor (PDGF) (47). This triggers smooth muscle cells to migrate from the tunica media into the intima $(48,49)$. The invading SMC's are non-contractile in contrast to normal vascular smooth muscle cells. In the intima, replication further contributes to a slow, but steady increase in smooth muscle cells content of the lesion ( 47 , $50,51)$. Smooth muscle cells contribute to the growth in plaque volume due to their potent production of extracellular matrix components (52). A considerable amount of advanced plaque volume consists of interstitial collagen (type I and III), proteoglycan (versican, decorin, biglycan) produced by these SMCs (53). In complex lesions, the smooth muscle cells release cytokines and bone morphogenic proteins, stimulating calcification of the plaque (54). This process of vascular calcification is similar to the formation of skeletal bones, albeit less organized (55). At a certain point during the growth of the atherosclerotic lesion, diffusion as 
means of oxygen and nutrient transport is no longer sufficient and becomes a limiting factor in plaque growth. The formation of new blood vessels, or angiogenesis, takes place. Endothelial cells migrate into the lesion under influence of growth factors and develop small intra-plaque vasculature $(54,56,57)$. These newly formed micro-vessels, however, are prone to rupture; often resulting in haemorrhage and thrombus formation inside the plaque.

Cell death is a serious complication in the progression of atherosclerosis. Cell migration and division is followed by death of increasing numbers of SMCs and macrophages (58). Although the exact mechanism is still controversial, programmed cell death or apoptosis is considered to be chiefly responsible. Apoptosis in the plaque is provoked by various inflammatory cytokines excreted by the macrophages and T-lymphocytes (59). Besides active cell death, the cytotoxic effect of oxidized LDL also contributes to death of macrophages inside the lesion (60). The remnants of the decaying smooth muscle cells and macrophages accumulate and develop into an unstructured necrotic core. This necrotic core is enriched with free cholesterol released from death foam cells $(61,62)$.

The stability of an atherosclerotic plaque is affected by the size and consistency of the lipid core, the thickness of the fibrous cap and the level of inflammation

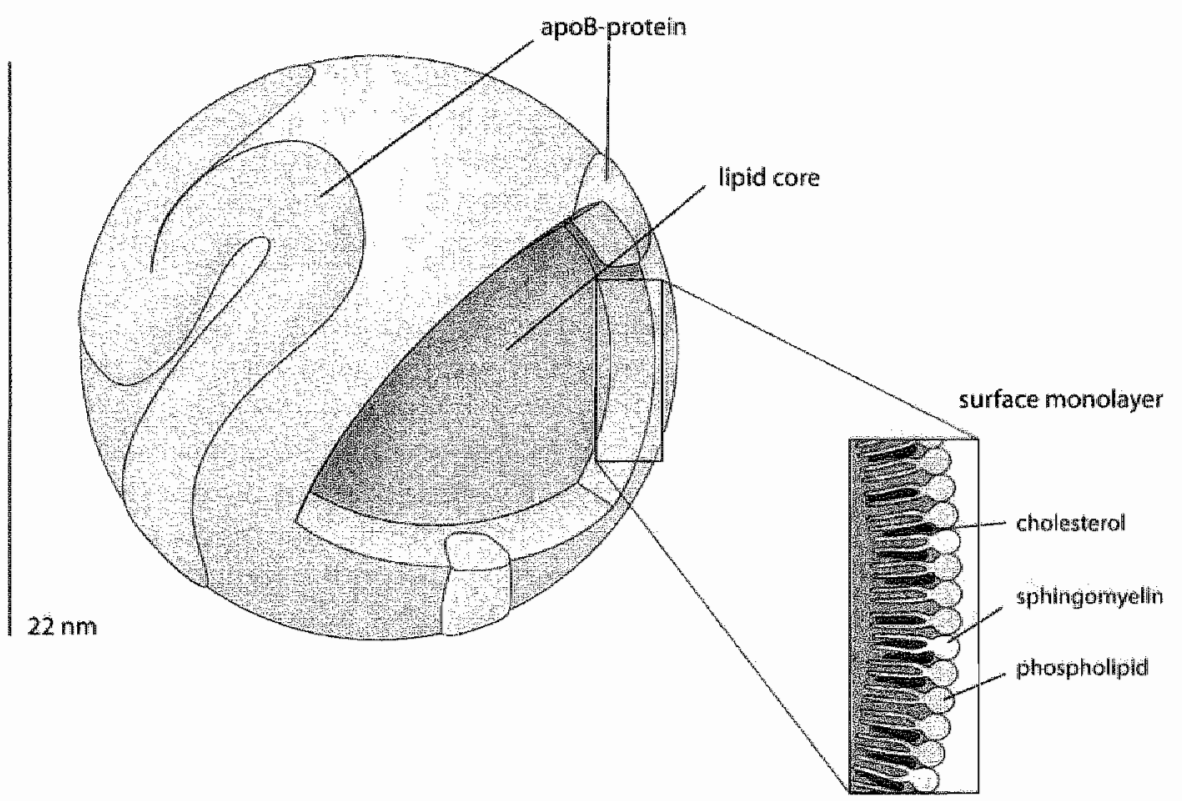

Fig. 4. Structure of LDL

Low density lipoproteins (LDL) are cholesterol carriers of the lipid transport system in the human body. A single apoB-100 protein embedded in a lipid monolayer surrounds a core, filled with mainly cholesteryl esters and triglycerides. The surface monolayer consists of phospholipids and a few triglycerides and cholesterol esters. The structure and properties of LDL depends on both the conformation of the apo $B$ protein and the lipid composition. 
and repair in the plaque (63). A typical stable plaque consists of a small lipid core, covered by a thick collagen rich cap. Inflammation is limited and the endothelium at the luminal side is not disrupted. The fibrous cap is essential to protect the plaque against heamodynamic forces and reduces the risk on erosion and rupture. The development of a large necrotic core and increased free cholesterol enhances plaque fluidity (64). As result of this, biomechanical forces start to concentrate on the shoulder regions, common sites for rupture (65). The thickness and consistency of the fibrous cap determines the resistance to plaque rupture: In atherosclerosis, there is a balance in production and degradation of cap components. Thinning of the cap is caused by the activity of metalloproteinases MMP-1 and MMP-2 secreted by macrophages (66). Macrophages are in fact the primary cells responsible for breakdown of the structural important collagen components of the cap (67). In contrast, smooth muscle cells contribute to cap thickening as they produce extracellular matrix components (52). In lesions with relative limited quantities of SMC's, a thin cap develops, resulting in rupture prone lesions (68). If plaque stability is impaired, erosion and rupture can readily occur. Plaque erosion is a superficial process in which thrombus formation occurs due to damage of the lesion's surface. However, the molecular basis of plaque erosion is not well understood. Defects in the endothelial barrier due to apoptosis and matrix degradation, as well as formation of cholesterol crystals in the plaques (69) can induce cap erosion. Rupture of atherosclerotic plaques is better defined and occurs when a plaque is unable to cope with the heamodynamic forces (70). Rupture immediately results in thrombus formation. This causes either a local occlusion of the artery, or a downstream obstruction of the vessel if the thrombus detaches and is transported with the circulation. Plaque rupture is the principal cause of death in acute myocardial infarctions, accounting for a proximal $70 \%$ of fatal myocardial infarctions and sudden coronary deaths (71).

Development of atherosclerosis is not a constant process, but is characterized by a step-wise growth. Periods of exacerbation are followed by quiescent periods. Infections, plaque disruptions and intra-plaque haemorrhages enhance temporary eruption of lesion formation $(72,73)$. Symptoms of atherosclerosis rarely develop before the fourth decade of life. During early development of atherosclerotic lesions, the vessel functions are hardly impaired. In the first place, growth of the plaque is directed to the periphery of the artery. Secondly, remodelling of the artery ensures rapid accommodation. As a result of this adaptive mechanism a decrease in lumen size is prevented (47). However, when the capacity to compensate is exceeded, the lumen narrows and arterial stenosis develops $(74,75)$. In general, lumen reductions from 60 percent and more have the potency to become pathological. Even then, physical activity is often necessary to provoke symptoms. Typical examples are angina pectoris and claudicatio intermittent. In the first case, stenosis of the coronary arteries reduces the blood flow to the heart muscles, resulting in acute chest pain under physical exercise. In the latter case, stenosis in the arteries supplementing the leg muscles produces a similar ischemic condition during walking. These are relative benign symptoms of progressive atherosclerosis. Myocardial infarction, unstable angina and stroke are severe complications that often appear suddenly and are life-threatening. 
Despite the complexity of atherosclerosis, continuous progress is made in unravelling its complex pathogenesis. Understanding the mechanisms behind the onset and development of atherosclerosis is essential for developing future therapeutic interventions.

\section{Aim of this thesis.}

The relation between LDL modification and atherosclerosis is complex, and its mechanism is poorly understood. The objective of this thesis is to elucidate the role of phospholipases in lipid modification and atherosclerosis. Phospholipases are a large group of enzymes, of which many have been reported in relation to inflammation and atherosclerosis. An extensive overview of the phospholipases and their functions is given in chapter 2.

For more than a decade, it is known that phospholipase IIA plays a role in inflammation (24). The enzyme was identified in human atherosclerotic lesion (23). The development of a transgenic mouse model (76), over-expressing human sPLA IIA, delivered a new tool to study the role of SPLA, ITA in inflammation. This general over-expression mouse model expressed the enzyme indifferently in all organs. On a high fat diet, development of significant atherosclerotic lesions was observed (77). However, the lipid profile in this model is very pro-atherogenic, with decreased HDL and elevated LDL levels, and signs of general inflammation.

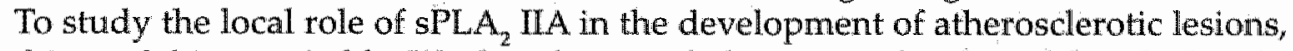
this model is unsuitable. We therefore needed a more refined model with specific expression at the lesion site. A new transgenic mouse model was made, with macrophage specific over-expression. Bone marrow transplantation to the LDL receptor knockout mouse model allowed us to examine the role of SPLA IIA in lesion formation in detail. Chapter 3 contains the results and discussion of our findings in our novel mouse model.

While group IA has little impact on intact cell membranes and native LDL, group $\mathrm{X}$ is known as a very potent modifier of eukaryotic phospholipids (78). It has been discovered that $s \mathrm{PLA}_{2} X$ modified LDL induces potent foam cell formation in macrophages (79). Combined with the reports of sPLA $X$ being present in atherosclerotic lesions of $A P O E$ knockout mice (79), sPL $\mathrm{A}_{2} X$ became an interesting candidate for more detailled examination. An animal model over-expressing sPL $A_{2} X$ at the site of the atherosclerotic lesions was needed to reveal the role of group $X$ in the inflammation and atherosclerosis. In a first step, we created a macrophage specific sPLA $A_{2} X$ construct, similar to our approach for the sPLA IIA mouse model. Murine macrophage cell lines were transfected and selected for stable expression of human sPLA $\mathrm{A}_{2} X$. These cell lines allowed us to perform in vitro experiments related to foam cell formation and inflammatory regulation. In chapter $\mathbf{4}_{\text {, these }}$ experiments are described in detail. The same construct was used to make a transgenic mouse. Unfortunately, the viability of these mice was extremely low, proving it hard to establish sPLA $X_{2}$ mouse lines. Nevertheless, we carefully examined the mice we obtained and found very interesting initial clues about the role of sPLA $X$ in lung pathology (chapter 5 ).

As mentioned before, the phospholipases are a large and diverse group of enzymes. Recent discoveries show specific expression and biological functions for 
the various phospholipases. Many of the phosphollipases mediate inflammation and modulate lipid accumulation. However, little is known about their role and presence in the different stages of atherosclerosis. We therefore decided to look at the expression patterns of the most prominent phospholipases in human plaques. Early lesions were compared with advanced stable and unstable plaques. To verify our results and to examine macrophage specific expression we performed in-vitro experiments with human macrophages under inflammatory conditions. At the same time we also looked at mice lesions and collected data from in vitro experiments with murine macrophages. We believe that combining these data can contribute to a better understanding of the role of phospholipases in atherosclerosis and inflammation. Chapter 6 describes the outlines, results and discussion of this study.

Finally, in Chapter 7 the results of our experiments and future perspectives are discussed.

\section{References}

1. MoGill, H.C, Jr, MoMahan, C.A, Zieske, A.W, Sloop, G.D., Walcott, J.V., Troxclair, D.A., Malcom, G.T., Tracy, R.E., Oalmann, M.C, and Strong, J.P. 2000. Associations of coronary heart disease risk factors with the intermediate lesion of atherosclerosis in youth. The Pathobiological Determinamts of Atherosclerosis in Youth (PDAY) Research Group. Arterioscler Thromb Vasc Biol 20:1998-2004.

2. Stamlex, I., Daviglus, M.L., Garside, D.B., Dyer, A.R., Greenland, P., and Neaton, J.D. 2000. Relationship of baseline serum cholesterol levels in 3 large cohorts of younger men to longterm coronary, cardiovascular, and all-cause mortality and to longevity. Jama 284:311-318.

3. Ruffer, M.A. 1911. Om arterial lesions found in Egyptia mummies. / Pathol Bacteriol:453-465.

4. Graul, E.H. 1985. Environtologie - Fakten und Spekulationen. Medicef:1-24.

5. Fallopius, G. 1575. Lectiones de partibus simularibus humani corporis. Padua.

6. Harvey, W. 1628. Exercitatio anatomica de notu cordis et sanguinis animalibus. London.

7. Morgagni, G.B. 1761. De sedibus et causis morborum. Venice.

8. von Haller. A. 1774. Bibliotheca anatomica. Zurich.

9. Parry, CH. 1799. An inquiry into the sympthoms and causes of the syncope anginosa, commonly called angina pectoris.

10. Jenner, 1 . 1799. Letter on the relationship of coronary artery disease to angina pectoris.

11. Virchow, R. 1852. Uber parenchymatose Entzunding. In Wirchows Archro Path Arat. 261-276.

12. Saltykow, A, editor. 1908. Atherosklerose bei Kaninchen nach wiederholter Staphylokokkeninjektion:: Fischer:

13. Stuckey. 1910. Uber die Veranderungen der Kanichenaorta unter dem Einflusse einer reichlichen animalischen Futterung. Inaugeral Dissertation. St. Petersburg.

14. Anitschkow, N. 1913. Uber die Veranderungen der Kaninchenaorta bei experimenteller Cholesterinsteatose. Beitr. Pathol. Anat:379-404.

15. Ross, R. and Glomset, I.A. 1976. The pathogenesis of atherosclerosis (second of two parts). N Engl J Med 295:420-425.

16. Ross, R., and Glomset, J.A. 1976. The pathogenesis of atherosclerosis (first of two parts). $N$ Engl J Met 295:369-377.

17. Kannel, W.B., Castelli, W.P., Gordon, T., and McNamara, PM. 1971. Serum cholesterol, lipoproteins, and the risk of coronary heart disease. The Framingham study. Anw Intem Med 74:1 12.

18. Brown, M.S, and Goldstein, J.L. 1986. A receptor-mediated pathway for cholesterol homeos- 
tasis. Science 2323447 .

19. Fowler, S., Shio, IH, and Haley, N.J. 1979. Characterization of lipid laden aortic cells from dholesterol-fed rabbits. IV. Investigation of macrophage-like properties of aortic cell populations. Lab Invest 4:1372-378.

20. Goldstein, I.L.,Ho, Y.K., Basu, S.K., and Brown, MS. 1979. Binding site on macrophages that mediates uptake and degradation of acebylated low density lipoprotein, producing massive cholesterol deposition. Proc Natl Acad Sci U S A 76333-337.

21. Herriksen, T., Mahoney, E.M., and Steinberg, D. 1981. Enlvanced macrophage degradation of low density lipoprotein previously incubated with cultured endothellal cells; recognition by receptors for acetylated low density lipoproteins. Proc Natl Acad Sci U S A 78:6499-6503.

22. Ya-Herttuala, S, Palinski, W, Rosenfeld, M.E, Parthasarathy, S, Carew, T:E, Butler, $S_{,}$, Witztum, J.L., and Steinberg, D. 1989. Evidence for the presence of oxidatively modified low density lipoprotein in atherosclerotic lesions of rabbit and man. J Clm Iwvest 84:1086-1095.

23. Menschikowski, M., Kasper, M., Lattke, P., Schiering, A., Schiefer, S., Stockinger, $H_{\text {, }}$ and Jaross, W. 1995. Secretory group II phospholipase $A_{2}$ in human atherosclenotic plaques. Atherosclerosis 118:173-181.

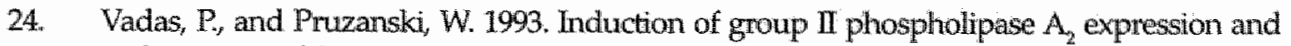
pathogenesis of the sepsis syndrome. Circ Shock 39:160-167.

25. Hanke, H. Lenz, C, and Finking, G. 2001. The discovery of the pathophysiological aspects of atherosclerosis-a neview. Acta Chir Belg 101:162-169.

26. Kwon, H.M., Sangiorgi, G., Spagnoli, L.G., Miyauchi, K., Holmes, D.R., Jr, Schwartz, R.S., and Lerman, A. 1998. Experimental hypercholesterolemia induces ultrastructural changes in the internal elastic lamina of porcine coronary arteries. Atherosclerosis 139:283-289.

27. Gimbrone, M.A., Jr. 1999. Vascular endothelium, hemodynamic forces, and atherogenesis. Am J Pathol 155:1-5.

28. Williams, K.J and-Tabas, I. 1995. The response-to-retention hypothesis of early atherogenesis. Arterioscler Thromb Vasc Biol 15:551-561.

29. Nievelstein, P.F, Fogelman, A.M. Mottino, G. and Frank, J.S. 1991. Lipid accumulation in rabbit aortic intima 2 hours after bolus infusion of low density lipoprotein. A deep-etch and immunolocalization study of ultrarapidly frozen tissue. Arterioscler Thomb 11:1795-1805.

30. Camejo, G., Hurt-Camejo, E., Wiklund, O., and Bondjers, G. 1998. Association of apo B lipoproteins with arterial proteoglycans: pathological significance and molecular basis. Atherosclerosis $139: 205-222$.

31. Tabas, I. 1999. Nonoxidative modifications of lipoproteins in atherogenesils, Amur Rev Nutr 19:123-139.

32. Boren. I. Lee, I., Zhu, W., Amold, K., Taylor, S, and Innerarity, T.L. 1998. Identifictition of the low density lipoprotein receptor-binding site in apolipoprotein $\mathrm{B} 100$ and the modulation of uts binding activity by the carboxyl teminus in familial defective apo-Blo0. I Clin Inoest 101:1084-1093.

33. Glass, C.K, and Witztum, J.L. 2001. Atherosclerosis, the road ahead. Coll 104503-516.

34. Leeuwenburgh, C., Hardy, M.M., Hazen, S.L., Wagner, P., Oh-ishi, S, Steinbrecher, U.P, and Heinecke, J.W. 1997. Reactive nitrogen intermediates promote low density lipopirotein oxida tion in human atherosderotic intima. / Biol Chem 272:1433-1436.

35. Carr, A. C. MoCall, M.R, and Frei, B. 2000. Oxidation of LDL by myeloperoxidase and reactive nitrogen species: reaction pathways and antioxidant protection. Arteriosder Thromb Vasc Biol 20:1716-1723.

36. Cathcart, M.K., and Folcik, V.A. 2000. Lipoxygenases and atherosclerosis: protection versus pathogemesis. Free Radic Biol Med 28:1726-1734.

37. Aviram, M., Rosenblat, M., Etzioni, A., and Levy, R. 1996. Activation of NADPH oxidase required for macrophage-mediated oxidation of low-density lipoprotein. Metabolism 45:10691079. 
38. $\mathrm{Xu}, \mathrm{X}_{\mathrm{w}, \mathrm{and}}$ Tabas, 1. 1991. Sphingomyelinase enhances low density lipoprotein uptake and ability to induce cholesteryl ester accumulation in macrophages. I Biol Chem 266:2484924858.

39. Six, D.A, and Denuis, E.A. 2000. The expanding superfamily of phospholipase A(2) enzymes: dassification and characterization. Biochim Biophys Acta 1488:1-19.

40. Sparrow, C.P. Parthasarathy, S, and Steinberg D 1988. Enzymatic modification of low density lipoprotein by purified lipoxygenase plus phospholipase $A_{2}$ mimics cell-mediated oxidatwe modification. / Lipid Res 29:745-753.

41. Needleman, P, Turk, J., Jakschik, B.A. Morrison, A.R, and Lefkowith, J.B. 1986. Arachidonic acid metabolism. Awnu Rev Brochem 55.69-102.

42. Smith, WL., Garavito, R.M, and DeWitt, D. L. 1996. Prostaglandinendoperoxide H synthases (cyclooxygenases)-1 and -2. B Bol Chern 271:33157-33160.

43. Ishii, L, Fukushima, N., Ye, X, and Chun, J. 2004. Lysophospholipid receptors: signaling and biology. Annu Rev Biochem 73:321-354.

44. Price, D.T, and Loscalzo, J. 1999. Cellular adhesion molecules and atherogenesis. Am IMed 107:85-97.

45. Luster, A.D. 1998. Chemokines-chemotactic cytokines that mediate inflammation. N Engl] Med 338:436-445.

46. Gimbrone, M.A., Jir, Cybulsky, M.I., Kume, N., Collins, $T_{\text {, }}$ and Resnick, N. 1995. Vascular endothelium. An integrator of pathophysiological stimuli in atherogenesis. Am $N$ Y Acad Sci 748:122-131; discussion 131-122.

47. Ross, R. 1999. Atherosclerosis-an inflammatory disease. N Engl J Med 340:115-126.

48. Stary, H.C., Chandlex, A.B., Dinsmore, RE., Fuster, V., Glagov, S., Insull, W. Jr, Rosenfeld, M.E., Schwartz, C. J. Wagner, W.D., and Wissler, RW. 1995. A definition of advanoed types of atherosclerotic lesions and a histological dassification of atherosclerosis. A report from the Committee on Vascular Lesions of the Council on Arteriosclerosis, American Heart Association. Circulation $92: 1355-1374$.

49. Schombeck, U., Sukhova, G.K., Shimizu, K., Mach, F, and Libby, P. 2000. Inihibition of CD40 signaling limits evolution of established atherosclerosis in mice. Proc Natl Acad Sci U S A. 97:7458-7463.

50. Gerhard, G.T., and Duell, P.B. 1999. Homocysteine and atherosclerosis. Curr Opin Lipidol 10:417-428.

51. Aikawa, M., Kim, H.S., Kuro-o, M., Manabe, I., Watanabe, M., Yamaguchi, H., Yazaki, Y, and Nagai, R, 1995. Phenotypic modulation of smooth muscle cells during progression of human atherosclenosis as determined by altered expression of myosin heavy chain isoforms. Ann $N$ Y Acad Sci 748:578-585.

52. Rekhter, M.D. 1999. Collagen synthesis in atherosclerosis: too much and not enough. Cardiowasc Res 4:1:376-384.

53. Wight, TN. 1995. The extracellular matrix and atherosclerosis. Cum Opin Lipidol 6:326-334.

54. Watson, K.E., Bostrom, K, Ravindranath, R., Lam, T, Norton, B., and Demer, L.L. 1994. TGFbeta 1 and 25 -hydroxycholesterol stimulate osteoblast-like vascular cells to calcify. / $\mathrm{Clin}$. $\mathrm{n}$ vest 93:2106-2113.

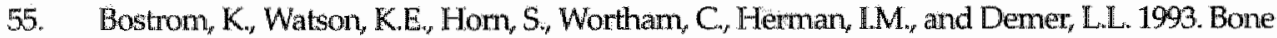
morphogenetic protein expression in human atherosclerotic lesions. I Clin Iroest 91:18001809.

56. O'Brien, E.R., Garwin, M.R., Dev, R., Stewart, D.K. Hinohara, T., Simpson, J.B, and Schwartz, S.M. 1994. Angiogenesis in human coronary atherosclerotic plaques. Am J Pathol 145:883894.

57. Vasse, M.r Pourtau, I., Trochon, V., Muraine, M. Vannier, J.P., Lu, H. Soria, I.x and Soria, C. 1999. Oncostatin M induces angiogenesis in vitro and in vivo. Arterioscler Thromb Vasc Biol 19:1835-1842. 
58. Tabas, 1, Marathe, S, Keesler, G.A., Beatini, N, and Shiratori, Y 1996. Evidence that the initial up-regulation of phosphatidylcholine biosynthesis in tree cholesterol-loaded macrophages is an adaptive response that prevents cholesterol-induced cellular necrosis. Proposed role of an eventual failure of this response in foam cell necrosis in advanced atherosclerosis. I Biol Chen $271: 22773-22781$.

59. Geng, Y.. Wu, Q. Muszynski, M., Hansson, G.K, and Libby, P. 1996. Apoptosis of wasculax smooth muscle cells induced by in vitro stimulation with interferon-gamma, tumor necrosis factor-alpha, and interleukin-1 beta. Arterioscler Thromb Vasc Biol 16:19-27.

60. Hakamata, H. Miyazaki, A., Sakai, M., Sakamoto, YI, and Horiuchi, S. 1998. Cytotoxic effect of oxidized low density lipoprotein on macrophages. I Atheroscter Thtom 5:66-75.

61. Tabas, 1. 2000. Cholesterol and phospholipid metabolism in macrophages. Biochm Biophys Acta 1529:164-174.

62. Tabas, I. 2005. Consequences and therapeutic implications of macrophage apoptosis in atherosclerosis: the importance of lesion stage and phagocytic efficiency. Arterioscler Thromb Vase Biol 25:2255-2264.

63. Zhou, $\mathrm{J}_{2}$, Chew, M. Ravn, H.B., and Falk, E. 1999. Plaque pathology and coronaty thrombosis in the pathogenesis of acute coronary syndromes. Scand I Clin Lab Invest Supyl 230:3-11.

64. Richardson, PD. Davies, M.I, and Bom, G.V. 1989. Influence of plaque configuration and stress distribution on fissuring of coronary atherosclerotic plaques. Lancet 2:941-944.

65. Cheng, G.C., Loree, HM, Kanm, R.D. Fishbein, M.C. and Lee, R.T. 1993. Distribution of circumferential stress in ruptured and stable atherosclerotic lesions. A structural analysis with histopathological correlation. Crrculation 87:1179-1187.

66. Galis, Z.S., Sukhova, G.K., Lark, M.W, and Libby, P. 1994. Increased expression of matrix metalloproteinases and matrix degrading activity in vilnerable regions of human atherosclerotic plaques. J Clin Inzest 94:2493-2503.

67. Davies, M. J., Richardson, P.D., Woolf, N., Katz, D.R, and Mann, J. 1993. Risk of thrombosis in human atherosclerotic plaques: role of extracellular lipid, macrophage, and smooth muscle cell content. Br Heart / 69:377-381.

68. Libby, P. 1995. Molecular bases of the acute coronary syndromes. Circulation 91:2844-2850.

69. Abela, G.S and Aziz, K. 2005. Cholesterol crystals cause mechanical damage to biological membranes: a proposed mechanism of plaque rupture and erosion leading to arterial thrombosis. Clin Cardiol $28: 413-420$.

70. Lee, R.T, and Libby, P. 1997. The unstable atheroma. Arterioscler Thromb Vasc Biol 17:18591867.

71. Davies, M.J.. and Thomas, A. 1984. Thrombosis and acute coronary-artery lesions in sudden cardiac ischemic death. N Engl J Med 310:1137-1140.

72. Mann, J., and Davies, M.J. 1999. Mechanisms of progression in native coronary artery disease: role of healed plaque disruption. Heart 82:265-268.

73. de Boen, O.I, van der Wal, A.C., Teeling, P., and Becker, A.E. 1999. Leucocyte recruitment in rupture prone regions of lipid-rich plaques: a prominent role for neovascularization? Cardio vasc Res 41:443-449.

74. Glagov, S., Weisenberg, E., Zarins, C.K. Stankunavicius, R., and Kolettis, G.J. 1987. Compensatory enlargement of human atherosclerotic coronary arteries. N Engl J Med 316:1371-1375.

75. Clarkson, T.B., Prichard, R.W., Morgan, T.M., Petrick, G.S., and Klein, K.P. 1994. Remodeling of coronary arteries in human and nonhuman primates. Jama 271:289-294.

76. Nevalainen, T.J., Laine, VI, and Grass, D.S. 1997. Expression of human group II phospholipase $\mathrm{A}_{2}$ in transgenic mice. / Histochen Cytochem 45:1109-1119.

77. Ivandic, B., Castellani, I.W. W., Wang, X.P., Qiao, J.H., Mehrabian, M., Navab, M., Fogelman, A.M., Grass, D.S., Swanson, M.E, de Beer, M.C., et al. 1999. Role of group II secretory phospholipase $A_{2}$ in atherosclerosis: 1. Increased atherogenesis and altered lipoproteins in transgenic mice expressing group Ila phospholipase $A_{2}$. Arteriosclet Thromb Vasc Biol 19:1284-1290. 
78. Pain, MH, Yu, B, Z, Singer, AG., Ghomashchi, F, Lambeau, G., Gelb, M.H, Jain, M.K, and Bahnson, B.J. 2002. Crystal structure of human group $X$ secreted phospholipase $A_{2}$. Electrostatically neutral interfacial surface targets zwitterionic membranes. J Biol Chen 2772908629093.

79. Hanasaki, K., Yamada, K., Yamamoto, S, Ishimoto, Y., Saiga, A., Ono, T, Ikeda, M., Notoya, M., Kamitani, S, and Arita, H. 2002. Potent modification of low density lipopiotein by

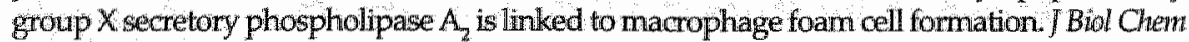
$27729116-29124$. 


\section{Chapter 2}

\section{The role of phospholipases $\mathrm{A}_{2}$ in lipid modification and atherosclerosis}

Stijn A.I. Ghesquiere', Marten H. Hofker', Berit Johansen", Menno P.J. de Winther ${ }^{1}$

1. Dept. of Molecular Genetics, Cardiovascular Research Institute Maastricht, Maastricht University, The Netherlands.

2. Dept. of Biology, Norwegian University of Science and Technology, N-7491 Trondheim, Norway

Cardiovascular Toxicology. 2005;5(2):161-82. 


\section{Abstract}

Phospholipases have received wide attention as it has become clear that several isoforms of the phospholipase family play a role in onset and progression of atherosclerosis. The release of free fatty acids (FFA) and lysophospholipids (lysoPL) provide metabolites for various inflammatory pathways, and this has been considered the main mechanism of phospholipase-driven inflammation. However generation of FFA and lysoPL are only part of the story. The induction of low-density phospholipoprotein (LDL) aggregation and accumulation, receptor binding, co-regulation with cyclooxygenase (COX) and lipoxygenase (LO) pathways, internalization through heparan sulfate proteoglycan (HSPG) shuttling, and crosstalk between phospholipases all play a role in atherosclerosis.

Group IIA phospholipase has long considered a key enzyme in the initiation of various inflammatory diseases, but new data also indicates a role in the subsequent resolution of inflammatory processes. Recently, secreted group $\mathrm{V}$ and group $\chi$ phospholipase and platelet activating factor acetylhydrolase (PAF-AH) are also recognized as important enzymes in atherosclerosis, modifying LDL and leading to lipid accumulation.

The phospholipases and their function in atherosclerosis are not fully understood. Future investigations can deliver better insight in the complex role of these enzymes. The present review summarizes the current state of phospholipase research related to atherosclerosis.

\section{Introduction}

Atherosclerosis is a progressive disease of the large arteries. Accumulation of low-density lipoprotein (LDL) and inflammation in the intima of vessel walls is a crucial event in the early onset and the progression of plaques (1). It is widely accepted that LDL needs to be either enzymatically modified or oxidized to become atherogenic (2). Modified LDL attracts monocytes, which differentiate into macrophages and transform into foam cells after uptake of the LDL. In addition, inflammatory mediators are released from the modified lipids, accelerating the inflammatory response (3).

Several enzymes modify LDL to such an extent that they become pro-atherogenic. In particular, phospholipases ( $\mathrm{PLA}_{2}$ ) have received wide attention. The catalytic activity of phospholipases -hydrolysis of phospholipids- results in the formation of free fatty acids (AA) and lysophospholipids (lysoPL) (4). AA provides a substrate for the production of pro-inflammatory mediator products such as prostaglandins, thromboxanes and leukotrienes (5-8). Lysophospholipids also have various biological functions that play a role in atherosclerosis. Both the release of inflammatory metabolites and the modification of lipoproteins create pro-atherogenic conditions. LDL aggregates, fuses and accumulates in the vessel walls due to phospholipase activity. Accumulation and retention in the vessel wall is a strong pro-atherogenic condition (1). Besides their enzymatic properties, phospholipases $A_{2}$ act through phospholipase $A_{2}$ receptor (PLA $R$ ) binding (9). This activates the mitogen activated protein kinase (MAPK) pathway (10) and released chemokines (11). The receptor pathway also activates intracellular phospholipase, resulting in 
the production of pro-inflammatory and vaso-regulating mediators (12).

\section{Overview of phospholipases}

Phospholipases $A_{2}$ are a diverse group of enzymes capable of hydrolyzing ester bonds of glycerophospholipids. The members of the $A_{2}$ subgroup hydrolyze glycerophospholipids at the $\mathrm{sn}-2$ position. Classification is based on the structure, molecular weight, and the substrate preference $(13,14)$. Three main groups can be distinguished: the secreted PLA $\mathrm{s}_{2}\left(\mathrm{sLA}_{2}\right)$, the cytosolic PLA $\mathrm{A}_{2} \mathrm{~s}\left(\mathrm{CPLA} \mathrm{A}_{2}\right)$ and the $\mathrm{CA}^{2 *}$ independent PLA ${ }_{2}$ s (iPLA $)_{2}$, sometimes regarded as a subgroup of $\mathrm{CPLA}_{2}$. The enzymatically active site of $s \mathrm{PL} \mathrm{A}_{2}$ is surrounded by the interfacial-binding surface (IBS) $(15,16$ ). The IBS contains cationic, aromatic and aliphatic residues, determining the substrate preference (17-21). Binding to zwitterionic (e.g. phosphatitylcholine) and anionic membranes (e.g. phosphatidylglycol) depends on the presence of aromatic residues, such as tryptophan $(17,21-23)$. In the active domain, $\mathrm{CA}^{2+}$, a water molecule and a His-Asp dyad participate in the hydrolysis of the sn-2 ester of phospholipids $(15,16)$.

\section{sPL $\mathrm{A}_{2}$ group IIA}

sPLA $_{2}$ group IIA is present in spleen, thymus, intestines, tonsils, bone marrow, liver (24-27), prostate (28), cartilage (29) and placenta $(30,31)$. On cellular level, IIA can be found in smooth muscle cells (32), endothelial cells (33), neutrophils $(34,35)$, mast cells $(36,37)$, hepatic cells (38) and macrophages (39-43). It should be noted, however, that group IIA antibodies used in some experiments cross react with group $V$, which might invalidate some earlier findings $(44,45)$. Elevated levels of group IIA in plasma and serum are found in sepsis (46), chronic rheumatic arthritis (47), and coronary heart diseases (48). In arteries, group IIA is associated with smooth muscle cells in the intima. Group IIA is present in atherosclerotic lesions, where it is located in macrophage rich areas, lipid atheromas, and damaged intima, associated with collagen fibers $(41-43)$. The enzyme binds extracellular matrix components such as glypican (49), decorin(49) and biglycan(50), allowing accumulation in the vessel wall (51) and exerting enzymatic activity on LDL particles. Clinical studies indicated that elevated group IIA concentration in the plasima is related to increased risk for coronary heart diseases (52). Various inflammatory pathways $(38,53,54)$ regulate group IIA. Secretion is induced by interleukin-1 $\beta$ (IL-1 $\beta)$ and tumor necrosis factor (TNF) $(53,55)$. Studies with transgenic mice indicate a minor importance for IIA in AA and eicosanoid formation (56-58). Group IIA activity on mammalian cell membranes is low due to inability to bind phosphatidylcholine $(57,59,60)$. The enzyme plays a role in bacterial host defense (61) and functions as the primary anti-bacterial defense in eye fluid (62).

The mice strain C57BL/6, 129/sv and B10.RIII are natural "knockouts" for group IIA due to a frameshift mutation (63). However, no obvious phenotype is present in these mice strains, except for the finding that group IIA is involved in prevention of intestinal neoplasm formation (64), although there is no firm evidence for this $(65,66)$.

To elucidate the role of phospholipase group IIA in inflammation, mouse models 
have been created. The sPLA, IIA over-expressing transgenic mouse model (56) uses the human SPLA $_{2}$ IIA gene with its natural promoter. Interestingly, these mice already developed atherosclerotic lesions on a normal chow diet (67). However, LDL levels are increased, while HDL levels are lowered, resulting in a concomitant reduction in paraoxonase activity. The systemic changes observed in this model increase atherosclerosis susceptibility. Recently, Webb et al. (68) avoided the systemic effects by transplanting transgenic bone marrow to lethally irradiated LDLreceptor knockout mice (LDLR $\left.{ }^{-1}\right)$. On a mild fatty diet, the mice showed a $73 \%$ increase in lesion size at the aortic root area. We performed similar experiments with macrophage specific transgenic group IIA mice and found a 2.5 fold increase in atherosclerotic lesion size. Interestingly the collagen content in the lesions is strongly increased (69).

Group IIA can be internalized through the heparan sulfate proteoglycan (HSPG) shuttling pathway (Fig. 1A), and induce the production of intracellular FFAs, which serve as precursor for various metabolic pathways $(49,57,70-72)$. Redundancy in phospholipases exists as group IIA $s P L A_{2}$ functions can be taken over by group V (73).

\section{sPLA $_{2}$ group V}

The human group $V$ is related to group IIA and is thought to share the same origin (74). The IBS binds efficiently to zwitterionic PC membranes (75). Group V releases AA and lysophosphatidylcholine from intact cell membranes (Fig. 1B) $(57,71,76)$. The cationic charge facilitates cell membrane proteoglycans binding (Fig. 1C)(70). Group V hydrolysis of LDL is 30 times higher compared to group IIA (77). Group $V$ exhibit antibacterial effects, albeit much smaller than those of sPLA, IIA (78). The enzyme is capable to follow the HSPG shuttling pathway $(49,57,72)$.

Phospholipase $\mathrm{V}$ is highly expressed in the heart, the placenta and in lesser quantities in lung and liver $(79,80)$. Expression is regulated by pro-inflammatory stimuli such as lipopolysaccharide (LPS) (73). Group V is present in human and mouse atherosclerotic lesions (81) and is a potent modifier of LDL phospholipids. LDL particles decrease in size and their phospholipid content is reduced, rendering them susceptible to aggregation (81). In contrast with group IIA, no binding to the proteoglycans in the extracellular matrix has been described. Mouse peritoneal macrophages incubated with group V modified LDL show enhanced LDL uptake and develop into foam cells (81). The presence in atherosclerotic lesion and the increased foam cell formation, in combination with LDL aggregation and the resulting accumulation in the vessel wall, makes it interesting to study the rolle of group $V$ in atherogenesis using an in vivo model.

\section{sPLA $\mathrm{A}_{2}$ group VII (PAF-AH)}

Platelet activating factor (PAF) is a potent lipid mediator promoting atherosclerosis through induction of superoxide anions in macrophages $(82,83)$. The PAF-hydrolyzing enzyme PAF-acetylhydrolase (PAF-AH, also known as lipoprotein-associated phospholipase $\mathrm{A}_{2}$ ) is present in human plasma (84). PAF-AH is classified as group VII phospholipase. The primary sources of PAF-AH are hematopoietic cells (85). Bone marrow transplantation in a Japanese patient who received a trans- 
plant from a donor lacking PAF-AH activity, resulted in complete abolition of the PAF-AH activity (86), supporting the role of the hematopoietic system. PAF-AH is expressed in differentiated macrophages, but not in monocytes (87). Despite its phospholipase activity, PAF-AH structure differs substantially from most phospholipases (88). PAF-AH is calcium independent, with preference for short acyl groups $(\mathrm{C}<6)$ at the $\mathrm{sn}-2$ position $(89,90)$. In this respect, it differs from other phospholipases, which do not show acyl length specificity. This prevents hydrolysis of lipoproteins and cell membranes (91). Three isoforms are known, two of which are present only in tissues and one of which is produced by macrophages and is present in plasma (92).

Oxidation of phospholipids results in shortened acyl groups. This makes them susceptible to PAF-AH hydrolysis (93-95). Therefore, PAF-AH may play a role in anti-oxidative scavenging (96). Besides phospholipase activity, PAF-AH shows trans-acetylase activity, transferring the acetate group from PAF to lyso-PC (97, 98).

PAF-AH in human plasma is associated with LDL and to a lesser extent with HDL, with the latter containing between 11 to $30 \%$ of the total amount $(89,99,100)$. Within the LDL population, PAF-AH mainly associates with small, dense LDL particles (99). In mice, PAF-AH is mainly associated with HDL (101), It is importantly to realize that not all PAF-AH activity found in HDL is necessarily produced by PAF-AH. Recent publications indicate that other enzymes, such as paraoxonase 1 (PON1) (102) and lecithin-cholesterol acyltransferase (LCAT) (97, 103-106) exhibit PAF-AH-like activity.

The role of PAF-AH in atherosclerosis is ambiguous, since both pro- and anti-atherogenic properties have been reported. PAF-AH is capable of removing PAF-like oxidized phospholipids from the surface of oxidized LDL particles, resulting in a reduction of the pro-atherogenic properties (107). ApoE-deficient mice overexpressing human plasma PAF-AH develop less atherosclerosis due to reduced lipid accumulation, inhibition of neo-intima formation, and reduced macrophage attraction (108). However, the metabolites produced by PAF-AH activity are pro-inflammatory lysoPC and oxidized FFA (93-95, 109, 110). Moreover, increased levels of PAF-AH were shown to be a strong risk factor for coronary artery disease, although it is unclear whether this is cause or consequence (111). While the majority of the publications favor a protective role of PAF-AH in atherosclerosis (112), the production of pro-inflammatory molecules may have adverse long-term effects.

\section{sPLA $\mathrm{A}_{2}$ group $X$}

Structurally, group $X$ contains sequences similar to both group IB and group IIA (113). Enzymatic activity is only present after proteolytic removal its propeptide $(114,115)$. Phospholipase group $X$ is very active on both anionic and zwitterionic phopholipids and hydrolyzes phosphatidylcholine (59). Its catalytic efficiency resembles cobra venom $\operatorname{sPLA}_{2}(116,117)$. The hydrophobic nature of $s P L A_{2} X$ enhances its ability to reach phospholipids in cell membranes (75). Although both group $X$ and group $V$ are capable to bind intact cell membrane surfaces, group $X$ is far more potent (118).

sPLA $_{2} X$ modified LDL induces formation of small intracellular lipid droplets in 
peritoneal macrophages, leading to the formation of foam cells. The morphology of the lipid droplets differs from that of those seen in oxidized LDL loading of macrophages, and resembles that of acetylated LDL (119). The lipid content and the overall charge of the LDL particles is changed, but no fragmentation or aggregation of the apoB-100 molecules occurs (119). The uptake increase of the modified LDL is not induced by changes in LDL charge, but more likely due to conformational changes in the apoB-100 protein. In this manner, group $X$ resembles group $V$ LDL modifications. Aggregation of group $X$ modified LDL has not been described, but can be expected:

Group $X$ is expressed in spleen, thymus, and peripheral blood leukocytes, and in low quantities in lung, pancreas, and colon cells (113). In mice immunohistochemistry confirmed its presence in splenic macrophages (115). Atherosclerotic lesions of high fat-fed apolipoprotein $\mathrm{E}$ knockout mice show increased presence of group $X$ in foam cells and vascular smooth muscle cells (119). Although the exact role of phospholipase group $X$ in atherosclerosis remains to be elucidated, the properties described here strongly suggest a proatherogenic role for group $X$ phospholipase.

\section{Phospholipase $\mathrm{A}_{2}$ interactions}

Phospholipases induce intracellular release of AA through the heparan sulfate proteoglycan (HSPG) shuttling pathway (Fig. 1A). This involves binding of phospholipase to HSPG at the membrane surface near caveolae and subsequent internalization. Phospholipases capable of following the HSPG route are IIA and its close relatives IID and IIE, as well group V. HSPG molecules accumulate in caveolae of activated cells and play a role in transporting phospholipases into the cell and to subcellular compartments $(49,57,70-72)$. Intracellular distribution allows phospholipases to contact specific substrates and release local FFA and lysoPL, precursors for the eicosanoid pathway (120). Not only does the HSPG pathway deliver intracellular lipid metabolites, it also inactivates PLA $_{2}$ by degradation in the lysosomes (121). Phospholipase group $V$ and $X$ can act directly on intact cell membranes and release AA and lysoPL, bypassing the $\mathrm{HSPG}$ pathway $(21,71,75$, $77,114,115,121-123)$. The neutral charge of group $X$ prevents HSPG binding (71). Phospholipases can also bind to the phospholipase $A_{2}$ receptor ( $P L A_{2} R$ ) (Fig. 1D) (9), PLA $R$ is expressed in alveolar type II epithelial cells and in a subset of splenic lymphocytes. It is absent in peritoneal macrophages, although these express the closely related mannose receptor (10). In mice, group IB is a strong ligand for the PLA $\mathrm{A}_{2}$ receptor $(124,125)$ in contrast to group IIA (125). Binding to PLA 2 elicits lipid mediator production, cell proliferation $(9,126)$, activation of the mitogenactivated protein kinases (MAPK) pathway (10), and chemokine production (11). However, in mouse peritoneal macrophages, group IB induces hardly any FFA release (122). PLA $R$ R knockout mice are highly resistant to endotoxic shock. Survival rate after sublethal dose of LPS in combination with lethal SPLA $A_{2}$ IB injection is prolonged. The decreased TNF and IL-1 $\beta$ plasma levels in PLA $\mathrm{R}_{2}$ knockout mice indicate a potential role for $\mathrm{PLA}_{2} \mathrm{R}$ in the onset and progression of endotoxic shock (127).

Group $X$ has high affinity for the $\mathrm{PLA}_{2} \mathrm{R}$ in mice, but requires its prepropeptide 
A

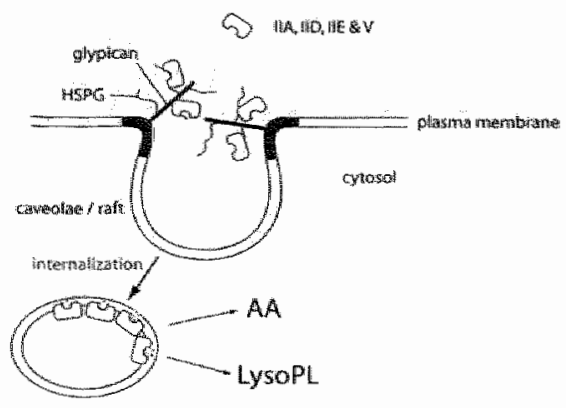

C

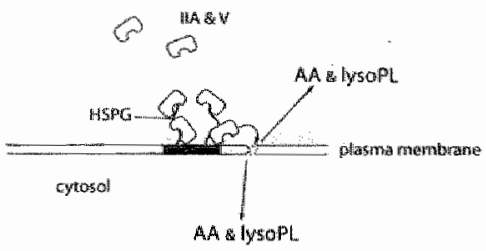

$E$

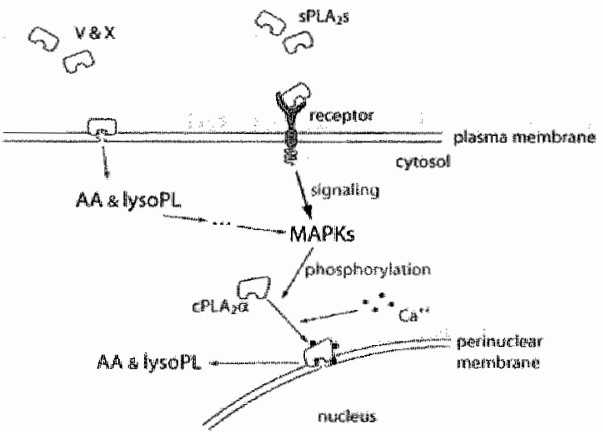

B

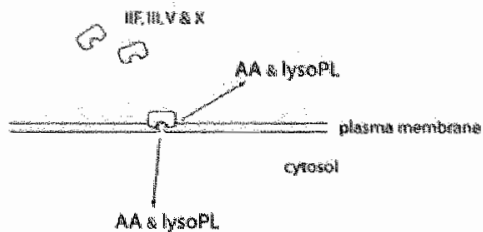

D

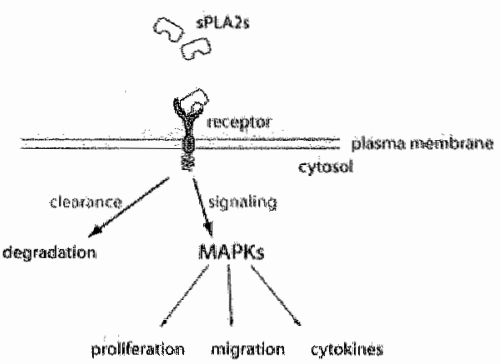

Fig. 1. A: The heparan sulfate proteoglycan (HSPG) shuttling pathway. Phospholipase group IIA, IID, ME, and V bind glypican molecules on the cell membranes, near caveolae of activated cells. Internalization occurs and transports the phospholipases to intracellular compartments. B: Direct enzymatic activity on intact mammalian cell membranes. Phospholipase groups IIF, III, $\mathrm{V}$, and $\mathrm{X}$ are capable of binding and hydrolyzing intact membranes. This results in the release of FFA and lysoPL from the membrane. $C$ : Heparan sulfate proteoglycan (HSPG) phospholipase accumulation. Binding of group IIA and $V$ to heparan sulfate proteoglycan-rich areas on cell membranes allows local accumulation and facilitates enzymatic activity, resulting the release of FFA and IysoPL. D: Phospholipase receptor pathway. Binding of phospholipases to the phospholipase receptor elicits signaling and MAPK pathway activation. Internalization followed by phospholipase degradation aids in phospholipase clearance. E: Cytosolic and secreted phospholipase cross talk. Phospholipase receptor binding and metabolites from phospholipase activate the MAPK pathway. Subsequently, cytosolic group IVa is activated by phosphorylation and binds to the perinuclear membranes, were it releases AA and lysoP'L. Calcium presence is essential for the cPLA $\mathrm{A}_{2}$ membrane binding. 
to be removed. The same applies to group $\mathrm{IB}$, which binds only in its active state (128). Clearance of group $X$ in mice is provided through PLA $A_{2} R$ binding, internalization and degradation (129). In contrast to rodents, human PLA ${ }_{2} R$ ligands are not well defined. Group IB binds weakly to the human PLA $R(10)$ and group IIA does not bind at all. It is not clear if human sPLA $A_{2} X$ is a ligand for the human $\mathrm{PLA}_{2} \mathrm{R}$.

Interestingly, snakes have soluble $\mathrm{PLA}_{2}$ receptors circulating in their blood as protection for leakage of venom phospholipases into circulation (130). A similar soluble receptor has been found in mice (131), binding and inhibiting sPLA, IB and $X$. There are no confirmations of the existence of soluble PLA $R$ in humans (131), although a potential alternative splicing variant of $P L A_{2} R$ in kidneys suggest this possibility (132).

For years it has been clear that there is a cross talk between secreted and cytosolic phospholipases (Fig. 1E). In macrophages, functional $\mathrm{CPLA}_{2} \alpha$ strongly enhances the enzymatic effects of group IIA $(133,134)$. Translocation of $c P L A_{2} \alpha$ to perinuclear membranes provides coupling to 5-LO and COX pathways $(135,136)$. To fully exert its enzymatic activity, $\mathrm{CPLA}_{2} \alpha$ must be activated through phosphorylation by MAPK pathways $(137,138)$. Binding to the P'LA $A_{2} \mathbb{R}$ and subsequent activation of MAPK pathways provide a mechanism explaining the coupling between group IIA and CPLA $\mathrm{A}_{2} \alpha(12)$. Indirectly, the production pro-inflammatory lipid metabolites descending from sPLA ${ }_{2} \mathrm{~s}$ AA release (12) can provide a coupling between sPLA $\mathrm{A}_{2} \mathrm{~s}$ and $\mathrm{CPLA}_{2} \alpha$. In neutrophils, leukotriene $\mathrm{B}_{4}\left(\mathrm{LTB}_{4}\right)$-initiated $\mathrm{CPLA}_{2} \alpha$ activation and subsequent amplification of $\mathrm{LTB}_{4}$ production has been described (139). Mice deficient for with $\mathrm{CPLA}_{2} \alpha$ show a reduced anaphylactic response and exhibit increased resistance to ischemic brain injury (140). Intestinal epithelium of $\mathrm{CPLA}_{2} \alpha$ knockout mice shows small ulcerations, indicating reduced production of protective $\mathrm{PGE}_{2}$ (141). Activated macrophages and mast cells in $\mathrm{CPLA}_{2}$ knockout mice produce only small amounts PGs and LTs upon activation (140), emphasizing the importance of $\mathrm{cPLA}_{2} \alpha$ in the PG and LT production. Phenotype of the knockout mice is similar to the phenotype of mice lacking a functional COX and 5-LO gene. However ${ }_{r}$ pros- $^{-}$ taglandins, prostacyclins, and leukotrienes are still produced in cPLA $\alpha$ knockout mice, indicating that other phospholipases $A_{2}$ play a role in the production of the precursor metabolite arachidonic acid.

\section{Phospholipase metabolites and atherosclerosis}

\section{Cyclooxygenases and phospholipases}

FFAs produced by phospholipase activity are metabolized into bioactive molecules, in particular eicosanoids. Eicosanoids regulate inflammation and play an important role in atherosclerosis $(142,143)$. Cyclooxygenase (COX) converts AA into prostaglandin $\mathrm{H}_{2}\left(\mathrm{PGH}_{2}\right)$. Further modification of $\mathrm{PGH}_{2}$ results in the production of prostacyclins, thromboxanes (Txs), and prostaglandins (PGs) (142, 144-146). The lipoxygenase (LOX) pathways metabolize AA into leukotrienes (LTs) (Fig. 2). Three COX isoforms are known, which are regulated in different ways. COX-1 is constitutively expressed in various tissues, such as kidney, stomach, and plate- 
lets $(143,147,148)$. Peritoneal mouse macrophages are also know to express COX-1 (149-151). In general, COX-1 can be considered as a "housekeeping" enzyme that controls the production of AA metabolites necessarily to maintain physiological tissue integrity. It serves functions in the renal regulation, maintaining gastric mucosa, and hemostasis. Recently a splice variant of COX-1 was identified as COX-3 $(152,153)$.

In contrast with COX-1, COX-2 is inducible. It is expressed in response to hormones, growth factors, inflammatory cytokines such as IL-1 $1 \beta$, TNF and interferon- $\gamma$, and bacterial endotoxins $(8,143,154)$. COX-2 is an important target in cancer research as various tumors, such as in colon, pancreas and lung, show expression of COX-2 (149, 155). The COX-2 promotor region contains elements that are recognized by peroxisome proliferator-activated receptors (PPARs). In turn PPARs can be activated by eicosanoids (156). COX-2 is found in SMC, macrophages, and endothelial cells in and near atherosclerotic lesions (157-159). The presence of COX-2 expression in atherosclerotic lesions $(157,158)$ and its observed elevated expression in destabilized plaques (160) relates it to the development of atherosclerosis.

\section{Prostacyclin and thromboxane}

COX-2 determines the production rate of $\mathrm{PGI}_{2}$ (prostacyclin) from the precursor $\mathrm{PGH}_{2}$ by PGI synthase (PGIS) $(161,162)$. PGIS is widely expressed in tissues, most notably by endothelial cells (163-165). The expression of PGIS is regulated by proinflammatory cytokines as TNF $(33,166), \mathrm{IL}-1(167)$, and IL-6 $(166,168)$. In vessel walls, endothelial cells are the main prostacyclin producers. The thromboxane-producing pathway is regulated by $\operatorname{COX}-1(169,170)$, and inhibition of COX-2 does not affect thromboxane production (171). Prostacyclin plays a protective role in atherosclerosis and thrombosis through vasodilatation and inhibition of platelet aggregation and leukocyte adhesion (172-174). Thromboxane induces vasoconstriction and platelet aggregation $(169,175-180)$. The interplay between thromboxane and prostacyclin is crucial for platelets-vessel wall interactions (173) and epithelial damage repair $(181,182)$. Animal experiments with increased PGIS synthase show inhibition of neointimal formation in baloon-injured arteries (175). 
Mice lacking the $\mathrm{PGL}_{\mathrm{s}}$ receptor exhibit increased platelet activation and vascular proliferation after injury of the vessel walls (182).

Blocking both the COX-1 and the COX-2 pathway reduces prostacyclin and thromboxane production. Classic, non-selective NSAIDS such as aspirin and naproxen, block the COX-1 and the COX-2 pathway. This results in gastrointestinal problems through the reduction of protective prostaglandins (183-185). Selective COK-2 inhibitors have been developed to bypass the detrimental effects $(184,185)$. However COX-2 specific inhibitors influence the balance between the protective prostacyclin and the pro-thrombotic and vasoconstrictive thromboxane, increasing the risk for cardiovascular events (186). COX-2 selective inhibitors have become controversial due to increased cardiovascular risks associated with their use (184, 185, 187-189). Results from the Vioxx Gastrointestinal Outcomes Research (VIGOR) trial, which compared rofecoxib with naproxen, showed an alarming increase in acute myocaridal infarctions (AMI). Initially, this was attributed to cardioprotective properties of naproxen, instead of cardiotoxic effects of rofecoxib (190-192). However, careful reexamination of available data revealed little protection provided by naproxen and indicates a detrimental effect of COX-2 inhibition $(187,189)$. Rofecoxib increases the risk for AMI by 3.7 fold (192) and Juni et al. (189) found a relative risk in the randomized controlled trials of 2.30 initially and 2.24 after a year. Little or no evidence indicated changes in the control groups that could explain the observed increased risk for AMT.

Although COX-2 inhibition might increase the risk for myocardial events, it is not necessarily pro-atherogenic. Inhibition of COX-2 is expected to decrease the production of pro-inflammatory prostaglandins, thus lowering the inflammatory processes involved in atherosclerosis. However, chronic inhibition of COX-2 in apolipoprotein $\mathrm{E}$ knockout mice does not alter lesion compositions (193) and has no effects on lesion development and progression (194). This indicated that other pathways might influence the onset and progression of inflammation in these mice. Experiments with COX-1 and COX-2 deficient mice (195) shows antagonistic effects of these enzymes. COX-1 deficient mice exhibit decreased response to angiotensin II, compared with the increased response in COX-2 deficient mice. Prostacyclin and Prostaglandin $\mathrm{E}_{2}\left(\mathrm{PGE}_{2}\right)$ production in kidneys is severely affected in $\mathrm{COX}-2$ deficient mice, resulting in reduced renal vaso-regulation. $\mathrm{COX}-1$ deficiency shows opposite effects possibly due to reduced thromboxane and $\mathrm{PGF}_{2} \alpha$ production (195).

Despite its effects on $\mathrm{PGE}_{2}$ and prostacyclin production, mice lacking a functional COX-2 gene, exhibit normal inflammatory responses after activation or arachidonic acid addition (196).

\section{Prostaglandin $\mathbf{E}_{2}$}

$\mathrm{PGE}_{2}$ is produced from $\mathrm{PGH}_{2}$ by the PGE synthase enzymes cPGES, a cytosolic PGES (197), and the membrane-bound PGES (mPGES) $(58,198,199)$. cPGES is constitutively expressed, and shows little variation after pro-inflammatory stimulation (197), while mPGES is induced by pro-inflammatory interleukines $(200,201)$. mPGES regulation is coupled with COX-2 expression $(58,202)$ and does not show COX-1 co-expression (58). In SMC and macrophages, $\mathrm{PGE}_{2}$ is the main prostaglan- 
din produced after activation and upregulation of mPGES and COX-2 $(203,204)$. Group ILA and V induce efficient production of prostanoids, while only minimal prodiction is seen with group X (71). Despite its potent production of $A A$, group $X$ induced only minimal $\mathrm{PGE}_{2}$ biosynthesis and production of $\mathrm{PGE}_{2}$ and $T X A_{2}$. However, addition of LPS, inducing COX-2 upregulation, resulted in strong eicosanoid production. sPLA 2 X does not regulate COX-2 expression directly, but $\mathrm{COX}-2$ potentates its effects.

Similar to prostacyclin, $\mathrm{PGE}_{2}$ inhibits platelet activation and induces vasodilatation (205). It induces SMC proliferation (206) and upregulates MMP-2 and MMP-9 in macrophages $(160,207,208)$. These MMPs facilitate macrophage migration and may decrease plaque stability (209-211). $\mathrm{PGE}_{2}$ also induces the production of proinflammatory IL-6 (212). Despite its mainly pro-inflammatory properties, $\mathrm{PGE}_{2}$ downregulates various inflammatory cytokines (213) and reduces chemokine production in macrophages through binding at the EP4 receptor (213).

\section{Prostaglandin $\mathrm{D}_{2}$ and $\mathrm{F}_{2} \alpha$}

$\mathrm{PGF}_{2} \alpha$ is biosynthesized from $\mathrm{PGH}_{2}, \mathrm{PHE}_{2}$ and $\mathrm{PGD}_{2}$ through distinct pathways and promotes vasoconstriction (214-217). $\mathrm{PGD}_{2}$ plays an important role in asthma (218) and allergic inflammatory reactions (219). It recruits eosinophils and Th2 cells in pulmonary inflammation (220), modulates pain perception (221), induces vasodilatation $(222,223)$ and reduces coagulation (224). $\mathrm{PGD}_{2}$ metabolites inhibit NF- $\kappa B$ (225-227) and IKK2 (228) and activate peroxisome proliferator-activated receptor $\gamma(\operatorname{PPAR} \gamma)(229)$, reducing inflammatory response.

\section{Lipoxygenases and phospholipases $A_{2}$}

The lipoxygenase pathway converts AA in precursor molecules for LT production. In humans 5-lypoxygenase (5-LO) and 15-lypoxygenase-1 (15-LO-1) are the most prominent lypoxygenases (230). The 5-LO pathway produces leukotriene $A_{4}$ $\left(\mathrm{LTA}_{4}\right)$, which is further metabolized to leukotriene $\mathrm{B}_{4}\left(\mathrm{LTB}_{4}\right)$ or other leukotrienes $\left(\mathrm{LTC}_{4}, \mathrm{LTD}_{4}\right.$ and $\mathrm{LTE}_{4}$ ). In mice the 12/15-LO is the ortholog to human 15-LO-1 (230). 5-LO expression is almost exclusively exhibited in myeloid descendant leukocytes (146). High levels of 5-LO are found in macrophages, dentritic cells, and mast cell within human atherosclerotic lesions $(3,231)$. 5-LO concentrations are positively correlated with the severity of the lesions (231). Products from 5-LO stimulate the expression and release of vascular endothelial cell growth factor (VEGF) (232). In apolipoprotein E / B100 double knockout mice, VEGF increases monocyte levels and lesion formation (233), linking the 5-LO pathway with atherosclerosis. Absence of 5-LO expression protects mice against atherosclerosis. Combined 5-LO and low-density lipoprotein receptor (LDLR) knockout mice show a remarkable decrease $(>26 x)$ in aortic lesions. 5-LO colocalizes with macrophages in lesions of LDL receptor knockouts. (234).

Another 5-LO AA metabolite, LTA $_{4}$ is secreted from leukocytes and taken up by other cells, where it is transformed in $\mathrm{LTB}_{4}$ and other leukotrienes (235-237). This amplifies leukotriene production in inflamed tissues. LTB ${ }_{4}$ is a potent polymorphonuclear neutrophil leukocytes (PMNs) recruiting agent (146) and induces PMN and monocyte adherence to the vessel wall (238) through integrin changes 
(239). Human endothelial cells showed increased leukocyte adherence (240-242). Blocking the $\mathrm{LTB}_{4}$ receptor in mice results in reduced lesions, accompanied by reduced monocyte chemoattractant protein-1 (MCP-1) (243). The peptide-leukotrienes induce vasoconstriction and increase vascular wall permeability, release of pro-inflammatory cytokine IL-1 $3(244,245)$, and proliferation of SMC (246).

The 12/15-LO pathway results in the production of 15-hydroperoxyeicosatetraenoic acid (15-HpETE) and 15-Hydroxyeicosatetraenoic acid (15-HETE), which both exhibit strong oxidative properties on cell membranes and LDL particles ( 5 , 247,248 ). Phospholipases work in synergy with the $12 / 15$-LO pathway as they deliver the A.A substrate and at least group IIA is up-regulated by the 12/15-LO metabolites (248). Cytosolic phospholipases are involved in the production of intracellular AA and the induction of group ILA regulation. The exact mechanism of the group IIA in this context has not been fully elucidated (248). Mice lacking $12 / 15-\mathrm{LO}$ show reduced atherosclerosis $(249,250)$. 12/15-LO is essential for foam cell formation and endothelial activation (249).

\section{LysoPC production and effects}

Lysophospholipids (LPs) consist of a sphingoid backbone with a single acyl chain and a phosphate chain. The most common lysophospholipids are lysophosphatidic acid (LPA), sphingosine 1-phosphate (SP1), lysophosphatidylcholine (lysoPC), and sphingosylphosphorycholine (SPC). Lysophospholipids are not only metabolites of phosphilipid degradation; they are also a key molecule in phospholipid synthesis. LysoPC up-regulates the adhesion molecules ICAM-1 and VCAM- 1 in endothelial cells (251) and inhibit vasodilatation (252). Furthermore, lysoPC induces macrophage and SMC proliferation $(6,253)$ and increase monocyte $(6,254)$ and T lymphocytes attraction (255).

Oxidized LDL contains contains large quantities of lysoPC (256). This is the result of phospholipase-like activity exhibited in the LDL particles during oxidative modifications, which converts up to $40 \%$ of the phoshaditylcholine molecules (257). High levels of lysoPC are present in atherosclerotic lesions $(258,259)$. LysoPC stimulates $\mathbb{L}-1 \beta$ production in macrophages (260).

Extracellular lysophospholipids are hydrolyzed by lysophospholipase D (lysoPLD) to LPA $(261,262)$. Intracellular LPA is produced from LP by several pathways, but likely not secreted (261). Intracellularly, LPA serves as substrate for glycerolipid and phosphatidylinositol synthesis (261). Extracellular LPA exerts various biological functions through binding to LP receptors (263). Four LPA (LPA1-4) receptors have been characterized (reviewed in [(264)]). A whole range of downstream signaling cascades are mediated by LPA signaling and lead to cell proliferation and differentiation, cell survival, and cell motility (265).

\section{LDL aggregation and fusion}

Aggregation, retention, and fusion of LDL in the vessel wall is important in the onset of early atherosclerosis (266). Lipoproteins found in atherosclerotic lesions are derived from circulating LDL entering the vessel wall $(267,268)$. The transformation of macrophages into foam cells is enhanced with modified and aggregated LDL $(269,270)$ (Fig. 3). 


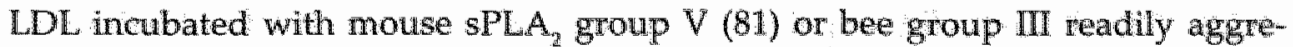
gates. In the latter, LDL fusion is induced (271). Results from group $X$ indicate that it does not cause LDL aggregation (119), despite its extensive enzymatic activity. However, it is suggested (81) that the absence of albumin in the medium in these experiments, prevented AA and lysoPC transfer out of the LDL particles, thereby inhibitinh particle decrease and preventing ApoB-100 conformational changes, lipid reorganization, and subsequently aggregation $(272,273)$.

LDL binding to extracellular matrix components (EMC) is a key event in atherosclerosis. Glyco-amino-glycan (GAG) molecules in the arterial proteoglycan (PG) matrix bind LDL particles through ApoB-100 interaction $(1,274)$ and enhance accumulation in the intima. Binding to GAG induces irreversible changes in the apoB-100 molecule (275) and alters the lipid distribution within the LDL particle (276). Other elements from the EMC that interact with apoB-100 are biglycan and decorin (277). Group IIA effects are neglectable on non-modified LDL due to its low activity on the membranes (278). However, in the presence of decorin, group IIA becomes a very potent modificator of LDL (51). The combination binding of decorin to LDL (277) and decorin co-localization with collagen in atherosclerotic lesions (279) makes group IIA an important player in the development of atherosclerosis.

\section{Phospholipases, sphingomyelinase (SMase) and LDL} Sphingomyelin is abundant in LDL (280). Subendothelial lipoprotein accumulation is associated with SMase activity (281-283). LDL modified with SMase aggregates, fuses, and shows increased affinity for binding to aortic proteoglycans (271, 284). At neutral $\mathrm{pH}$ conditions, SMase does not exert pro-atherosclerotic actions, unless the LDL particles are modified with group IIA phospholipase (282). In vitro experiments revealed increased susceptibility of SMase modified LDL particles to group V modifications (77). The combination of group IIA, SMase and group $V$ action on LDL in the vessel walls might act synergistically and can thus lead to induction and progression of atherosclerosis.

\section{SPLA IIA and plaque composition}

Although, phospholipase $\mathrm{A}_{2}$ IIA in atherosclerotic lesions increases the size of the plaques (68), few detailed studies have looked at the effects on plaque composition. To study that in detail, we created a macrophage SPLA ${ }_{2}$ IIA overexpression. model with the myeloid-specific CD11b promoter (285) combined with the human genomic PLA $_{2}$ IIA gene (69). Bone marrow was transplanted to LDLR ${ }^{-j}$ mice to study atherogenesis. Group IIA induced remarkable increase in atherosclerosis. One of the main features of the lesions in the sPLA, IIA mice was increased collagen content. The combination of more collagen (i.e. cap thickening) and the $a b-$ sence of increased necrosis or apoptosis, suggests a more stable plaque development. It has not been described before that SPLA, IIA affects collagen production or fibrosis in general. There is no indication that changes in the number of SMC and fibroblasts attribute significantly to the increased collagen production. Gilroy et al. (286) described a role for phospholipase in resolution of inflammation. 
Both group ILA and V are capable of inducing release of pro-resolving eicosanoids (286-288). Experiments with a carrageen-induced air pouch inflammation model in group IIA lacking C57BL/6 mice, revealed an increased number of inflammatory cells during resolution. This difference is not observed during the initiation of inflammation (286). This indicates that $S P L A_{2}$ II can reduce attraction of inflammatory cells and increase the pace of inflammatory resolution. Part of inflammatory resolution is the deposition of extra cellular matrix components (289). The role of phospholipase IIA in atherosclerosis thus appears to be more complicated than initially expected.

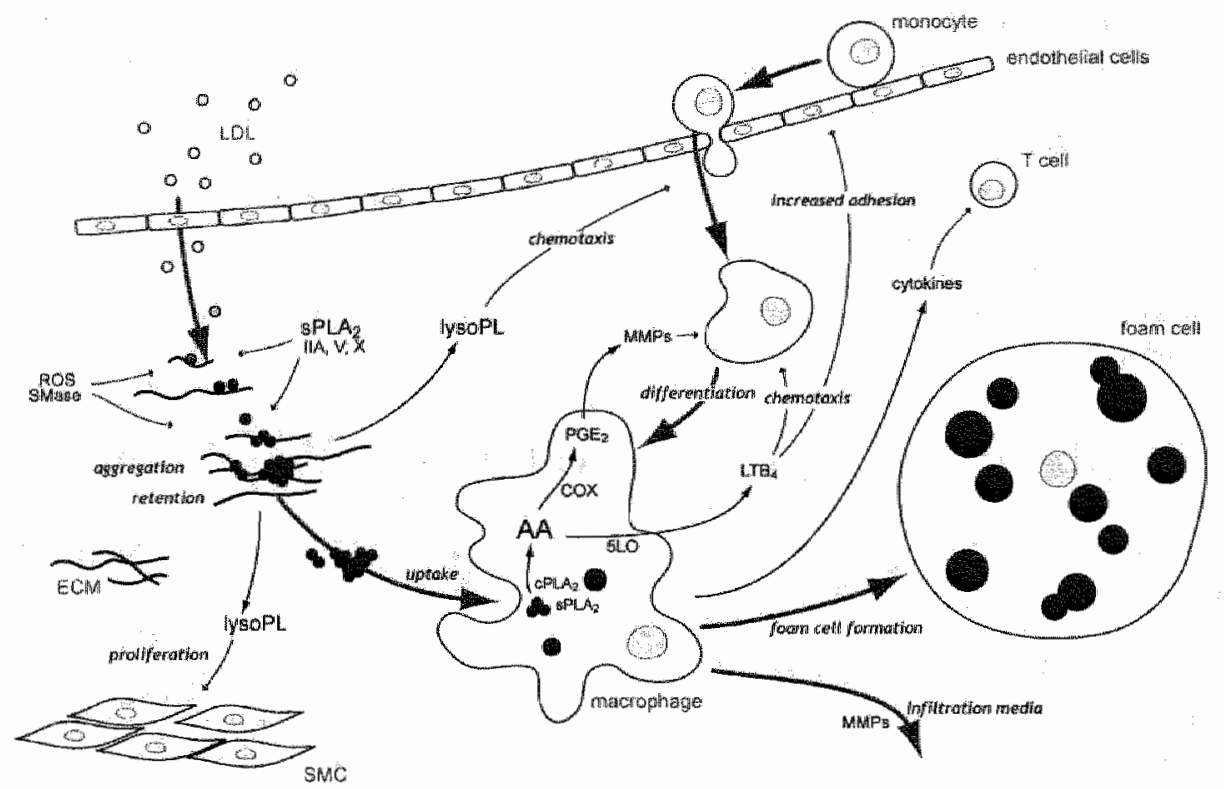

Fig. 3. LDL entering the vessel walls is oxidized and enzymatically modified. Modified LDL binds to the extracellular matrix. The enzymatic action of phospholipases induces LDL aggregation and releases AA and lysoPL. LysoPL provides monocyte chemotaxis and SMC proliferation. The aggregated LDL is taken up by macrophages. AA is released from the LDL particles and metabolized through $\mathrm{CO} X, 5-\mathrm{LO}$, and $12 / 15-\mathrm{LO}$ pathways, resulting in the production of $P G E_{2}$ and LTB. Inflammation increases due to the $A A$ and $5-\mathrm{LO}$ products. $M M P$ production is increased and facilitates monocyte and macrophage motility in the lesion. The macrophages transform into foam cells after contimuously uptake of modified LDL. The development from an early fatty streak into an atherosiclerotic lesion is initiated.

\section{Concluding remarks}

It is clear that phospholipases are involved in various processes that are pro- as well anti-atherosclerotic. The release of arachidonic acid and lysoPC are key events leading to the production of various eicosanoids. Despite the fact that many phospholipase-induced effects are pro-inflammatory, the role of PAF-AH illustrates protective mechanisms. Mice overexpressing PAF-AH have reduced lipid accumulation, intima formation, and macrophage attraction (108).

The role of phospholipase group IIA in atherosclerosis and inflammatory diseases 
has been intensively studied in the last decades. The complex mechanism behind phospholipase IIA is not completely understood. The recent finding of group IAinduced collagen formation in atherosclerotic lesions (69) illustrates this. The primary role of phospholipase IIA appears to be protection against Gram-positive bacteria $(290,291)$. The expression and presence in atherosclerotic lesions might be the results of activation of defense pathways in macrophages and neutrophils. The role of infections in atherosclerosis should be considered in this context. However, group IIA can play a role in normal cell metabolism when taken up through the HSPG shuttle pathway, releasing phospholipid metabolites at specific cell compartments.

Recently, phospholipase group $\mathrm{V}$ and $\mathrm{X}$ and PAF-AH gathered more attention and are recognized as important enzymes in atherosclerosis (81). Future investigation will certainly shift the focus to a broader spectrum of phospholipases. Aggregation and retention of LDL particles are a know effect of phospholipase IIA. Similar results have been obtained for group $V(81)$, and there are strong indications that group $X$ will show similar effects. Phospholipases are pro-atherogenic because lipid accumulation in the vessel wall is key element in the onset of lesion formation (1).

Phospholipase $A_{2}$ receptor binding is another aspect of the phospholipase $A_{2}$-mediated actions that has not been fully elucidated. The interspecies differences indicate the subtle differences between related phospholipases $\mathrm{A}_{2}$.

The redundancy of group IIA in mice, which has not been reported in humans, indicates that care should be taken to interpret the obtained results in mice. Nev-

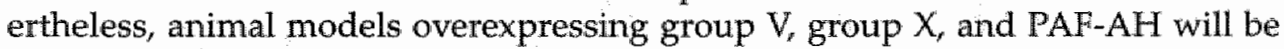
of great importance to elucidate the role of these phospholipases. In combination with models deficient in downstream pathways of phospholipase, metabolites could deliver new insights in the complex role of these enzymes. The distinction between inflammatory responses, lipid accumulation, and inflammation-resolving functions needs further clarification.

Therapeutic approaches should take in account the differences between the phospholipases to be successful and to avoid side effects that ameliorate the beneficial properties of putative phospholipase blockers. 


\section{References}

1. Williams, KJ., and Tabas, I. 1995. The response-to-retention thypothesis of early atherogenesis. Arteriascler Thromb Vasc Biol 15.551:561.

2. Glass, C.K, and Witzturn, I.L. 2001. Atherosclerosis. the road ahead. Cell 104,503-516.

3. Libby, P., Ridkex, PM, and Maseri, A. 2002. Inflammation and atherosclerosis. Criculation 105:1135-1143.

4. Six, D.A, and Dennis, E. A 2000. The expanding superfamily of phospholipase A(2) enzymes: dassification and characterization. Bioctim Biophys Acta 1488:1-19.

5. Sparrow, CP. Parthasarathy, S, and Steinberg, D. 1988. Enzymatic modification of low density lipoprotejn by purified. lipoxygenase plus phospholipase $\mathrm{A}_{2}$ mimics cell-mediated oxidative modification. J Lipid Res 29:745-753.

6. Sakai, M., Mryazaki, A., Hakamata, H., Sasaki, T, Yui, S., Yamazaki, M., Shichiri, M., and Horiuchi, S. 1994. Lysophosphatidylcholine plays an essential role in the mitogenic effect of oxidized low density lipopiotein on murine macrophages. I Biol Chem 269:31430-31435.

7. Needleman, P., Turk, J., Jakschik, B.A., Morrison, A.R., and Lefkowith, J.B. 1986. Arachidonic acid metabolism. Annu Rev Biochem 55:69-102.

8. Smith, W.L., Garavito, R.M., and DeWitt, D.L. 1996. Prostaglandin endoperoxide H synthases (cyclooxygenases)-1 and -2./ Biol Chem 271:33157-33160.

9. Hanasaki, $K$, and Arita, H. 1999. Biological and pathological functions of phospholipase $\mathrm{A}(2)$ receptor. Arch Biochem Biophys 372:215-223.

10. Hanasaki, K 2004. Mammalian phospholipase $A_{2}$ : phospholipase $A_{2}$ receptor Biol Pharm Bull 27:1165-1167.

11. Kanemasa, $\mathrm{T}_{\text {, }}$ Hanasaki, $\mathrm{K}$, and Arita, H. 1992. Migration of vascular smooth muscle cells by phospholipase $\mathrm{A}_{2}$ via specific binding sites. Biochint Biophys Acta 1125:210-214.

12. Houliston, R.A., and Wheeler-Jones, CP. 2001. sPLA.(2) cooperates with CPLA(2)alpha to regulate prostacyclin synthesis in human endothelial cells. Biochem Biophys Res Commun 287:881887 .

13. Dennis, E.A. 1997. The growing phospholipase $\mathrm{A}_{2}$ superfamily of signal transduction enzymes. Trends Biochem Sci 22:1-2.

14. Derunis, E.A. 2000. Phospholipase $\mathrm{A}_{2}$ in eicosanoid generation. Am J Respir Crit Care Med 161: S32-35.

15. Scot, DL. White, S.P. Otwinowski, Z, Ywan, W, Gelb, MH, and Sigler, PB. 1990. Intertacial calalysis: the medhanism of phospholipase $A_{2}$. Science 250:1541-1546.

16. Scott, D.L. and Sigler, PB. 1994. Structure and catalytic mechanism of secretory phospholipases $\mathrm{A}_{2}$. Ado Protein Chem 45:53-88.

17. Lee, B.I., Yoon, E.T, and Cho, W. 1996. Roles of surface hydrophobic residues in the intertacial catalysis of bovine pancreatic phospholipase $\mathrm{A}_{2}$. Biochemistry 35:4231-4240.

18. Han, S.K., Yoon, E.T. Soott, D.L., Sigler, P.B, and Cho, W. 1997. Structural aspects of interfacial adsotption. A crystallographic and site-directed mutagenesis study of the phospholipase $\mathrm{A}_{2}$ from the venom of Agkistrodon piscivorus piscivorus. J Biol Chem 272:3573-3582.

19. Snitko, Y, Koduri, R.S., Han, S.K., Othman, R., Baker, S.F, Molini, B.J., Wilton, D.C., Gelb, $\mathrm{M} . \mathrm{H}$, and Cho, W. 1997. Mapping the interfacial binding surface of human secretory group Ila phospholipase $\mathrm{A}_{2}$. Biodumistry 36:14325-14333.

20. Bittova, L., Sumandea, M., and Cho, W. 1999. A structure-function study of the C2 domain of cytosolic phospholipase $A_{2}$. Identification of essential calcium ligands and hydrophobic membrane binding residues. J Biol Chem 274:9665-9672.

21. Han, SK., Kim, K.P., Koduri, R., Bittova, L., Munoz, N.M., Leff, A.R, Wilton, D.C., Gelb, M.H. and $C_{h o}$ W. 1999. Roles of Trp31 in high membrane binding and proinflammatory activity of human group V phospholipase $A_{2}$. J Biol Chem 274:11881-11888.

22. Baker, S.F., Othman, R, and Wilton, D.C. 1998. Tryptophan-containing mutant of human 
(group Ha) secreted phospholipase $A_{2}$ has a dramatically increased ablity to hydrolyze phosphatidylcholine vesides and cell membranes. Biochewishy $37 / 13203-13211$.

23. Gelb, $\mathrm{MH}, \mathrm{Cho}_{\%} \mathrm{~W}_{2}$ and Wilton, D.C 1999. Interfacial bunding of secreted phospholipases A(2): more than electrostaties and a major role for myptophan. Cur Opun Strict Bio 9:28432.

24. Kramer, R.M., Hession, C, Johansen, B., Hayes, G. MoGray, P. Chow, E.P, Tizard, R, and Pepinsky, RB. 1989. Structure and properties of a human non-pancreatic phospholipase $A_{2}$. Bial Chem 264:5768-5775.

25. Minami, T., Tojo, H., Shinomura, Y., Matsuzawa, Y. and Okamoto, M. 1993. Purification and characterzation of a phospholipase $\mathrm{A}_{2}$ from human ileal nucosa. Biodhim Bioplyss Acta 1170:125-130.

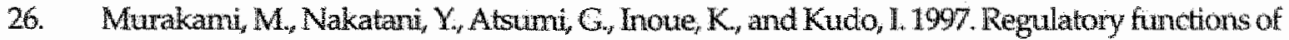
phospholipase $\mathrm{A}_{2}$. Crit Rev Immonol 17:225-283.

27. Newalainen, T. J, Gronroos, IM, and Kallajoki, M. 1995. Expression of group II phospholipase $\mathrm{A}_{2}$ in the human gastrointestinal tract Lab hroest 72:201-208:

28. Nevalainen, T., Meri, K.M., and Niemi, M. 1993. Synovial-type (group II) phospholipase A, human seminal plasma. Andrologia 25355-358.

29. Nevalainen, T., Marki, F, Kortesuo, PT, Grutter, M.G, Di Marco, S. and Sdomitz, A. 1993. Synovial type (group II) phospholipase $A_{2}$ in cartilage. / Rhewnalol 20:325 330 .

30. Aitken, M.A., Thomas, T, Bremecke, S.P., Solt, K.E, and Rice, G.E. 1996. Localization of type I phospholipase $A_{2}$ messenger RNA and immunoactivity in human placenta and fretal membranes. Placenta 17:423-429.

31. Rice, G.E., Wong, M.H, Farrugia, $W_{\text {, }}$ and Scott, K.F. 1998. Contribution of type II phospholipase $A_{2}$ to in vitro phospholipase $A_{2}$ enzymatic activity in human term placenta. J Endocrinol 157:25-31.

32. Kurihara, H., Nakano, T., Takasu, N., and Arita, H. 1991. Intracellular localization of group II phospholipase $A_{2}$ in rat vascular smooth muscle cells and its possible relationship to eicosanoid fomation. Biochin Biophys Acta 1082:285-292.

33. Murakami, ${ }_{1}, K u d o, I_{1}$ and notue, K. 1993. Molecular nature of phospholipases $A_{2}$ involved in prostaglandin $\mathbb{L}_{2}$ synthesis in human umbilical ven endothelial cells. Possible participation of cytosolic and extracellular type II phospholipases $\mathrm{A}_{2}$.J Biol Chem 268:839-844.

34. Rosenthal, M.D., Gordon, M.N., Buescher, E.S. Stusser, J.H., Harris, L.K, and Franson, R.C. 1995. Human neutrophits store type II 14-kDa phospholipase $\mathrm{A}_{2}$ in granuies and secrete active enzyme in response to soluble stimuli. Biochem Biophys Res Commun 208:650-656.

35. Bamette, M.S, Rush, J., Marshall, L.A., Foley, JI, Schmidt, D.B., and Sarau, H.M. 1994, Effects of scalaradial, a nowel inhibitor of $14 \mathrm{kDa}$ phospholipase $\mathrm{A}_{2}$, on human neutrophil function. Biochem Pharmacol 47:1661-1667.

36. Murakami, M, Kudo, 1., Umeda, M. Matsuzawa, A., Takeda, M., Konada, M. Fujimori, $Y_{\text {s }}$ Takahashi, K., and Inoue, K. 1992. Detection of three distinct phospholipases $A_{2}$ in cultured mast cells. J Biochem (Tokyo) 111:175-181.

37. Reddy, S.T, and Herschman, H.R. 1996. Transcellular prostaglandin production following mast cell activation is mediated by proximal secretory phospholipase $\mathrm{A}_{2}$ and distal prostaglandin synthase 1. J Biol Chem 271:186-191.

38. Crowl, RM., Stoller, T.I., Conroy, R.R, and Stoner, C.R. 1991. Induction of phospholipase A, gene expression in human hepatoma cells by mediators of the acute phase response. I Biol Chem 266:2647-2651.

39. Barbour, S.E., and Dennis, E.A. 1993. Antisense inhibition of group II phospholipase $\mathrm{A}_{2}$ expression blocks the production of prostaglandin $\mathrm{E}_{2}$ by P388D1 cells. I Biol Chem 268:2187521882.

40. Vial, D., Senorale-Pose, M., Havet, N., Molio, L., Vargaftig, B.B., and Touqui, L. 1995. Expression of the type-II phospholipase $A_{2}$ in alveolar macrophages. Down-regulation by an in- 
flammatory signal. J Biol Chem 27017327-17332.

41. Anthonsen, M.W, Stengel, D., Hourton, D, Ninio, $E_{\text {, }}$ and Johansen, B. 2000 . Milldy oxidlized CDL induces expression of group Ha secretory phospholipase A(2) in liuman monocyte-derived macrophages. Arterioscler Thromb Vasc Biol 201276-1282.

42. Menschikowski, M, Kasper, M. Lattke, P., Schiering, A., Schiefer, S, Stockinger, H., and Jaross, W. 1995 Secretory group If phospholipase $A_{2}$ in human atherosclerotic plaques. Atherosclerosis 18:173-181.

43. Elinder, L.S., Dumitrescu, A., Larssoon, P., Hedin, U., Frostegard, J. and Claesson, H.E. 1997. Expression of phospholipase $A_{\text {, }}$ isoforms in human normal and atherosclerotic arterial wall. Arterioscler Thromb Vasc Biol 17,2257-2263.

44. Balboa, M.A. Balsinde, J., Winstead, M.V. Tischfield, J.A., and Dernis, E.A. 1996. Novel group $V$ phospholipase $A_{2}$ involved in arachidonic acid mobilization in murine P388D1 macrophages. I Buil Chen $27132381-32384$.

45. Tischfield, J.A. 1997. A reassessment of the low molecular weight phospholipase $\mathrm{A}_{2}$ gene family in mammals. J Biol Chem 272:17247-17250.

46. Vadas, P., and Pruzanski, W. 1993. Induction of group II phospholipase $\mathrm{A}_{2}$ expression and pathogenesis of the sepsis syndrome. Circ Shock 39:160-167.

47. Pruzanski, W., Keystone, E.C., Steinby, B., Bombardier, C, Snow, K.M, and Vadas, P. 1988. Serum phospholipase $A_{2}$ correlates with disease activity in rheumatoid arthritis. I Rheumntol 15:1351-1355.

48. Rader, D.J 2000. Inflammatory mankers of coronary risk. N Engl J Med 343:1179-1182.

49. Murakami, M., Kambe, T., Shimbara, S., Yamamoto, S., Kuwata, H., and Kudo, I. 1999. Functional association of type IIA secretory phospholipase A(2) with the glycosylphosphatidylinositol-anchored heparan sulfate proteoglycan in the cyclooxygenase-2-mediated delayed prostanoid-biosynthetic pathway. I Biol Chem 274:29927-29936.

50. Flood C., Gustafsson, M. Pitas, R.E., Arnaboldi, L., Walzem, R. L., and Boren, J. 2004. Molecular mechanism for changes in proteoglycan binding on compositional changes of the core and the surface of low-density lipoprotein-containing human apolipoprotein B100. Arterioscler Thromb Vasc Biol 24:564-570.

51. Sartipy, $\mathrm{P}_{*}$ Johansen, $\mathrm{B}_{,}$Gasvik, $\mathrm{K}$, and Hurt-Camejo, E. 2000. Molecular basis for the association of group IIA phospholipase $\mathrm{A}(2)$ and decorin in human atherosclerotic lesions. Circ Res 86:707-714.

52. Kugiyama, K., Ota, Y., Sugiyama, S, Kawano, H., Doi, H., Soejima, H., Miyamoto, S., Ogawa, H., Takazoe, K, and Yasue, H. 2000. Prognostic value of plasma levels of secretory type II phospholipase $A_{2}$ in patients with unstable angina pectoris. Am J Cardiol 86:718-722.

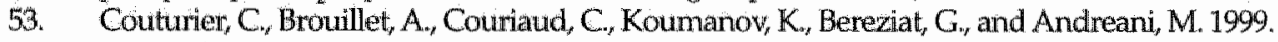
Interleukin Ibeta induces type II-secreted phospholipase A(2) gene in vascular smooth musde cells by a nuclear factor kappaB and peroxisome proliferator-activated receptor-mediated process. J Biol Chem 274:23085-23093.

54. Antonio, V., Brouillet, A., Janvier, B., Monne, $\mathrm{C}_{,}$Bereziat, G., Andreani, M., and Raymondjean, M. 2002. Transcriptional regulation of the rat type IIA phospholipase $A_{2}$ gene by $C A M P$ and interleukin-1beta in vascular smooth muscle cells: interplay of the CCAAT/enhancer binding protein (C/EBP), nuclear factor-kappaB and Ets transcription factors. Biochemt /368:415-424.

55. Pfeilschifter, J, Schalkwijk, C., Briner, V.A., and van den Bosch, H. 1993. Cytokine-stimulated secretion of group II phospholipase $A_{2}$ by rat mesangial cells. Its contribution to arachidonic acid release and prostaglandin synthesis by cultured rat glomerular cells. I Clin Invest 92:25162523.

56. Grass, D.S, Felkner, R.H., Chiang, M.Y, Wallace, R.E., Nevalainen, T.]., Bennett, C.F., and Swanson, ME. 1996. Expression of human group I PLA ${ }_{2}$ in transgenic mice results in epidermal hyperplasia in the absence of inflammatory infiltrate. J Clin Inoest 97:2233-2241.

57. Murakami, M. Koduri, R.S., Enomoto, A., Shimbara, S., Seki, M. Yoshihara, K., Singer, A. 
Valentin, E., Ghomashchi, F, Lambeau, G, et al. 2001. Distinct arachidonate-releasing func tions of mammalian secreted phospholipase $\mathrm{A}_{2}$, in human embryonic kidney 293 and rat mastocytoma $\mathrm{RBL}-2 \mathrm{H} 3$ cells through heparan sulfate shuttling and extemal plasma mem brane meehanisms. J Biol Chen 276:10083-10096.

58. Murakanui, M, Naraba, H., Tanioka, T, Semmyo, N., Nakatani, Y, Kojima, F, Ikeda, T, Fueki, M. Ueno, A. Oh, $S_{\text {, }}$ et al. 2000 . Regulation of prostaglandin $E_{2}$ biosynthesis by inducible membrane-associated prostaglandin $\mathrm{E}_{2}$ synthase that acts in concert with cyclooxygenase-2. I Biol Chem 275:32783-32792.

59. Bezzine, S., Koduri, R.S., Valentin, E., Murakami, M., Kudo, I, Ghomashohi, F, Sadilek, M. Lambeau, $G$, and Gelb, M.H. 2000. Exogenously added human group X secreted phospholipase $\mathrm{A}(2)$ but not the group $\mathrm{IB}, \mathrm{MA}$, and $\mathrm{V}$ enzymes efficiently release arachidonic acid from adherent mammalian cells.) Biol Chem 275:3179-3191.

60. Enomoto, A. Murakami, M., Valentin, E, Lambeau, G., Gelb, M.H., and Kudo, 1. 2000. Redundant and segregated functions of granule-associated heparin-binding group II subtamily of secretory phospholipases $A_{2}$ in the regulation of degramulation and prostaglandin D2 synthesis in mast cells. I wmmnol 165:4007-4014.

61. Laine, V., Grass, D.S., and Nevalainen, T.J. 1999. Protection by group II phospholipase A, against Staphylococcus aureus. I Inmmol 162:7402-7408.

62. Qu, X.D., and Lehrer, R.I. 1998. Secretory phospholipase $A_{2}$ is the principal bactericide for staphylococci and other gram-positive bacteria in human tears. Infect Immun 66:2791-2797.

63. Kennedy, B. P. Payette, P. Mudgett, J., Vadas, P., Pruzanski, W., Kwan, M. "Tang, C, Ranoourt; D.E., and Cromlish, W.A. 1995. A natural disruption of the secretory group II phospholipase A gene in inbred mouse strains. / Biol Chem 270:22378-22385.

64. MacPhee, M, Chepenik, K.P, Liddell, R.A., Nelson, K.K., Siracusa, L.D., and Buchberg, A.M. 1995. The secretory phospholipase $A_{2}$ gene is a candidate for the Mormll locus, a major modifier of ApcMin-induced intestinal neoplasia. Cell 81:957-966.

65. Gould, K.A. and Dove, W.F. 1997. Localized gene action controlling intestinal neoplasia in mice. Proc Natl Acat Sci U S A 94:5848-5853.

66. Dove, W.F. Cormier, R.T., Gould, K.A., Halberg, R.B., Merritt, A. ., Newton, M.A., and Shoemaker, A.R. 1998. The intestinal epithelium and its neoplasms: genetic, cellular and tissue interactions. Philos Trans R Soc Lond B Biol Sci 3539915-923.

67. Ivandic, B., Castellani, L.W., Wang, X.P., Qiao, J.H., Mehrabian, M., Navab, M., Fogelman, A.M., Grass, D.S., Swanson, M.E., de Beer M.C., et al. 1999. Role of group II secretory phospholipase $A_{2}$ in atherosderosis: 1. Increased atherogenesis and altered lipoproteins in tranisgenic mice expressing group lla phospholipase $\mathrm{A}_{2}$. Arterioscler Thromb Vhic Biol 19:1284-1290.

68. Webb, N.R., Bostrom, M.A., Szilvassy, S.I., van der Westhuryen, D.R, Daugherty, A., and de Beer, FC. 2003. Maciophage-expressed group IIA secretory phospholipase A, increases atherosclerotic lesion formation in LDL receptor-deficient mice. Arterioscler 77 romb Vasc Biol 23:263-268.

69. Ghesquiere, S.A., Gijbels, M.I., Anthonsen, M., van Gorp, PJ.; van der Made, I, Johansen, B. Hofker, M.F., and de Winther, M.P. 2004. Macrophage-speciftc overexpression of group Ma $\mathrm{SPLA}_{2}$ results in increased atherosclerotic lesion size and enhanced collagen deposition. . Lipia Res 46:201-210.

70. Murakami, M., Shimbara, S., Kambe, T., Kuwata, H., Winstead, MV., Tischfield, J.A., and Kudo, I. 1998. The functions of five distinct mammalian phospholipase $A_{2} S$ in regulating arachidonic acid release. Type lla and type $\mathrm{V}$ secretory phospholipase $\mathrm{A}_{2} \mathrm{~S}$ are functionally redundant and act in concert with cytosolic phospholipase $\mathrm{A}_{2}$. J Biol Chew 273:14411-14423.

71. Murakami, M., Kambe, "T., Shimbara, S. Higashino, K., Hanasaki, K., Arita, H., Horiguchi,

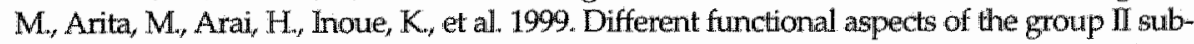
family (Types IIA and $V$ ) and type $X$ secretory phospholipase $A(2)$ s in regulating arachidonic acid release and prostaglandin generation. Implications of cyclooxygentase-2 induction and 
phospholipid scramblase-mediated cellular membrane perturbation. J Biol Chem 274:3143531444 .

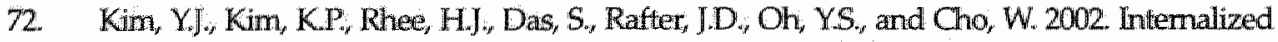
group $V$ secretory phospholipase $A_{2}$ acts on the perinudear membranes. J Biol Chem 277.9358 9365.

73. Sawada, HL, Murakami, M, Enomoto, A, Shimbara, S, and Kudo, I. 1999. Regulation of type $V$ phospholipase $A_{2}$ expression and function by proinflammatory stimuli. Eur / Biochen 263:826-835.

74. Tischfield, I.A., Xia, YR, Shih, D.M. Kisak, L, Chen, J., Engle, S.I., Siakotos, AN., Winstead, MV, Seillhamer, J.I, Allaniand, $V_{s}$ et al. 1996. Low-molecular-weight, calcium-dependent phospholipase $\mathbb{A}_{2}$ genes are linked and map to homologous dhromosone regions in mouse and human. Genomics 32:328-333.

75. Pan, YH, Yu, B.Z., Singer, A.G., Ghomashchi, $\mathbb{E}$, Lambeau, G., Gelb, M.H., Jain, M.K., and Bahnson, B. 2002. Crystal structure of human group X secreted phospholipase $A_{2}$. Electrostatically neutral interfacial surface targets zwitterionic membranes. / Biol Chen 277:2908629093.

76. Murakami, M., Masuda, S., Shimbara, S., Bezzine, S., Lazdunski, M., Lambeau, G., Gellb, M.H., Matsukura, $S_{u}$ Kokubu, $F_{y}$. Adachi, $M_{\text {. }}$, et al. 2003. Cellular arachidonate-releasing function of novel classes of secretory phospholipase $A_{2}$ s (groups III and XII). J Biol Chem 278:1065710667.

77. Gesquiere, L., Cho, W., and Subbaiah, P.V. 2002. Role of group IIa and group V secretory phospholipases A(2) in the metabolism of lipoproteins. Substrate specificities of the enzymes and the regulation of their activities by sphingomyelin. Biochemistry 41:4911-4920.

78. Gronroos, J.O., Laine, V.J., Janssen, M.J., Egmond, M.R, and Nevalainen, T.J, 2001. Bactericidal properties of group IIA and group V phospholipases A. I Immunol 166:4029-4034.

79. Chen, J., Engle, S.J., Seilhamer, J.J, and Tischfield, J.A. 1994. Cloning, expression and partial characterization of a novel rat phospholipase $A_{2}$. Biochim Biophys Acta 1215:115-120.

80. Chen, I., Engle, S.I. Seilhamer, I.J., and Tischfield, J.A. 1994. Cloning and recombinant expression of a novel human low molecular weight $\mathrm{Ca}(2+)$-dependent phospholipase $\mathrm{A}_{2}$, $/$ Biol Chem 269:2365-2368.

81. Wooton-Kee, C.R., Boyanovsky, B.B., Nasser, M.S, de Villiers, W.], and Webb, N.R. 2004. Group V sPLA, hydnolysis of low-density lipoprotein results in spontaneous particle aggregation and promotes macrophage foam cell formation. Arterioscler Thromb Whsc Biol 24:762767.

82. Evangelou, A.M. 1994. Platelet-activating factor (PAF): implications for coronary heart and vascular diseases. Prostaglandits Leukot Essent Fatty Acids 50:1-28.

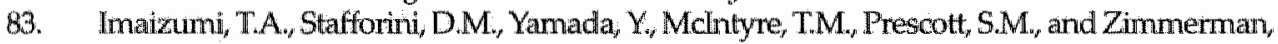
G.A. 1995. Platelet-activating factor: a mediator for clinicians. Intern Med 238:5-20.

84. Farr, R.S., Cox, C.P., Wardlow, M.L., and Jorgensen, R. 1980. Preliminary studies of an acid-labile factor (ALF) in human sera that inactivates platellet-activating factor (PAF). Clin Immwnol Jimmonopathol 15:318-330.

85. Hakkinen, T, Luoma, J.S., Hiltunen, M.O. Macphee, C.H. Milliner, K., ., Patel, Lu, Rice, S.Q., Tew, D.G. Karkola, K, and Ya-Herttuala, S. 1999. Lipoprotein-associated phospholipase $A(2)$, platelet-activating factor acetylhydnolase, is expressed by macrophages in human and rabbit atherosclerotic lesions. Arterioscler Thromb Vasc Biol 19:2909-2917.

86. Asano, K., Okamoto, S., Fukunaga, K., Shiomi, T., Mori, T., Iwata, M., Ikeda, Y., and Yamaguchi, K. 1999. Cellular source(s) of platelet-activating-factor acetylhydrolase activity in plasma. Biochem Biophys Res Commun 261:511-514.

87. Tjoelker, L.W., Wilder, C., Eberhardt, C., Stafforini, D.M., Dietsch, G., Schimpf, B., Hooper, S., Le Trong, H., Cousens, L.S, and Zimmerman, G.A. 1995. Anti-inflammatory properties of a platelet-activating factor acetylhydrolase. Nature 374:549-553. 
88. Tjoelker, LW., Eberhardt, C., Unger, I, Trong, H.L., Zimmerman, G.A., Mdntyre; TM, Statforini, DM. Prescott, SM., and Gray, PW. 1995. Plasma platelet-activating factor acetyllydrolase is a secreted phospholipase $A_{2}$ with a cataly tic triad. J Biol Chw 270.25481-25487.

89. Stafforini, D.M, Prescott, SM, and Mclntyre, T.M. 1987. Human plasma platelet-activating factor acetylhydrolase. Purification and properties. I Biol Chem 2624223-4230.

90. Wardlow, M.L, Cox, C. P., Meng, K.E, Greene, D.E, and Farn; RS. 1986. Substrate specificity and partial characterization of the PAF-acylhydrolase in human serum that rapidly inactvates platelet-activating factor. / Hommol 136:3441-3446.

91. Imaizumi. 1996. The fate of platelet-activating factor. PAF acetylhydrolases from plasma and tissues. In Chapter in Lipobiology. R. Gross, editor: IAI Press, Connecticut. 141-162.

92. Noto, H., Hara, M., Karasawa, K., Iso, ON., Satoh, H., Togo, M., Hashimoto, Y, Yamada, $Y_{,}$Kosaka, $T_{v}$ Kawamura, M., et al. 2003. Human plasma platelet-activating factor acetylly. drolase binds to all the murine lipoproteins, conferring protection against oxidative stress. Arterioscler Thromb Vasc Biol 23:829-835.

93. Steinbrecher, U.P., and Pritchard, P. 1989. Hydrolysis of phosphatidyldholine during LDL oxidation is mediated by platelet-activating factor acetylhydrolase. / Lipid Res 30305-315.

94. Stremler, K.E., Stafforini, D.M., Prescott, S.M., and Mclntyre, T.M. 1991. Human plasma platelet-activating factor acetylhydrolase. Oxidatively fragmented phospholipuds as substrates. I] Biol Chem 266:11095-11103.

95. Stremler, K.E., Stafforini, D.M., Prescott, S.M. Zimmerman, G.A., and Mdintyre, TM. 1989. An oxidized derivative of phosphatidylcholine is a substrate for the platelet-activating factor acetylhydrolase from human plasma. J Biol Chem 264:5331-5334.

96. Min, J.H., Wilder, C., Aoki, J., Arai, H., Inoue, K, Paul, Lu, and Gelb, M.H. 2001. Platelet-activating factor acetylhydrolases: broad substrate specificity and lipoprotein binding does not modulate the catalytic properties of the plasma enzyme. Biochemisiry 40:4539-4549.

97. Lix, M., and Subbaiah, PW 1994. Hydrolysis and transesterification of platelet-activating factor by lecithin-cholesterol acyltransferase. Proc Natl Acad Sci UIS A 91:6035-6039.

98. Tsoukatos, D.C, Liapikos, T.A.,Tselepis, A.D., Chapman, M.J., and Ninio, E. 2001. Plateletactivating factor acetylhydrolase and transacetylase activities in human plasma low-density lipoprotein. Biochem J 357:457-464.

99. Tselepis, A.D., Dentan, C., Karabina, S.A., Chapman, M.J. and Ninio, E. 1995. PAF-degrading acetylhydrolase is preferentially associated with dense LDL and VHDL-1 in human plasma. Catalytic characteristics and relation to the monocyte-derived enzyme. Arterioscler 77 romb Vasc Biol 15:1764-1773.

100. Caslake, M.J.r Packard, C.., Suckling, K.E., Holmes, S.D., Chamberlain, P, and Macphee, C.H. 2000. Lipoprotein-associated phospholipase A(2), platelet-activating factor acetylhydrolase a potential new risk factor for coronary artery disease. Atherosclerosis 150:413419.

101. Tsaoussis, V., and Vakirtzi-Lemonias, C. 1994. The mouse plasma PAF acetylhydrolase: II. It consists of two enzymes both associated with the HDL J Lipid Mediat Cell Signal 9:317-331.

102. Rodrigo, L., Mackness, B., Durrington, P.N., Hernandez, .r. $_{*}$ and Mackness, M.1. 2001. Hydrolysis of platelet-activating factor by human serum paraoxonase. Biochen I 354:1-7.

103. Glomset, J.A. 1968. The plasma lecithins:cholesterol acyltransferase reaction. J Lipid Res 9:155167.

104. Aron, L., Jones, S, and Fielding, C.J. 1978. Human plasma lecithin-cholesterol acyltransferase. Characterization of cofactor-dependent phospholipase activity. ) Biol Chem 2537220-7226.

105. MoCall, MR, van den Berg, IJ., Kuypers, F.A., Tribble, D.L., Krauss, RM., Knoff, L.I., and Forte, T.M. 1994. Modification of LCAT activity and HDL structure. New links between cigarette smoke and coronary heart disease risk. Arterioscler Thromb 14:248-253.

106. Subbaiah, PV, and Liu, M. 1996. Disparate effects of oxidation on plasma acyltransferase activities: inhibition of cholesterol esterification but stimulation of transesterification of oxidized phospholipids. Biochim Biophys Acta 1301:115-126. 
107. Chisolm, G.M, and Steinberg D. 2000. The oxidative modification hypothesis of atherogenesis: an overview. Free Radic Eitol Med 28:1815-1826.

108. Quarck, R, De Geest, B., Stengel, D. Mertens, A., Lox, M., Theilmeier, G, Michiels, C, Raes, M. Bult, H., Collen, D, et al. 2001. Adenovirus-mediated gene transfer of human plateletactivating factor-acetylhycdrolase prevents infury-induced neointima formation and reduces spontanecus atherosclerosis in apolipoprotein E-deficient mice Circulation 103:2495-2500.

109. Min, J.H, Jain, M.K. Wilder, C. Paul, L, Apitz Castro, R, Aspleaf, D.C, and Gelb, MH. 1999. Membrane bound plasma platelet activating factor acetylhydrolase acts on substrate in the aqueous phase Biochemistry 38:12935-12942

110. MacPhee, CH, Moores, KE, Boyd, HF, Dhanak, D., Ife, R., Leach, C.A., Leake, D.S., Milliner, K., Patterson, RA, Suckling, KE, et al 1999. Lipoprotein-associated phospholipase $A_{y}$ pllatelet-aclivating factor acetyllhydrolase; generates two bioactive products during the oxidation of low density lipoprotein use of a novel inhibitor. Biochem /338 ( Pt 2):479-487.

111. Packard, C.J., Orelly, D.S., Caslake, M. J. McMahon, A.D., Ford, I, Cooney, I, Macphee, CH., Suckling K.E., Krishma, M. Wilkinson, F.E., et al. 2000. Lipoprotein-associated phospholipase $A_{i 2}$ as an independent predictor of coronary heart disease. West of Scotland Coronary Prevention Study Group. N Engl I Med 343:1148-1155.

112. Tselepis, A.D., and John Chapman, M. 2002. Inflammation, bioactive lipids and atherosclerosis: potential roles of a lipoprotein-associated phospholipase $A_{2}$ platelet activating factoracetyllhydrolase. Atheroscler Suppl 357-68.

113. Cupillard, L., Koumanov, K, Mattei, M.G., Lazdunski, M., and Lambeau, G. 1997. Cloning, chromosomal mapping, and expression of a novell human secretory phospholipase $A_{2^{\prime}}$ / Biol Chevit $272: 15745-15752$.

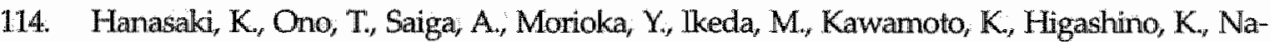
kano, K, Yarnada, K, Ishizaki, Jo, et al. 1999. Purified group X secretory phospholipase A(2) induced prominent rellease of arachidonic acid from human myeloid leukemia cells. I Biol Chew 274:34203-34211.

115. Morioka, Y., Saiga, A., Yokota, Y, Suzuki, N., Ikeda, M., Ono, T., Nakano, K., Fujii, N. Ishizaki, J., Arita, $H_{\text {, et al }} 2000$. Mouse group $X$ secretory phospholipase $A_{2}$ induces a potent release of arachidonic acid from spleen cells and acts as a ligand for the phospholipase $\mathrm{A}_{2}$ receptor. Arch Biochern Biophys 381:31-42.

116. van Eijk, J.H., Verheij, H.M., Dijkman, R, and de Haas; G.H. 1983. Interaction of phospholipase $A_{2}$ from Naja melanoleuca snake venom with monomeric substrate analogs. Activation of the enzyme by protein-protein or lipid-protein interactions? Eur / Biochen 132:183-1.88.

117. Jain, M.K. Egmond, MR., Verheij, H.M., Apitz-Castro, R., Dijkman, R, and De Haas, G.H. 1982. Interaction of phospholipase $\mathrm{A}_{2}$ and phospholipid bilayers. Biochim Biophys Acta $688: 341-348$.

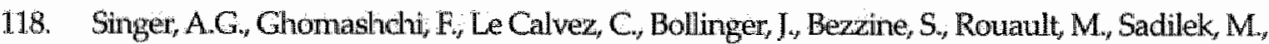
Nguyen, E, Lazdunski, M, Lambeau, $\mathrm{G}$, et al, 2002. Interfacial kinetic and binding properties of the complete set of human and mouse groups I, II, V, X, and XII secreted phospholipases $\mathrm{A}_{2}$.J Biol Chen 277:48853-48549.

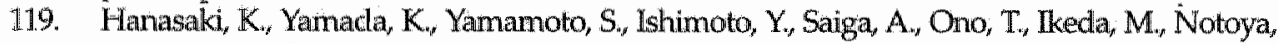
M. Kamitani, $S_{\text {, }}$ and Arita, H. 2002. Potent modification of low density lipoprotein by group $X$ secretory phospholipase $A_{z}$ is linked to macrophage foam cell formation. / Biol Chem 277:29116-29124.

120. Murakami, $\mathrm{M}_{x}$ and Kudo, I. 2004. Secretory phospholipase $\mathrm{A}_{2}$. Biol Pharm Bull 27:1158-1164.

121. Kim, K.P., Rafter, ].D., Bittova, L., Han, S.K, Snitko, Y, Munoz, N.M, Leff, A.R., and Cho, W. 2001. Mechanism of human group V phospholipase $A_{2}\left(P L A_{2}\right)$-induced leukotriene biosynthesis in human neutrophils. A potential role of heparan sulfate binding in PLA $A_{2}$ internalization and degradation. J Biol Chent 276:11126-11134.

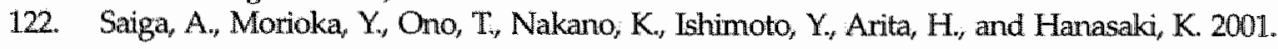


Group $X$ secretory phospholipase A(2) induces potent productions of various lippid mediators in mouse peritoneal macrophages. Biochtin Biophys Actn 153067-76.

123. Morioka, $Y_{\text {, }}$ Ikeda, M., Saiga, A., Fuju, N, Ishimoto, $Y_{y}$ Arita, H, and Hanasaki, K. 2000. Potential role of group $X$ secretory phospholipase $A(2)$ in oyclooxygenase-2-dependent $P G E(2)$ formation during colon tumorigenesis. FEBS Lett 487:262-266.

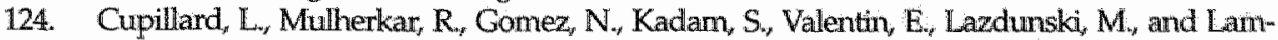
beau, G. 1999. Both group IB and group II A secreted phospholipases A, are natural ligands of the mouse 180-kDa M-type receptor. I Biol Chem 2747043-7051.

125. Arita, H, Hanasaki, K, Nakano, T, Oka, S, Teraoka, H, and Matsumoto, K 1991. Novel proliferative effect of phospholipase $\mathrm{A}$, in Swiss $3 \mathrm{~T} 3$ cells via specific binding site. $/ \mathrm{Biol}$ Chem 266:19139-19141.

126. Hanasaki, $K_{\text {, }}$ and Arita, H. 2002. Phospholipase A, receptor: a regulator of biological functions of secretory phospholipase A. Prostaglandins Other Lipid Medial 68-6971-82.

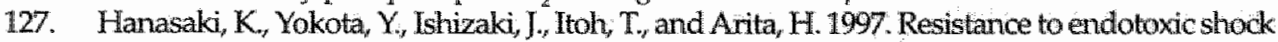
in phospholipase $A_{2}$ receptor-deficient mice. / Biol Chem 2723279232797.

128. Yokota, Y., Higashino, $\mathrm{K}$, Nakano, $\mathrm{K}_{\text {, }}$ Arita, H, and Hanasaki, $\mathrm{K}$. 2000. Identification of group $X$ secretory phospholipase A(2) as a natural ligand for mouse phospholipase A(2) receptor. FEBS Lett 478:187-191.

129. Yokota, Y., Notoya, M., Higashino, K., Ishimoto, Y, Nakano, K., Arita, H., and Hanasaki, K. 2001. Clearanoe of group $X$ secretory phospholipase A(2) via mouse phospholipase $A(2)$ receptor. FEBS Lett 509:250-254.

130. Kini, R.M., and Evans, H.J. 1989. A model to explain the phamacological effects of snake venom phospholipases $A_{2}$. Toxicon 27:613-635.

131. Higashino Ki, K, Yokota, Y., Ono, T., Kamitani, S., Arita, H, and Hanasaki; K 2002. Identification of a soluble form phospholipase $\mathrm{A}_{2}$ receptor as a circulating endogenous inhibitor for secretory phospholipase $A_{2}$. B Biol Chem 277:13583-13588.

132. Ancian, P., Lambeau, G., Mattei, M.G., and Lazdunski, M. 1995. The human 180-kDa receptor for secretory phospholipases $A_{2}$. Molecular cloning identification of a secreted soluble form, expression, and chromosonval localization. I Biol Chem 270:8963-8970.

133. Balsinde, J., Balboa, M.A., and Dennis, E.A. 1998. Functional coupling between secretory phospholipase $\mathrm{A}_{2}$ and cyclooxygenase-2 and its regulation by cytosolic group IV phospholipase A. Proc Natl Acad Sci U S A 95:7951-7956.

134. Balsinde, J., and Dennis, E.A. 1996. Distinct roles in signal transduction for each of the phospholipase $\mathrm{A}_{2}$ enzymes present in P388D1 macrophages. J Biol Chen 271:6758-6765.

135. Evans, J.H., Spencer, D.M., Zweifach, A, and Leshie, C.C. 2001. Intracellular calcium signals regulating cytosolic phospholipase $A_{2}$ translocation to internal membranes. J Bio! Chem 276:30150-30160.

136. Hirabayashi, T., Kume, K., Hirose, K., Yokomizo, T, Ino, M., Itoh, H., and Shimizu, "1, 1999. Critical duration of intracellular $\mathrm{CA}_{2}+$ response required for continuouss translocation and activation of cytosolic phospholipase $\mathrm{A}_{2}$. J Biol Chem 274:5163-5169.

137. Lin, L.L., Wartmann, M., Lin, A.Y., Knopf, I.L., Seth, A., and Davis, R.J. 1993, CLLA is phosphorylated and activated by MAP kinase. Cell 72,269-278.

138. Hefner, $Y_{\text {, B }}$ Borsch-Haubold, A.G., Murakami, M., Wilde, J.I., Pasquet, S., Schieltz, D., Chow mashchi, F., Yates, J.R., 3rd, Armstrong, C.G., Paterson, A., et al. 2000. Serine 727 phosphorylation and activation of cytosolic phospholipase $\mathrm{A}_{2}$ by MNK1-related protein kinases. / Biol Chem 275:37542-37551.

139. Wikkander, J., O Flaherty, J.T., Nixon, A.B. and Wykle, RL 1995, 5-Lipoxygenase products modulate the activity of the $85-\mathrm{kDa}$ phospholipase $\mathrm{A}_{2}$ in human neutrophils. I Biol Chem 270:26543-26549.

140. Uozami, N., Kume, K, Nagase, T, Nakatani, N., Ishii, S., Tashiro, F, Komagata, Y., Maki, K,

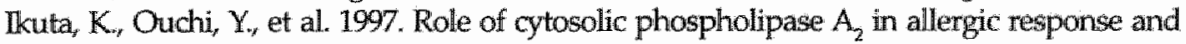


parturition. Nature 390618-622

141. Takaku, K, Sonoshita, M, Sasaki, N, Uozum, N., Doi, $Y$, Shimizu, T, and Taketo, MM. 2000. Suppression of intestinal polyposis in Apc(delta 716) knockout mice by an additional mutation in the cytosolic phospholipase A(2) gene. I Bid Chem 275:34013-34016.

142. Smith, WL, and Mamett, L.J 1991. Prostaglandin endoperoxide synthase: structure and catallysis: Biochinn Biophys Acta 1083:1-17.

143. Dubois, RN, Abramson, SB, Crofford, L., Gupta, RA, Simon, LS., Van De Putte, L.B., and Lipsky, P.E. 1998. Cyclooxygenase in biology and disease. Faseb J 12:1063-1073.

144. Samuelsson, B. 1983. From studies of biochemical mechanism to novel biological mediators: prostaglandin endoperoxides, thromboxanes, and leukotrienes. Nobel Lecture, 8 Deoember 1982. Biosci Rep 3791-813.

145. Vane, IR 1971. Inhibition of prostaglandin synthesis as a mecharvism of action for aspirin-like drugs: Nat New Biol 231:232-235.

146. Vila, L. 2004. Cydooxygenase and 5-lipoxygenase pathways in the vessel wall: role in atherosclerosis. Med Res Rev 24:399-424.

147. Willoughby, D.A., Moore, A.R, and Colville-Nash, P.R. 2000. COX-1, COX-2, and COX-3 and the future treatment of chronic inflammatory disease. Lancet 355:646-648.

148. Botting, R.M. 2000. Mechanism of action of aoetaminophen: is there a cyclooxygenase 3? Clin Infect Dis 31 Suppl 5:S202-210.

149. Kim, B.H. Kang, KS., and Lee, YS. 2004. Effect of retinoids on LPS-induced COX-2 expression and COX-2 associated PGE(2) release from mouse peritoneal macrophages and TNFalpha release from rat peripheral blood mononuclear cells. Toxicol Lett 150:191-201:

150. Guastadisegni, C., Nicolini, A., Balduzzi, M., A.jmone-Cat, M.A., and Minghetti, L. 2002. Modulation of PGE(2) and TNFalpha by nitric oxide and LPS-activated RAW 264.7 cells. Cytokine 19:175-1.80.

151. Mitchell, J.A., Belvisi, M.G., Akarasereenont, P., Robbins, R.A., Kwon, O.f, Croxtall, J., Bames, P. ., and Vane, J.R. 1994. Induction of cyclo-oxygenase-2 by cytokines in human pulmonary epithelial cells: regulation by dexamethasone. Br J Pharmacol 113:1008-1014.

152. Chandrasekharan, N.V., Dai, H., Roos, K.L., Evanson, N.K., Tomsik, J., Elton, T.S., and Simmons, D.L. 2002. COX-3, a cyclooxygenase-1 variant inhibited by acetaminophen and other analgesic/antipyretic drugs: cloning, structure, and expression. Proc Natl Acad Sci UI S A 99:13926-13931.

153. Schwab, J.M., Schluesener, H.I., and Laufer, S. 2003. COX-3: just another COX or the solitary elusive target of paracetamol? Lancet $361: 981-982$.

154. Simon, L.S. 1999. Role and regulation of cyclooxygenase-2 during inflammation. Am / Medt $106375-42 \mathrm{~S}$

155. Khuri, F.R., Wu, H. Lee, J.J., Kemp, B.L., Lotan, R, Lippman, S.M., Feng, L., Hong, W.K., and $\mathrm{Xu}_{*}$ X.C. 2001. Cydooxygenase-2 overexpression is a marker of poor prognosis in stage I nonsmall cell lung cancer. Cin Cancer Res 7:861-867.

156. Meade, E.A., Mclintyre, T.M., Zimmerman, G.A., and Prescott, SM. 1999. Peroxisome proliferators enhance cydooxygenase-2 expression in epithelial cells. J Biol Chem 274:8328-8334.

157. Baker, C.S., Hall, R.J., Evans, T. . , Pomerance, A, Madouf, J, Creminon, C, Yacoub, M.H. and Polak, J.M. 1999. Cydooxygenase-2 is widely expressed in atherosclerotic lesions affecting native and transplanted human coronary arteries and colocalizes with inducible nitric oxide synthase and nitrotyrosine particularly in macrophages. Arterioscler Thromb Vasc Biol 19:646655.

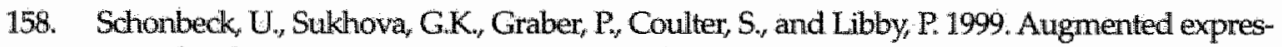
sion of cyclooxygenase-2 in human atherosclerotic lesions. Am / Pathol 155:1281-1291.

159. Belton, O., Byme, D. Keamey, D. Leahy, A., and Fitzgerald, D.J. 2000. Cyclooxygenase-1 and 2-dependent prostacydin formation in patients with atherosclerosis. Circulation 102:840 845. 
160. Cipollone, F, Prontera, C, Pini, B., Marini, M., Fazia, M., De Cesare, D. Iezzi, A, Ucchino, S. Boccoli, G., Saba, V, et al. 2001. Overexpression of functionally coupled cy dooxygenase-2 and prostaglandin $E$ synthase in symptomatic atherosderotic plaques as a basis of prostaglandin E(2)-dependent plaque instability. Circulation 104:921-927.

161. McAdam, BF., Catella-Lawson, F. Mardini, LA . Kapoor, S., Lawson, J A., and FitzGerald, G.A. 1999. Systemic biosynthesis of prostacydlin by cyclooxygenase (COX)-2: the human pharmacology of a selective inhibitor of COX-2. Proc Nat Aod Sci U S A 96272-277.

162. Catella-Lawson, F, McAdam, B., Morrison, B.W., Kapoor, S. Kujubu, D., Antes, L.., Lasseter, K.C, Quan, H, Gertz, B.J, and Fit.Gerald, G.A. 1999. Effects of specific inhibition of cyclooxygenase-2 on sodium balance, hemodynamics, and vasoactive eicosanoids. / Pharmacol Exp Ther 289:735-741.

163. Siegle, L., Klein, T., Zou, M.H., Fritz, P, and Komhoff, M. 2000. Distribution and cellular localization of prostacyclin synthase in human brain. I Histochen Cytodhem 48:631-641.

164. Liou, J.Y., Shyue, S.K., Tsai, M.J., Chung, C.L., Chu, K.X, and Wu, K.K. 2000 . Colocalization of prostacyclin synthase with prostaglandin $\mathrm{H}$ synthase-1 (PGHS-1) but not phorbol esterinduced PGHS-2 in cultured endothelial cells. / Biol Chern 275:15314-15320.

165. Korita, D., Sagawa, N., Itoh, H., Yura, S., Yosliida, M., Kalkui, K., Takemura, M., Yokoyama, C., Tamabe, T, and Fujii, S. 2002. Cyclic mechanical stretch augments prostacydin production in cultured human uterine myometrial cells from pregnant women: possible involvement of up-regulation of prostacyclin synthase expression. I Clin Endocrinol Metab 87:5209-5219.

166. Miyata, A., Hara, S., Yokoyama, C., Inoue, H. Ullrich, V. and Tanabe, T. 1.994. Molecular cloning and expression of human prostacydin synthase. Biodiem Biophys Res Commum 200:17281734.

167. Fleisher-Berkovich, S., and Danon, A. 1999. IL-1alpha but not IL-1beta-induced prostaglandin synthesis is inhibited by corticotropin-releasing factor: Cytokine 11:239-243.

168. Chevalier, D., Cauffiez, C, Bemard, C, Lo-Guidice, JM., Allorge, D., Fazio, F., Ferrari, N, Libersa, C, Lhermitte, M. D'Halluin, J.C., et al. 2001. Characterization of new mutations in the coding sequence and $5^{\prime}$-untranslated region of the human prostacylcin synthase gene (CYP8A1). Hum Genet 108:148-155.

169. Moncada, S., Gryglewski, R., Bunting, S., and Vane, J.R. 1976. An enzyme isolated from arteries transforms prostaglandin endoperoxides to an unstable substance that inhibits platelet aggregation. Nature 263:663-665.

170. Numaguchi, Y., Naruse, K., Harada, M., Osanai, H., Mokuno, S., Murase, K, Matsui, H., Toki,

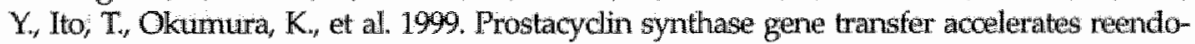
thelialization and inhibits neointimal formation in rat carotid arteries after balloon injury. Arterioscler Thronb Wasc Biol 19:727-733.

171. Mukherjee, D., Nissen, S.E, and Topol, E.J. 2001. Risk of cardiowasculler events associatied with selective COX-2 inhibitors. Jawa 286:954-959:

172. Blumenstein, M, Keelan, J.A. and Mitchell, M.D. 2001. Hypoxia attenuates PGE(2)but increases prostacyclin and thromboxane production in human term villous trophoblast. Plitcenta 22:519-525.

173. Moncada, S., and Vane, J.R. 1979. Arachidonic acid metabolites and the interactions between platelets and blood-vessel walls. N Engl J Med 300:1142-1147.

174. Vane, JR., and Botting, R.M. 1995. Pharmacodynamic profile of prostacydin. Am J Cardiol 75:3A-10A.

175. Yokoyama, $\mathrm{C}_{\text {, }}$ Miyata, A., thara, $\mathrm{H}_{s}$ Ullich, $\mathrm{V}_{\mathrm{s}}$ and Tanabe, $\mathrm{T}, 1991$. Molecular cloning of human platelet thromboxane A synthase. Biochem Biophys Res Conmum 178:1479-1484.

176. Ohashi, K, Ruan, KH., Kulmac, R. J., Wu, KK, and Wang, L.H. 1992. Primary structure of human thromboxane synthase determined from the CDNA sequence ] Biol Cherr 267:789. 793.

177. Shen, R.F., and Tax, H.H. 1998. Thromboxanes: synthase and receptors. / Biomed Sci 5:153- 


\section{2}

178. Dusting, G. J, Moncada, S., and Vane, JR. 19T7. Prostacyclin (PGX) is the endogenous metabollite responsible for relaxation of coronary arberies induced by arachindonic acid. Prostaglandins 133015.

179. Hamberg, $M$, Swensson, $J$, and Samuelsson, B. 1975. Thromboxanes: a new group of biologically active compounds derived from prostaglandin endoperoxides. Proc Natl Acad Sci U SA 72.29942998.

180. Hornby, EI, and Skidmore, IF. 1982. Exidence that prostaglandin endoperoxides can induce platelet aggregation in the absence of thromboxane $\mathrm{A}_{2}$ production. Biochem Phamacol 31:1158-1160.

181. Yamada, M, Numaguchi, $Y_{.}$Okumura, $K_{\text {, }}$ Harada, M., Naruse, $K_{\text {, }}$ Matsui, H., Ito, T., and Hayakawa, T. 2002. Prostacyclin symthase gene transfer modulates cyclooxygenase-2-derived prostanoid synthesis and inhibits neointimal formation in rat balloon-injured arteries. Arterios der Thomb Vasc Biol 22:256-262.

182. Cheng Y, Austin, S.C, Rocca, B, Koller, B.H, Coffman, TM, Grosser, T., Lawson, J.A., and FitzGerald G.A. 2002. Role of prostacy din in the cardiovascular response to thromboxane $\mathrm{A}_{2}$. Science 296539-541.

183. Vane, J.R, and Botting, R.M. 1998. Anti-inflammatory drugs and their mechanism of action. Inflamm Res 47 Suppl 2s:8787.

184. Silwerstein, FE, Faich, $G_{\text {s, }}$ Goldstein, JL, Simon, L.S., Pincus, T, Whelton, A., Makuch, R, Eisen, G., Agrawal, N.M., Stenson, W.F, et al. 2000. Gastrointestinal toxicity with celecoxib vis nonsteroidal anti-inflammatory drugs for osteoarthritis and rheumatoid arthritis: the CLASS study: A randomized controlled trial. Celecoxib Long-term Arthritis Safety Study. Jama 284:1247-1255.

185. Bombardier, C., Laine, L., Reicin, A., Shapiro, D., Burgos-Vargas, R., Davis, B., Day, R., Ferraz, M.B., Hawkey, C..., Hochberg M.C i, al. 2000. Comparison of upper gastrointestinal toxicity of rofecoxib and naproxen in patients with rheumatoid arthritis. VIGOR Study Group. $N$ Engl T Med 343:1520-1528, $1522 \mathrm{p}$ following 1528.

186. Konstam, M.A., Weir, M.R, Reicin, A., Shapiro, D., Sperling, R.S, Barr, E, and Gertz, B.J. 2001. Cardiovascular thrombotic events in controlled, clinical trials of rofecoxib. Circulation. $104: 2280-2288$.

187. Graham, D.J. 2004. Risk of acute infaction and sudden cardiac death in patients treated with COX-2 selective and non-selective NSAIDs. In Inflammopharmacology: Office of Drug Safety.

188. FitzGerald, G.A. 2003. COX-2 and beyond: Approaches to prostaglandin inhibition in human disease. Nat Rev Drug Discov 2879-890.

189. Juni, P., Nartey, L, Reichenbach, S., Sterchi, R., Dieppe, P.A., and Egger, M. 2004. Risk of cardiovascular events and rofecoxib: cumulative meta-analysis. Lancet 364:2021-2029.

190. Solomoin, D.H., Glynn, R.J., Levin, R, and Avorn, J. 2002. Nonsteroidal anti-inflammatory drug use and acute myocardial infarction. Arch Intem Med 162:1099-1104.

191. Watson; D.J., Rhodes, $\mathrm{T}_{\text {o, }}$ Cai, B., and Guess, H.A. 2002. Lower risk of thromboembolic car diovasicullar events with naproxen among patients with rheumatoid arthritis. Arch Intern Med $162: 1105-1110$.

192. Rahme, 紫, Pilote, $L_{4}$ and LeLorier, J. 2002. Association between naproxen use and protection. against aculte myocandial infarction. Arch Intern Med 162:1111-1115.

193. Bea, $\mathrm{F}_{*}$ Blessing, E., Bennett, B.J., Kuo, C.C., Campbell, L.A, Kreuzer, I. and Rosenfeld, M.E. 2003. Chronic inhibition of cyclooxygenase-2 does not alter plaque composition in a mouse model of advanced unstable atherosclerosis. Cavdiowasc Res 60:198-204.

194. Belton, OA, Duffy, A., Toomey, S, and Fitzgerald, D.J. 2003. Cyclooxygenase isoforms and platelet vessel wall interactions in the apolipoprotein $\mathrm{E}$ knockout mouse model of atherosclerosis. Circulation 108:3017-3023.

195. Qi, Z, Hao ${ }_{*}$ C.M., Langenbach, R.I., Breyer, R.M., Redha, R, Morrow, J.D., and Breyer, M.D. 
2002. Opposite effects of cyclooxygenase-1 and -2 activity on the pressor response to angioterisin II. J Clin lnvest 110:61-69.

196. Motham, S.G., Langenbach, R., Loftin, C.D., Tuano, HF, Vouloumanos, N. Jennette, J.C, Mahler, J.F, Kluckman, KD. Ledford, A., Lee, C.A, et al. 1995. Prostaglandin synthase 2 gene distuption causes severe renal pathology in the mouse Cull 83473482 .

197. Tanioka, T., Nakatani, Y, Semmyo, N., Murakami, M, and Kudo, I. 2000. Molecular identification of cytosolic prostaglandin $\mathrm{E}_{2}$ symthase that is functionally coupled with cyclooxygenase-1 in immediate prostaglandin $\mathrm{E}_{2}$ biosynthesis. J Biol Chem 275:327/5-32782.

198. Jakobsson, P.:. Thoren, S., Morgenstern, R., and Samuelsson, B. 1999. Identification of himman prostaglandin E synthase: a microsomal, glutathione-dependent, inducible enzyme, constituting a potential novel drug target. Proc Natl Acad SAU S A 96:7220-7225.

199. Forsberg, L., Leeb, L., Thoren, S., Morgenstem, R, and Jakobsson, P. 2000. Human glutathione dependent prostaglandin E synthase: gene structure and regulation. FEBS Lett 471:7882.

200. Stichtenoth, D.O., Thoren, S., Bian, H. Peters-Colden, M., Jakobsson, P. ${ }_{*}$, and Crofford, L. J. 2001. Microsomal prostaglandin $\mathrm{E}$ synthase is regulated by proinflammatory cytokines and glucocorticoids in primary rheumatoid synovial cells. I Immwnol 167:469-474.

201. Naraba, H., Yokoyama, C, Tago, N., Murakani, M., Krdo, I. Fueki, M., Oh-Ishi, S., and Tanabe, T. 2002. Transcriptional regulation of the membrane-associated prostaglandin $\mathrm{E}_{2}$ synthase gene. Essential role of the transcription factor Egr-1./ Brol Chem 277:28601-28608.

202. Kojima, $F$, Naraba, $H_{\text {, Sasaki }} Y_{,}$, Okamoto, R, Koshino, $T_{\text {,r }}$ and Kawai, $S$. 2002. Coexpression of microsomal prostaglandin $E$ synthase with cyclooxygenase- 2 in human rheumatoid synovial cells. I Rheumatol 29:1836-1842.

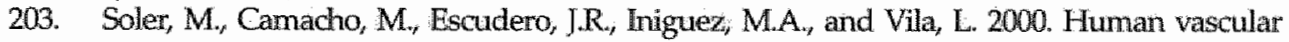
smooth muscle cells but not endothelial cells express prostaglandin E synthase. Cinc Res $87: 504-507$.

204. Matsumoto, $H_{\text {, Naraba, }}$, Murakami, M., Kudo, $\mathrm{I}_{\text {, }}$ Yamaki, K, Ueno, A, and Oh-ishi, $\mathrm{S}$. 1997. Concordant induction of prostaglandin $\mathrm{E}_{2}$ synthase with cyclooxygenase-2 leads to preferred production of prostaglandin $\mathrm{E}_{2}$ over thromboxane and prostaglandin $\mathrm{D}_{2}$ in lipopolysaccharide-stimulated rat peritoneal macrophages. Biochem Biophys Res Commm 230:110114.

205. Coleman, R.A., Smith, WL, and Narumiya, S. 1994. International Union of Phamacology classification of prostanoid receptors: properties, distribution, and structure of the receptors and their subtypes. Phamracol Rev 46:205-229.

206. Libby, P. Warner, S.j, and Friedman, G.B. 1988. Interleukin 1: a mitogen for human vascular smooth muscle cells that induces the release of growth-inhibitory prostanoids I Clin Inost. $81: 487-498$.

207. Corcoran, M.L., Stetler-Stevenson, W.G., DeWitt, D.Lat, and Wahl, L.M. 1994. Effect of cholera toxin and pertussis toxin on prostaglandin $\mathrm{H}$ synthase-2, prostaglandin $\mathrm{E}_{2}$ and matrix metalloproteinase production by human monocytes. Arch Biochem Biophys 310:481 - 488 .

208. Cipollone, F., Fazia, M., Jezzi, A., Ciabattoni, G., Pini, B., Cuccurullo, C, Ucchino, S., Spigonardo, F. De Luca, M. Prontera, C., et al. 2004. Balance between PGD synthase and PGE synthase is a major determinant of atherosclerotic plaque instability in humans. Artarioscler Thomb Vas Biol 24:1259-1265.

209. Callejas, N.A. Casado, M. Diaz-Guerra, M.J., Bosca, L. and Martin-Sanz, P. 2001. Expression of cyclooxygenase-2 promotes the release of matrix metalloproteinase- 2 and -9 in fetal rat. hepatocyttes. Hepatology 33:860-867.

210. Shankavaram, U.T., Lai, W.C., Netzel-Amett, S., Mangan, P.R., Ardans, J.A., Caterina, N., Stetler-Stevenson, W.G., Birkedal-Hansen, $H_{\text {, }}$ and Wahl, L.M. 2001. Monocyte membrane type 1-matrix metalloproteinase. Prostaglandin-dependent regulation and role in metalloproteinase-2 activation. / Biol Chem 276:19027-19032. 
211. Wesley, RB., 2nd, Meng, X, Godin, D, and Gallis, ZS. 1998. Extracellular matrix modulates macrophage functions characteristic to atheroma: collagen type I nhanoes acquisition of resident macrophage traits by human peripheral blood monocytes in vitro. Arterioscler Thromb Vasc Biol 18:432-440.

212. Hinson RM, Willams, J A, and Shacter, E. 1996. Elevated interleukin 6 is induced by prostaglandin $E_{2}$ in a murine model of inflammation possible role of cyclooxygenase 2 Proc Natl Acad Sc U S A 93:4885-4890.

213. Takayama, K, Garcia-Cardena, G., Sukhowa, G.K, Comander, J, Gimbrone, M.A., Jr, and Libby, 2002 Prostaglandin $E_{2}$ suppresses chemokine production in human macrophages through the EP4 receptor. / Biol Chem 277:44147-44154.

214. Haugen, $\mathrm{G}_{\text {, }}$ and Helland, L. 2001. Influence of preedampsia or matemal intake of omega-3 fatty acids on the wasoactive effect of prostaglandin F-two-alpha in human umbilical arteries. Gynecol Obstet Invest 5275-81.

215. Palea, S., Toson, G., Pietra, C., Trist, D. G., Artibani, W., Romano, O, and Corsi, M. 1998. Pharmacological characterization of thromboxane and prostanoid receptors in human isolated urinary bladder. Br J Pharmacol 124.865-872.

216. Peri, K.G., Quiniou, C., Hou, X, Abran, D, Varma, D.R., Lubell, W.D., and Chemtob, S. 2002. "HHG113: a novel selective FP antagonist that delays preterm labor. Semin Perinatol 26:389397.

217. Stier, CT, Jr, Roberts, L. J, 2nd, and Wong, P.Y. 1987. Renal response to 9 alpha, 11 beta-pros taglandin $\mathrm{F}_{2}$ in the rat. / Pharmaiol Exp Ther 243.487-491.

218. Honda, K., Arima, M. Cheng, G., Taki, S., Hirata, H., Eda, F, Fukushima, F, Yamaguchi, B., Hatano, M., Tokuhisa, $T$, et al. 2003. Prostaglandin $\mathrm{D}_{2}$ reinforces Th2 type inflammatory responses of arways to low-dose antigen through bronchial expression of macrophage-derived chernokine I Exp Med 198533-543.

219. Arimura, A., Yasui, K., Kishino, J, Asanuma, F, Hasegawa, H., Kakudo, S., Ohtani, M., and Arita, H. 2001. Prevention of allergic inflammation by a novel prostaglandin receptor antagonist, 5-5751. J Pharmacol Exp Ther 298:411-419.

220. Fujitani, Y., Kanaoka, Y., Aritake, K, Uodome, N., Okazaki-Hatake, K., and Urade, Y. 2002. Pronounced eosinophilic lung inflammation and Th2 cytokine release in human lipocalintype prostaglandin D synthase transgenic mice. / Lnmumol 168:443-449.

221. Minami, $T_{\text {, }}$ Okuda-Ashitaka, E., Nishizawa, M., Mori, $H_{.}$and Ito, S. 1997. Inhibition of nociceptin-induced allodymia in conscious mice by prostaglandin D2. Br / Pharmacol 122*605-610.

222. VanderEnde, D.S, and Morrow, J.D. 2001. Release of markedly increased quantities of prostaglandin $\mathrm{D}_{2}$ from the skin in vivo in humans after the application of cimamic aldehyde. J Am Acad Dermato $45: 62-67$.

223. Walch, L, Labat, C., Gascard, J.P, de Montpreville, V., Brink, C, and Norel, X. 1999. Prostanoid receptors involved in the rellaxation of human pulmonary vessels. Br I Phornhacol 12688594666 .

224. Cooper; B. 1979. Diminished platelet adenylate cyclase activation by prostaglandin $\mathrm{D}_{2}$ in acute thrombosis. Blood 54:684-693.

225. Egudhi, $Y_{,}$Eguchi, N., Oda, H., Seiki, K., Kijima, Y., Matsu-ura, Y, Urade, $Y_{\text {, }}$ and Hayaishi, O. 1997. Expression of lipocalin-type prostaglandin D synthase (beta-trace) in human heart and its accumulation in the coronary circulation of angina patients. Proc Natl Acad ScI U S A 94:14689-14694.

226. Garcia-Femandez, L.F., Iniguez, M.A., Eguchi, N., Fresno, M., Urade, $Y_{,}$and Mumoz, A. 2000. Dexamethasone induces lipocalin-type prostaglandin D synthase gene expression in mouse neuronal cells. Newrochem 75:460-470.

227. Straus, D.S., Pascual, G., Li, M., Welch, J.S., Ricote, M., Hsiang, CH., Sengchanthalangsy, L.L., Ghosh, $G_{,}$and Glass, C.K. 2000. 15-deoxy-delta 12,14-prostaglandin $J_{2}$ inhibits multiple steps in the NF-kappa B signaling pathway. Proc Nati Acad Sci U S A 97:4844-4849. 


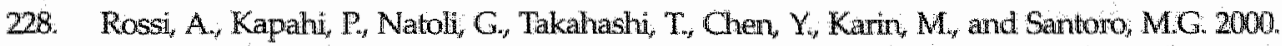
Anti-inflammatory cyclopentenone prostaglandins ane direct inhibitors of 1kappaB kinase. Nature 403:103-108.

229. Ricote, M, Li, A.C, Willson, TM, Kelly, C., and Glass, CK. 1998. The peroxisome prolifexator-activated receptor gamma is a negative regulator of macrophage activation. Natun 391:79-82.

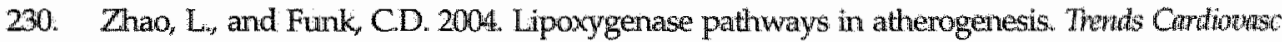
Med 14:191-195.

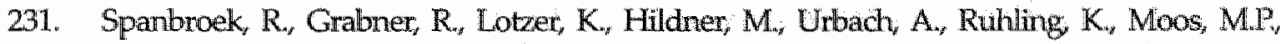
Kaiser, $\mathrm{B}$. Cohnert, T.U., Wahlers, T, et al. 2003. Expanding expression of the 5 -lipoxygenase pathway within the arterial wall during human atherogenesis. Proc Natl Acad Sci U S A $100: 1238-1243$.

232. Romano, M., Catalano, A., Nutini, M., DUrbano, E. Crescenzi, C, Claria, ], Libner, R., Davi, G., and Procopio, A. 2001.5-lipoxygenase regulates malignant mesothelial cell survival; in volvement of vascular endothelial growth factor. Faseb / 15:2326-2336.

233. Celletti, F.L., Waugh, JM., Amabile, P.G., Brendolan, A, Hilfiker, P.R, and Dake, M.D. 2001. Vascular endothelial growth factor enhances atherosclerotic plaque progression. Nat Mud 7:425-429.

234. Mehrabian, M. Allayee, H., Wong, I. Shi, W., Wang, X.P. Shaposhnik, Z, Funk, CD., Lusis, A.J., and Shih, W. 2002. Identification of 5-lipoxygenase as a major gene contributing to atherosderosis susceptibility in mice. Circ Res 91:120-126.

235. Sala, A., Testa, T., and Folco, G. 1996. Leukotriene $A_{y}$ and not leukotriene $B_{\phi}$ is the main 5lipoxygenase metabolite released by bovine leukocytes. FEBS Let 388:94-98.

236. Sala, A., Bolla, M., Zarini, S., Muller-Peddinghaus, R, and Folco, G. 1996. Release of leukotriene $\mathrm{A}_{4}$ wersus leukotriene $\mathrm{B}_{4}$ from human polymorphonuclear leukocytes. I Biol Chim 271:17944-17948.

237. Maclouf, $J_{2}$ Murphy, R.C, and Henson, PM. 1989. Transcellular sulfidopeptide leukotriene biosynthetic capacity of vascular cells. Blood 74:703-707.

238. Yokomizo, T., Izumi; T, and Shimizu, T. 2001. Leukotriene $\mathrm{B}_{4}$ : metabolism and signal transduction. Arch Biochem Bioplnys 385:231-241.

239. Friedrich, EB., Tager, A.M., Liu, E, Pettersson, A., Owman, C., Munn, L., Luster, A.D., and Gerszten, RE. 2003. Mechanisms of leukottiene B-triggered monocyte adhesion. Arterioscler Thromb Vasc Biol 23:1761-1767.

240. Melntyre, TM, Zimmerman, G.A., and Prescott, S.M. 1986. Leukotrienes $\mathrm{C}_{4}$ and D, slimulate human endothelial cells to synthesize platelet-activating factor and bind neutrophils. Proc Natl Acad Sci U S A 83:22042208.

241. Lehr, H.A., Hubner, C., Finckh, B., Angermuller; S., Nolte, D., Beisiegel, U., Kohlschutter; A., and Messmer, K. 1991. Role of leukotrienes in leukocyte adhesion following systemic administration of oxidatively modified human low density lipoprotein in hamsters. J Clin Invest 88:9-14.

242. Datta, Y.H., Romano, M., Jacobson, B.C., Golan, D.E, Serhan, C.N., and Ewenstein, B.M. 1995. Peptido-leukotrienes are potent agonists of von Willebrand factor secretion and P-selectin surface expression in human umbilical vein endothelial cells. Circulation 92:3304-3311.

243. Aiello, R.J., Bourassa, P.A., Lindsey, S., Weng, W., Freeman, A., and Showell, H.J. 2002. Leu. kotriene $\mathrm{B}_{4}$ receptor antagonism reduces monocytic foam cells in mice. Arteriosder Thromb Vasc Biol 22:443-449.

244. Porneca, E., Conti, P., Feliciani, C., Di Febbo, C, Reale, M., Mincione, G., Neri, M., Amerio, $\mathbb{P}_{\text {, }}$ and Cuccurullo, F. 1995. Cysteinyl-leukotriene $\mathrm{D}_{4}$ induced $\mathrm{IL}-1$ beta expression and release in rat vascular smooth muscle cells. Atherosderosis 115:181-189.

245. Devarai, S., and Jialal, I. 1999. Alpha-tocopherol decreases interleukin-1 beta release from activated human monocytes by inhibition of 5-lipoxygenase. Arterioscler Thromb Vasc Biol 
$191125-1133$.

246. Porreca, E, Di Febbo, C, Di Sciullo, A, Angelucci, D., Nasuti, M., Vitullo, P, Reale, M., Conti,

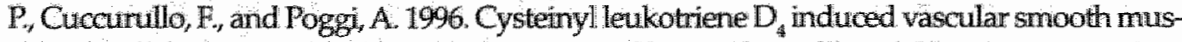
de cell proliferation: a possible role in myountimal hyperplasia. Thromb Haenost 76:99-104.

247. Nigam, $S_{\text {, }}$ and Schewe, T. 2000. Phospholipase A(2)s and lippid peroxidation Brochim Biophys Acta 1488167-181.

248. Kuwata, H, Yamamoto, S., Talkekura, A, Murakami, M, and Kudo, 1. 2004. Group IlA secretory phospholipase $A_{2}$ is a unique 12/15-lipoxygenase-regulated gene in cytokine-stimulated rat frbroblastic 3Y1 cells. Biochiom Biophys Acta 1686:15-23.

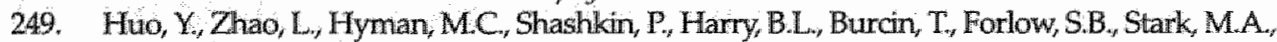
Smith, D.F, Clarke, S, et al. 2004. Critical role of macrophage 12/15-lipoxygenase for atherosclerosis in apolipoprotein E-deficient mice. Circulation 110:2024-2031.

250. George, I., Afek, A, Shaish, A., Levkovitz, H., Bloom, N., Cyrus, T., Zhao, L, Funk, C. D., Sigall, $\mathrm{E}$, and Harats, D. 2001. 12/15-Lipoxygenase gene disruption attenuates atherogenesis in LDL receptor-deficient mice. Circulation 104:1646-1650.

251. Kume, N., Cybulsky, M.L., and Gimbrone, M.A., Ir. 1992. Lysophosphatidylcholine, a component of atherogenic lipopnoteins, induces mononuclear leukocyte adhesion molecules in cultured human and rabbit arterial endothelial cells. J Clin Invest 90:1138-1144.

252. Murohara, T, Kugiyama, K, Ohgushi, M. Sugiyama, $S_{,}$Ohta, $Y_{\text {, and }}$ aasue, H. 1994. LPC in oxidized LDL elicits vasocontraction and inhibits endothelium- dependent relaxation. Am I Physiol 267: $12441-2449$.

253. Chai, Y., Howe, P.H., DiCorleto, P.E, and Chisolm, G.M. 1996. Oxadized low density lipoprotein and lysophosphatidylcholine stimulate cell cycle entry in vascular smooth muiscle cells. Evidence for release of fibroblast growth factor-2. Biol Chem 271:17791-17797.

254. Lauber, K., Bohn, E, Krober, S.M., Xiao, Y. J. Blumenthal, S.G., Lindemann, RK., Marini, P.s Wiedig, $C_{x}$ Zobywalski, A., Baksh, S., et al. 2003. Apoptotic cells induce migration of phagocytes via caspase-3-mediated release of a lipid attraction signal. Cell 113:717-730.

255. MoMurray, H.F., Parthasarathy, $S_{\text {, }}$ and Steinberg, D. 1993. Oxidatively modified low density lipoprotein is a chemoattractant for human T lymphocytes. / Clin Invest 92:1004-1008.

256. Steinberg, D., Parthasarathy, S., Carew, T.E, Khoo, J.C, and Witztum, J.L. 1989. Beyond cholesterol. Modifications of low-density lipoprotein that increase its atherogenicity. $N$ Engl I Med 320-915-924.

257. Steinbrecher, U.P., Parthasarathy, S. Leake, D.S., Witztum, I.L., and Steinberg, D. 1984. Modification of low density lipoprotein by endothelial cells involves lipid peroxidation and degradation of low density lipoprotein phospholipids. Proc Nall Acad Sc U S A 81:3883-3887.

258. Keaney, J.F., Jr, Xu, A., Cumningham, D., Jackson, T., Frei, B. and Vita ${ }_{\text {, }}$ J.A. 1995. Dietary probuool preserves endothelial function in dholesterol-fed rabbits by limiting vascular oxidative stress and superoxide generation. J Clin linwest 95:2520-2529.

259. Portman, O.W, and Alexander, M. 1969. Lysophosphatidylcholine conoentrations and metabolism in aortic intima plus inner media: effect of nutritionally induced atherosclerosis. I Lipud Res 10:158-165.

260. Liu-Wu, $X_{,}$Hurt-Camejo, E, and Wiklund, O. 1998. Lysophosphatidyldholine induces the production of IL-1beta by human monocytes. Atherostlerosis 137351-357.

261. Pages, C., Simon, M.F, Valet, P. and Saulnier-Blache, J.S. 2001. Lysophosphatidic acid synthesis and rellease. Prostaglandins Other Lipid Mediat 64:1-10.

262. Xie, $Y$, and Meier, KE. 2004. Lysophospholipase D and its role in LPA production. Cell Signal 16:975-981.

263. Ishii, I, Fukushima, $N$., Ye, $X_{\text {, }}$ and Chun, $J_{\text {. } 2004}$. Lysophospholipid receptors: signaling and biology. Annu Rev Biochem 73:321-354.

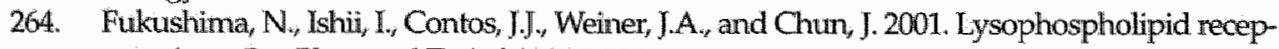
tors. Amwu Reo Pharmuol Toxicol 41:507-534. 
265. Anliker, $B_{*}$ and Chun, J. 2004. Cell surface receptors in lysophospholipid signaling. Sembin Cell Dev Biol 15:457-465.

266. Guyton, IR 2001. Phospholipid hydrolyticenzymes in a "eesspool' of arterial intimal lipoproteins: a mechanism for atherogenic lipid accumulation. Arteriogder Thomb Vasc Biol 21:884 886.

267. Tabas, I. 1999. Nonoxidative modifications of lipoproteins in atherogenesis. Awmu Ret Nutr 19:123-139.

268. Oomi, $\mathrm{K}_{w}$ Pentikainen, M.O. Ala-Koxpela, M., and Kovanen, P.T. 2000. Aggregation, fusion, and veside formation of modified low density lipoprotein particlest molecular mednanisms and effects on matrix interactions. J Lipid Res 41:1703-1714.

269. Khoo, J.C, Miller, E, McLoughlin, P, and Steinberg, D. 1988. Enhanced macrophage uptake of low density lipoprotein after self-aggregation. Arteriosclerosis 8:348-358.

270. Suits, A.G., Chait, A., Aviram, M., and Heinecke, J.W. 1989. Phagocytosis of aggregated Jipoprotein by macrophages: low density lipoprotein receptor-dependent foam-oell formation. Proc Nall Acad Sci US A 86:2713-2717.

271. Oorni, K., Hakala, J.K., Annila, A., Ala-Korpela, M., and Kovanen, P.T: 1998. Sphingonyelinase induces aggregation and fusion, but phospholipase $\mathrm{A}_{2}$ only aggregation, of low density lipoprotein (LDL) particles. Two distinct mechanisms leading to increased binding strength of LDL to human aortic proteoglycans. J Biol Chem 273:29127-29134.

272. Kleinman, Y., Krul, E.S., Burnes, M., Aronson, W, Pfleger, B., and Schonfeld, G. 1988. Lipoly sis of LDL with phospholipase $A_{2}$ alters the expression of selected apoB-100 epitopes and the interaction of LDL with cells. J Lipid Res 29:729-743.

273. Gorshkova, I.N., Menschikowski, M., and Jaross, W. 1996. Alterations in the physiochemical characteristics of low and thigh density lipoproteins after lipolysis with phospholipase $A_{2}$. A spin-label study. Biochim Biophys Acta 1300:103-113.

274. Hurt-Camejo, E. Andersen, S., Standal, R., Rosengren, B., Sartipy, P., Stadberg, E, and Johansen, B. 1997. Localization of nonpancreatic secretory phospholipase $A_{2}$ in normal and atherosclerotic arteries. Activity of the isolated enzyme on low-density lipoproteins. Arterioscler Thromb Vasc Biol 17:300-309.

275. Camejo, G., Hurt, E., Wiklund, O., Rosengren, B. Lopez, F, and Bondjers, G. 1991. Modifications of low-density lipoprotein induced by arterial proteoglycans and chondroitin-6-sulfate. Biochim Biophys Acta 1096:253-261.

276. Mateu, L. Avila, EM., Camejo, G., Leon, V., and Liscano, N. 1984. The structural stability of low-density lipoprotein. A kinetic X-ray scattering study of its interaction with artertal proteoglycans. Biochim Bioptyss Acta 795:525-534.

277. Pentikainen, M.O, Oomi, K., Lassila, R, and Kovanen, P.T. 1997. The proteoglycan decorin links low density lipoproteins with collagen type I. J Biol Chew 2727633-7638.

278. Han, S.K., Yoon, E.T., and Cho, W. 1998. Bacterial expression and characterization of human secretory class V phospholipase $\mathrm{A}_{2}$ Biochem 331 ( Pt 2) $353-357$.

279. Riessen, R., Isner, J.M., Blessing, E., Loushin, C., Nikol, S., and Wight, T.N. 1994. Regrional differences in the distribution of the proteoglycans biglycan and decorin in the extracellular matrix of atherosclerotic and restenotic human coronary arteries. Am J Pathol 144:962-974.

280. Austin, M.A., King, M.C. Vranizan, K.M., Newman, B., and Krauss, R.M. 1988. Inheritance of low-density lipoprotein subclass patterns: results of complex segregation analysis. Am J Hitm Genet 43:838-846.

281. Schissel, S.L., Tweedie-Handman, J., Rapp, J.H., Graham, G., Williams, K.J., and Tabas, I. 1996. Rabbit aorta and human atherosclerotic lesions hydrolyze the sphingomyelin of retained low-density lipoprotein. Proposed role for arterial-wall sphingomyelinase in subendothelial retention and aggregation of atherogenic lipoproteins. J Clin Invest 98:1455-1464.

282. Schissel, S.L., Jiang, X., Tweedie-Hardman, J, Jeong, T., Camejo, E.H., Najib, J., Rapp, J.H., Williams, KJ., and Tabas, I. 1998. Secretory sphingornyelinase, a product of the acid sphin 
gonyelinase gene, can hydrolyze atherogenic lipoproteins at neutral $\mathrm{pH}$. Implications for atheroselerotic lesion development. / Biol Chem $2732738-2746$.

283. Pentikainen, MO, Lehtonen, EM, and Kovanen, PT. 1996. Aggregation and fusion of modified low density lipoprotein. I Lipid Res 37:2638-2649.

284. $\mathrm{Xu}_{\mathrm{u}}, \mathrm{X}_{\mathrm{X}}$, and Tabas, I. 1991. Sphingomyelinase enhances low density lipoprotein uptake and ability to induce cholesteryl ester accumulation in macrophages. J Biol Chem 266:2484924858.

285. Dziennis, S, Van Etten, RA, Pahl, HL, Morris, DL, Rothstein, TL, Blosch, C.M., Ierlmutter, R.M. and Tenen, D.G. 1995. The CD11b promoter directs high-level expression of reporter genes in mactophages in transgenic mice. Blood 85319-329.

286. Gilroy, D.W. Newson, $J_{4}$, Sawnynaden, $P_{v}$, Willoughby, D.A., and Croxtall, J.D. 2004. A novel role for phospholipase $A_{2}$ isoforms in the checkpoint control of acute inflammation. Faseb) 18:489-498.

287. Levy, B.D, Clish, C.B., Schmidt, B, Gronert, K, and Serhan, CN. 2001. Lipid mediator class switching during acute inflammation: signals in resolution. Nat Immunol 2:612-619.

288. Gilroy, D.W., Colville-Nash, PR, Willis, D., Chivers, I., Paul-Clark, M. J., and Willoughby, D.A. 1999. Inducible cyclooxygenase may have anti-inflammatory properties. Nat Med 5:698-701.

289. Steed, D.L. 2003. Wound-healing trajectories. Surg Clin North Am 83.547-555, vi-vii.

290. Harwig, S.S., Tan, L., Qu, X.D., Cho, Y., Eisenhauer, P.B., and Lehrer, R.I. 1995. Bactericidal properties of murine intestinal phospholipase $\mathrm{A}_{2}$ J Clin linvest 95:603-610.

291. Buckland, A.G.; Heeley, E.L., and Wilton, D.C. 2000. Bacterial cell membrane hydrolysis by secreted phospholipases A(2): a major physiological role of human group Ila sPLA(2) involving both bacterial cell wall penetration and interfacial catalysis. Biochim Biophys Acta 1484:195206. 
8$$
\text { . }
$$ 


\section{Chapter 3}

\section{Macrophage specific overexpression of group IIA $\mathrm{sPLA}_{2}$ increases atherosclerosis and enhances collagen deposition}

Stijn A.I. Ghesquiere, Marion J.J. Gijbels ${ }^{1.2}$, Marit Anthonsen ${ }^{3}$, Patrick J.J. van Gorp ${ }^{1}$, Ingeborg van der Made ${ }^{1}$, Berit Johansen ${ }^{3}$, Marten H. Hofker ${ }^{1}$ and Menno P.J. de Winther ${ }^{1}$.

1 Dept. of Molecular Genetics, Cardiovascular Research Institute Maastricht, Maastricht University, The Netherlands.

2 Dept. of Pathology, Cardiovascular Research Institute Maastricht, Maastricht University, The Netherlands.

3 Dept of Biology Section on Molecular Biology and Biotechnology, Norwegian University of Science and Technology, Trondheim, Norway.

Journal of Lipid Research. 2005 Feb;46(2):201-10 


\section{Abstract}

Atherosclerosis is a chronic inflammatory disease of the vessel wall, characterized by the accumulation of lipid-loaden macrophages and fibrotic material. The initiation of the disease is accompanied by accumulation of modified lipoproteins in the vessel wall. Group IIA secretory phospholipase $\mathrm{A}_{2}$ (SPLA $\mathrm{A}_{2}$ IIA) is a key candidate player in the enzymatic modification of low-density lipoproteins. To study the role of $\$$ PLA, HA in macrophages during atherogenesis, transgenic mice were generated using the human sPLA ILA gene and the CD11b promoter. Bone marrow transplantation to $L D L$, receptor-deficient mice was performed to study sPLA IIA in atherosclerosis. After 10 weeks of high fat diet, mice overexpressing sPLA IIA in macrophages showed 2.3-fold larger lesions as compared to control mice. Pathological examination revealed that sPLA IIA-expressing mice had increased collagen in their lesions, independent of lesion size. However, smooth muscle cells or fibroblasts in the lesions were not affected. Other parameters studied, including T-cells and cell turnover, were not significantly affected by overexpression of SPLA $A_{2}$ IIA in macrophages. These data clearly show that macrophage SPLA IIA is a proatherogenic factor and suggests that the enzyme regulates collagen production in the plaque and thus fibrotic cap development.

\section{Introduction}

Atherosclerosis is a progressive disease of the large arteries. The accumulation of LDL in the intima of the vessel wal]. is a crucial factor in driving atherogenesis in both the early onset and subsequent progression to an advanced plaque (1). It is widely accepted that oxidized and enzymatically modified LDLs are pro-atherogenic (2). Modified LDLs attract monocytes, which subsequently differentiate into macrophages. The macrophages transform into foam cells as they take up the modified LDL particles. In addition, inflammatory mediators are released from the modified lipids, which contribute to an inflammatory response in the vessel wall $(3,4)$.

Several enzymes are known to modify LDL particles. Group IIA secretory phospholipase $\mathrm{A}_{2}$ (sPLA $\mathrm{SPA}_{2}$ ) has been detected in atherosclerotic lesions in CD68-posi-

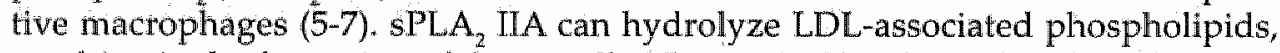
resulting in the formation of the so-called "bio-active" lipids, such as lysophospholipids and arachidonic acid. SPLA $A_{2}$ IIA is a member of a large family of related enzymes that are able to catalyze the hydrolysis of phospholipids at the sn-2 ester bond, a process that results in the generation of free fatty acids and lysophospholipids (8). sPLA IIA is widely expressed in the human body (9) and is considered to be important in the amplification of inflammation in many disease processes, including atherosclerosis $(6,7,10,11)$. Furthermore, sPLA ${ }_{2}$ IIA-modified LDL also show an enhanced affinity for proteoglycans $(10,12,13)$ and glycosaminoglycan binding (14).

Recent experiments with phospholipase group V, which is potent modifier of LDL, showed reduction in LDL particle size and subsequent aggregation (15). Smaller LDL particles have an increased preference for binding to proteoglycans (13). Although sPLA $\mathrm{A}_{2}$ IIA exhibits low enzymatic activity on intact LDL particles, binding 
to extracellular matrix components like decorin, versican and biglycan enhances the hydrolytic activity dramatically $(11,13,16)$. The interaction between LDL and proteoglycans changes the LDL properties; enabling human $\$ P L A, I M$, which is normally weakly active on LDL, to induce LDL aggregation and fusion, further increasing binding to the proteoglycan molecules $(17,18)$ and making it more proatherogenic.

Grass et al. (19) generated a transgenic mouse model to study the role of $\mathrm{PPLA}_{2}$ IIA in inflammation. In this model, the human SPLA, IIA gene was used with its own promoter and regulatory elements, leading to a natural pattern of overexpression. Interestingly, these mice developed atherosclerotic lesions even on a normal chow diet (20). However, LDL levels in these mice were increased, combined with decreased HDL levels and a reduction in paraoxonase activity: All of the systemic changes observed in this overexpression model are known nisk factors contributing to increased atherosclerosis, which makes this mouse model not very well suited to study the precise role of $s$ PLA II in the vessel wall on lesion formation. More recently, Webb et al. (21) used an elegant approach to avoid systemic effects by transplanting transgenic bone marrow from the above mentioned model to lethally irradiated LDL receptor $k$ nockout $\left(\mathrm{LDL} \mathbb{R}^{-1}\right)$ mice. After a period of a mild fatty diet, the mice showed a $73 \%$ increase in lesion size at the aortic root area. It was concluded that sPLA, IIA can contribute to atherosclerotic lesion development independent of the systemic lipoprotein metabolism. However; how SPLA IIA affects the pathology of lesion development was not addressed in detail.

We have previously shown that SPLA, IIA is not detectable in monocytes or differentiated, unstimulated macrophages, but its expression is induced upon minimally modified LDL stimulation of the latter (5). To acquire a better understanding of the role of SPLA IIA in lesion development and the effects on the lesion composition, we created a macrophage SPLA, IIA overexpression mouse model. In this mouse model, a selective expression was obtained by using the myeloidspecific CDI1b promoter fused to the human genomic SPLA IIA gene lacking the endogenous promoter. The CD11b promoter has been show to drive transgene expression in granulocytes, monocytes, and macrophages (22). Bone marrow from these mice was transplanted to LDLR mice to study atherogenesis. Macrophage $S P L A_{2}$ was shown to strongly increase atherosclerosis and increase collagenous cap formation. Other inflammatory parameters such as T-cells, granulocytes, and cell turnover, were not affected.

\section{Materials \& Methods}

\section{Mouse models}

A $3.8 \mathrm{~kb}$ fragment, containing the genomic SPLA, IIA gene, was isolated from vector pBG34:3.8 with HindIII and blunted. This fragment corresponds to the Eagl/ NotI fragment described by Kramer et al. (23). The blunted HindIII fragment was ligated into a pB202 vector containing a $1.7 \mathrm{~kb}$ human CD11b promoter (22) (a generous gift from Dr. D. Tenen, Beth Israel Hospital, Boston, MA), which was cut with BamHI and NolI and also blunted. Correct orientation was confirmed with digestion and sequencing from the CD11b promoter. To generate transgenic mice, 
the pB202:sPLA $\mathrm{A}_{2}$ construct was partial digested with HindIII and SacII restriction enzymes. The complete $5.6 \mathrm{~kb}$ fragment (CDI1b $+\mathrm{sPLA}_{2}$ ПIA) was isolated with electrophoresis in agarose gel, followed by electroelution. Oocyte injection to generate transgenic mice was performed according to standard procedures (24). Two transgenic mice lines were obtained (line 1 and 2). Before their use in experiments, the transgenic mice were tested for presence of endogenous sPL $A_{2}$ IIIA with Southern blot analysis using a ${ }^{32} \mathrm{P}$-labeled probe.

Because of a mutation, C57B1/6 mice are natural knockouts for mouse sPLA $\mathrm{A}_{2}$ ILA (25). The transgenic SPLA IIA bone marrow donors were backcrossed 5 times with C57B1/6 mice. LDLR $/ 1$ mice have been described (26). They were backcrossed four times to $\mathrm{C} 57 \mathrm{Bl} / 6 \mathrm{~J}$ mice and originally obtained from the Jackson Laboratory (Bar Harbor, ME). All animal experiments were approved by the Committee for Animall Welfare of Maastricht University.

\section{Northern blotting}

To study the expression of the transgene, total RNA was isolated from various tissues and from thioglycollate-elicited and bone marrow-derived macrophages, which were isolated as described before (27). RNA Instapure System (Eurogentec S.A. Seraing, Belgium) was used to isolate RNA from the samples. When appropriate, the tissues were first frozen and mechanically pulverized. The RNA samples were separated by electrophoresis through a denaturing agarose gel $(1 \% \mathrm{w} / \mathrm{v})$ containing $7.5 \%$ formaldehyde and then transferred to Hybond $\mathrm{N}$ according to the manufacturer's recommendations. Hybridization was performed on the blots with ${ }_{2}^{2}$ P-labeled human SPLA, IIA DNA probe at $54^{\circ} \mathrm{C}$ in hybridization mixture $(50 \%$ formamide, $1 \%$ SDS, $10 \%$ dextransulphate, $5 \times$ SSC, $1 \times$ Denhardts, $0.2 \mathrm{M} \mathrm{NA}_{2} \mathrm{PO}_{4^{\prime}}$ and $50 \mathrm{mg} / \mathrm{ml}$ sonicated salmon sperm DNA).

\section{Phospholipase activity}

Levels of sPLA $\mathrm{A}_{2}$ protein in cell lysates of peritoneal macrophages were assessed by measuring the hydrolysis of FFAs from 1-palmitoyl-2-oleoyl-sn-glycero-3-phosphoglycerol (Sigma), as described in detail before (28). Phospholipase activity in blood of the transplanted mice was measured in pooled plasma samples collected at week 8 after the start of the diet, using a photometric assay (no. 765001; Cayman Chemical Co., Ann Arbor, MI).

\section{In vitro foam cell formation}

Bone marrow macrophages were cultured as described before (27). LDL was isolated according to standard procedures and modified as described before (27). Cells were incubated for $24 \mathrm{~h}$ in culture medium with or without $25 \mu \mathrm{g} / \mathrm{ml}$ native LDL or $25 \mu \mathrm{g} / \mathrm{ml} \mathrm{Cu}^{2+}$ oxidized LDL. Cholesterolesters were determined as described before (29).

\section{Bone marrow transplantation}

Thirty-four 9-week old female littermate LDLR $^{-1}$ mice were put in filter-top cages. The mice received acidified water supplemented with neomycin $(100 \mathrm{mg} / \mathrm{l})$ and polymixin B sulfate $(60,000 \mathrm{U} / 1)$, during the week before transplantation. One day 
before the actual transplantation, the mice were irradiated with a lethal dose of 10 Gy röntgen. The bone marrow of five female wildtype mice and five female trans ${ }^{-}$ genic sPLA, IIA littermates was collected and pooled. Bone marrow cells were derived by flushing the femur and tibia of the mice. For transplantation, 16 mice received wildtype bone marrow (wt-tp) and 18 mice received transgenic derived bone marrow ( $\left(\mathrm{PLA}_{2}-\mathrm{tp}\right.$ ). Bone marrow cells $\left(10^{7}\right)$ were injected in the tail vein of each mouse.

\section{Blood samples and analysis}

Four weeks after transplantation, the mice were put on a high-fat diet containing $16 \%$ fat, $0.15 \%$ cholesterol, and no cholate (Hope Farms, Woerden, The Netherlands) for 10 weeks. At two time points ( 4 weeks and 8 weeks of diet), blood was collected from the mice after overnight fasting. Plasma cholesterol was determined with an enzymatic essay kit (catalog number 401; Sigma-Aldrich, Zwijndrecht, The Netherlands). The blood lipid profile was analyzed with pooled plasma collected after 8 weeks of diet. The samples were separated over an Superose 6PC $3.2 / 30$ column in an AKTABasic chromotography system (Amersham Biosciences, Roosendaal, The Netherlands). In the collected fractions (50), the cholesterol levels were determined by adding Roche Cholesterol CHOL_PAP reagent (catalog number 1489232; Roche Diagnostics, Mannheim, Germany) and measured with plate reader (Bio-Rad laboratories, Veenendaal, The Netherlands). Paraoxonase activity was measured in the blood of 10 randomly selected mice ( 5 wt-tp and 5 sPLA $A_{2}$ tp). The activity was determined as the rate of conversion of paraoxon into $p$-nitrophenol and diethylphosphate by hydrolysis $(30,31)$. Serum of each mouse was incubated with $5 \mathrm{mM}$ Diethyl p-nitrophenyl phosphate (Sigma-Aldrich Chemie Gmbh, Steinberg, Germany). The reaction was kept at $37^{\circ} \mathrm{C}$ and the extinction rate was recorded at $450 \mathrm{~nm}$ with a microplate reader (BioRad Laboratories).

\section{Atherosclerosis assessment and lesion analysis}

After 10 weeks of high-fat diet the mice were killed. Atherosclerosis was analyzed as described before (27). Briefly, the animals were dissected and hearts and aortic arches were removed and bisected perpendicularly to the heart axis, just below the atrial tips. The tissue was frozen in tissue-tec (Shandon, Veldhoven, The Netherlands) with the base facing downward. Cryosectioning was performed from the atrioventricular area. Sections $(7 \mu \mathrm{m})$ were made with an interval of $42 \mu \mathrm{m}$ and collected on slides. The aortic lesion area was analyzed using serial sections with $42 \mu \mathrm{m}$ interval, beginning from the onset of the aortic valves until the valves had disappeared. The collected sections were stained with toluidin blue and digitally photographed and quantified using digital image software (Adobe Photoshop 6.0).

\section{Pathology}

All pathology measurements were done without knowledge of the genotype. Lesion sections from the aortic root were fixed in acetone and incubated with antibodies against various cell types and cell markers. The following antibodies were used: FA11 (macrophages), NIMP (granulocytes), 1A4 (smooth muscle 
cells), ERTR7 (fibroblasts), KT3 (T-cells), Ki-67 (cell proliferation), and sPLA, IA (a generous gift from Dr. Timo Nevalainen, Turku University, Turku, Finland). Terminal deoxynucleotidyl transferase end labeling (TUNEL) assay (Roche) was used to detect apoptosis. Sirius Red staining was performed to visualize collagen. The stained sections were all photographed in the same conditions with a digital microscope camera (Nikon DXM1200). To quantify the percentage of collagen within the lesions, the lesion area was selected manually and subtraction filters (red channel minus the green channel) were applied to select the stained pixels (Adobe Photoshop 6.0). The same filter preferences were used on all sections, and quantification was assessed blindly (i.e., without knowledge of genotype).

To quantify necrosis, necrotic areas were measured using toluidin-stained sections as described before (27). Cellular density was determined by counting nuclei and measuring area. All data are expressed relative to the lesion area size. For statistical analysis, one observation was the average value per mouse.

\section{Statistical analysis}

All data were analyzed using Graphpad Prism 4.01. Groups were compared using Welch's corrected two-tailed, non paired t-tests and data are expressed as means \pm SEM. Tests were considered statistically significant at $p<0.05$.

\section{Results}

\section{Generation and phenotyping of the SPLA IIA transgenic mice}

To asses the local, vascular role of SPLA, IIA in atherosclerosis, in the absence of systemic effects of sPLA, IIA, a macrophage overexpression mouse model was created. The human genomic sPLA IIA gene was cloned behind the CDI1b promoter (22) (Fig. 1A). Two transgenic mouse lines were successfully generated. The mRNA expression pattern was examined by Northern blot analysis. The mice of line 1 showed expression (Fig. 1B) in liver, spleen, lung, and isolated primary macrophages. A similar expression pattern was observed in line 2 , but expression was lower (data not shown). Therefore, all following experiments described here were performed with line 1. Both bone marrow derived macrophages (not shown) and thioglycollate-elicited macrophages (Fig. 1B) exhibited high expression of sPLA IIA. To test if the observed mRNA expression patterns translated into effective production and presence of the SPLA IIA protein, immunohistochemistry using

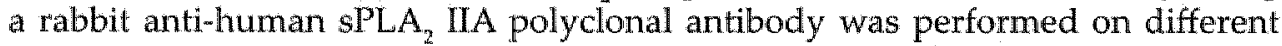
organs. The antibody used is known not to show cross-reactivity with endogenous mouse sPLA IIA and is specific for the sPLA ${ }_{2}$ of group IIA (32), confirmed by the lack of signal in wildtype tissues. Immunostainings (Fig. 1C) showed presence of SPLA, IIA in macrophages in different tissues. An abundance of positive stained cells were observed in the spleen of the transgenic mice. Lung showed a moderate level of positive cells, whereas liver had only a few cells. In all organs tested, willdtype mice remained negative for $s \mathrm{PLA}_{2}$ IIA. Staining with an antibody directed against CD11b (Mac1) confirmed the myeloid-specific expression of the sPLA $\Pi$ IA transgene (not shown). Finally, phospholipase activity was measured in cell lysates from thioglycollate-elicited macrophages. In cells from transgenic mice 12-18 


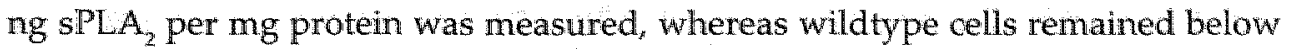
detection level. In vitro foam cell formation (i.e. cholesterolester accumulation) of wildtype or sPLA $A_{2}$ transgenic bone marrow macrophages was not different after overnight incubation without $\mathrm{LDL}(0.47 \pm 0.2$ and $0.62 \pm 0.1 \mu \mathrm{g} / \mathrm{mg}$ protein, respectively), $25 \mu \mathrm{g} / \mathrm{ml}$ native $\mathrm{LDL}(0.88 \pm 0.1$ and $0.83 \pm 0.2 \mu \mathrm{g} / \mathrm{mg}$ protein), or $25 \mu \mathrm{g} / \mathrm{ml}$ oxidized LDL $(5.2 \pm 0.2$ and $5.1 \pm 0.2 \mu \mathrm{g} / \mathrm{mg}$ protein).

\section{Bone marrow transplantation, lipid analysis, and phospholipase activity}

To test the effect of sPLA 2 IIA on atherogenesis, bone marrow of wildtype mice and transgenic littermates was transplanted to lethally irradiated atherosclerosissusceptible LDLR $^{-1}$ mice. The resulting mice were all LDLR ${ }^{-*}$ with either sPLA, IIA transgenic hematopoietic cells (sPLA $A_{2}-t p$ ) or wildtype hematopoietic cells (wt-tp). Both groups were allowed to recover for 4 weeks prior to high-fat feeding for 10 weeks.

Plasma cholesterol levels in the blood of the mice were examined after 4 and 8 weeks of diet (Fig. 2A). After 4 weeks, the cholesterol levels in the sPLA ${ }_{2}$-tp mice were slightly higher than in the wt-tp mice $(26.8 \pm 1.1$ and $22.1 \pm 1.0 \mathrm{mM}$, respectively; $\mathrm{p}<0.01$ ). After 8 weeks, cholesterol levels were further increased but were no longer significantly different between groups $(37.2 \pm 2.7$ and $30.8 \pm 2.7 \mathrm{mM}$ for sPLA $A_{2}$-tp and wt-tp respectively; $p=0.10$ ). Paraoxonase activity in the blood of the

A

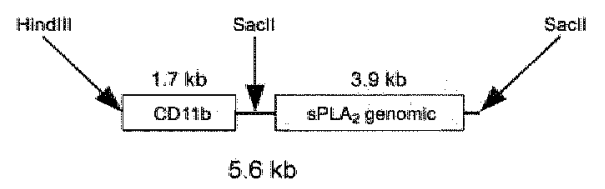

B

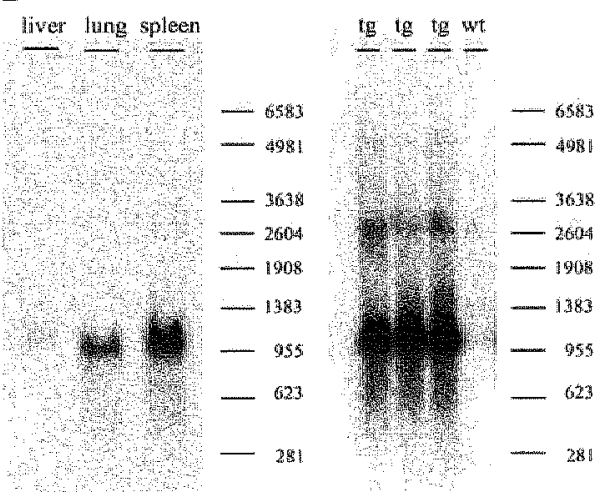

C
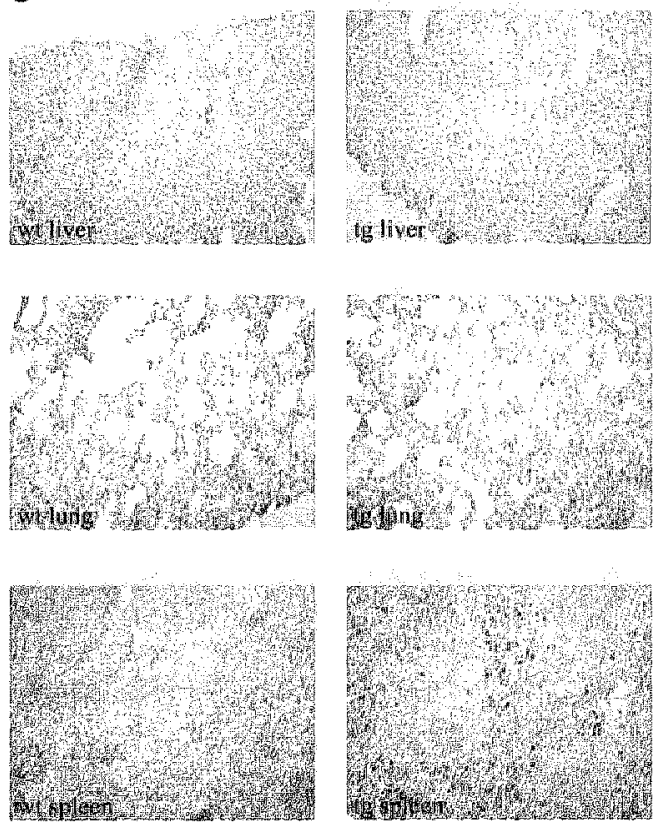

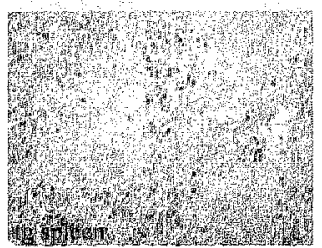

Fig. 1: Generation and characterization of CD11b-sPLA, IIA mice. A: Schematic representa tion of the CD11b-sPLA IMA construct. The $5.6 \mathrm{~kb}$ fragment was used for oocyte injection. $\mathrm{B}$ : Northern blot analysis of liver, lung, and spleen (left blot) and thioglycollate-elicited macrophages (right blot) from line 2 mice hybridized with a human SPLA LIA probe. $\operatorname{tg}$, SPLA IIA transgenic; wt, wildtype. C: Immunostaining of tissues with rabbit-anti-human $S P_{L A} A_{2}$ IIA serum. Liver, lung, and spleen from wildtype (wt) and transgenic (tg) mice are shown. 

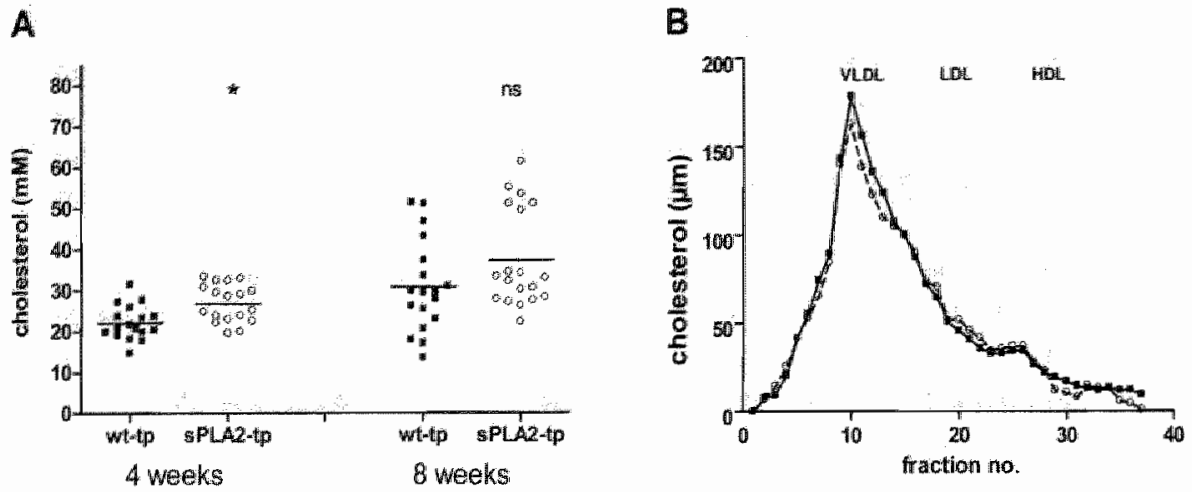

Fig. 2: Cholesterol. levels and lipoprotein profile of SPLA, IIA and wildtype transplanted LDLR mice. A: Cholesterol levels in wildtype (wt-tp; closed squares) and sPLA IIA ( $\left(\mathrm{PLA}_{2}\right.$-tp; open circles) transplanted LDLR ${ }^{*-}$ mice after 4 and 8 weeks of high-fat diet. B: Lipoprotein cholesterol profiles of wildtype (closed squares) and SPLA ILA (open circles) transplanted LDLR ${ }^{-1}$ mice after 8 weeks of high fat diet. The values represented in the graph show the cholesterol content in each fraction.

mice after 8 weeks on diet did not differ between the wildtype and the transgenic group ( $1.37 \pm 0.11$ and $1.39 \pm 0.26 \mathrm{IU} / \mathrm{ml}$, respectively). To examine the blood lipid levels in more detail, lipid profiles were generated using plasma samples from week 8 (Fig. 2B). No major differences in VLDL, LDL, and HDL fractions were observed between the wt-tp and sPLA -tp mice.

Phospholipase activity of the pooled plasma samples was measured at 8 weeks, and no significant difference was detected $(22.4 \pm 0.2$ and $22.3 \pm 0.7 \mu \mathrm{mol} / \mathrm{min} / \mathrm{ml}$ for wt-tp and sPLA $A_{2}$-tp, respectively).

Effect of macrophage-specific sPLA 2 IIA overexpression on atherosclerotic lesion size

Bone marrow-transplanted mice were sacrificed after 10 weeks of high-fat diet. Analysis of atherosclerotic lesions was done at the aortic root, near the heart valves. Quantification of the lesion area revealed a 2.3 -fold increase in lesion size (Fig. 3) in sPLA $-t p$ animals compared to $w t-t p$. The sPLA ${ }_{2}$-tp mice had an average lesion size of $130.0 \pm 15.1\left(\times 1000 \mu \mathrm{m}^{2} ; \mathrm{n}=18\right)$, whereas the wt-tp mice had an area of $56.0 \pm 11.3\left(\times 1000 \mu \mathrm{m}^{2} ; n=16\right)(\mathrm{P}<0.001)$. Regression analysis did not show a clear correlation between lesion area and cholesterol levels at either 4 weeks of diet $\left(R^{2}=0.11\right.$, $p=0.25$ and $R^{2}=0.04, p=0.51$ for $w t-t p$ and $s P L A_{2}-t p$, respectively) or 8 weeks of diet $\left(\mathrm{R}^{2}=0.019, \mathrm{p}=0.60\right.$ and $\mathrm{R}^{2}=0.16, \mathrm{p}=0.12$ for $\mathrm{wt}-\mathrm{t} \mathrm{p}$ and $\mathrm{sPLA} \mathrm{A}_{2}$-tp, respectively)

In addition to the quantitative approach of measuring the lesion area, the plaques were also studied in more detail for their composition. Representative lesions stained with toluidin blue are shown in Fig. $4 \mathrm{~A}$, and $4 \mathrm{~B}$. The major constituents of the lesions were macrosialin-positive macrophages (Fig. 4C, and 4D) while also some collagenous cap formation was also observed using Sirius red staining (Fig. $4 \mathrm{E}$, and $4 \mathrm{~F})$. The presence of sPLA ${ }_{2}$ IIA in the lesions was confirmed by immunostaining (Fig. 5). The sPLA ${ }_{2}$-tp mice showed clear staining in the lesions, whereas the wt-tp mice remained negative. Interestingly, lesions from sPLA $A_{2}-t p$ mice were 
positive in their macrophage areas, but the majority of the SPLA IIA staining was in the media. This may indicate accumulation of macrophage-derived sPLA $A_{2}$ in the medium.

In addition, the lesions were classified according to three different types as described before (27): 1) early lesions, with fatty streaks consisting of only foam cells; 2) moderate lesions, or foam cell lesions with a fibrotic cap; 3) severe lesions, with increased fibrosis and media involvement. Interestingly, although the lesions in the sPLA $\mathrm{A}_{2}$-tp mice were 2.3 fold larger, no signifi-

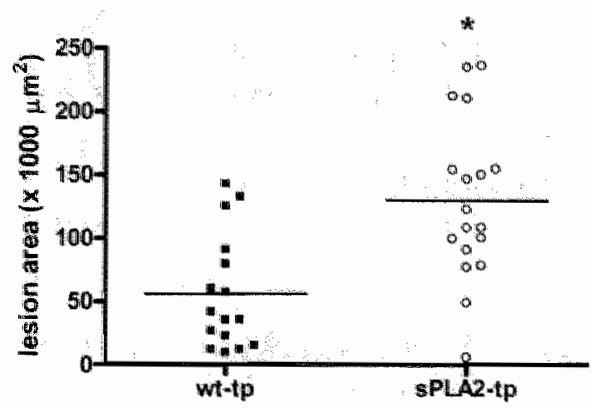

Fig. 3: Atherosclerotic lesion size in SPLA IIA and wildtype transplanted LDLR mice. ${ }^{+1}$ Lesion area measurements of wildtype (wt-tp) and SPLA. IIA (sPLA -tp) transplanted LDL mice. Symbols represent individual mice.

cant shift towards a more severe phe$* P<0.001$.

notype of the lesions was observed (early lesions: 19.5 and 15.7; moderate lesions: 65.9 and 74.5 ; advanced lesions; 14.6 and 9.8; for wt-tp and sPLA $A_{2}$-tp, respectively; all as relative percentages of the total number of lesions). This demonstrates that the lesions in $\mathrm{sPA}_{2}$-tp mice are much larger but not more severe as compared to their controls.

\section{Plaque phenotype}

To characterize atherosclerosis in more detail different cellular parameters were determined. All were expressed relative to the size of the lesions.

Two factors important for plaque stability (i.e., necrosis and collagen content) were analyzed. Necrotic area did not differ between the two groups (Fig. 6A). Also in both groups, no clear difference in correlation between lesion size and necrosis could be found (Fig. 6B). Interestingly, collagen, as measured by Sirius red staining of the lesions, was 2 -fold increased in SPLA - tp lesions $(6.5 \pm 1.5 \%$ and $13.6 \pm 2.9 \%$ for wt-tp and $s P L A_{2}-t p$, respectively; $\mathrm{p}<0.05$ ), even though the values were corrected for lesion size (Fig. $6 \mathrm{C}$ ). Regression analysis confirmed this difference, showing correlation between lesion size and collagen content $\left(R^{2}=0.62\right.$, $p<0.0001$ and $R^{2}=0.73, P<0.0001$ for wt-tp and sPLA ${ }_{2}$-tp, respectively) with a 2-fold steeper slope for sPLA ${ }_{2}$ tp mice $\left(0.20 \pm 0.02\right.$ and $0.38 \pm 0.03$ for $w t-t p$ and $s P L A_{2}{ }^{-t p}$, respectively; $P<0.001$ ) (Fig. $6 D$ ). These data show that overexpression of $s P L A_{2}$ in macrophages does not affect necrosis but results in atherosclerotic lesions with more collagen content.

Other cellular parameters were also studied. Smooth muscle cell (SMC) content was analyzed because increased collagen might be a reflection of increased SMC in the lesions. However, quantification of these cells after SMC $\alpha$-actin staining did not reveal any differences between sPL $\mathrm{A}_{2}$-tp and controls (Fig. 7A). Moreover, fibroblasts (ERTR7 positive cells) also did not differ between groups ( $4.6 \pm 1.1 \%$ and $5.7 \pm 1.6 \%$, for wt-tp and $\mathrm{sPLA}_{2}-\mathrm{t}$, respectively). Next , T-cells were quantified. Although they appeared to be reduced (Fig. 7B) the difference did not reach statistical significance $(\mathrm{p}=0.10)$. For cell turnover, proliferation (i.e., Ki-67 positivity), 
and apoptosis (TUNEL staining) were examined. Proliferation appeared to be reduced in $s P L A_{2}$-tp mice, but the difference was only borderline significant $(\mathrm{p}=0.06$; Fig. 7C). Finally, apoptosis was not changed in sPLA,-tp group as compared With wt-tp mice (Fig. 7D).

Because changes in cell turnover (i.e. apoptosis, necrosis, and proliferation), and SMC or collagen content could not completely account for the 2.3-fold increase in total lesion size observed, macrophage density was determined. The increase in lesion size could be the result of either increased cell size or just increased cell number. Counting of the number of macrophages per selected area showed no differences in cell density between wt-tp and sPLA ${ }_{2}-t p$ (574.5 \pm 42.8 and $548.2 \pm 24.3$
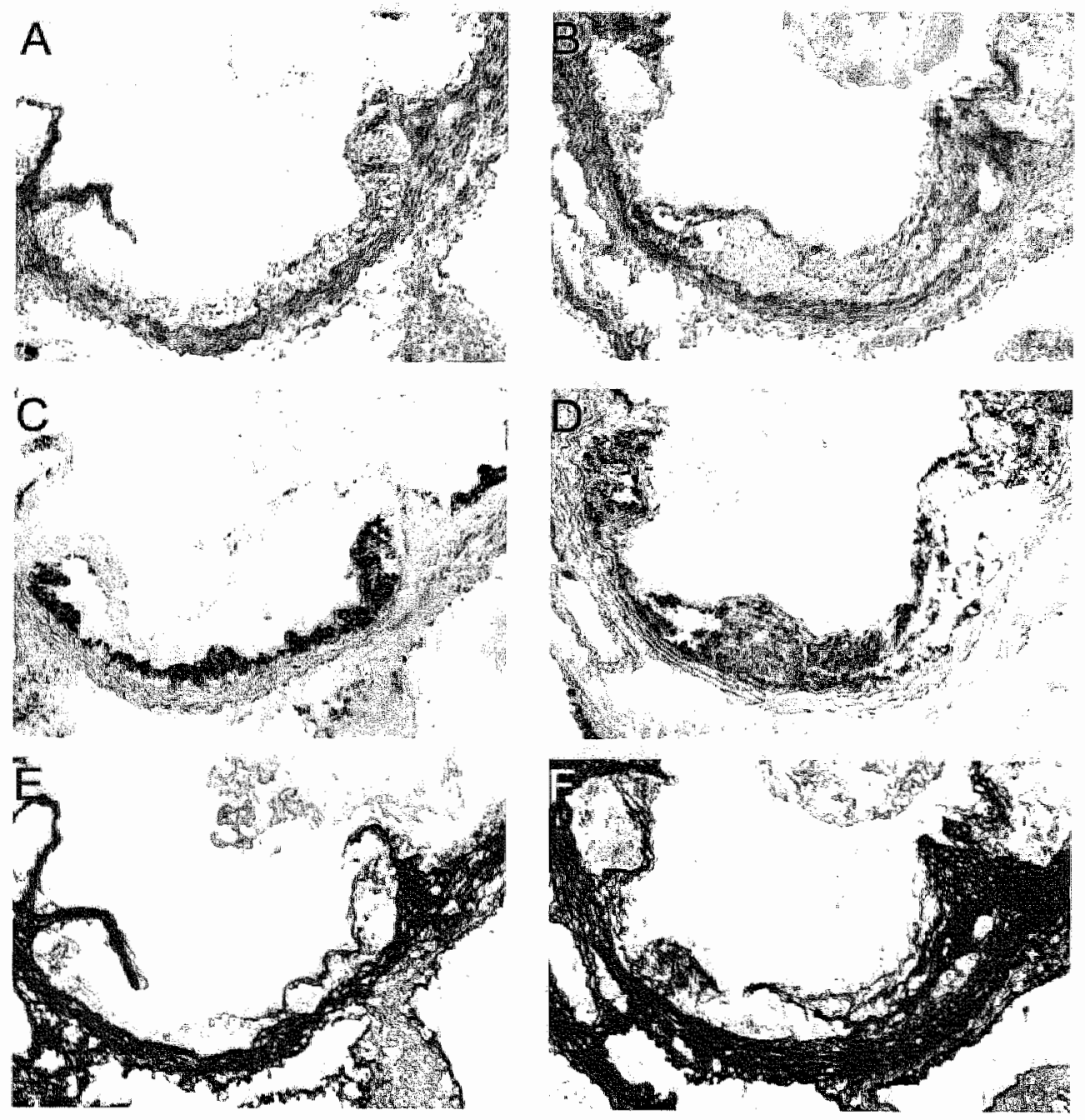

Fig. 4: Atherosclerotic lesions in SPLA IIA and wildtype transplanted LDLR ${ }^{+}$mice. Representative lesions from wild type $(A, C, E)$ and SLLA $_{2}$ IA $(B, D, F)$ transplanted LDLR ${ }^{* / *}$ mice stained with toluidin blue $(A, B)$ for general cellular composition, macrosialin (C, D) for macrophages and sirius red (E, F) for collagen. 

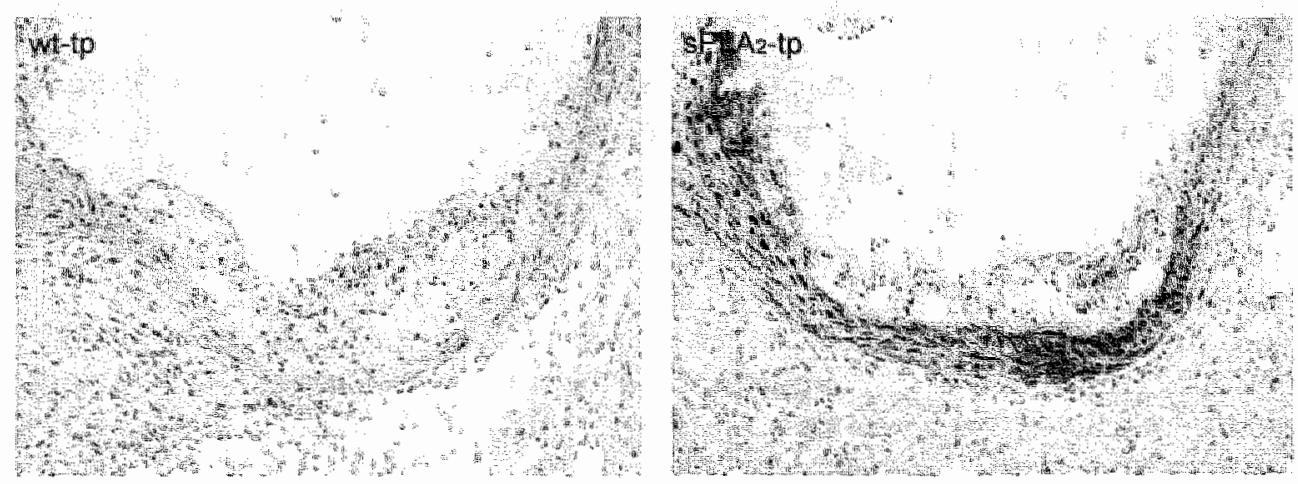

Fig. 5: SPLA ILA immunostaining. Immunostaining for human SPLA $A_{2}$ ILA of lesions from wildtype (wt-tp) and SPLA, IIA (sPLA, - tp) transplanted LDLR ${ }^{-1}$ mice.

cells $/ \mu \mathrm{m}^{2}$, respectively), indicating that the size of the macrophages was not changed. Therefore, the increased lesion size is due to the increased number of macrophages and not due to their increased size.

A

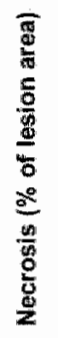

通

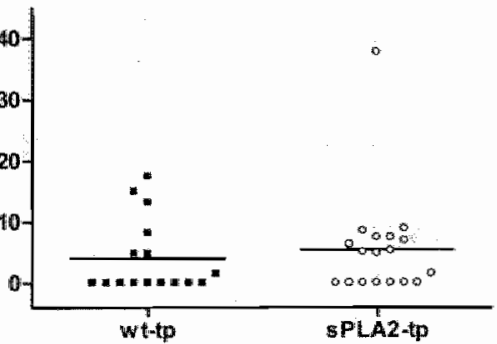

C

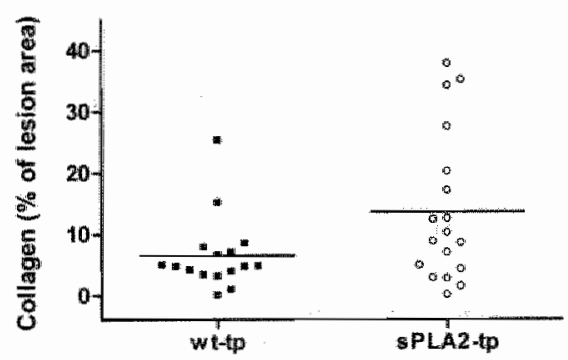

B

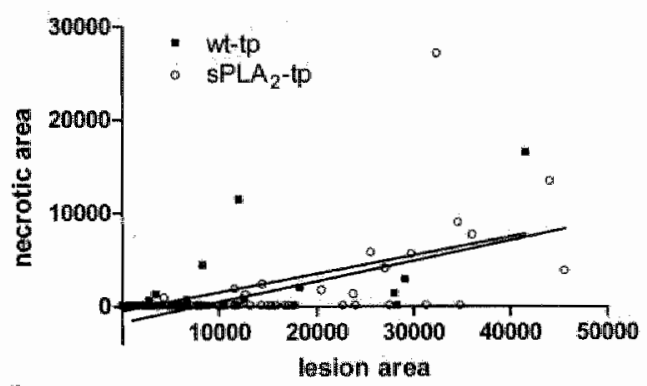

D

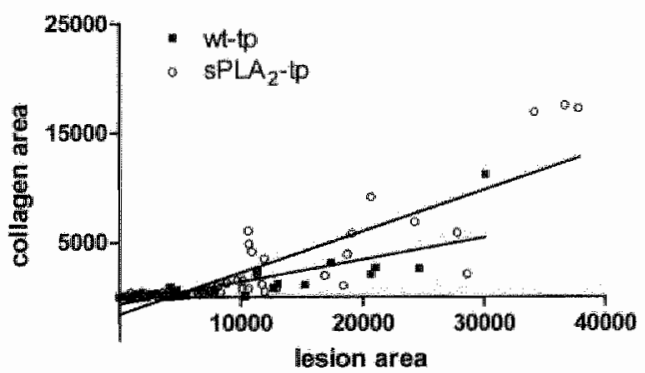

Fig. 6: Necrosis and collagen in lesions from sPLA IIA and wildtype transplanted LDLR mice. Necrosis $(A, B)$ and collagen $(C, D)$ were quantified in the lesions of wildtype ( $w t-t p)$ and sPLA IIA (sPLA ${ }_{2}$-tp) transplanted LDLR ${ }^{+}$mice as described in Material and Methods. Both are expressed as a relative percentage of lesion area per animal $(A, C)$ and as an individual area correlated to the lesion size (B, D). In $A$ and $C$, each symbol represents one animal, and in $B$ and $D$, each symbol represents one lesion. ${ }^{*} p<0.05$. 


\section{Discussion}

In this study, we examined the effects of macrophage sPLA, IIA on atherogenesis. We show that macrophage-specific overexpression strongly increases atherosclerotic plaque size without the normally associated lesion progression to a more severe phenotype. In addition, collagen deposition in the lesions was also increased even when corrected for lesion size. Remarkably, other cellular parameters were not affected by SPLA, IIA.

We could demonstrate that sPLA ${ }_{2}$ IIA is present at the site of the atherosclerotic lesions of the mice transplanted with sPLA bone marrow. Only minimal systemic effects on cholesterol levels were observed, with no change in circulating SPLA or paraoxonase activity. Hence, we have generated an animall model to investigate the direct lesional role of sPLA ${ }_{2}$ IIA in plaque development and progression. Quantification of the atherosclerotic lesions revealed a 2.3-fold increase in lesion

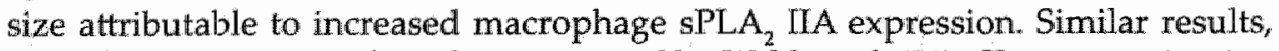
albeit less pronounced, have been reported by Webb et al. (21). Closer examination of the lesions in our experimental animals revealed interesting changes in plaque morphology in response to increased levels of sPLA $A_{2}$. Both collagen content and increased macrophage numbers contributed to lesion enlargement in the sPLA tp mice. Apoptosis and necrosis were not altered, and cell proliferation did not increase, indicating that the increased cell number in sPLA 2 -tp mice must be attributed to increased monocyte infiltration in the vessel wall. It was recently shown that one of the products of sPLA ${ }_{2}$ activity lysophosphatidylcholine, can be chemotactic for monocytes (33), so this may account, at least in part, for the observed increased cell number and increased atherosclerosis. No other signs of increased inflammation could be measured. No changes were observed in T-cells, inflammatory cells that are often associated with atherosclerotic plaques. Also, granulocyte count (data not shown) did not reveal any differences.

Despite the cell-specific expression of the transgene, the sPLA IIA produced in macrophages and monocytes proved to be sufficient to increase the cholesterol levels in mice after 4 weeks of diet. However, at later times, this difference was no longer significant. No significant correlation between lesion area and cholesterol levells at either 4 or 8 weeks of high-fat diet was found. Additionally, no clear change in the blood lipoprotein profile or in paraoxonase activity was detected. Paraoxonase levels have been previously described to be reduced in SPLA, transgenic animals, and it can act as a protective factor against lipoprotein modification (20). From these data, we conclude that total systemic effects of SPLA IIA were rather limited in our experimental setup, and it is unlikely that they contributed significantly to the phenotype. This is in contrast with the drastic lipid changes observed by Ivandic et al. (20). They demonstrated that general overexpression results in decreased levels of HDL-cholesterol and increased levels of LDL/VLDL on chow diet, and even more prominent changes were observed on a high-fat diet.

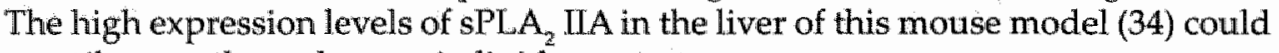
contribute to these changes in lipid parameters.

Immunohistochemistry for SPLA IIA revealed the presence of the enzyme in the media of the aorta near atherosclerotic lesions in the SPLA $\mathrm{A}_{2}-\mathrm{tp}$ mice. Nevalainen et al. (34) observed similar accumulation of SPLA $A_{2}$ IIA protein in de media without 
A

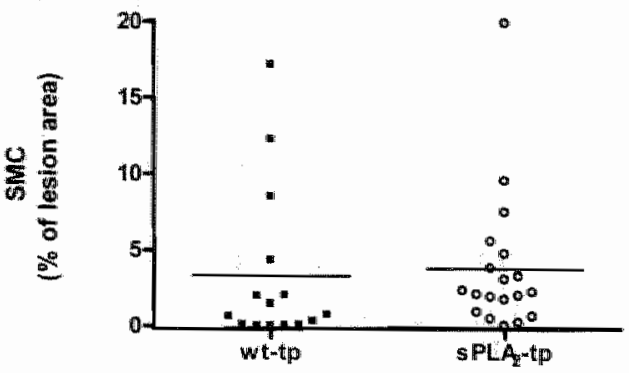

C

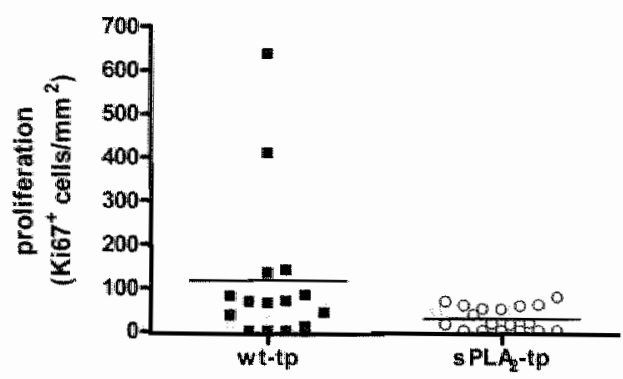

B

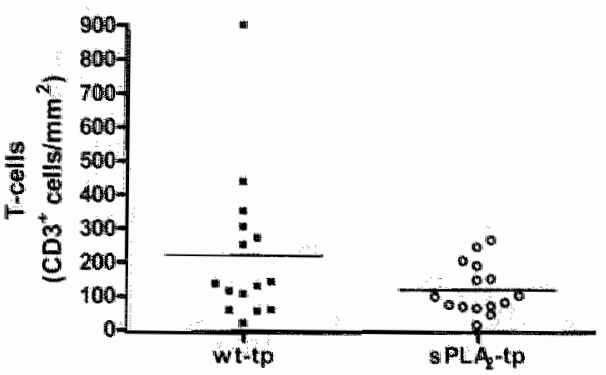

D

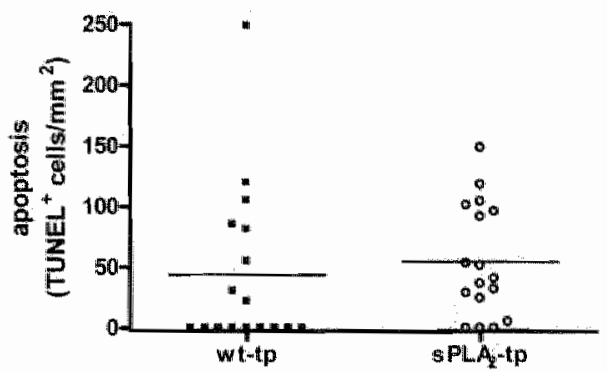

Fig. 7: Cellular characterization of lesions from sPLA, IIA and wildtype transplanted

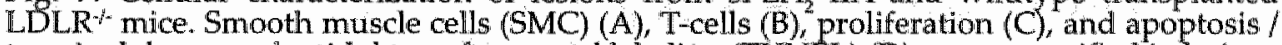
terminal deoxymucleotidyl transferase end labeling (TUNEL) (D) were quantified in lesions of wildtype (wt-tp) and sPLA IIA (sPLA - tp) transplanted LDLR $\%$ mice and expressed relative to the lesion size. Each symbol represents one animal.

the presence of mRNA for sPLA IIA. A mechanism for this specific localization is offered by Sartipy et al. (35), showing binding of secreted SPLA IIA to such proteoglycan molecules as decorin and versican. We observed medial sPLA ${ }_{2}$ IIA presence only near the lesions, suggesting thr accumulation of diffused SPLA IIA from within the lesion. SPLA ${ }_{2} \Pi A$ has been shown to bind to a whole range of extracellular matrix components, such as glypican, a glycosulphophatidylinosol (GPI)-anchored proteoglycan (36), decorin (36), and biglycan $(12,14,16,35)$. Kovanen et al. (37) demonstrated an increased affinity of modified LDL to collagen as a result of decorin linkage. Moreover, Flood et al. (12) also demonstrated increased affinity for proteoglycans of $S P L A_{2}$ IIA-modified LDL. Interaction with the extracellular matrix components may result in rearrangement of the phospholipids in the LDL particles, which may increase the susceptibility to SPLA IIA modifications, in accordance with results shown by Sartipy(11). These mechanisms in turn attribute to prolonged LDL retention and subsequent modifications (38) in the extracellular matrix, resulting in increased atherogenicity of the lipoproteins (39). Besides direct binding to the matrix, sPLA 2 IIA-modified LDL has been previously shown to aggregate more and fuse in presence of proteoglycans $(17,40,41)$, which may also increase atherogenesis. The absence of clear inflammatory effects in the lesions of our sPLA $A_{2}$-tp mice, despite the increased lesion size, may indicate that LDL retention in the vessel wall is an important factor in sPLA $A_{2}$ IIA amplified atherosclerosis. 
One of the main features of the lesions in the sPLA IIA mice was increased collagen content. The combination of more collagen (i.e., cap thickening) and the absence of increased necrosis or apoptosis suggests a more stable plaque development attributable to the presence of sPLA IIA. It has not been described before that sPLA $A_{2}$ IIA affects collagen production or fibrosis in atherogenesis. However, using SPLA, IIA transgenic mice in a model of acute pancreatitis, Mayer et al. (42) also observed increased fibrosis in the pancreas of the transgenic animals, whereas fibrosis was absent in the wildtype mice. SMC and fibroblast contents were not changed in SPLA $-t p$ mice, which may indicate that the difference in collagen in the lesions cannot be attributed to an increase in specific cell types producing collagen. The exact source of the collagen remains unclear, but it should be noted that collagen VIII can be produced by macrophages in atherosclerotic lesions (43). More collagen in atherosclerotic lesions can be the result of either increased overall production in the lesion or decreased degradation. Degradation may be affected by reduction in matrix metalloproteases (MMPs), which degrade collagen, or increases in tissue inhibitor of MMPs. However, no data are available on the effect of sPLA IIA on these kinds of enzymes; future experiments should focus on this issue. In the lesions of our sPLA IIA-transplanted mice, we found an increase in macrophages and foam cells but no clear signs of increased inflammation (i.e., changes in T-cells or granulocutes). Fibrosis or scar formation is often considered to be a final anti-inflammatory phase (44) and reflects the resolution of inflammation. Interestingly, using an air pouch model, Gilroy et al. (45) recently described a new role for phospholipases in inflammation. SPLA $A_{2}$ IA and group V were shown to be important in the resolution phase of inflammation, whereas these enzymes did not contribute to the initiation phase of inflammation. Both were capable of upregulating platelet-activating factor and lipoxin $\mathrm{A}_{4^{\prime}}$ resulting in group IV cy tosolic PLA ${ }_{2}$-mediated release of proresolving eicosanoids (45-47). Moreover, they showed an increase number is inflammatory cells in the resolving phase in C57BL/6 mice, a natural knockout for sPLA 2 IIA compared with BALB/C animals, a difference not observed in the initiating phase (45). These results may indicate a role for SPLA, IIA in the termination of inflammatory responses. Our observed increased collagen in the atherosclerotic plaques may be in agreement with such an anti-inflammatory role. Combining our model with activation through other pro-inflammatory stimuli may shed light on the specific effects in the initiation and resolution of inflammation.

In conclusion, we have generated a novel mouse model to study the function of SPLA $A_{2}$ IIA in macrophages and atherogenesis. We show that SPLA IIA in macrophages is a proatherogenic factor. Our findings may also suggest an LDL-accumulation and retention-based mechanism as major cause for the effects of sPLA IIA. Moreover, we found that overexpression of sPLA IIA also affects collagen deposition in the plaque, which indicates a novel function of SPLA IIA in the vessel wall. The exact mechanisms involved in SPLA $\mathrm{A}_{2}$ IIA induced collagen deposition remain speculative, and more detailed mechanistic studies are needed. Future studies may also focus on longer lasting atherosclerosis experiments to investigate how more advanced atherosclerosis is affected by SPLA $\Pi$ IA and how plaque stability develops in the presence of increased levels of this enzyme. 


\section{References}

1. Williams $\mathrm{KJ}$, Tabas I. The response-to-retention hypothesis of early atherogenesis. Arteriasiltr Throwb Vasc Biol 1995;15:551-561.

2. Glass CK, Witztum JL. Atherosderosis, the road ahead. Cell 2001;104:503-516.

3. Lusis Al. Atherosclerosis. Nature 2000,407:233-241.

4. Libby $\mathrm{P}$, Ridker $\mathrm{PM}_{*}$ Maseri A. Inflammation and atherosclerosis. Circulation 2002; 105:11351143.

5. Anthonsen MW, Stengel D, Hourton D, Ninio E, Johansen B. Mildly oxidized LDL induces expression of group IIA secretory phospholipase A(2) in humain monocyte-derived macro phages. Arteriosder Thromb Vasc Biol 2000;20:1276-1282.

6. Menschikowski M, Kasper M, Lattke $\mathrm{P}_{r}$ Schiering A, Schiefer S, Stockinger $\mathrm{H}$ et al . Secretory group II phospholipase $\mathrm{A}_{2}$ in thuman atherosderotic plaques. Aherosderosis 1995,118:173. 181.

7. Elinder LS, Dumitrescu A, Larsson P, Hedin U, Frostegard J, Claesson HE. Expression of phospholipase $A_{2}$ isoforms in human nomal and atherosclerotic arterial wall. Arterioscler Thromb Vasc Biol 1997;17:2257-2263.

8. Six DA, Dennis EA. The expanding superfamily of phospholipase A(2) enzymes: classification and characterization. Biochin Bioplys Acta 2000,1488:1-19.

9. Dennis EA. The growing phospholipase $A_{2}$ superfamily of signal transduction enzymes. Tremds Biochem Soi 1997;22:1-2.

10. Hurt-Camejo $\mathrm{E}$, Camejo $\mathrm{C}$. Potential involvement of type Il phospholipase $\mathrm{A}_{2}$ in atherosclerosis. Atherosclerosis 1997;132:1-8.

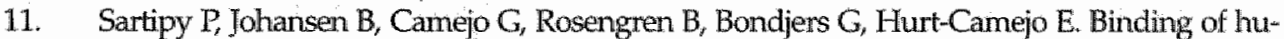
man phospholipase $A_{2}$ type II to proteoglycans. Differential effect of glycosaminoglycans on enzyme activity. J Biol Chem 1996:271:26307-26314.

12. Flood C, Gustafsson M, Pitas RE, Arnaboldi L, Walzem RL., Boren J. Molecular mechanism for changes in proteoglycan binding on compositional changes of the core and the surface of low-demsity lipoprotein-containing human apolipoprotein B100. Arterioscler Thromb Vasc Biol $2004: 24.564-570$.

13. Hurt-Camejo $E_{\text {, Camejo }} G_{2}$ Sartipy P. Phospholipase $A_{2}$ and small, dense low-density lipoprotein. Cum Opin Lipidol 2000;11:465-471.

14. Sartipy $P_{r}$ Camejo $G_{x}$ Svensson $L$, Hurt-Camejo E. Phospholipase A(2) modification of low density lipoproteins forms small high density particles with increased affinity for proteogly. cans and glycosaminoglycans. J Biol Chem 1999;274:25913-25920.

15. Wooton-Kee CR, Boyanovsky BB, Nasser MS, de Villiers WJ, Webb NR. Group V s IPLA $_{2}$ hy. drolysis of low-density lipoprotein results in spontaneous particle aggregation and promotes macrophage foam cell formation. Arterioscler Thromb Vasc Biol 2004,24:762-767.

16. Sartipy $P_{3}$ Bondjers $G$. Hurt-Camejo E. Phospholipase $A_{2}$ type II binds to extracellultar matrix biglycan: modulation of its activity on LDL by colocalization in glycosaminoglycan matrixes. Arterioscler Thromb Vasc Biol 1998; 18:1934-1941.

17. Hakala JK, Oorni K, Pentikainen MO, Hurt-Camejo E, Kovanen PT. Lipolysis of LDL by human secretory phospholipase A(2) induces particle fusion and enthatices the retention of LDL to human aortic proteoglycans. Arterioscler Thromb Vasc Bial 2001;21:1053-1058.

18. Oestrang J, Bonnefont-Rousselot D, Ninio E, Hakala JK, Johansen B, Anthonsen MW. Modification of LDL with human secretory phospholipase A(2) or sphingomyrelinase promotes its arachidonic acid-releasing propensity. J Lipid Res 2004;45:831-838.

19. Grass DS, Felkner RH, Chiang MY, Wallace RE, Nevalainen T), Bennett CF et al. Expression of human group II PLA $\mathrm{A}_{2}$ in transgenic mice results in epidermal hyperplasia in the absence of inflammatory infiltrate. / Clin Irizest 1996,97:2233-2241.

20. Ivandic B, Castellani LW, Wang XT, Qiao JH, Mehrabian M, Navab M et al. Role of group II 
secretory phospholipase $\mathrm{A}_{2}$ in atherosclerosis: 1. Increased atherogenesis and altered lipoproteins in transgenic mice expressing group IIA phospholipase $\mathrm{A}_{2}$. Arteriascler TTromb Vasc Bisl $1999,19.1284-1290$.

21. Webb NR, Bostrom MA, Szivassy S], van der Westhuyzen DR, Daugherty A, de Beer FC Macrophage-expressed group $\mathrm{LA}$ secretory phospholipase $\mathrm{A}_{2}$ increases atherosclerotic lesion formation in LDL receptor-deficient mice Arterioscler Thromb Vasc Biol 2003;23:263-268.

22. Dziennis S, Van Etten RA, Pahl HL, Morts DL, Rothstein TL, Blosdh CM et al. The CD11b promoter dinects high-level expression of reporter genes in macrophages in transgenic mice. Blond 1995,85,319-329.

23. Kramer RM, Hession C, Johansen B, Hayes G, MoGray P, Chow EP et al. Structure and propetties of a human non-pancreatic phospholipase A. I Biol Chem 1989;264:5768-5775.

24. Hogan B, Beddington, R, Constantini, F and Lacy, E. Manipulating the Mouse Embryo: A Laboratory Manual: Cold Spring Harbor Laboratory; 1994

25. Kennedy BP, Payette P, Mudgett J, Vadas P, Pruzanski W, Kwan M et al. A natural disruption of the secretory group II phospholipase $A_{2}$ gene in inbred mouse strains. J Biol Chem 1995;270:22378-22385.

26. Ishibashi S, Brown MS, Goldstein LL, Gerard RD, Hammer RE, Herz J. Hypercholesterolemia in low density lipoprotein receptor knockout mice and its reversal by adenovirus-mediated gene delivery. J Clin Invest 1993;92:883-893.

27. Kanters E, Pasparakis M, Gijbels M], Vergouwe MN, Partouns-Hendriks I, Fijneman RJ et al. Inhibition of NF-kappaB activation in macrophages increases atherosclerosis in LDL receptor-deficient mice. / Cin Invest 2003,112:1176-1185.

28. Hurt-Camejo E, Andersen S, Standal R, Rosengren B, Sartipy $P$, Stadberg E et al. Localization of nompancreatic secretory phospholipase $\mathrm{A}_{2}$ in normal and atherosclerotic arteries. Activity of the isolated enzyme on low-density lipoproteins. Arterioscler Thromb Vasc Biol 1997;17:300309.

29. de Winther MP, van Dijk KW, van Vlijmen B], Gijbels MI. Heus J, Wijers ER et al. Macrophage specific overexpression of the human macrophage scavenger receptor in transgenic mice, using a $180-\mathrm{kb}$ yeast artificial chromosome, leads to enhanced foam cell formation of isolated peritoneal macrophages. Atherosclerosis 1999;147:339-347.

30. Senti $\mathrm{M}$, Tomas $\mathrm{M}$, Fito $\mathrm{M}$, Weinbrenner $\mathrm{T}_{s}$ Covas Ma, Sala J et al. Antioxidant paraoxonase 1 activity in the metabolic syndrome. / Clin Endocrinol Metab 2003,88:5422-5426.

31. Mackness MI Harty D, Bhatnagar D, Winocour PH, Arrol S, lchola M et al Serum paraoxonase activity in familial hypercholesterolaemia and insulin-dependent diabetes mellitus. Atherosclerosis 1991;86:193-199.

32. Nevalainen TI, Marki F, Kortesuo PT, Grutter MG, Di Marco S, Schmitz A. Synovial type (group i) phospholipase $A_{2}$ in cartilage. J Rheumatol 1993;20:325-330.

33. Lauber K, Bohn E, Krober SM, Xiao Y], Blumenthal SG, Lindemann RK et al. Apoptotic cells induce migration of phagocytes via caspase-3-mediated release of a lipid attraction signal. Cell $2003 ; 1137717-730$.

34. Nevalainen TJ Laine VI, Grass DS. Expression of human group II phospholipase $\mathrm{A}_{2}$ in transgenic mice. I Histochen Cytochem 1997:45:1109-1119.

35. Sartipy P, Johansen B, Gasvik K, Hurt-Camejo E. Molecular basis for the association of group IA phospholipase $A(2)$ and decorin in human atherosclerotic lesions. Circ Res 2000;86:707714.

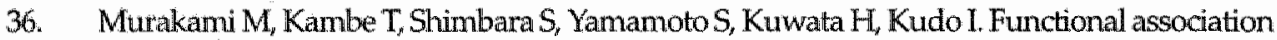
of type IIA secretory phospholipase A(2) with the glycosylphosphatidylinositol-anchored heparan sulfate proteoglycan in the cyclooxygenase-2-mediated delayed prostanoid-biosynthetic pathway. J Biol Chem 1999;274:29927-29936.

37. Kovanen PT, Pentikainen MO. Decorin links low-density lipoproteins (LDL) to collagen: a novel mecharism for retention of LDL in the atherosclerotic plaque. Trends Cardionas Med 
$1999,986-91$.

38. Jaross W, Eckey $R$, Menschikowski M. Biological effects of secretory phospholipase A(2) group IIA on lipoproteins and in atherogenesis. Eur J Clin Invest 2002,32383-393.

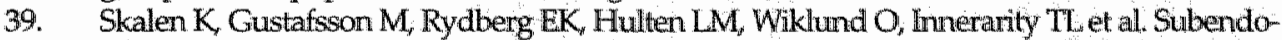
thelial retention of atherogenic lipoproteins in early atherosclerosis. Nature 2002,417:750-754.

40. Paananen $\mathrm{K}$, Saarinen J, Annila A, Kovanen PT. Proteolysis and fusion of low density lipoprotein particles strengthen their binding to human aortic proteoglycans. I Buld Ohew $1995 ; 270: 12257-12262$.

41. Oomi $K$, Pentikainen MO, Annila $A_{,}$Kovanen PT. Oxidation of low density lipoprotein particles decreases their ability to bind to human aortic proteoglycans. Dependence on oxidative modification of the lysine residues. I Biol Chom 1997,27221303-21311.

42. Mayer JM, Laine VJ, Kolodziej S, Nevalainen T], Beger HG. Acute pancreatitis in transgenic mice expressing human group IIA phospholipase $\mathrm{A}_{2}$. Pancreas 2002,25:188-191.

43. Weitkamp B, Cullen $\mathbb{P}$, Plenz G, Robenek H, Rauterberg J. Human macrophages synthesize type VIII collagen in vitro and in the atherosclerotic plaque. Faseb 1999;13:1445-1457.

44. Steed DL. Wound-healing trajectories. Strg Clin North Am 2003;83:547-555, vi-vii.

45. Gilroy DW, Newson I, Sawmynaden P, Willoughby DA, Croxtall JD. A novel role for phospholipase $\mathrm{A}_{2}$ isoforms in the checkpoint control of acute inflammation. Faseb J 2004:18:489498.

46. Levy BD, Clish CB, Schmidt B, Gronert $\mathrm{K}$, Serhan $C N$. Lipid mediator class switching during acute inflammation: signals in resolution. Nat Immmol 2001;2612-619.

47. Gilroy DW, Colville-Nash PR, Willis D, Chivers J, Paul-Clark M.J, Willoughby DA. Inducible cyclooxygenase may have anti-inflammatory properties. Nat Med 1999:5:698-701. 
के

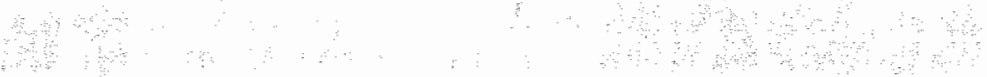

is 


\section{Chapter 4}

\section{Secretory Phospholipase $A_{2}$ group $X$ expression mediates foam cell formation and inhibits lipopolysaccharide induced activation of murine macrophages.}

Stijn A.I. Ghesquiere', Ingeborg van der Made', Monique N. Vergouwe ${ }^{1}$, David $\mathbb{R}_{\text {. }}$ Greaves ${ }^{2}$ Marten H. Hofker' and Menno P.J. de Winther'.

1 Dept. of Molecular Genetics, Cardiovascular Research Institute Maastricht, Maastricht University, The Netherlands.

2 The Sir William Dunn School of Pathology, University of Oxford, United Kingdom

Ready for submission 


\section{Abstract}

Phospholipases are a diverse group of enzymes capable of hydrolyzing phospholipids, releasing free fatty acids (FFA) and lysophospholipids (lysoPL). Several phospholipases have been shown to be involved in atherosclerosis in which they can modulate lesion formation by influencing inflammation and lipoprotein modification. However, the role of the distinct phosptiolipases in these processes is not fully elucidated. In this paper, we examined the role of secreted phospholipase $A_{2}$ group $X\left(s P L A_{2} X\right)$ in murine macrophages. sPL $A_{2} X$ is one of the most potent phospholipases in mammals, capable of hydrolyzing intact cell membranes and it has been reported in murine atherosclerotic lesions. Here we show that the sPLA $A_{2} X$ gene is expressed in murine macrophages. We found that sPLA $X$ overexpression in macrophages strongly increases foam cell formation upon incubation with native LDL. Moreover, we could show that SPLA $_{2} X$ expression inhibits lipopolysaccharide-induced macrophage-activation, characterized by reduced cell adhesion, lower levels of TNF secretion and increased interleukin-10 production. These effects are likely mediated by increased production of two anti-inflammatory prostaglandins, prostaglandin $\mathrm{E}_{2}$ and 15-deoxy $-\Delta 12$, 14-prostaglandin $\mathrm{J}_{2}$. This study shows a potentially two-faced role for sPLA $\mathrm{A}_{2} \mathrm{X}$ in atherosclerosis, with foam cell promoting capacities and also anti-inflammatory properties reducing macrophage activation.

\section{Introduction}

Atherosclerosis is a progressive disease of the large arteries. The accumulation of low-density lipoprotein (LDL) and the development of inflammation in the vessel wall are essential events in the early onset and progression of plaque formation (reviewed in (1)). Oxidation and enzymatic modifications highly contribute to LDL accumulation (2). LDL modifications result in the release of various inflammatory mediators and modulate inflammatory responses. Monocytes attracted to the site of inflammation differentiate into macrophages and subsequently transform into foam cells after uptake of the LDL (3). Phospholipases are known to modify LDL to the extent that they become pro-atherogenic. Recent mouse studies confirmed a pro-atherogenic role for group Ila secretory phospholipase $A_{2}$ (sPLA $A_{2}$ (4-7).

The common property of the phospholipases is that they hydrolyze phospholipids at the sn-2 position, resulting in the formation of free fatty acids, such as arachidonic acid (AA), and lysophospholipids (lysoPL) (8). Classification of the phospholipases is based on structure, molecular weight and substrate preference (9). Three groups are distinguished: the secreted PLA $\mathrm{A}_{2}$ (sPLA), the cytosolic PLA $\mathrm{s}_{2} \mathrm{~s}$

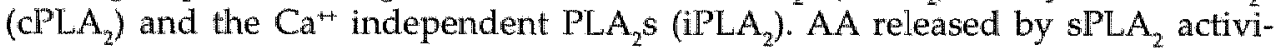
ty is the substrate for the production of inflammatory products like prostaglandins, thromboxanes and leukotrienes. Besides enzymatic activity, phospholipase $A_{2}$ receptor $\left(\mathrm{PLA}_{2} \mathrm{R}\right)$ binding is reported and results in the release of chemokines through the mitogen activated protein kinase (MAPK) pathway (10-12).

The potent group $X$ sPLA $_{2}$ ( SPLA $_{2}$ X), discovered by Cupillard et al. (13) is structurally related to both $\mathrm{SPLA}_{2}$ group IB and IIA. sPLA $\mathrm{X}$ displays potent activity on both anionic as well zwitterionic phospholipids and hydrolyzes phosphatidyl- 
choline (14). Although comparable with group V in terms of cell binding, the hydrophobic nature of sPLA $X$ enables the enzyme to be far more potent $(15,16)$. Addition of sPLA $X$ to cell cultures elicits cellular AA release. This is in contrast with the weak activity of group IIA which needs HSPG-binding, internalization (HSPG-shuttling pathway) and coupling to $\mathrm{CPLA}_{2}$ to produce AA (17). Human sPLA $A_{2} X$ is present in many organs including spleen, thymus, peripheral blood leukocytes, testis, lung, pancreas and colon cells $(13,18)$. Expression of murine sPLA $X$ is found in brain, spleen, lung, testis, thymus and uterus (19). Group $X$ protein has been shown to be present in macrophage foam cells and smooth muscle cells in the vessel walls of high fat-fed apolipoprotein E knockout mice (20). Mouse macrophages incubated with LDL modified by purified human $S P L A_{2} X$ readily transform into foam cells. The lipid droplet distribution and pattern of these foam cells resembles acetylated LDL loading and the cholesterol ester content increased vastly (20). Moreover, spleen macrophages are reported to contain SPLA 2 X (19), indicating a possible role for $\mathrm{PLA}_{2} \mathrm{X}$ in inflammation or immune responses.

sPLA $X$ activity is capable of liberating large quantities of AA, the substrate in the production of inflammatory mediating prostaglandins. Therefore, in addition to its role in foam cell formation, we examined the effect of $s P L A_{2} X$ overexpression on macrophage-activation and found powerful anti-inflammatory effects demonstrated by reduced TNF and increased IL-10 levels, accompanied with an increase in prostaglandin $\mathrm{E}_{2}\left(\mathrm{PGE}_{2}\right)$ and 15-deoxy- $\triangle 12,14$-prostaglandin $\mathrm{J}_{2}\left(15 \mathrm{~d}-\mathrm{PG} \mathrm{I}_{2}\right)$ production. At the same time, we show that $s \mathrm{PLA} \mathrm{A}_{2} \mathrm{X}$ overexpression itself in unstimulated macrophages does not elicit an inflammatory response.

\section{Material and Methods}

\section{Cell culture}

The murine macrophage cell line RAW264.7 was cultured in RPMI 1640 (Invitrogen) supplemented with $10 \%$ heat inactivated fetal calf serum (FCS), $100 \mathrm{U} / \mathrm{ml}$ penicillin, $100 \mathrm{ug} / \mathrm{ml}$ streptomycin, $2 \mathrm{mM} \mathrm{L}$-glutamine and $50 \mu \mathrm{M} \beta$-mercaptoethanol, hereafter referred to as RAW medium. Experiments were performed in the same RAW medium but w/o $\beta$-mercaptoethanol. Bone marrow derived macrophages (BMM) were generated and cultured from C57/Bl6 mice as described before (21). After differentiation, cells were replated in R10 medium (RPMT 1640 medium, containing $10 \%$ heat inactivated $\mathrm{FCS}, 100 \mathrm{U} / \mathrm{ml}$ penicillin, $100 \mathrm{ug} / \mathrm{ml}$ streptomycin, 2 mM L-glutamine and $10 \mathrm{mM}$ Hepes) supplemented with $15 \%$ L-929 cell conditioned medium (LCM) (22).

\section{RNA isolation and PCR analysis}

In order to analyze sPLA 2 Xexpression, RNA was isolated from C57/B6 mice BMM or RAW264.7 cells using Tri Reagent (Sigma), according to the manufacturers protocol. RNA concentration was measured using the nanodrop (Witec $A G_{r}$ Germany). $1 \mu \mathrm{g}$ total RNA was converted into cDNA. Oligo dT primers and RevertAid M-MuLV reverse transcriptase (Fermentas) were used according to the manufacturers protocol. Presence of $s$ PLA 2 X expression was tested by PCR with appropri- 
ate primers (forward: GGCTGTTATTGTGGCCTTGGT; reverse: TCCTGAGCCCGAGAGTAGCA), which are selected in such way that an intron was included to prevent genomic amplification. Product length was checked on regular agarose gel electrophoresis. Quantitative realtime $\mathrm{PCR}(\mathrm{qPCR})$ with the same primers for murine $\mathrm{SPLA}_{2} X$ was performed to quantify $\triangle P L \mathrm{~A}_{2} X$ expression. For $\mathrm{qPCR}$ (TAQMan) analysis with $300 \mathrm{nM}$ primer/ $200 \mathrm{nM}$ probe sets, the qPCR Mastermix Plus kit (Eurogentec) was used on $10 \mathrm{ng}$ cDNA. Analysis was performed on an ABI Prism 7700 Sequence Detector. The housekeeping genes cyclophillin A and $\beta$-Actin were used to correct for RNA concentration differences between the samples.

\section{Construct}

Human SPLA, $X$ cDNA (a generous gift from Dr. Cupillard) was isolated from a $\mathrm{pRc} / \mathrm{CMV}$ vector (Invitrogen), containing the sPLA $\mathrm{A}_{2} \mathrm{XDNA}$ starting at the second methionine start site (met-32) (13). The met-32 fragment was selected using convenient restriction sites and inserted in a pcDNA 3 expression vector behind a $C D 68$ promoter construct ( $2.9 \mathrm{~kb}$ CD68 + IVS-1 sequence (23)). The CD68 - sPLA $\mathrm{A}_{2} \mathrm{X}$ in pCDNA3 plasmid was verified by sequencing the start and the end of the met-32 construct and boundaries of the CD68 promotor region. Additional verification was performed using various restriction enzymes and subsequent gel electrophoresis.

A

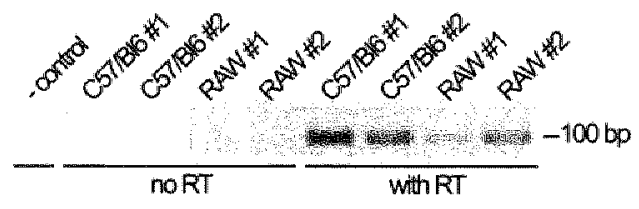

B

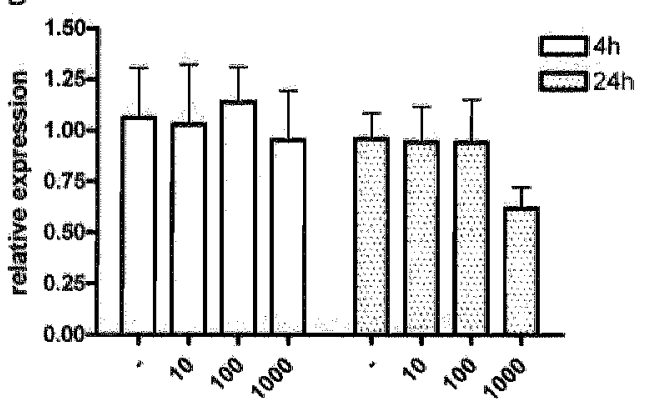

Fig. 1. Expression of SPLA $X$ in bone marrow derived and RAW264.7 macrophages. $A: P C R$ with murine SPLA $\mathrm{A}_{2} X$ specific primers on CDNA isolated from bone marrow derived macrophages and RAW264.7 cell lines. RT negative controls (left) have been included to check for genomic DNA amplification. B: sPLA, X expression in RAW264.7 macrophages after stimulation with 10,100 and $1000 \mathrm{ng} / \mathrm{ml}$ LPS after 4 and 24 hours.

\section{Electroporation}

For electroporation, $10 \mu \mathrm{g}$ CD68 - sPLA, X plasmid DNA was combined with $2 \mu \mathrm{g}$ of a Neomycin resistance plasmid and added to $9 \mathrm{x}$ 106 RAW264.7 cells resuspended in $500 \mu l$ Optimem (Invitrogen) and electroporated with a BioRad Gene Pulser II at $1070 \mu \mathrm{F}$ and 280 Volt in $4 \mathrm{~mm}$ cuvettes. Following electroporation, the cells were replated in large flasks with RAW medium and allowed to recover for $48 \mathrm{~h}$. The cells were selected with 0.1 $\mu \mathrm{g} / \mathrm{ml}$ Geneticin one week. Surwiving cells were replated in 96 wells plates for clonal selection and individual colonies were selected and screened with PCR for presence of the human sPLA $\mathrm{A}_{2}$ construct.

\section{Northern blotting}

To verify the expression of human SPLA $\mathrm{A}_{2} X$ in transfected RAW264.7 cells, RNA was isolated using Tri- 
Reagent (Sigma) according to the manufacturers protocol. RNA concentration was measured using a smartspec 3000 photospectrometer (BioRad). The RNA samples were separated by electrophoresis through a denaturing agarose gel $(1 \% \mathrm{w} / \mathrm{v})$ containing $7.5 \%$ formaldehyde and then transferred to Hybond $\mathrm{N}$ according to the manufacturer's recommendations. Hybridization was performed on the blots with $32 \mathrm{P}$-labeled sPLA 2 X fragment at $54^{\circ} \mathrm{C}$ in hybridization mixture $(50 \%$ formamide, $1 \%$ SDS, $10 \%$ dextransulphate, $5 \times \mathrm{SSC}, 1 \times$ Denhardts, $0.2 \mathrm{M} \mathrm{NA}_{2} \mathrm{PO}_{4}, 50 \mathrm{mg} / \mathrm{ml}$ sonicated salmon sperm DNA).

\section{Phospholipase activity}

Phospholipase activity was tested in culture media from RAW264.7 controls and

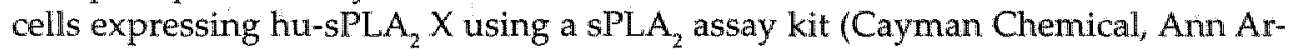
bor, MI, US) according to the manufacture's instructions.

\section{LDL isolation and modification}

Normal LDL was isolated from the serum of healthy blood donors (obtained from 'Stichting Sanquin', the Netherlands). The serum was brought to $1.21 \mathrm{~g} / \mathrm{ml}$ density with $\mathrm{KBr}$ addition and placed in $\mathrm{a} \mathrm{NaCl}$ density gradient and centrifuged for 18 hours with $134.000 \mathrm{~g}$ at $4^{\circ} \mathrm{C}$ (Beckman SW28.1 rotor and $25 \times 89 \mathrm{~mm}$ U1tra-tubes). The LDL fraction (density $1.019-1.063 \mathrm{~g} / \mathrm{ml}$ ) was isolated and dialyzed against sterile PBS contain-

Fig. 2. CD68 sPLA $X$ construct, Northern blot and phospholipase activity assay. A: CD68 met-32 sPLA $X$ construct. The $3-\mathrm{kb}$ CD68 promotor and IVS- 1 preceding the methionin-32 humane $S P L A_{2} \times$ fragment. This construct is used for electroporation into RAW264.7 macrophages. B: Northern blot analysis of RNA isolated from CD68 methionin -32 sPLA $A_{2} \times$ expressing RAW264.7 cell lines. Control cell lines (ctrll 1-3 on the left) have undergone electroporation, but failed incorporating the hu-sPLA $A_{2} \times$ construct. hu-sPLA $X$ positive cell lines (grX 1-3) are on the right side. C: Phospholipase activity assay. PLA $A_{2}$ activity assays were performed on culture medium from the hu-sPLA, $X$ expressing RAW264.7 cell lines and the negative control cell lines. The essay measures the PLA, activity as the rate $(\mathrm{mmol} / \mathrm{min} / \mathrm{ml})$ in which the 1,2-dithio analog of diheptanoylphosphatidylcholine is hydrolyzed.
A

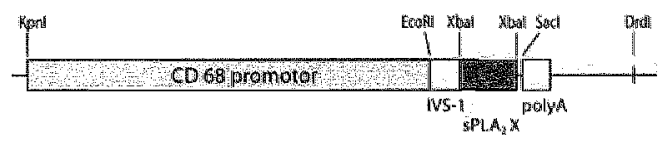

B
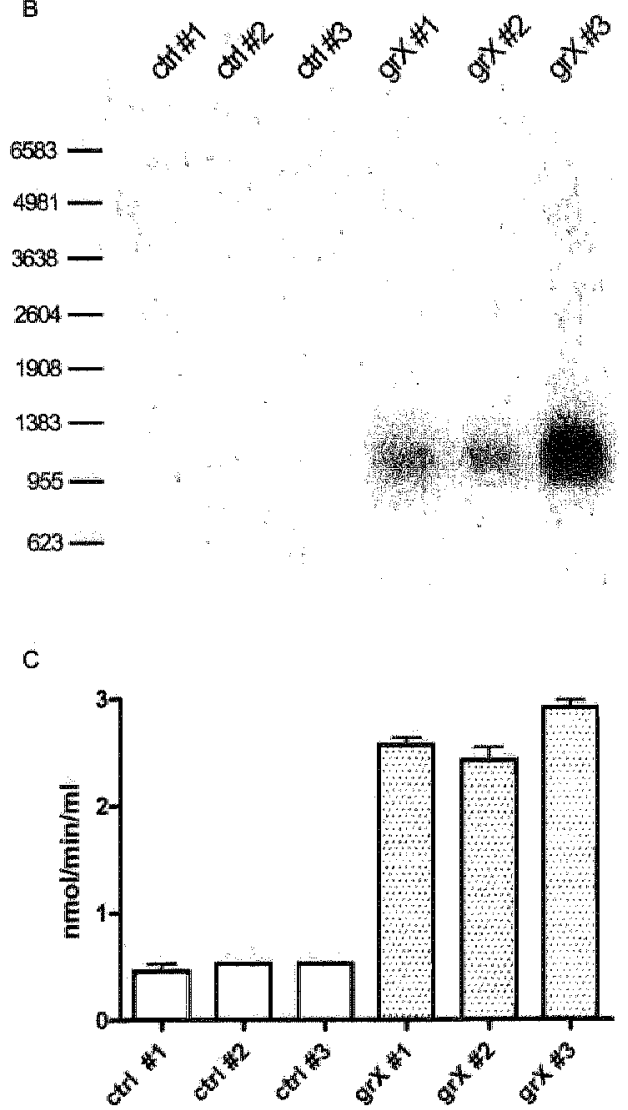
ing $10 \mu \mathrm{M}$ EDTA and stored under $\mathrm{N} 2$ at $4{ }^{\circ} \mathrm{C}$. The concentration of LDL was quantified by protein determination (BioRad Protein Assay).

\section{LDL loading and HPTLC}

$2 \times 106$ cells were plated out in 6-well plates in serum free medium (Optimem, Invitrogen) constituted with $100 \mathrm{U} /$ ml penicillin, $100 \mu \mathrm{g} / \mathrm{mll}$ streptomycin, $2 \mathrm{mM} \mathrm{L-glutamine.}$ After a 4 h period at $37^{\circ} \mathrm{C}, 25$ $\mu \mathrm{g} / \mathrm{ml}$ LDL was added to the medium. The cells were incubated for 24 hours after which they were washed, lifted and resuspended in $300 \mu \mathrm{M}$ MilliQ and lysed by freezing, fol-

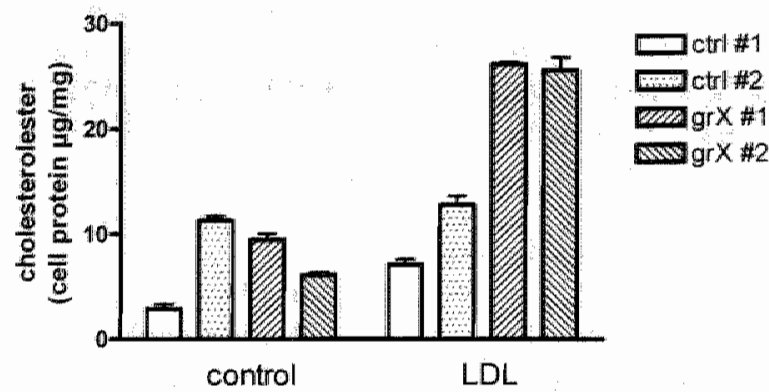

Fig. 3. Cholesterolester accumulation in RAW264.7 cell lines. The amount of cholesterol esters present in RAW264.7 cell lines transfected with CD68 hu-sPLA $X$ after $24 \mathrm{~h}$ incubation without or with LDL.

lowed by passage through a $27 \mathrm{G}$ hypodermic needle. The lysates were diluted in MilliQ to $200 \mu \mathrm{g}$ protein in a total volume of $800 \mu \mathrm{l}$. Chloroform, internal standard ( $20 \mu \mathrm{g}$ Cholesterolacetate/ml Chloroform), and additional water $(1 \mathrm{ml})$ was added and mixed. After centrifugation at $3000 \mathrm{rpm}$ for 10 minutes, the chloroform fraction was isolated and dried at $50^{\circ} \mathrm{C}$ under $\mathrm{N}_{2}$. HPTLC plates (Alltech/Applied Science) were activated overnight at $130^{\circ} \mathrm{C}$ and prepared with Methanol / Chloroform (2:1), followed by intermediate drying at $130^{\circ} \mathrm{C}$. A run with $\mathrm{NaOH}(10 \%$ in methanol) was performed and the plates were incubated $o / n$ at $130^{\circ} \mathrm{C}$. Lipid samples were dissolved in $50 \mu \mathrm{l}$ chloroform and applied in spots on the HPTLC plate. The chromatography was performed with a hexane, diethylether and 2-propanol mixture (90:10:3). Thereafter the plate was dried at $130^{\circ} \mathrm{C}$ and stained $\left(\mathrm{H}_{2} \mathrm{SO}_{4}\right.$ dissolved $\mathrm{MnCL}_{2}$ in $50 \%$ methanol) for 20 seconds and incubated at $130^{\circ} \mathrm{C}$ for 30 minutes.

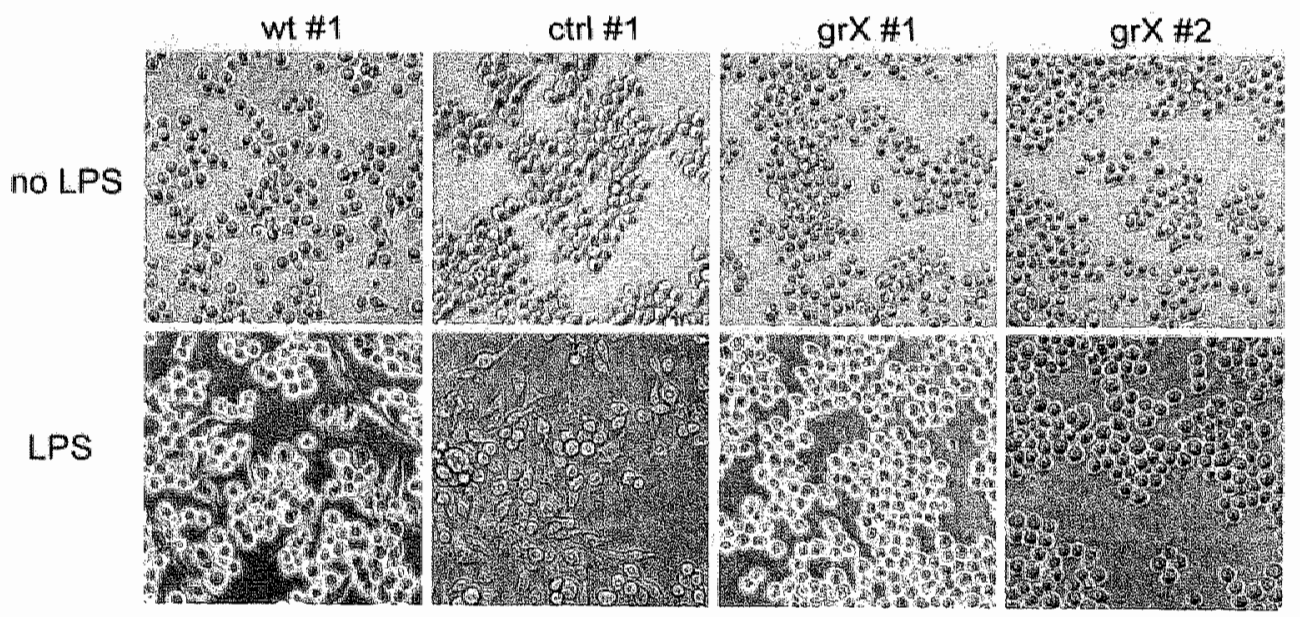

Fig. 4. Effect of hu-sPLA $A_{2} X$ expression on cellular activation. Microscopic pictures of RAW264.7 cells not expressing (wt, ctrl) or expressing hu-sPLA $\times$ ( $\mathrm{grX}$ ) were activated with LPS for $24 \mathrm{~h}$. 
The HPTLC plate was scanned and the samples were quantified against the internal standard with the Bio-Rad Quantity One (version 4.2.3) software package. The LDL loading experiment was performed several times, with two different media (RAW medium and RAW medium with the heat inactivated fetal calf serum substituted with free fatty acid free bovine serum albumin). Results (data not shown) were similar in all experiments.

\section{ELISA for cytokines and prostaglandins}

$5 \times 105$ cells were plated in 24 -well plates in $0.5 \mathrm{ml}$ RAW medium. The cells were left to attach for 4 hours and then activated writh LPS. The medium was analyzed for TNF and IL-10 after 4 hours and 24 hours using commercially available ELISA kits (Biosource Inc., Camarillo, CA). PGE, and 15d-PGJ were measured with competitive immunoassay kits according to the manufactures instructions (Assay Designs, Ann Arbor, MI).

\section{Results}

We first examined SPLA $A_{2} \times$ mRNA expression in primary murine bone marrow derived and RAW264.7 macrophages and found sPLA $A_{2} X$ expression in both (Fig. 1A). Control samples, without reverse transcriptase added remained negative, confirming mRNA specificity and excluding genomic amplification. To study the effects of inflammatory stimulation on SPLA $\mathrm{X}_{2}$ mRNA expression, we incubated RAW264.7 macrophages with three different LPS concentrations (10-100-1000 $\mathrm{ng} / \mathrm{ml}$ ) and isolated mRNA at 4 and 24 hours. As the results show (Fig. 1B) ${ }_{n}$ sPLA $X$ expression did not change under the influence of LPS. A small, but non-significant $(\mathrm{p}=0.2)$ decline in $s$ PLA ${ }_{2} X$ expression after $24 \mathrm{~h} 1000 \mathrm{ng} / \mathrm{ml}$ LPS activation was observed.

To study the function of $s P L A_{2} X$ in macrophages we overexpressed human sPLA $X$ (Fig. 2A) in murine RAW264.7 macrophages. The human CD68 promoter was selected for its ability to deliver high expression in mouse macrophages(23). The methionin-32 start site of the human sPLA $X_{2}$ gene has proven to deliver potent sPLA $X$ production (13) and was cloned behind the CD68 promotor. Stably transfected RAW264.7 cell lines were established and the expression of human SPLA $A_{2} X$ was confirmed by Northern blotting (Fig. 2B). Clones overexpressing sPLA $X$ were selected for subsequent experiments and clones that were negative on the Northern blot were used as controls, alongside non-transfected cells referred to as wildtype cells. Next, we measured phospholipase activity in the medium of transfected cells and control cells (Fig. 2C). Phospholipase activity showed a 5-fold increase in cells expressing the $\mathrm{SPLA}_{2} X$ construct compared to control cell lines. LPS treatment of the macrophages cells did not change sPLA activity (data not shown).

To study the effects of $\mathrm{SPLA}_{2} \mathrm{X}$ overexpression on foam cell formation, we incubated RAW264.7 overexpressing sPLA $X_{2}$ with native LDL for 24 h. Interestingly, a two-fold increase in cholesterolester accumulation was observed in cells expressing $s \mathrm{PLA}_{2} \mathrm{X}$ compared to controls. These data show that sPLA $\mathrm{A}_{2} X$ expression in macrophages promotes foam cell formation.

Activation experiments were performed to investigate the role of sPLA $X$ in inflammation. Upon incubation with LPS $(250 \mathrm{ng} / \mathrm{ml})$ wildtype and control cell lines 
A

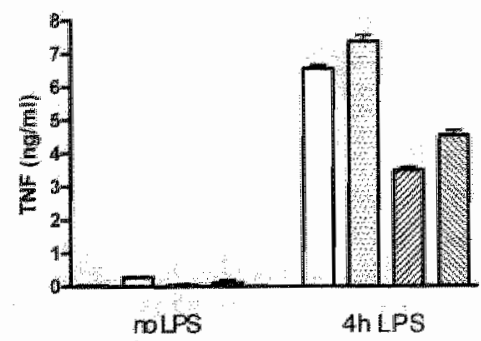

$B$

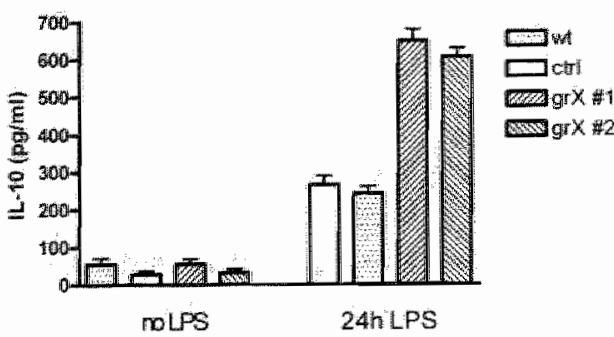

1. 5. ELISA for TNF and IL-10 rellease during activation of RAW264.7 cells expressing hu-sPLA, $X$. KAW2647 cells expressing hu-sPL $A, X$ after 4 and 24 h activation with $L P S$. A: Levels of TNF; B: levels of IL 10 measured by ELISA. The results of a wildtype (wt) cell line, a control cell line (ctrl), negative for hu-sPL $A_{2} X$ expression and two hu-sPL $A_{2}$ Xexpressing cell lines $(\mathrm{grX})$ are depicted.

showed morphological characteristics of cellular activation (i.e. cell flattening, increased adherence, and extension of pseudopodia). Strikingly, this was not observed in macrophages overexpressing sPLA $X$ (Fig. 4). To explain the absence of activation features in LPS activated SPLA ${ }_{2} X$ overexpressing cells we measured cytokines released by the cells. The macrophages were incubated with LPS for 4 and 24 hours. TNF levels were strongly induced after 4 h LPS, but sPLA $\times$ overexpressing cells showed considerable less TNF release compared to control and wildtype cells (Fig. 5A). The same observation was made after $24 \mathrm{~h}$ (data not shown). Real-time quantitative PCR showed a similar effect on TNF gene expression (data not shown). In addition to TNF, the anti-inflammatory cytokine interleukin-10 (IL-10) was also measured. IL-10 levels were detectable after 24 hours of LPS and a two-fold increase was observed in the sPLA $X$ overexpressing cells compared with control and wildtype cells (Fig. 5B). These data show that SPLA $X$ expression results in a more anti-inflammatory phenotype after LPS activation of macrophages.

To investigate the prostaglandins that can be generated from the AA that is released by the action of SPLA $\mathrm{A}_{2}, \mathrm{PGE}_{2}$ and $15 \mathrm{~d}-\mathrm{PG} \mathrm{J}_{2}$ were rneasured upon activation

A

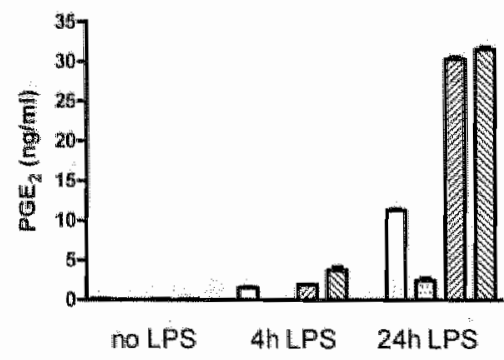

B

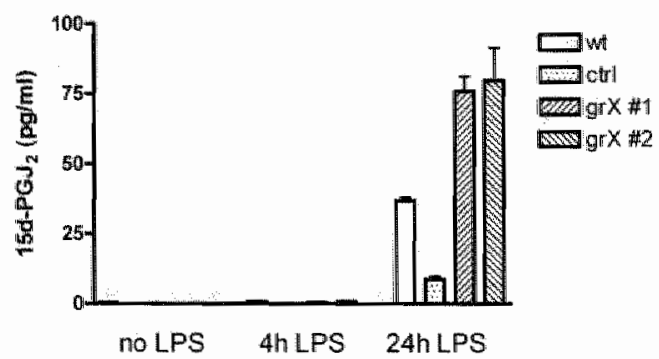

Fig. 6. PGE, and 15d-PGy release during activation of RAW264.7 cells expressing hu-sPLA $\mathrm{X}$. RAW264.7 cells expressing hu-sPLA, $X$ after 4 and 24 h activation with LPS. A: Levels $P G E_{2}$ and $B$ : levels $15 \mathrm{~d}-\mathrm{P}_{\mathrm{B}} \mathrm{J}_{2}$ with competitive ELISA. The results of a wildtype (wt) cell line, a control cell line (ctrl), negative for hu-sPLA $X$ expression and two hu-sPLA, $X$ expressing cell hines $(\mathrm{gr} X)$ are depicted. 
with LPS (250 ng/ml). PGE $E_{2}$ and 15d-PGJ levels in non LPS-treated macrophages showed no differences between the cell lines (Fig. 6). After 4 hours LPS activation, $\mathrm{PGE}_{2}$ levels increased, with more $\mathrm{PGE}_{2}$ being produced by the overexpression cell lines. At 24 hours activation, $\mathrm{PGE}_{2}$ levels in sPLA ${ }_{2}$ overexpressing macrophages increased more than two-fold compared to the wildtype and control macrophages. A similar pattern developed in $15 \mathrm{~d}-\mathrm{PG} \mathrm{j}_{2^{\prime}}$ except that $15 \mathrm{~d}-\mathrm{PGJ} \mathrm{J}_{2}$ levels did not show a potent induction after 4 hours. These results show that both $P G E_{2}$ and $15 \mathrm{~d}-\mathrm{PGI}_{2}$ levels increased under influence of LPS stimulation, and SPLA $X$ overexpression results in a strong increase in the release of these prostaglandins.

\section{Discussion}

sPLA $\mathrm{A}_{2} X$ has been implicated in atherosclerosis and immune functions $(19,20)$. We now demonstrate a two-faced function of macrophage-expressed SPLA X. First, it can mediate the formation of foam cells by modification of native LDL resulting in enhanced uptake and cholesterolester accumulation in macrophages. In addition, we show that activation of sPLA $\mathrm{X}_{2} \mathrm{X}$ overexpressing macrophages results in an enhanced release of both $\mathrm{PGE}_{2}$ and $15 \mathrm{~d}-\mathrm{PGI} \mathrm{z}_{2^{\prime}}$ which exert anti-inflammatory effects on macrophages. These data, combined with the previously described presence of $s \mathrm{PLA}_{2} \mathrm{X}$ in atherosclerotic lesions (20). make sPLA $\mathrm{X}_{2} \mathrm{X}$ a potentially important player in atherosclerosis development.

The $S P L A_{2} X$ protein has previously been detected in macrophage derived foam cells (20) and spleen macrophages (19) by immunohistochemistry. However, as macrophages are capable of binding and internalizing sPLA $X$ protein $(19,24)$ it was not conclusive so far whether the enzyme originates from macrophages or from other cells. We now demonstrate sPLA $X_{2}$ mRNA expression in both C57/B16 bone marrow derived macrophages and the macrophage cell line RAW264.7 which implicates that macrophages are capable of producing sPLA $X$ themselves.

The regulation of the SPLA $X_{2}$ gene has not been fully elucidated, but we could not detect major changes in sPLA $A_{2} X$ expression after LPS activation. In general sPL $A_{2}$ $X$ production appears to be unaffected by inflammatory processes. For example, no differences have been reported in synovial lining cells and interstitial fibers between active and inactive RA sections (25) and in lung and diaphragm tissue during carageenin-induced rat pleurisy (18). However, no detailed investigations into the expression of sPLA $X$ in cultured cells treated with different inflammatory stimuli have been described. Also, analyses to characterize the promoter sequences of the $\mathrm{PLA}_{2} X$ gene have not been performed. Its strong capacity to release AA makes sPLA $A_{2} X$ an interesting enzyme to study the role of phospholipase activity in inflammatory diseases such as atherosclerosis.

sPLA $X_{2}$ proved to be a potent modifier of LDL, which subsequently induces foam cell formation (20). Similarly, we observed a two-fold increase in cholesterol esters in macrophages overexpressing sPLA $X$ in the presence of native LDL. This confirms the potential role of $\mathrm{SPLA}_{2} \mathrm{X}$ in atherogenesis, as foam cell formation is a key factor in this disease $(1,26)$.

Our results show that $s$ PLA 2 Xverexpression alone is not sufficient to elicit an inflammatory response in macrophages. Both $\mathrm{PGE}_{2}$ and $15 \mathrm{~d}-\mathrm{PGJ}_{2}$ did not increase, despite the capacity of $S P L A_{2} X$ to release abundant quantities of $A A_{\text {, the substrate }}$ 
for prostaglandin production. However, prostaglandin production is also dependent on the cyclooxygenases (27). Cyclooxygenases- 1 and 2 (COX-1 and $\mathrm{COX}-2)$ convert AA into $\mathrm{PGH}_{2}$, which is the substrate for a whole myriad prostaglandins, each catalyzed by a specific prostaglandin synthases (28). COX-2 is induced in response to inflammatory stimuli, such as LPS $(19,29)$. In our experiments, the limited availability of COX-2 in unstimulated macrophages (30), and thus limited $\mathrm{PGH}_{2}$ production, will restrain $\mathrm{PGE}_{2}$ and $15 \mathrm{~d}-\mathrm{PGI}_{2}$ production, even though $\mathrm{PLLA}_{2}$ $X$ overexpression delivers sufficient $A A$ substrate. Only in combination with LPS COX-2 is induced and the AA generated by sPLA $A_{2}$ Xoverexpression shows its antiinflammatory potential. Both $P G E_{2}$ and $15 \mathrm{~d}-\mathrm{PG} \mathrm{J}_{2}$ levels increased significantly more in sPLA $A_{2} X$ transfected macrophages compared to non-transfected, and this was accompanied by a strong anti-inflammatory change in cytokine production, with reduced TNF secretion and increased IL-10 production.

$\mathrm{PGE}_{2}$ is a potent anti-inflammatory prostaglandin, that exerts it actions through specific $P \mathrm{PGE}_{2}$ receptors (31) and is the principal prostaglandin produced in LPS stimulated macrophages (32). PGE 2 is synthesized by membrane bound PGEsynthase in response to pro-inflammatory interleukines such as IL-1 $\beta$ and TNF $(33,34) . \mathrm{PGE}_{2}$ provides a feedback mechanism in macrophages that regulates and reduces inflammatory responses $(35,36)$. This is illustrated by the fact that LPS induced $\mathrm{PGE}_{2}$ reduces TNF production, effectively limiting the inflammatory response (37). In the same way, it reduces the effects of macrophage activation by zymosan through down-regulation of TNF and IL-10 up-regulation (38). Whereas the anti-inflammatory properties of $\mathrm{PGE}_{2}$ are well established, $15 \mathrm{~d}-\mathrm{PGJ}_{2}$ is emerging as an even more potent anti-inflammatory prostaglandin $(39,40)$. 15d-PGJ is a metabolite of prostaglandin $\mathrm{D}_{2}\left(\mathrm{PGD}_{2}\right)$, with no specific synthase known for its formation $(28,41)$. $\mathrm{PGD}_{2}$ and $15 \mathrm{~d}-\mathrm{PGJ}_{2}$ are known to play a role in inflammatory resolution and are produced after the onset of $\mathrm{PGE}_{2}$ production (42). This supports our observed delay $15 \mathrm{~d}-\mathrm{PGJ} \mathrm{J}_{2}$ in respect to $\mathrm{PGE}_{2} .15 \mathrm{~d}-\mathrm{PGJ}_{2}$ may exert its anti-inflammatory properties through inhibition of the NF-KB pathway (43-45). RAW264.7 macrophages have been reported to produce $\mathrm{PGD}_{2}$ in response to LPS treatment, while COX-2 inlibition diminishes $\mathrm{PGD}_{2}$ production (46).

Based on these anti-inflammatory properties of $P \mathrm{PE}_{2}$ and $15 \mathrm{~d}-\mathrm{PG} \mathrm{I}_{2}$ we conclude that $s P L A_{2} X$ overexpression in macrophages provides increased AA quantities to the prostaglandin synthesis pathway, which depends on COX-2 and is activated under influence of an inflammatory stimulus like LPS. As such, sPLA $A_{2}$ X provides an anti-inflammatory feedback mechanism through the production of anti-inflammatory prostaglandins, which reduce macrophage activation. This may have consequences for therapeutic interventions based on COX-2 suppression. COX-2 specific inhibition has the potency to eliminate the anti-inflammatory effects of $s$ PLA $X$ in macrophages. In the light of the recent controversy around $\mathrm{COX}-2$ selective inhibitors, its use in macrophage driven inflammatory diseases should be investigated more in detail. Certainly as COX-2 is the limiting factor in prostaglandin production and is expressed in chronic inflammatory diseases and during inflammatory resolution $(42,47)$.

Our results show that $s P L A_{2} X$ contributes to foam cell formation and at the same time reduces macrophage activation through enhancing $\mathrm{PGE}_{2}$ and $15 \mathrm{~d}-\mathrm{PGF}_{2}$ pro- 
duction. Because both foam cell formation and inflammation are pivotal in this disease, the role of sPLA $A_{2}$ in atherosclerosis is ambiguous. Future in vivo experiments with mouse models overexpressing sPLA, $X$ in atherosclerotic lesions may elucidate the role of this enzyme in atherosclerosis in more detail.

\section{References}

1. Lusis, A.J. 2000. Atherosclerosis. Nature 407:233-241.

2. Glass, C.K, and Witztum, J.L. 2001. Atherosclerosis, the road ahead. Cell 104:503-516.

3. Libby, P., Ridker, P.M, and Maseri, A. 2002. Inflammation and atherosclerosis. Circulation 105:1135-1143.

4. Ivandic, B., Castellani, L.W., Wang, X.P., Qiao, J.H., Mehrabian, M., Navab, M., Fogelman, A.M., Grass, D.S., Swanson, M.E., de Beer, M.C, et al. 1999. Role of group II secretory phospholipase $A_{2}$ in atherosclerosis: 1. Increased atherogenesis and altered lipoproteins in transgenic mice expressing group Ila phospholipase $\mathrm{A}_{2}$. Atterioscler Thronb Visc Biol 19:1284-1290.

5. Webb, N.R, Bostrom, M.A., Szilvassy, S.], van der Westhuyzen, D.R., Daugherty, Aw and de Beer, F.C. 2003. Macrophageexpressed group IIA secretory phospholipase $A_{2}$ increases atherosderotic lesion formation in LDL receptor-deficient mice. Atterioscler Thronb Vasc Biol 23:263-268.

6. Ghesquiere, S.A., Gijbels, M.J., Anthonsen, M., van Gorp, P.J, van der Made, I., Johansen, B., Hofker, M.H., and de Winther, M.P. 2004. Macrophage-specific overexpression of group II s. SLA, results in increased atherosclerotic lesion size and enhanced collagen deposition. I Lipid Res 46:201-210.

7. Thetge, U.J., Pratico, D., Ding, T, Funk, C.D., Hildebrand, R.B., Van Berkel, T, and Van Eck, M. 2005. Macrophage-specific expression of group IIA sPLA, results in accelerated atherogenesis by increasing oxidative stress. J Lipid Res 46:1604-1614.

8. Six, D.A., and Dennis, E.A. 2000. The expanding superfamily of phospholipase A(2) enzymes: classification and characterization. Biochim Biophys Acta 1488:1-19.

9. Dennis, E.A. 1997. The growing phospholipase $\mathrm{A}_{2}$ superfamily of signal transduction enzymes. Trends Biochem Sci 22:1-2.

10. Hanasaki, K, and Arita, H. 1999. Biological and pathological functions of phospholipase A(2) receptor. Arch Biachem Biopihys 372:215-223.

11. Hanasaka, K. 2004. Mammalian phospholipase $\mathrm{A}_{2}$ : phospholipase $\mathrm{A}_{2}$ receptor. Biol Pharm Bull 27:1165-1167.

12. Kanemasa, T., Hanasaki, K, and Arita, H. 1992. Migration of vascular smooth muscle cells by phospholipase $\mathrm{A}_{2}$ via specific binding sites. Biochim Biophys Acta 1125:210-214.

13. Cupillard, L., Koumanov, K., Mattei, M.G., Lazdunski, M., and Lambeau, G. 1997. Cloning, chromosomal mapping, and expression of a novel human secretory phospholipase $\mathrm{A}_{2}$. Biol Chem 272:15745-15752.

14. Bezzine, S., Koduri, RS., Valentin, E., Murakami, M., Kudo, I., Ghomashchi, F., Sadilek, M. Lambeau, G., and Gelb, M.H. 2000. Exogenously added human group X secreted phospholipase $\mathrm{A}(2)$ but not the group $I \mathrm{~B}, \mathrm{IIA}$, and $\mathrm{V}$ enzymes efficiently release arachidonic acid from adherent mammalian cells. I Biol Chem 275:3179-3191.

15. Singer, A.G., Ghomashchi, F, Le Calvez, C., Bollinger, J., Berzine, S, Rouault, M, Sadilek, M, Nguyen, E., Lazdunski, M., Lambeau, $\mathrm{G}_{y}$ et al. 2002. Interfacial kinetic and binding properties of the complete set of human and mouse groups I, II, V, X, and XII secreted phospholipases A J Biol Chem 277:48535-48549.

16. Pan, Y.H., Yu, B.Z., Singer, A.G., Ghomashchi, F, Lambeau, G., Gelb, M.H., Jain, M.K., and Bahnson, BJ. 2002. Crystal structure of human group X secreted phospholipase $A_{2}$. Electrostatically neutral interfacial surface targets zwitterionic membranes. J Biol Chem 277:29086- 


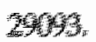

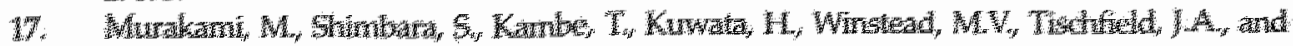

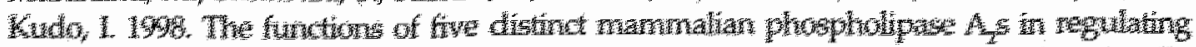

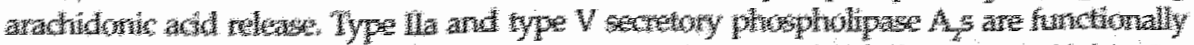

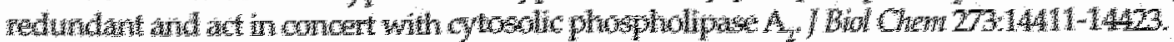

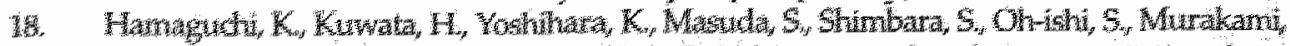

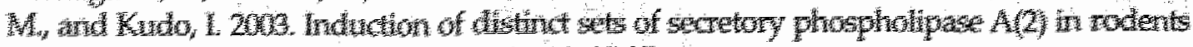

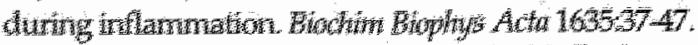

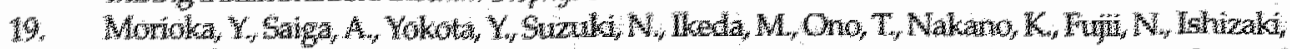

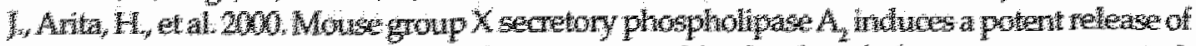

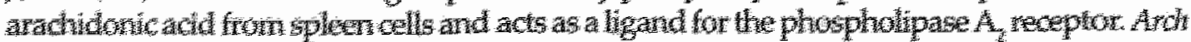

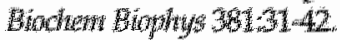

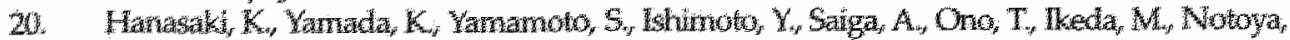

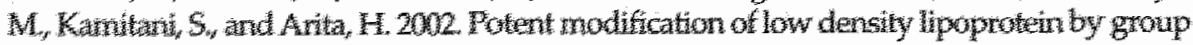

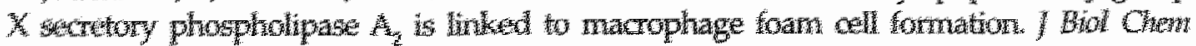
$27,2916-29124$

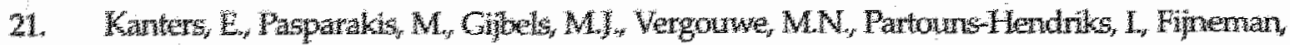

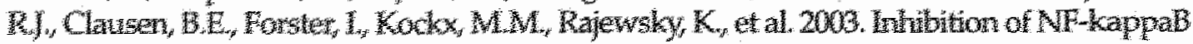

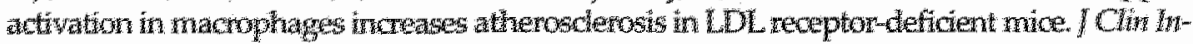
axs $1121176-1185$.

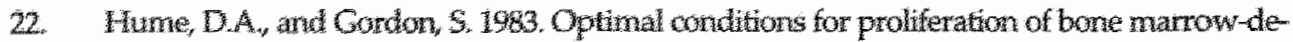

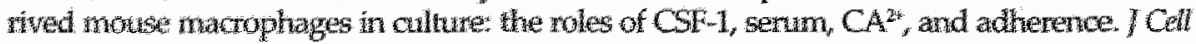
Physict 17,89494

23. Gough, 2 , Gordor, S, and Creaves, D.R 2001. The use of human CD68 transcriptional regulatory secutenos to drect high-level expression of dass A scavenger receptor in macrophages In wite and in wo. Thmology $103351-361$.

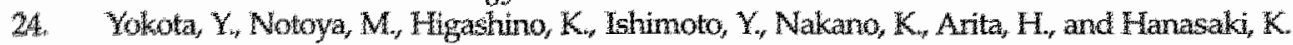
2001. Clearance of group $X$ secretory phospholipase A(2) wa mouse phospholipase A(2) receptor FEBS Let 509,250254

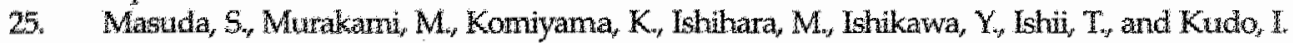
2005. Various secretory phospholipase $A_{2}$ encymes are expressed in rheumatoid arthritis and. augrant prostaglandin production in cultured synovial belis. Febs / 272655-672.

26. Guyton JR. 2001. Phospholipid hydrolytic enzymes in a cesspool of arterial intimal tipoproteins: a mechanism for atherogenic lipid accumulation. Arterioscler Thromb Vasc Biol 21:884 886.

27. Smith, WLL, DeWitt, D.L. and Garavito, R.M. 2000. Cyclooxygenases: structural, cellular, and molecular biology. Amm Reo Biochen 69:145-182.

28. Helliwell, R.J., Adams, L.F, and Mitchell, M.D. 2004. Prostaglandin symthases: recent developments and a novel hypothesis, Prostaglandins Lewkot Essent Fatty Acids 70:101-113.

29. Saiga, A., Morioka, Y, Ono, T., Nakano, K., Ishimoto, Y., Arita, H., and Hanasaki, K. 2001. Group $X$ secretory phospholipase $A(2)$ induces potent productions of various lipid mediators in nouse peritoneal macrophages. Biochim Biophys Acta 1530:67-76.

30. Yan, Z, Stapleton, P.P., Freman, T.A., Fuortes, M. and Daly, J.M. 2004. Enhanced expression of cyclooxygenase-2 and prostaglandin E2 in response to endotoxin after trauma is dependent on MAPK and NF-kappaB mechanisms. Cell lmwiwol 232:116-126.

31. Breyer, R.M., Bagdassarian, C.K., Myers, S.A., and Breyer, M.D. 2001. Prostanoid receptors: subtypes and signaling. Armu Rev Pharmacol Toxicol 41:661-690.

32. Matsumoto, H., Naraba, H., Murakami, M., Kudo, I., Yamaki, K., Ueno, A., and Oh-ishi, S. 1997. Concordant induction of prostaglandin $\mathbb{E}_{2}$ synthase with cyclooxygenase-2 leads to preferred production of prostaglandin $\mathrm{E}_{2}$ over thromboxane and prostaglandin $\mathrm{D}_{2}$ in lipopolysaccharide-stimulated rat peritoneal macrophages. Brochen Biophys Res Commun 230:110- 
114.

33. Stichtenoth, D.O., Thoren, S., Bian, H., Peters-Golden, M., Jakobsson, P., and Crofford, L.I. 2001. Microsomal prostaglandin E synthase is regulated by proinflammatory cytokines and glucoconticoids in primary rheumatoid synovial cells. / Iw ww 167:469-474.

34. Naraba, H., Yokoyama, C, Tago, N., Murakami, M, Kudo, I. Fuek, M, On-Ishi, S, andi Tanabe, T. 2002. Transcriptional regulation of the membrane-associated prostaglandin E, synthase gene. Essential role of the transcription factor Egr-1. / Biol Chem 277:28601-28608.

35. Hinz, B., Kraus, V., Pahl, A., and Brune, K. 2000. Salicylate metabolites inhibit cyclooxygenase-2-dependent prostaglandin E(2) synthesis in murine macrophages. Biochem Biophys Res Commun 274:197-202.

36. Harizi, H. Juzan, M., Grosset, C, Rashedi, M. and Gualde, N. 2001. Dendritic cells issued in vitro from bone marrow produce $\mathrm{PGE}(2)$ that contributes to the immunomodulation induced by antigen-presenting cells. Coll Immunol 209:19-28.

37. Ikegami, R., Sugimoto, Y., Segi, E., Katsuyama, M., Karahashi, H., Amano, F. Maruyama, T, Yamane, H., Tsuchiya, S., and Ichikawa, A. 2001. The expression of prostaglandin E receptors EP2 and EP4 and their different regulation by lipopolysaccharide in $\mathrm{C} 3 \mathrm{H} / \mathrm{HeN}$ peritomeal macrophages. I Immunol 166:4689-4696.

38. Shinomiya, S., Naraba, H., Ueno, A., Utsunomiya, I., Maruyama, T., Ohuchida, S., Ushikubi,

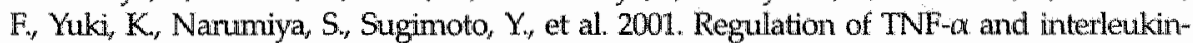
10 production by prostaglandins $I(2)$ and $E(2)$ : studies with prostaglandin receptor-deficient mice and prostaglandin E-receptor subtype-selective synthetic agonists. Biochew Pharmacol 61:1153-1160.

39. Kawahito, Y., Kondo, M., Tsubouchi, Y., Hashiramoto, A., Bishop-Bailey, D., Inoue, K., Kohno, M. Yamada, R., Hla, T., and Sano, H, 2000.15-deoxy-delta(12,14)-PGI(2) induces synoviocyte apoptosis and suppresses adiuvant-induced arthritis in rats. J Clin Invest 106:189-197.

40. Harris, S.G., Padilla, J, Koumas, L., Ray, D., and Phipps, R.P. 2002. Prostaglandins as modulators of immunity. Trends Inmunol 23:144-150.

41. Sluibata, T., Kondo, M., Osawa, T., Shibata, N., Kobayashi, M., and Uchida, K. 2002 15-deoxydelta 12,14-prostaglandin $\mathrm{I}_{2}$. A prostaglandin $\mathrm{D}_{2}$ metabolite generated during inflammatory processes. J Biol Chem 277:10459-10466.

42. Gilroy, D.W., Colville-Nash, P.R., Willis, D., Chivers, J, Paul-Clark, M.J, and Willoughby, D.A. 1999. Inducible cyclooxygenase may have anti-inflammatory properties. Nat Med 5:698-701.

43. Giri, S, Rattan, R., Singh, A.K., and Singh, I. 2004. The 15-deoxy-delta12,14-prostaglandin I, inhibits the inflammatory response in primary rat astrocytes via down-regulating multiple steps in phosphatidylinositol 3-kinase-Akt-NF-kappaB-p300 pathway independent of peroxisome proliferator-activated receptor gamma. /lmmunol 173.5196-5208.

44. Bianchi, A., Moulin, D., Sebillaud, S., Koufany, M., Galteau, M.M., Nelter, P., Terlain, B., and Jouzeau, J.Y. 2005. Contrasting effects of peroxisome-proliferator-activated receptor (PPAR)gamma agonists on membrane-associated prostaglandin $\mathrm{E}_{2}$ synthase-1 in $1 \mathrm{~L}-1 / 3-\mathrm{stim}-$ ulated rat chondrocytes: evidence for PPARgammawindependent inhibition by 15-deoxyDelta12,14prostaglandin $\mathrm{J}_{2}$. Arthritis Res Ther 7:R1325-1337.

45. Pande, V, and Ramos, M.J.2005. Molecular recognition of 15-deoxy-delta(12,14)-prostaglandin $\mathrm{J}_{2}$ by muclear factor-kappa B and other cellular proteins. Bioorg Med Chent Lett 15:4057-4063.

46. Tanaka, Y., Takizawa, M., Igimi, S., and Amano, F. 2004. Enhanced release of prostaglandin $\mathrm{D}_{2}$ during re-incubation of RAW 264.7 macrophage-like cells after treatment of both lipopolysaccharide and non-steroidal anti-inflammatory drugs. Biol Pharm Bull 27:985-991.

47. Willoughby, D.A. Moore, A.R., and Colville-Nash, P.R. 2000. COX-1, COX-2, and COX-3 and the future treatment of chronic inflammatory disease. Lancet 355:646-648. 


\section{Chapter 5}

\section{Phospholipase group X}

overexpression induces fatal pulmonary inflammation and protein accumulation in mice.

Stijn A.I. Ghesquiere", Marion J.J. Gijbels" ${ }^{1,}$, Sjef J. Verbeek, Marten H. Hofker, and Menno P.J. de Winther'.

1 Dept. of Molecular Genetics, Cardiovascular Research Institute Maastricht, Maastricht University, The Netherlands.

2 Dept. of Pathology, Cardiovascular Research Institute Maastricht, Maastricht University, The Netherlands.

3 Dept. of Human Genetics, Leiden University Medical Center The Netherlands.

In preparation 


\section{Abstract}

Secreted phospholipases $A_{2}$ are a large family of enzymes, characterized by the hydrolysis of phospholipids at the $\mathrm{sn}-2$ position, releasing free fatty acids (FFA) and lysophospholipids (lysoPL). Secreted phospholipase $\mathrm{A}_{2}$ group $X\left(s P L A_{2} X\right.$ ) is one of the most potent phospholipase enzymes in mammals, capable of hydrolyzing intact cell membranes. sPL $A_{2} X$ has been shown in atherosclerotic lesions and lungs. In this paper, we studied the role of sPLA $X$ in vivo. We created a macrophage specific SPLA $X_{2} X$ overexpression mouse model to investigate the role of SPLA $X$ in atherosclerosis. Our results showed a potential involvement in inflammatory lung disease. Mice expressing sPLA $\mathrm{X}_{2}$ in their macrophages develop fatal lung pathology, with massive macrophage invasion and additional protein accumulation. This study emphasizes that phospholipase activity affects a broad range of organs. We conclude that more refined models with sPLA $\mathrm{A}_{2} \mathrm{X}$ expression would be a valuable tool to elucidate the role of phospholipase activity in inflammation. Both vascular and pulmonary research can potentially benefit from future phospholipase models.

\section{Introduction}

Phospholipases are a large group of related enzymes. Typical is their hydrolysis of phospholipids at the sn-2 position, resulting in the liberation of free fatty acids and lysophospholipids, which are involved in various inflammatory processes (1). Phospholipases received a lot of attention in the last decades and are often associated with chronic and acute inflammation $(2,3)$. However, the exact role of phospholipases in inflammation and atherosclerosis is still not fully elucidated. In this study, our aim was to establish a novel model for phospholipase overexpression in atherosclerosis. For this, we developed a mouse model with macrophage specific overexpression of phospholipase $\mathrm{A}_{2}$ group $X\left(\mathrm{sPLA}_{2} \mathrm{X}\right)$.

sPLA $_{2} X$ was discovered in 1997 (4) and is present in many organs, such as spleen, thymus, testis, and lung of humans, mice, and rats (4-6). Interesting is the detection of SPLA $X$ in macrophages in atherosclerotic lesion of high fat-fed apolipoprotein $E$ knockout mice and has a strong capacity to induce foam cell formation (7). In general, sPLA $A_{2} X$ is a very potent enzyme and, in contrast to most other mammalian phospholipases, sPLA $X_{2} X$ acts on intact cell membranes $(8,9)$.

The regulation of the sPLA $A_{2} X$ gene has not been fully elucidated, but in a previous study we could not detect major changes in SPLA $_{2} X$ expression after LPS activation (Ghesquiere et al. 2006, chapter 4). In general sPLA $A_{2}$ production appears to be unaffected by inflammatory processes. For example, no differences have been reported in synovial lining cells and interstitial fibers between active and inactive RA sections (10) and in lung and diaphragm tissue during carageenin-induced rat pleurisy (5). However, no detailed investigations into the expression of $\operatorname{sPLA}_{2} X$ in cultured cells treated with different inflammatory stimuli have been described. Also, analyses to characterize the promoter sequences of the sPLA $X$ gene have not been performed.

We have previously shown (Ghesquiere et al. 2006, chapter 4) that SPLA $X$ overexpression in macrophages elicits an enhanced anti-inflammatory response after LPS 
addition. In these macrophages, sPLA, $X$ increased the production of arachidonic acid (AA), which is converted to prostaglandin $E_{2}$ and 15-deoxy- $\Delta 12,14$-prostaglandin $\mathrm{J}_{2}$, both known to exert anti-inflammatory properties in macrophages. The general phospholipase A, IIA (sPLA, HA) overexpression (11) and a macrophages specific overexpression model (12), did not show generalized inflammation.

To study the role of sPLA $X$ in inflammation, we developed an in vivo mouse model with macrophages specific overexpression. Establishing an $\mathrm{SPLA}_{2} X$ mouse model with macrophages specific expression proved difficult. We observed lung problems in the transgenic mice, with massive macrophage invasion, thickening of the interstitium and accumulation of proteins in the lungs.

\section{Materials and methods}

\section{Construct}

Human sPLA $\mathrm{A}_{2} \mathrm{XDNA}$ containing the $\mathrm{PLA}_{2} X \mathrm{XDNA}$ starting at the second methionine start site (met-32) (4) (a generous gift from Dr. Cupillard), was isolated from a $\mathrm{pRc} / \mathrm{CMV}$ vector (Invitrogen). The met-32 fragment was selected using convenient restriction sites and inserted in a pCDNA 3 expression vector behind a CD68 promoter construct ( $2.9 \mathrm{~kb}$ CD68 + IVS- 1 sequence (13), a generous gift of Dr. D.R. Greaves). The CD68 - sPLA $A_{2} X$ in pcDNA3 plasmid was verified by sequencing the start and the end of the met-32 construct and boundaries of the CD68 promotor region. Additional verification was performed using various restriction enzymes and subsequent gel electrophoresis.

\section{Mouse}

The complete $4.56 \mathrm{~kb}$ fragment (CD68 $+\mathrm{sPLA} \mathrm{A}_{2} \mathrm{X}$ ) was isolated with electrophoresis in agarose gell, followed by electroelution. Oocyte injection to generate transgenic mice was performed according to standard procedures (14) in C57BL/6J. Two transgenic mice were obtained. All experiments were approved by the local committee for Animal Welfare. The animals were held under pathogen-free conditions. Microbiological status was checked regularly by routine serological, bacteriological and histological procedures.

Transgenic mice were identified by polymerase chain reaction (PCR) with human SPLA $\mathrm{X}_{2} \mathrm{X}$ specific primers. Additionally we performed southern blot analysis. Tail DNA was isolated, digested with $B a n H I$ and labeled with ${ }^{32} \mathrm{P}$ tagged sPLA $X$ probe. To estimate the integrated copy number, linearized CD68 sPLA $\mathrm{A}_{2} \mathrm{X}$ construct vector mixed in 1/1,10/1, and 100/1. ratio with genomic DNA was included on the blot.

\section{Histology}

Whole mice were fixed with $10 \%$ formalin in PBS. After fixation, transversal section of the mice or of the organs were made and embedded in paraffin. Histological slides of three micron were stained with hematoxilyn and eosin (H\&E). 


\section{Results}

To establish sPLA $X$ transgenic mice, three oocyte injection rounds were performed with the CD68 sPLA $X$ construct (table 1). Only three founder mice, of a total of 55 born, were positive by $\mathrm{PCR}$. The success rate of this construct $(5.5 \%)$ was compared with mice produced at the same time, and in the same facility under the same conditions, but with SRA-PAFAH and SRA-mA20 constructs. The results show that these constructs yielded $18.6 \%$, respectively $8.9 \%$ transgenic mice. Moreover, the

Table 1

\begin{tabular}{|c|c|c|c|c|c|}
\hline 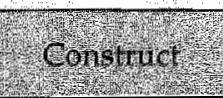 & Humber 6 & 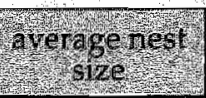 & 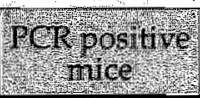 & $\begin{array}{l}\text { Mansgenesis } \\
\text { stresess rate }\end{array}$ & (Trand I \\
\hline CD68 SPLA2X & 55 & 4.1 & $3^{*}$ & $5.5 \%$ & $0 / 3$ \\
\hline SRAPAEAH & 43 & 5.1 & 8 & $18.6 \%$ & $7 / 8$ \\
\hline SRA mA20 & 45 & 5.0 & 4 & $89 \%$ & $4 / 4$ \\
\hline
\end{tabular}

Table 1. Number of transgenic mice born after oocyte injection rounds. The number of born after CD68 sPLA $X$, SRA-PAFAH, and SRA-MA20 construct injections in the oocytes. " two died at -3 weeks of age.

founder mice from these latter constructs mostly transmitted the transgenes to $F 1$ and F2 (7/8 and 4/4, respectively). For the sPLA $A_{2} \times$ transgenic mice, the first one (female, founder \#1) died before three weeks of age and unfortunately no material was obtained for pathological examination. Later on, a second founder mouse (male, \#2) was obtained. Southern blot was performed to check the transgene and to estimate the copy number (Fig. 1). Two bands were visible in the transgenic mouse, from which the small fragment $(538 \mathrm{bp})$ corresponds with the BamHI sites in SPLA $_{2} \mathrm{X}$ and the promotor and is also present in the linearized construct vector. The Southern blot indicates that a single copy of the transgene was integrated

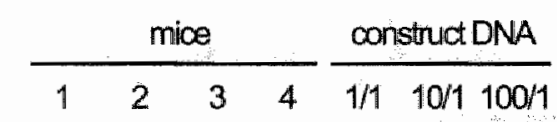

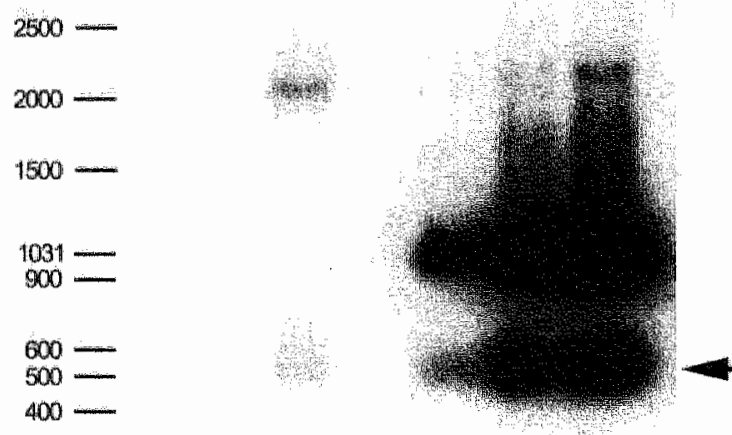

Fig. 1. Southem blot. BamHI digested mouse DNA and controls (CD68 sPLA $X$ construct material) blotted with sPLA $\times$ probe. Southern blot from 4 mice is shown on the left, at the right are controls with different construct / genomic copy number ratios. in the genome of the mouse. This animal showed very poor growth and died at 3 weeks of age after which total histopathology was performed. The animal showed severe lung pathology (Fig. 2) in combination with focal rhabdomyopathy. The cause of death was an interstitial pneumonia with severe infiltration of alveolar macrophages and edema (Fig. 2). In a small part of the serratus dorsalis muscle, rhabdomyopathy was observed characterized by necrosis of the myocytes, infiltration of macrophages and giant cell formation. No abnormalities were found in any other organs or muscles. The third oocyte injection round finally delivered one 


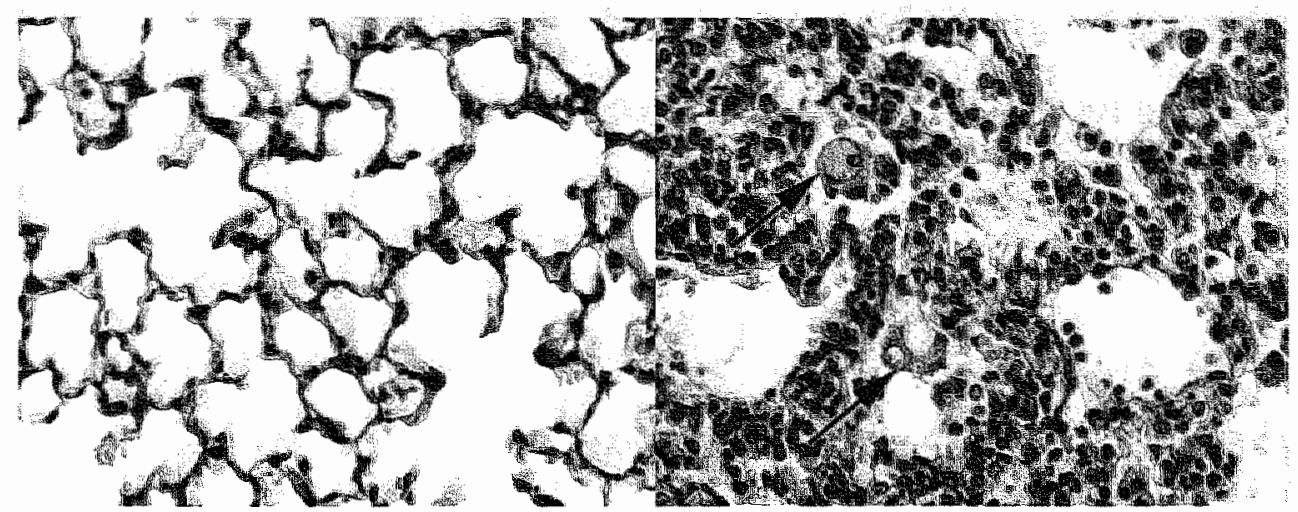

Fig. 2. Microscopy of the lung. A: Normal lung of a control C57BL/mouse (200x), B: Interstitial pneumonia of a sPLA $X$ mouse with massive infiltration of macrophages and granulocytes. Alveoli are filled with protein-lipid materiall loaden macrophages (arrows) (200x).

transgenic mouse that exhibited no external signs of pathology and reached adulthood. Total offspring of this mouse was 62 , with only one animal being positive for the transgene, indicating very poor transmission of the transgene. The only F1 animal also did not transmit the transgene to its offspring, from a total of 16 pups, all were negative for SPLA 2 X. Both transgenic mice from this line (i.e. the F0 and the F1 animal) were finally sacrificed and their pathology was carefully investigated. The lungs of these mice showed increased macrophage infiltration and signs of diffuse lung inflammation, indicating a similar but much milder phenotype as was observed in founder $\$ 2$.

\section{Discussion}

Our results show that macrophage specific overexpression of sPLA $X$ leads to severe lung pathology with massive macrophage invasion, interstitial thickening and edema. There were no signs of systemic inflammation, bacterial or viral infections in these animals held under SPF conditions.

We had limited success in our attempts to obtain viable transgenic SPLA $A_{2} X$ mice (table 1). In the first place only a few transgenic mice were born, despite repeated oocyte injection rounds. This is possibly caused by the fact that $s P L A_{2} X$ induced prostaglandin production can affect embryogenesis (15-17). Alternatively, some transgenic mice might have died shortly after parturition and were eaten by the mother. Thirdly, from the transgenic mice we were able to obtain, two founders died at early age of which one showed severe lung pathology (Fig. 2), while the founder that survived also showed some lung defects, albeit less severe, after being sacrificed. Possibly, the surviving mice had little sPLA $A_{2} X$ production in the lungs due to a low transgene copy number or due to integration in a less active region of the genome. In addition, this mouse may have been chimeric for the transgene since only one out of 62 offspring was transgenic. However, founder \#2, which died at early age, had only a single transgene copy (Fig. 1). We hypothesize that the genetic background inhibited the expression of the transgene in the surviving founder and in one of the offspring. As such, most of the transgenic off- 
spring might have died before or shortly after birth and skewed the transmission rate from the expected $1 / 1$ to $1 / 62$.

While we did observe lung pathology, no signs of generall inflammation were observed. We hypothesize that sPLA $A_{2} X$ activity in the lung degraded the surfactant in these mice, leading to respiratory distress and eventually death due to pulmonary failure. In the normal mouse, healthy lung, surfactant is degraded by lysosomal phospholipase $\mathrm{A}_{2}$ (LPLA) a specialized enzyme used by alveolar macrophages to process surfactant in their lysosomes (18-20). Surfactant turnover in the lungs is a delicate balance between production by alveolar type II epithelial cells and clearance by alveolar macrophages (20). In our $\mathrm{SPLA} \mathrm{A}_{2} X$ overexpression model, the phospholipids component of surfactant may have been degraded at an unusual high rate due to the sPLA $X$ activity in macrophages (21). As such sPLA $A_{2} X$ overexpression can tip the surfactant balance towards shortage, a condition associated with inflammatory lung diseases $(3,22)$.

Additionally, sPLA $\mathrm{A}_{2} \mathrm{X}$ releases free fatty acids and lysophospholipids from surfactant, which are metabolized into inflammatory mediators. As result of this, sPLA $X$ can either promote as well reduce inflammation, depending on the produced eicosanoids. In the case of increased 5-lipoxygenase (5-LO) production, lung injury is enhanced $(23,24)$, while the production of prostaglandin $\mathrm{PGE}_{2}$ and $15 \mathrm{~d}-\mathrm{PGJ}_{2}$ has the potency to reduce inflammation in macrophages and other cells (25-27)(Ghesquiere et al. 2006, chapter 4). However, current data is not conclusive whether increased phospholipase activity in the lungs induces or enhances inflammation. The respiratory failure we observed in one of the $s P L A_{2} X$ mice shows some similarities with what is known as acute respiratory distress (ARD), a disease related to pulmonary inflammation and surfactant degradation, and associated with increased phospholipase activity (28). sPLA ${ }_{2}$ group IIA activity has been proposed as the cause of ARD (28), but this enzyme shows little activity on lung surfactant (22) and probably has little contribution to the disease itself $(29,30)$. Potential alternative candidates involved in the onset and progression of ARD are phospholipase group $V$ and $X$, both are known as potent modifiers of lung surfactant (22) and are present in alveolar macrophages, alveolar epithelium and interstitium (3).

We propose a positive feedback loop for $\$ P L A_{2} X$ induced lung pathology and ultimately respiratory failure. In the initial phase, sPLA $A_{2} X$ produced by macrophages disturbs the surfactant balance due to increased surfactant phospholipid degradation. "The reduction in surfactant results in lung injury. At the same time, inflammatory mediators are being produced. The injury and inflammatory mediators elicit an inflammatory response and additional macrophages are attracted to the lungs. These can worsen the problems, when the newly arrived macrophages start to produce sPLA ${ }_{2} X$, increasing the pressure on surfactant and enhancing inflammation. While sPLA $X$ overproduction in macrophages can limit their inflammatory responses (Ghesquiere et al. 2005, chapter 4), massive sPLA $\mathrm{A}_{2}$ release in the lungs is not sustainable and has the capability to develop into acute lung failure, as we have observed in our mice. Our mice with limited sPLA $A_{2}$ production, showed indeed increased macrophages in the lungs, but did not develop lethal lung pathology.

Additionally to inflammation, we observed protein-lipid loaden macrophages in 
the lungs (Fig. 2). We hypothesize that partially degraded surfactant in the lungs is ingested by macrophages attracted to the area. Whereas native alveolar macrophages have the required mechanism to properly degrade surfactant (20), the invading macrophages might lack this mechanism, leading to intracellular accumulation of the remainders of surfactant. To some extent, this protein-lipid accumulation has similarities to pulmonary alveolar proteinosis (PAP), a rare human disease caused by alveolar surfactant protein accumulation due to insulficient surfactant degradation $(31,32)$. In this respect, our sPLA $A_{2} X$ mouse model delivers a model for protein accumulation, additionally to the current granulocyte macrophage colony stimulating factor (GM-CSF) deficient mouse model $(33,34)$. In the GM-CSF model, incomplete macrophage maturation limits surfactant clearance (35). It is very interesting to see that both surfactant degradation and accumulation can develop into protein accumulation, but it remains to be seen if our novel sPLA $X$ model is a suitable animal model for PAP.

Our initial goal was to create a mouse model to study the role of sPLA, $X$ in atherosclerosis. We have not been able to determine the effects on arterial lesion formation, but instead showed that a SPLA $\mathrm{X}_{2}$ overexpression model offers an interesting opportunity to investigate the role of phospholipases in lung pathology. Because it was hard to establish a viable mouse model with our sPLA $X$ overexpression construct, we propose alternative options, such as the use less potent variants of the CD68 promotor (13), a longer, less active $\mathrm{PLA}_{2} \mathrm{X}$ fragment (4), or restricting expression to alveolar macrophages using the LPLA $A_{2}$ promotor to drive sPLA $X$. In conclusion, a more subtle phospholipase group $X$ overexpression model would deliver a valuable tool for phospholipase studies both in the field of atherosclerosis and pulmonology.

\section{References}

1. Six, D.A., and Dennis, E.A. 2000. The expanding superfamily of phospholipase A(2) enzymes; classification and characterization. Biochin Biophys Acta 1488:1-19.

2. Rader, D.J. 2000. Inflammatory markers of coronary risk. N Engl J Med 343:1179-1182.

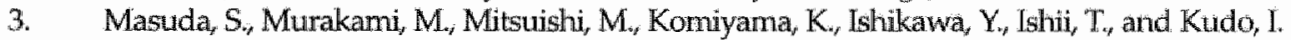
2005. Expression of secretory phospholipase $A_{2}$ enzymes in lungs of humans with pneumow nia and their potential prostaglandin-synthetic function in human lung-derived cells. Biochem ] $387: 27-38$.

4. Cupillard, L., Koumanov, K., Mattei, M.G. Lazdunski, M, and Lambeau, G. 1997, Cloning, chromosomal mapping, and expression of a novel human secretory phospholipase $A_{2 .}$ / Biol Chem 272:15745-15752.

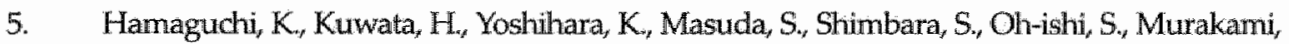
M. and Kudo, I. 2003. Induction of distinct sets of secretory phospholipase A(2) in rodents during inflammation. Biochim Biophys Acta 1635:37-47.

6. Morioka, Y., Saiga, A., Yokota, Y, Suzuki, N., Ikeda, M., Ono, T., Nakano, K, Fujiii, N., Ishizaki,

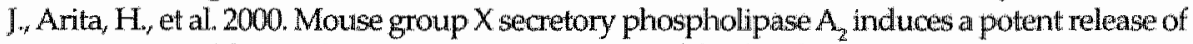
arachidonic acid from spleen oells and acts as a ligand for the phospholipase $A_{2}$ receptor. Arch Biochem Biophys 381:31-42.

7. Hanasaki, K., Yamada, K, Yamamoto, S., Lshimoto, Y, Saiga, A., Ono, T, Ikeda, M., Notoya, M., Kamitani, $S_{x,}$ and Arita, H. 2002. Potent modification of low density lipoprotein by group $X$ secretory phospholipase $A_{2}$ is linked to macrophage foam cell formation. / Biol Chem 277:29116-29124. 
8. Singer, A G, Chomashchi, F, Le Callvez, C, Bollinger, J, Bezzine, S, Rouault, M, Sadilek, M, Nguyen, E, Lazdunski, M., Lambeau; $G_{\text {, }}$ et al 2002 . Interfacial kinetic and binding properties of the complete set of human and mouse groups $I, I, V, X$, and $X I I$ secreted phospholipases $\mathrm{A}_{2}$. J Biol Chem 277:48535-48549.

9. Pan, YH., Yu, B.Z, Singer, A.G., Ghomashch, I, Lambeau, G., Gelb, M.H. Jain, M.K, and Bahnson, B. 2002 Crystal structure of human group $X$ secreted phospholipase $A_{2}$. Electrostatically neutral interfacial surface targets zwittericnic membrames, I Biol Chem $277,29086-$ 29093.

10. Masuda, S., Murakami, M, Komyama, K, Ishihara, M, Ishikawa, Y, Ishui, I, and Kudo, I. 2005. Various secretory phospholipase $A_{2}$ enzymes are expressed in rheumatoid arthritis and augment prostaglandin production in cuiltured synovial cells. Febs J 2726655-672.

11. Nevalainen, T.J, Laine, W. I, and Grass, D.S. 1997. Expression of human group II phospholipase $A_{2}$ in transgenic mice. I Histochem Cytochem 45:1109-1119.

12. Ghesquiere, S.A., Gijbels, MJ., Anthonsen, M., van Gorp, PJ, van der Made, L, Johansen, B., Hofker, M.H. and de Winther, M.P. 2004. Macrophage-specific overexpression of group IIa $s \mathrm{PLA} \mathrm{A}_{2}$ results in increased atherosclerotic lesion size and enhanced collagen deposition. J Lipid Res 46:201-210.

13. Gough, $P J_{.}$Gordon, $S$, and Greaves, D.R. 2001. The use of human CD68 transcriptional regulatory sequences to direct high-level expression of class. A scavenger receptor in macrophages in vitro and in vivo. Imtmutology 103:351-361.

14. Hogan, B., Beddington, R., Constantini, F, and Lacy, E. 1994. Manipulating the Mouse Embryo: A Laboratory Manual: Cold Spring Harbor Laboratory.

15. Simpson, K.S., Adams, M.H. B., Behrendt-Adam, C.Y, Baker, C.B., and McDowell, K.J. 1999. Identification and initial characterization of calcy din and phospholipase $\mathrm{A}_{2}$ in equine conceptuses. Mol Reprod Dev 53:179-187.

16. Wang, H., Wen, Y.s Mooney, S, Behr, B., and Polan, M.L. 2002. Phospholipase A(2) and cy. clooxygenase gene expression in human preimplantation embryos. J Clin Endocrinol Metab 87:2629-2634.

17. Valentin, E., Ghomashchi, F, Gelb, M.H, Lazdunski, M., and Lambeau, G. 1999. On the diversity of secreted phospholipases A(2). Cloning tissue distribution, and functional expression of two novel mouse group II enzymes. I Biol Chem 274:31195-31202.

18. Abe, A., Shayman, J.A., and Radin, N.S. 1996. A novel enzyme that catalyzes the esterification of N-acetylsphingosine. Metabolism of C2-ceramidles. B Biol Chem 271:14383-14389.

19. Abe, A., Hirtaoka, M., Wild, S., Wilcoxen, S.E, Paine, R., 3rd, and Shayman, J.A. 2004. Lysosomal phospholipase $A_{2}$ is selectively expressed in alveolar macrophages. I Biol Chem 279:42605-42611.

20. Whitsett, J.A, and Weaver, T.E. 2002. Hydrophobic surfactant proteins in lung function and disease. N Engl I Med 347:214L-21.48.

21. Chabot, S, Koumanov, KK, Lambeat, G., Gelb, M.H, Balloy, V., Chignand, M., Whitsett, J.A., and Touquit, L. 2003. Inhibitory effects of surfactant protein A on surfactant phospholipid hydrolysis by secreted phospholipases A. $_{2}$. I Inmunol 171:995-1000.

22. Touqui, $\mathrm{L}$, and $W u, Y Z, 2003$. Interaction of secreted phospholipase $\mathrm{A}_{\mathrm{z}}$ and pulmonary surfactant and its pathophysiological relevance in acute respiratory distress syndrome. Acta Pharmacol Sin 24:1292-1296.

23. Cernak, I, Savic, J., Malioevic, Z, Zunic, G., Radosevic, P., and Ivanovic, 1. 1996. Leukotrienes in the pathogenesis of pulmonary blast injury. I Tramma 40:S148-151.

24. Cuzzocrea, S., Rossi, A. Serraino, I., Di Paola, R, Dugo, L., Genovese, T., Britti, D., Sciarra, G., De Sarro, A, Caputi, A.P, et al. 2004. Role of 5-lipoxygenase in the multiple organ failure induced by zymosan. Intensive Cave Med 30:1935-1943.

25. Kawahito, Y, Kondo, M., Tsubouchi, Y, Hashiramoto, A., Bishop-Bailey, D., Inoue, K, Kohno, M., Yamada, $\mathbb{R}_{\text {, Hla, }}$., and Sano, H. 2000. 15-deoxy-delta(12,14)-PGJ(2) induces synoviocyte 
apoptosis and suppresses adjuvant-induced arthritis in rats. J Clin Ihwest 106:189-197.

26. Hinz, B., Kraus, V., Pahl, A, and Brune, K. 2000. Salicylate metabolites inhibit cyclooxygen ase-2-dependent prostaglandin $\mathrm{E}(2)$ synthesis in murine macrophages. Buchim Boplus $R$ Conmun 274:197-202.

27. Harizi, $H_{\text {, }}$ Juzan, M. Grosset, $C$, Rashedi, $\mathrm{M}_{\text {, }}$ and Gualde, N. 2001. Dendritic cells issued in vitro from bone marrow produce PGE(2) that contributes to the immunomodulation induced by antigen-presenting cells. Cell Imwnud 209:19-28,

28. Arbibe, L., Koumanov, K., Vial, D. Rougeot, C, Faure, $\mathrm{G}_{*}$ Havet, N., Longacre, S, Vargaftig, B.B., Bereziat, G., Voelker, D.R, et al. 1998. Generation of lyso-phospholipids from surfactant in acute lung injury is mediated by type-II phospholipase $A_{2}$ and inhibited by a dinect surfactant protein A-phospholipase A, protein interaction. J Cim linest 102:1152-1160.

29. Laine, V.J., Grass, D.S, and Nevalainen, T.J. 1999. Protection by group II phospholipase $\mathrm{A}_{2}$ against Staphylococous aureus. J Lmmunol 162:7402-7408.

30. Weinrauch, Y., Abad, C., Liang, N.S., Lowry, S.F, and Weiss, I. 1998. Mobilization of potent plasma bactericidal activity during systemic bacterial challenge. Role of group IIA phosphom lipase $\mathrm{A}_{2}$. J Clin Inoest 102:633-638.

31. Rosen, S.H., Castleman, B., and Liebow, A.A. 1958. Pulmonary alveolar proteinosis. N Engl] Med 258:1123-1142.

32. Ben-Dov, I., Kishinevski, X., Rornman, I., Soliman, A., Bishara, H., Zelligson, E, Grie, J, Mazar, A., Perelman, M., Vishnizer, R., et al. 1999. Pulmonary alveolar proteinosis in Israel:ethnic clustering. Is Med Assoc I 1:75-78.

33. Dranoff, G., Crawford, A.D. Sadelain, M., Ream, B. Rashid, A, Bronson, R. T., Dickersin, G.R., Bachurski, C.I., Mark, E.L., Whitsett, J.A., et al. 1994. Involvement of granulocyte-macrophage colony-stimulating factor in pulmonary homeostasis. Science 264713-716.

34. Stanley, E., Lieschke, G.J., Grail, D., Metcalf, D., Hodgson, G., Gall, J.A., Maher, D.W., Cebon, J. Sinickas, V., and Dumn, A.R. 1994. Granulocyte/macrophage colony-stimulating factor-deficient mice show no major perturbation of hematopoiesis but develop a characteristic pulmonary pathology. Proc Natl Acad Sci US S A 91:5592-5596.

35. Tarr, P.E. 1996. Granulocyte-macrophage colony-stimulating factor and the imnume system. Med Oncol 13:133-140. 
$48:$

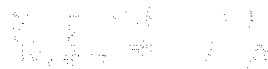




\section{Chapter 6}

\section{Phospholipase expression in different stages of human athero- sclerotic lesions.}

Stijn A.I. Ghesquiere, ${ }^{1}$ Mathijs Groeneweg ${ }^{1}$, Monique N. Vergouwe', Natasja Kisters $^{2}$, Sylvia Heeneman ${ }^{2}$, Marten H. Hofker ${ }^{1}$, and Menno P.J. de Winther'.

1 Dept. of Molecular Genetics, Cardiovascular Research Institute Maastricht, Maastricht University, The Netherlands.

2 Dept. of Pathology, Cardiovascular Research Institute Maastricht, Maastricht University, The Netherlands.

In preparation 


\section{Abstract}

Atherosclerosis is an inflammatory disease initiated by the accumulation of lowdensity lipoproteins (LDL) in the vessel wall of the arterial system. Native LDL is not retained in the vessel wall, unless it is oxidized and enzymatically modified. One of the most prominent enzymes responsible for LDL modification is the family of secreted phospholipases $A_{2}$ (sPLA $A_{2}$ ). The sPLA $A_{2}$ are a large group of enzymes, from which several members are present in atherosclerotic lesions. However, little is known about the role and expression of these phospholipases during human plaque development. We therefore investigated the expression patterns of phospholipase $A_{2}$ group IIA (sPLA $A_{2}$ IIA) and X (sPLA $A_{2}$ ) and platelet activatingfactor acetylhydrolase (PAF-AH) in human atherosclerotic lesions. sPLA $\mathrm{A}_{2}$ activity releases free fatty acids (FFA), such as arachidonic acid (AA), and lysophospholipids. Because AA can be metabolized into inflammatory eicosanoids, we included enzymes as 5-lipoxygenase (5-LO), cyclooxygenase-2 (COX-2) and prostaglandin $\mathrm{E}_{2}$ synthase (mPGES) in our analyses.

Arterial plaque material from 13 patients was collected and classified into an early (intimal thickening/xantoma), advanced (thick fibrous cap atheroma, fibrocalcified) and ruptured (luminal thrombus/intraplaque hemorrhage) group based on the Virmani classification. mRNA was isolated and the expression of selected genes was quantified by realtime PCR. Our results show a strong decrease in sPLA $\mathrm{A}_{2}$ IIA expression in ruptured lesions, indicating a role in lesion stability. Conversely, PAF-AH expression levels were increased in ruptured lesions. The expression of the potent sPLA $\mathrm{X}$ enzyme did not differ between the early, advanced and ruptured lesions. In the prostaglandin synthesis pathway, we observed increased COX-2 expression in the ruptured lesions, which was not accompanied by increased mPGES expression indicating that possibly other prostaglandins are produced in these lesions. 5-LO expression levels increased strongly in advanced and ruptured lesions, which may implicate leukotrienes (LTs) in atherosclerotic plaque severity.

The role of phospholipases in atherosclerosis is more complex than initially thought and the effect of their presence in atherosclerotic lesions depends largely on the closely connected eicosanoid synthesis pathways.

\section{Introduction}

In the last decades, it has become increasingly clear that lipid modification is an integral feature of atherosclerosis (1). Accumulation of low density lipoproteins (LDL) in the vessel walls is a hallmark of atherosclerosis (2). Crucial for LDL retention in the vessel wall is enzymatic modification. Subsequently monocytes are attracted and stimulated $(1,3)$. These monocytes differentiate into macrophages and transform into foam cells through unrestricted LDL uptake (1). Amongst the key enzymes known to modify LDL particles in the vessel wall are the phospholipases. Recent in vivo studies showed various pro-atherogenic properties of these enzymes (4-7).

At least 10 mammalian phospholipases are known, classified according structure, molecular weight and substrate preferences $(8)$. Three sub-families are dis- 
tinguished: the secreted PLA $\mathrm{A}_{2}$ ( $\left(\mathrm{PLA}_{2}\right)$, the cytosolic PLA $\mathrm{s}$ ( $\mathrm{CPLA}_{2}$ ) and the Ca* independent PLA $\mathrm{A}_{2} \mathrm{~s}$ (iPLA $\mathrm{A}_{2}$ ). Phospholipases hydrolyze phospholipids at the $\mathrm{sn}-2$ position, and release free fatty acids (FFA), often arachidonic acid (AA), and lysophospholipids (lysoPL) (9). AA is the key substrate for the production of inflammatory mediators like prostaglandins, thromboxanes and leukotrienes.

Phospholipase $A_{2}$ group IIA (sPLA $A_{2}$ IA) has been shown in various organs, such as spleen, thymus, intestines, tonsils, bone marrow, and liver (10-12). At cellular level, the enzyme is present in hepatic cells, endothelial cells, smooth muscle cells and macrophages (13-15). sPLA, IIA is often considered a marker for inflammatory processes, and elevated plasma and serum levels are found during sepsis. (16) and coronary heart disease (17). Mouse models expressing sPLA IIA showed increased lesion size $(5,6)$, accompanied by increased collagen content (6). sPLA $A_{2}$ group VII, also known as platelet activating-factor acetylhydrolase (PAF$\mathrm{AH}$ ) or lipoprotein associated phospholipase $\mathrm{A}_{2^{\prime}}$ is associated with LDL and HDL in human plasma $(18,19)$. The enzyme plays a role in membrane repair through removal of oxidized fatty acids (20). PAF-AH can potentially inhibit LDL accumulation through LDL repair (20), but the released oxidized FFA can enhance inflammation (21). PAF-AH is expressed in macrophages (22), and is involved in anti-oxidative scavenging (21). Overexpression in mice results in reduced atherosclerosis susceptibility (23), but human PAF-AH activity is associated with increased coronary artery disease (CAD) $(19,24,25)$. However, it is not fully elucidated whether the association of PAF-AH with CAD is cause or consequence. Despite this, recent cross-sectional studies (26) show that PAF-AH activity indicates increased risk of CAD independently of other established risk factors.

Structurally, phospholipase group $X\left(s P L A_{2} X\right)$ is related to both sPLA 2 group IB and IIA. sPLA $X$ is one of the most potent phospholipases $(27,28)$. In contrast to $s$ PLA IIA, sPLA 2 X elicits high AA release in cell cultures and does not bind

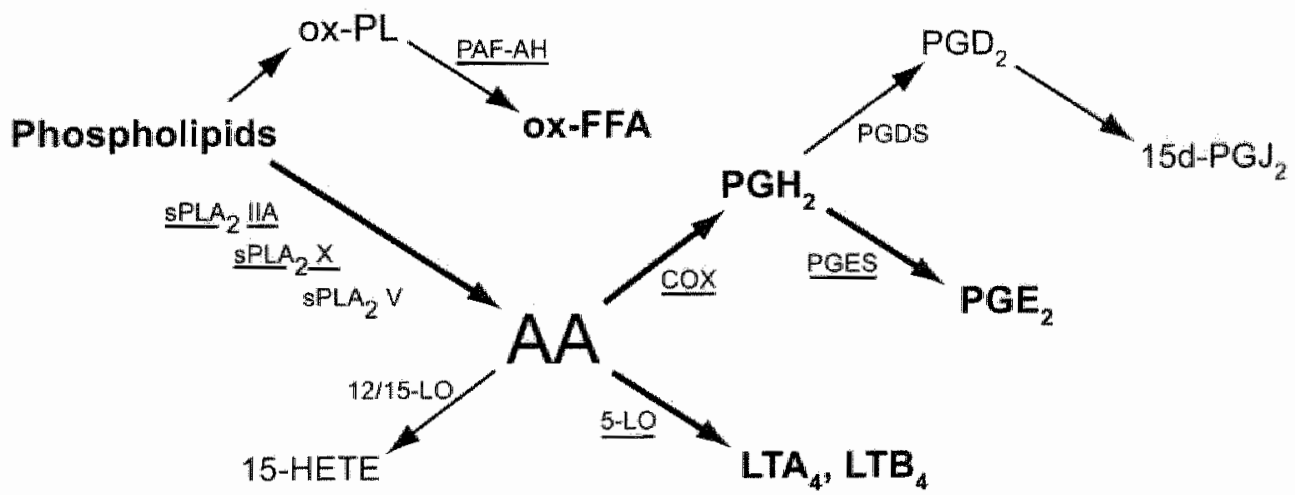

Fig. 1. Overview of the eicosanoid pathways and the production of oxidized free fatty acids. Phospholipase and eicosanoid pathways. Phospholipids are hydrolyzed by secreted phospholipases $A_{2}$ (SPLA, group II $A_{,} V$, and $X$ resulting in the release of arachidonic acid (AA). AA is transformed into $P_{1} H_{2}$ by cyclooxygenase $(C O X)$ and to leukotriene $A_{4}$ and $B_{4}$ by 5-lipoxygenase (5-LO). PG, prostaglandin; PGES, PGE-synthase; PGDS, PGD-synthase; 15d-PGJ2, 15-deoxy-A12,14-prostaglandin $\mathrm{J}_{2}$, LT, leukotrienes; 15-HETE, 15-Hydroxyeicosatetraenoic acid; 15-HETE, 15-hydroperoxyeicosatetratenoic acid. Additionally, PAH-AH liberates oxidized free fatty acids (ox-FFA) from oxidized phospholipids (ox-PL). 
to extracellular matrix components (29). Phospholipase group $X$ has been found in macrophage foam cells and vascular smooth muscle cells in the vessel wall of high fat-fed apolipoprotein $E$ knockout mice (30). Recently we found SPLA, $X$ expression in murine macrophages and have shown that $s P L A_{2} X$ overexpression induced potent foam cell formation (Ghesquiere 2006, chapter 4).

Phospholipase activity results in the release of free fatty acid, which are rapidly transformed into eicosanoids (31, 32). The cyclooxygenase (COX) enzymes are responsible for the initial step in eicosanoids production (33-35). Two major COX isoforms are know, with COX-1 being constitutively expressed, while COX-2 is inducible (32). Hormones, growth factors, inflammatory cytokines and bacterial endotoxins regulate COX-2 expression (32). Because COX-2 is expressed in atherosclerotic lesions $(36,37)$ and destabilized plaques (38) we included COX-2 in our study.

The lipoxygenase pathways convert AA in precursor molecules for leukotriene (LT) production. In humans 5-lypoxygenase (5-LO) and 15-lypoxygenase-1 (15LO-1) are the most prominent lypoxygenases (39). The 5-LO pathway produces leukotriene $A_{4}\left(\operatorname{LTA}_{4}\right)$, which is further metabolized to leukotriene $B_{4}\left(\operatorname{LTB}_{4}\right)$ or other leukotrienes $\left(\mathrm{LTC}_{4}, \mathrm{LTD}_{4}\right.$ and $\left.\mathrm{LTE}_{4}\right)$. Previous studies showed a correlation between lesion severity and 5-LO concentrations (40) and it has been proposed that LTs produced through the 5-LO pathway trigger arterial wall inflammation and remodeling during atherosclerosis development (41). As such we decided to include this enzyme in our study.

Currently, little is known about the relation between phospholipases and atherosclerotic lesion severity. We therefore analyzed the expression of a set of carefully selected genes in plaque material obtained from patients with atherosclerosis. We categorized the lesions according to their severity. Three groups were created: early lesions, advanced lesions and ruptured lesions. mRNA was isolated from the material and quantitative real-time PCR was performed for the selected genes.

\section{Material and Methods}

Tissue was obtained from the Maastricht Pathology Tissue Collection (MPTC). Collection, storage and use of tissue and patient data were performed in agreement with the "Code for Proper Secondary Use of Human Tissue in the Netherlands" (http://www:fmwv.nl). Tissues were processed as described previously (42). Tissue sections were snapfrozen for RNA isolation. Adjacent sections were fixed and embedded in paraffin. Based on haematoxylin-eosin stained sections (4 um), the vessel wall was classified and classified according to Virmani et al. (43). Lesions with intimal thickening, intimal xanthoma, and pathological intima thickening were combined in a group of early lesions. Thick fibrous cap atheroma's, and fibrocalcified lesions were categorized as advanced plaques. Lesions with a luminal thrombus of intraplaque hemorrhage were were labeled as ruptured.

The early and advanced lesion group contained material from 5 patients and the ruptured lesion group contained the material from 3 patients. Total RNA was isolated using Tri Reagent ('Sigma), according to the manufacturers' protocol. RNA concentration was measured using the nanodrop (Witec $\mathrm{AG}_{r}$ Germany). $0.5 \mu \mathrm{g}$ total RNA was converted into cDNA. Oligo dT primers and RevertAid M-MuLV 
reverse transcriptase (Fermentas) were used according to the manufacturers protocol. TAQMan analysis with SYBR Green was performed with the qPCR Mastermix Plus kit for SYBR green (Eurogentec) on $10 \mathrm{ng}$ CDNA. The following primers were used:
SPLA $\mathrm{A}_{2}$ ПA
F: GGCACCAAATTTCTGAGCTACA
PAF-AH
R: CCTTATCACACTCACACAGTTGACTTC
SPLA $X$
F:AGCAACGGTTATTCAGACTCTTAGTG
R:ACTTCATCACCCAGTGGAAACA
5-LO
F:TGGCAGTGCGTCAATCAGA
R:TTGCACAACAGTTCTTGGCATT
F:CGGCGATGTCGAGGTTGT
R:TTTACGTCGGTGTTGCTTGAGA
$\mathrm{COX}-2$
F:TCCCTCCCTTACCATCAAATCA
R:TCCGCCGTAGTCGGTGTAC
MPGES
F:ACACGGAGGCCCCCAGTA
R:TAGTCGAAGCCCAGGAAAAGG

The primers were verified not to amplify genomic DNA material. Analysis was carried out on an ABI Prism 7700 Sequence Detector. The housekeeping genes cyclophillin-A, B-actin, and gapdh were used to correct for RNA concentration differences between the samples. All housekeeping genes gave the same results, and as such cyclophilin- $A$ is used for the data presented in this paper. Expression levels in early, advanced, and ruptured lesions, obtained from the qPCR, were analyzed with the non-parametric Mann-Whitney test, significance levels of $p<0.05$, in GraphPad Prism version 4.01 (GraphPad Software, CA, USA)

\section{Results}

Phospholipids are converted into a whole range of eicosanoids (Fig1.). In the production of these inflammatory mediators, the role of phospholipase activity is pivotal, as this delivers the AA substrate for to the prostaglandin and lipoxygenase pathways. We also examined the expression of COX-2 and mPGES in the prostaglandin pathway and 5-LO in the lipoxygenase pathway. PAF-AH is a special case due to its ability to remove oxidized free fatty acid moieties from phospholipids in oxidized LDL (oxLDL) and exhibiting sn-2 phospholipase activity.

The sPLA $\mathrm{A}_{2}$ IIA expression in ruptured lesions (Fig. 2A) is very little compared to advanced lesions $(0.16$ compared to 1.91 , respectively; $p=0.036)$ and shows a large variation in the early lesions ( $\mathrm{SD}=2.72$ with an average of 2.22). $\mathrm{PAF}-\mathrm{AH}$ (Fig. 2B)
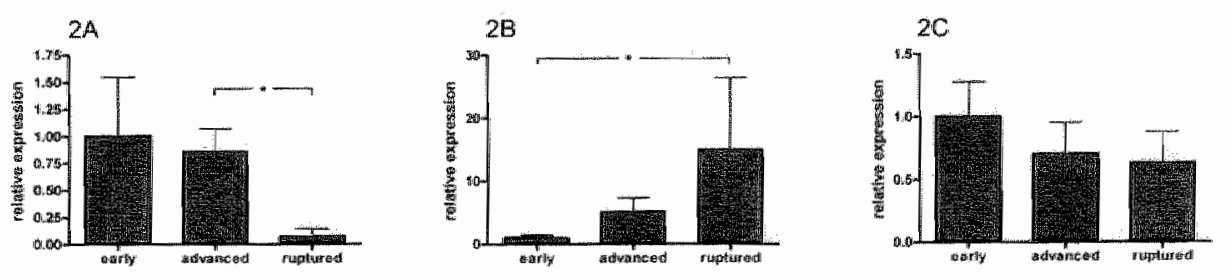

Fig. 2. Relative expression levels of phospholipases in the lesions. $2 \mathrm{~A}$ : secreted phospholipase $\mathrm{A}_{2}$ group IA (sPLA, $\left.\Pi \mathrm{A}\right) ; 2 \mathrm{~B}$ : platelet activating factory acetylhydrolase (PAF-AH) and $2 C$ : secreted phospholipase $A_{2}$ group $X\left(s_{P L A} X\right) .{ }^{*}=p<0.05$. 

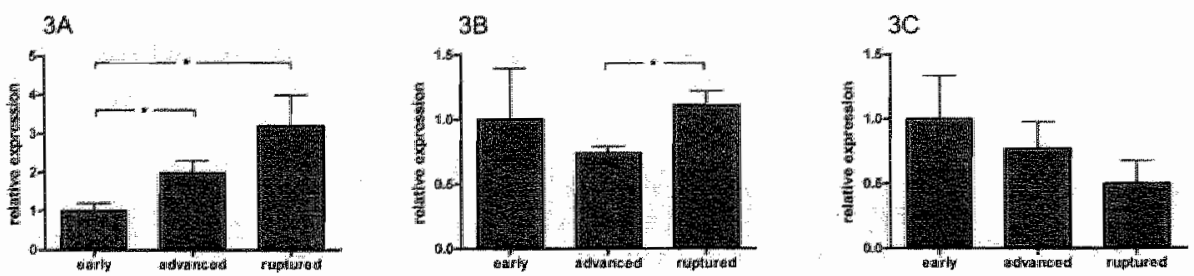

Fig. 3. Relative expression levels of enzymes in the arachidonic acid processing pathway. 3A: 5-lipoxygenase; 3B: cyclooxygenase-2 (COX-2) and $3 \mathrm{C}$ membrane bound prostaglandim $E_{2}$ synthase (mPGES). ${ }^{*}=$ p<0.05.

showed considerably ( 15 -fold increase, $\mathrm{p}=0.036$ ) more expression in ruptured lesions compared to early lesions. In advanced lesions PAF-AH levels were not significantly increased $(p=0.22)$, with an expression level intermediate of early and the ruptured lesions. Phospholipase $\mathrm{A}_{2}$ group $X$ (Fig. $2 \mathrm{C}$ ) did not reveal differences in expression levels and thus no relation with plaque severity could be observed. Little sPLA $A_{2} X$ expression was present in all the lesions.

We investigated several enzymes downstream the eicosanoid pathways, which use the AA produced by phospholipase activity as substrate. The most remarkable results were in the 5-LO expression (Fig. 3A). 5-LO expression was increased in both the advanced and the ruptured lesions; with advanced lesions showing 5-LO expression levels two-fold of those measured in the early lesions ( $\mathrm{P}=0.032$ ). Ruptured lesions exhibited a three-fold increase compared to the early lesions $(\mathrm{P}=0.036)$. In addition, $\mathrm{COX}-2$ expression in ruptured lesions (Fig. 3B) was 1.5-fold increased compared with the advanced lesions $(p=0.036$ ), but did not differ between early and advanced, and between early and ruptured lesions. Furthermore, the mPGES expression levels (Fig. 3C) showed no significant changes between the three groups, but we could observe a trend toward lower expression in advanced and ruptured lesions.

\section{Discussion}

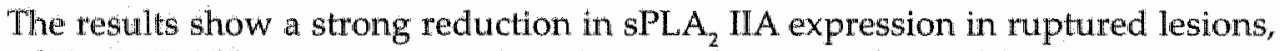
while PAF $A H$ expression on the other hand increased significantly in the ruptured lesions. Phospholipase group $X$ did not show considerable changes in expression between the early, advanced and ruptured lesion groups. In the phospholipase related pathways, the potent increase in 5-LO expression was remarkable. The increase in COX-2 expression was not accompanied by an increase in mPGES expression, indicating that other prostaglandins than PGE2 are activated.

The sPLA, IIA results are intriguing. The expression of the enzyme drops dramatically in ruptured lesions. We have previously shown that sPLA 2 IIA overexpression in atherosclerotic lesions improves plaque stability through increased collagen content (6). We therefore hypothesize that lesions low in SPLA IIA expression have the tendency to become prone to rupture due to low collagen levels in these lesions. While not quantified, early and advanced lesions in our study that exhibited high sPLA $\mathrm{PA}_{2}$ expression all have a thick, fibrous cap and a stable phenotype.

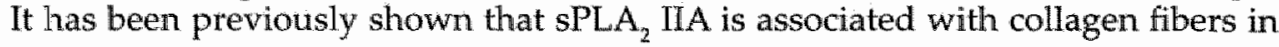


the vicinity of macrophage rich areas, lipid atheromas and damaged intima (15; 44). At the same time, sPLA, MA is associated with inflammatory diseases (16, 45, 46) and sPLA, IIA plasma levels have been proposed as a marker for acute myocardial infarction (17). However, plasma levels are not necessarily related to sPLA $\mathrm{A}_{2}$ MA presence in the atherosclerotic lesions, but are rather the result of a systemic inflammatory reaction to plaque rupture. As such, high SPLA, IIA plasma levels are indicative for acute coronary events as a result of plaque rupture, while $\mathrm{SPLA}_{2}$ WA in the lesions may have a preventive effect. Unfortunately the total number of patients in our study is too small to draw solid conclusions, but with the current knowledge therapeutic strategies involving sPLA ${ }_{2}$ IIA inhibition are not recommended. Prior to such interventions a better understanding of the relation between SPLA, IIA and plaque composition is required.

The dramatic increase in PAF-AH in the ruptured lesion compared to the early lesions supports the earlier established association between PAF-AH, CAD, and atherosclerosis $(19,24,25)$. However, these associations are made between PAF$A H$ plasma levels and $C A D$, and do not related $C A D$ with expression and production in atherosclerotic lesions. PAF-AH is located on circulating LDL partides (26, 47), and thus accumulation of these particles in the vessel wall, as seen in atherosclerosis (2), can transport PAF-AH into the lesions. We now show that PAF-AH in atherosclerotic lesions can be produced locally $y_{r}$ independent of plasma levels. Whether PAF-AH reduces lesion formation is not clear. PAF-AH can mediate and eventually enhance inflammation in atherosclerotic plaques through the release of oxidized phospholipids $(21,48)$, but is also capable to enhance anti-oxidative scavenging (21). Our results, in combination with the results published by other groups, show a potential active role of PAF-AH in atherosclerotic progression and rupture rather than being a mere risk marker, creating an opportunity for therapeutic strategies.

Phospholipase $\mathrm{A}_{2}$ group $X$ expression levels did not significantly differ between the early, advanced and ruptured lesions. Data available about the role of sPLA $X$ in inflammation is still not conclusive. Our previous in-vitro experiments revealed that the expression of sPLA $_{2} X$ is hardly affected by lipopolysaccharide (LPS) stimulation (Ghesquiere et al. 2006, chapter 4 ) and there are strong indications that sPLA $\mathrm{A}_{2} \mathrm{X}$ is constitutively expressed under most circumstances. For example in human synoviocytes SPLA $_{2} X$ expression remains constant despite cell activation (49). Similar in rat models for ear edema and carageenin-induced pleurisy (50), no changes in $\mathrm{PLA}_{2} \mathrm{X}$ expression occurred. However, strong individual differences in SPLA 2 expression levels have been observed in human joints (49) and in a small explorative pilot experiment, we found large differences between mice in macrophage sPLA $A_{2} X$ expression (data not shown). This suggests that $\$ P L A_{2} X$ can be under influence of environmental factors or the presence of genetic variations in expression levels. Although various cell types continuously produce sPLA $X$ in small quantities $(50,51)$, the potent enzymatic activity of the enzyme can severely affect the course of inflammation. Overexpression of $\mathrm{SPLA}_{2} \mathrm{X}$ in murine macrophages inhibits LPS induced inflammation through the production of anti-inflammatory prostaglandins (Ghesquiere et al 2006, chapter 4), while mice overexpressing the enzyme in the macrophages develop severe lung pathology (chapter 5). 
The exact role of sPLA $X$ in atherosclerosis might not be fully elucidated at the moment; it is at least known to induce potent foam cell formation (30)(Ghesquiere et al. 2006, chapter 4). We recommend more detailed population studies on SPLA $X$ in relation to atherosclerosis and inflammation.

The lipoxygenase pathways convert AA, liberated by phospholipase activity, in precursor molecules for leukotriene (LT) production. The increased 5-LO expression levels observed in this study are supported by previous studies, showing a relation between lesion severity and 5-LO concentrations (40). High levels of 5-LO have been shown in macrophages and mast cells within atherosclerotic lesions $(1,40)$. While the role of 5-LO has not been fully elucidated, the leukotrienes produced in the 5-LO pathway are responsible for various pro-atherogenic processes. Leukotrienes induce the release of vascular endothelial cell growth factor (VEGF) (52), enhance the recruitment of neutrophil leukocytes (PMNs) (35) and induce monocyte adherence to the vessell wall (53). The importance of 5-LO in atherosclerosis is emphasized by the observation that mice lacking 5-LO expression are protected against atherosclerotic lesion formation (54). Similarly, blocking LTB4, a metabolite from the 5-LO pathway, in mice reduces lesion formation (55). In a human population study, however, increased atherosclerosis was found in individuals with low 5-LO expression (56). The atuthors attribute this paradoxical finding to redundancy and interaction between the eicosanoid pathways as proposed by Serhan (57). Our data confirms the pro-atherosclerotic role of 5-LO.

Cyclooxygenase is a key enzyme in the regulation of inflammatory processes. The production of eicosanoids depends on the conversion of arachidonic acid to prostaglandin $\mathrm{H}_{2}(34,35)$. Increased COX-2 levels are often associated with increased inflammation and have been shown in atherosclerotic lesions $(36,37)$. During acute inflammation, $\mathrm{COX}-2$ delivers the substrate for the production of $\mathrm{PGE}_{2}$, a potent anti-inflammatory prostaglandin, that exerts it actions through specific $\mathrm{PGE}_{2}$ receptors (58). PGE $_{2}$ is the principal prostaglandin produced in LPS stimulated macrophages (59) and reduces macrophage activation $(60,61)$.

Our results did not show elevated mPGES expression in advanced and ruptured lesions, while COX-2 expression increased in ruptured lesions. This can imply that additional $\mathrm{PGH}_{2}$ is being produced under influence of $\mathrm{COX}-2$, while the production of $\mathrm{PGE}_{2}$ is not augmented. It could well be that other prostaglandin synthases are being upregulated and as such play a role in lesion development. Unfortunately, we have not been able to examine the expression of the whole range of prostaglandin synthases. For future research we would definitely recommend further exploration in this field. Genetically engineered mouse models for the prostaglandin synthases would deliver a valuable research-tool.

The number of genes explored in this study is far from complete. Future investigations should also include the secreted phospholipase $A_{2}$ group $V\left(s P L A_{2} V\right.$ ) and the cytosolic phospholipase group $\mathrm{A}_{2}$ IVa $\left(\mathrm{cPLA}_{2} \mathrm{a}\right)$. The human group $\mathrm{V}$ is closely related to group IIA (62), but is capable of acting on intact cell membranes (63, 64) and is enzymatically more potent (65). sPLA 2 V expression is induced during inflammation (66) and is potentially involved in atherosclerosis (67). CPLA $a$ is important through its interaction with other phospholipases, and its capability to regulate inflammation (68). Downstream the phospholipid hydrolysis pathway, 
other prostaglandin synthase genes as PGDS and PGIS are excellent candidates to include. This pilot study definitely reveals interesting findings for future research. The effects of sPLA, IIA on plaque stability, the effect of PAF-AH expression in the lesion and the absence of MPGES expression, while COX-2 is elevated are worth to investigate in more detail and with a larger patient population.

\section{References}

1. Libby, P., Ridker ${ }_{i}$ P.M., and Maseri, A. 2002. Inflammation and atherosclerosis, Cinculation 105:1135-1143.

2. Williams, K.J, and Tabas, I. 1995 . The response-to-retention hypothesis of early atherogenesis. Arterioscler Thromb Vasc Biol 15:551-561.

3. Glass, C.K, and Witztum, J.L. 2001. Atherosclerosis. the road ahead. Cell 104:503-516.

4. Ivandic, B., Castellani, L.W., Wang, X.P, Qiao, J.H., Mehrabian, M. Navab, M., Fogelman, A.M., Grass, D.S., Swanson, M.E. de Beer, M.C., et al. 1999. Role of group II secretory phos" pholipase $\mathrm{A}_{2}$ in atherosclerosis: 1. Increased atherogenesis and altered lipoproteins in transgenic nice expressing group Ila phospholipase $\mathrm{A}_{2}$. Arterioscler Throntb Vasc Biol 19:1284-1290.

5. Webb, N.R, Bostrom, M.A., Szilvassy, S.J, van der Westhuyzen, D.R., Daugherty, A., and de Beer, F.C. 2003. Macrophage-expressed group IIA secretory phospholipase $A_{2}$ increases atherosclerotic lesion formation in LDL receptor-deficient mice. Arterioscler Thromb Vasc Biol 23:263-268.

6. Ghesquiere, S.A., Gijbels, MJ., Anthonsen, M., van Gorp, P.., van der Made, I., Johansen, B., Hofker, M.H., and de Winther, M.P. 2004. Macrophage-specific overexpression of group Il sPLA, results in increased atherosclerotic lesion size and enhanced collagen deposition. I Lipid Res 46:201-210.

7. Tietge, UJ, Fratico, D., Ding, T, Funk, C.D., Hildebrand, R.B., Van Berkel, T, and Van Eck, M. 2005. Macrophage-specific expression of group MA sPLA results in acoelerated atherogenesis by increasing oxidative stress. J Lipid Res 46:1604-1614.

8. Dennis, E.A. 1997. The growing phospholipase $\mathrm{A}_{2}$ superfamily of signal transduction enzymes. Trends Biochem Sci 22:1-2.

9. Six, D.A., and Dennis, E.A. 2000. The expanding superfamily of phospholipase A(2) enzymes: classification and characterization. Biodim Biophys Acta 1488:1-19.

10. Kramer, R.M., Hession, C., Johansen, B., Hayes, G., McGray, P., Chow, E.P., Tizard, R., and Pepinsky, R.B. 1989. Structure and properties of a humann non-pancreatic phospholipase $A_{2} . J$ Biol Chem 264:5768-5775.

11. Minami, T., Tojo, H.r Shinomura, Y., Matsuzawa, Y., and Okamoto, M. 1993. Purification and characterization of a phospholipase $\mathrm{A}_{2}$ from human ileal nucosa. Biochim Biophys Acla 1170:125-130.

12. Nevalainen, T.J., Gronroos $f_{f}$ J.M., and Kallajoki, M. 1995. Expression of group II phospholipase $\mathrm{A}_{2}$ in the human gastrointestinal tract. Lab Invest 72:201-208.

13. Kurihara, H. Nakano, T., Takasu, N., and Arita, H. 1991. Intracellular localization of group II phospholipase $\mathrm{A}_{2}$ in rat vascular smooth muscle cells and its possible relationship to eicosanoid formation. Biochim Biophys Acta 1082:285-292.

14. Barbour, S.E.r. and Dennis, E.A. 1993. Antisense inhibition of group II phospholipase $A_{2}$ expression blocks the production of prostaglandin $\mathrm{E}_{2}$ by P388D1 cells. / Biol Chem 268:2187521882.

15. Anthonsen, M.W., Stengel, D., Hourton, D., Ninio, E, and Johansen, B. 2000. Mildly oxidized LDL induces expression of group lla secretory phospholipase A(2) in human monocyte-derived macrophages. Arteriosder Thromb Vasc Biol 20:1276-1282. 
16. Vadas, P. and Pruzanski, W. 1993. Induction of group II phospholipase $A_{2}$ expression and pathogenesis of the sepsis syndrome. Circ Shock 39:160-167.

17. Mallat, Z, Steg, P. G. Benessilano, J., Tanguy, M.L., Fox, K.A., Collet, J.P., Dabbous, O.H., Henry, $P_{y}$ Carruthers, KF, Dauphin, $A_{\text {, }}$ et al. 2005. Circulating secretory phospholipase $A_{2}$ activity predicts recurrent events in patients with severe acute coronary syndromes. I Am Coll Cardiol 46:1249-1257.

18. Stafforini, D.M. Prescott, S.M., and Mclntyre, T.M. 1987. Human plasma platelet-activating factor acetyllhydrolase. Purification and properties. / Biol Chem 262:4223-4230.

19. Caslake, M.J, Packard, C.J., Suckling, K.E., Holmes, S.D., Chamberlain, P, and Macphee, C.H. 2000. Lipoprotein-associated phospholipase A(2), platelet-activating factor acetylhydrolase: a potential new risk factor for coronary artery disease. Atherosclerosis 150:413-419.

20. Farr, R.S., Cox, C.P., Wardllow, M.L., and Jorgensen, R. 1980. Preliminary studies of an acid-labile factor (ALF) in human sera that inactivates platelet-activating factor (PAF). Clin inmunal Immwopathol 15318-330.

21. Min, J.H., Wilder, C., Aoki, J, Arai, H, Inoue, K., Paul, L., and Gelb, M.H. 2001. Platelet-activating factor acetylinydrolases: broad substrate specificity and lipoprotein binding does not modulate the catalytic properties of the plasma enzyme. Biochemistry 40:4539-4549.

22. Tjoelker, L.W., Wilder, C, Eberhardt, C., Stafforini, D.M., Dietsch, G., Schimpf, B., Hooper, S., Le Trong, H. Cousens, L.S., and Zimmerman, G.A. 1995. Anti-inflammatory properties of a platelet-activating factor acetyllhydrolase. Nature 374:549-553.

23. Quarck, R., De Geest, B., Stengel, D., Mertens, A., Lox, M., Theilmeier, G. Michiels, C., Raes, M., Bult, H., Collen, D, et al. 2001. Adenovirus-mediated gene transfer of human plateletactivating factor-acetylihydrolase prevents injury-induced neointima formation and reduces spontaneous atherosclemosis in apolipoprotein E-deficient mice. Circulation 1032495-2500.

24. Packard, C.J. O'Reilly, D.S., Caslake, M.J. McMahon, A.D. Ford, I. Cooney, J, Macphee, C.H. Suckling, K.E., Krishna, M., Wilkinson, F.E, et al. 2000. Lipoprotein-associated phospholipase $\mathrm{A}_{2}$ as an independent predictor of coronary heart disease. West of Scotland Coronary Preven. tion Study Group. N Engl J Med 343:1148-1155.

25. Blankenberg, Si, Stengel, D., Rupprecht, H.J., Bickel, C, Meyer, J., Cambien, F, Tiret, L., and Ninio, E. 2003. Plasma PAF-acetylhydrolase in patients with coronary artery disease: results of a cross-sectional analysis. / Lipid Res 44:1381-1386.

26. Winkler, K., Winkelmann, B.R., Schamagl, H., Hoffmann, M.M., Grawitz, A.B., Nauick, M., Bohm, B.O., and Marz, W. 2005. Platelet-activating factor acetylhydrolase activity indicates angiographic coronary artery disease independently of systemic inflammation and other risk factors: the Ludwigshafen Risk and Cardiovascular Health Study. Circulation 111:980-987.

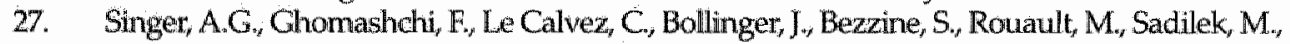
Nguyen, E, Lazdunski, M., Lambeau, $\mathrm{G}_{\text {, }}$ et al. 2002. Interfacial kinetic and binding properties of the complete set of human and mouse groups $\mathrm{I}, \mathrm{I}, \mathrm{V}, \mathrm{X}$, and $\mathrm{XII}$ secreted phospholipases $\mathrm{A}_{2}$. I Biol Chem 277:48535-48549.

28. Pan, Y.H., Yu, B.Z, Singer, A.G., Ghomashchi, F, Lambeau, G., Gelb, M.H. Jain, M.K., and Bahnson, B.J. 2002. Crystal structure of human group X secreted phospholipase $A_{2}$. Electrostatically neutral interfacial surface targets zwitterionic membranes. I Btol Chem $277.29086-$ 29093.

29. Murakami, M. Shimbara, S., Kambe, T., Kuwata, H., Winstead, M.V., Tischfield, J A., and Kudo, I. 1998. The functions of five distinct mammalian phospholipase $\mathrm{A}_{2} \mathrm{~s}$ in regulating arachidonic acid release. Type Ma and type V secretory phospholipase $A_{2}$ s ane functionally redundant and act in concert with cytosolic phospholipase $\mathrm{A}_{2}$. J Biol Chen 273:14411-14423.

30. Hanasaki, K., Yamada, K., Yamamoto, S. Ishimoto, Y., Saiga, A., Ono, T., Meda, M. Notoya, M., Kamitani, $S_{w}$ and Arita, $H_{2}$ 2002. Potent modification of low density lipoprotein by group $X$ secretory phospholipase $A_{2}$ is linked to macrophage foam cell formation. $J$ Biol Chem 277:29116-29124. 
31. Smith, WL. and Memett, LI. 1991. Prostaglandin endoperoxide symthase structure and catalysis. Biochim Biophays Acta 1083:1-17.

32. Dubois, RN., Abramson, S.B, Crofford, L., Gupta, R.A. Simon, LS, Van De Putte, L.B., and Lipsky, PE. 1998. Cyclooxygenase in biology and disease. Faseb 1 12:1063-1073.

33. Samuelsson, B. 1983. From studies of biochemical med anism to novel biological mediators: prostaglandin endoperoxides, thromboxanes, and leukotrienes. Nobel Lecture; 8 December 1982. Biosci Rep 3:791-813.

34. Vane, IR 1971. Inhibition of prostaglandin synthesis as a mechanisn of action for aspirin-like drugs. Nat New Biol 231232-235.

35. Vila, L. 2004. Cyclooxygenase and 5-lipoxygenase pathways in the vessel wall: role in atherosclerosis. Med Res Rew 24399-424.

36. Schonbeck, U., Sukhova, G.K, Graber, P, Coulter, S, and Libby, P. 1999. Augmented expression of cyclooxygenase-2 in human atherosclerotic lesions. Am I Pathol 155:1281-1291.

37. Baker, C.S, Hail, R. I, Evans, T.,., Pomerance, A., Maclouf, I, Creminon, C, Yacoub, M.H, and Polak, J.M. 1999. Cyclooxygenase-2 is widely expressed in athenosclerotic lesions affecting native and transplanted human coronary arteries and colocalizes with inducible nitric oxide syrthase and nitrotyrosine particularly in macrophages. Arteriascler Throwb Vasc Biol 19:646655.

38. Cipollone, F., Prontera, C, Pini, B, Marini, M., Fazia, M., De Cesare, D., Iezzi, A, Uohino, S., Boccoli, G., Saba, V., et al. 2001. Overexpression of functionally coupled cyclooxygenase-2 and prostaglandin $\mathrm{E}$ synthase in symptomatic atherosclerotic plaques as a basis of prostaglandin E(2)-dependent plaque instability. Circulation 104:921-927.

39. Thao, $\mathrm{L}$, and Funk, CD. 2004. Lipoxygenase pathways in atherogenesis. Thends Cardiovasc Med 14:191-195.

40. Spanbroek, R., Grabner, R., Lotzer, K., Hildner, M., Urbach, A., Ruhling, K, Moos, M.P, Kaiser, B., Cohnert, T.U, Wahlers, $\mathbb{T}_{\text {, }}$ et al. 2003. Expanding expression of the 5-lipoxygenase pathway within the arterial wall during human atherogenesis. Proc Nall Acad Sci US A 100:1238-1243.

41. Lotzer, $K$, Funk, C.D., and Habenicht, A.J. 2005. The 5-lipoxygenase patthway in arterial wall biology and atherosclerosis. Biochim Biophys Acta 1736:30-37.

42. Faber, B.C. Cleutjens, K.B., Niessen, R.L., Aarts, P.L, Boon, W., Greenberg, A.S., Kitslaar, P.). Tordoix, J.H., and Daemen, M.J. 2001. Identification of genes potentially involved in ruptune of human atherosclerotic plaques. Circ Res 89:547-554.

43. Virmani, R. Kolodgie, FD., Burke, A.P., Farb, A., and Schwartz, S.M. 2000. Lessons from sudden coronary death: a comprehensive morphological classification scheme for atherosclerotic lesions. Arterioscler Thromb Vasc Biol 20:1262-1275.

44. Menschikowski, M., Kasper, M. Lattke, P., Schiering, A, Schiefer, S, Stockinger, H, and Jaross, W. 1995. Secretory group II phospholipase $A_{2}$ in human atherosulerotic plagues. Atherosclerosis 118:173-181.

45. Pruzanski, W., Keystone, E.C., Stemby, B., Bombardier, C., Snow, K.M., and Vadas, P. 1988. Serum phospholipase $\mathrm{A}_{2}$ correlates with disease activity in theumatoid arthritis. / Rhewmatol' 15:1351-1355.

46. Rader, D.J. 2000. Inflammatory markers of coronary risk. N Engl I Med 343:1179-1182.

47. Tselepis, A.D., Dentan, C., Karabina, S.A., Chapman, M.J., and Ninio, E. 1995. PAl-degrading acetylhydrolase is preferentially associated with dense LDL and VHDL 1 in human plasma. Catalytic characteristics and relation to the monocyte-derived enzyme. Arterioscler "Throwib Vasc Biol 15:1764-1773.

48. Evangelou, A.M. 1994. Platelet-activating factor (PAF): implications for coronary heart and vascular diseases. Prostaglandins Leukot Essent Fatty Acids 50:1-28.

49. Masuda, S., Murakami, M., Komiyama, K., Ishihara, M., Ishikawa, Y, Ishiil, T, and Kudo, I. 2005. Various secretory phospholipase $A_{2}$ entymes are expressed in rheumatoid arthritis and 
augment prostaglandin production in cultured synovial cells. Febs ] 272.655-672.

50. Hamaguchi, K, Kuwata, H., Yoshihara, K, Masuda, S., Shimbara, S., Oh-ishi, S, Murakami, M. and Kudo, L. 2003. Induction of distinct sets of secretory phospholipase A(2) in rodents during inflammation. Biochin Bioplys Acta 1635:37-47.

51. Cupillard, L., Koumanow, K. Mattei, M.G., Lazdunski, M. and Lambeau, G. 1997, Cloning, chromosomal mapping, and expression of a novel tuman secretory phospholipase $\mathrm{A}_{2}$ / $\mathrm{Biol}$ Chem 272:15745-15752.

52. Tomano, M., Catalano, A., Nutin, M., DUrbano, E, Crescenzi, C., Claria, I., Libner, R., Davi, Q. and Procopio, A. 2001. 5-lipoxygenase regulates malignant mesothelial cell survival: involvement of wascular endothelial growth factor Faseb ] 15:2326-2336.

53. Yokomizo, T, Lzumi, $\mathbb{T}$, and Shümizu, T. 2001. Leukotriene B4: metabolism and signal transduction. Arch Biochem Biopltys 385:231-241.

54. Mehrabian, M. Allayee, H, Wong, I, Shi, W., Wang, XP., Shaposhnik, Z., Funk, CD., Lusis, A. J, and Shih, W. 2002. ldentification of 5-lipoxygenase as a major gene contributing to atherosderosis susceptibility in mice. Circ Res 91:120-126.

55. Aiello, R.I., Bourassa, P.A., Lindsey, S., Weng, W., Freeman, A., and Showell, H.J. 2002. Leukotriene B4 receptor antagonism reduces monocytic foam cells in mice. Arterioscler Thromb Wasc Biol 22:443-449.

56. Dwyer, J.H., Allayee, H., Dwyer, K.M. Fan, J., Wu, H., Mar, R., Lusis, A.J., and Mehrabian, M. 2004. Arachidonate 5-lipoxygenase promoter genotype, dietary arachidonic acid, and atherosclerosis. N Engl / Med 350:29-37.

57. Serhan, CN. 1997. Lipoxins and novel aspürin-triggered 15-ept-lipoxins (ATL): a jungle of cell-cell interactions or a therapeutic opportunity? Prostaglandins 53:107-137.

58. Breyer, R.M. Bagdassarian, C.K. Myers, S.A., and Breyer, M.D. 2001. Prastanoid receptors: subtypes and signaling. Antnu Rev Phammacol Toxicol 41:661-690.

59. Matsumoto, H., Naraba, H., Murakami, M., Kudo, I, Yamaki, K., Ueno, A., and Oh-ishi, S. 1997. Concordant induction of prostaglandin $\mathrm{E}_{2}$ synthase with cyclooxygenase-2 leads to preferred production of prostaglandin $\mathrm{E}_{2}$ over thromboxane and prostaglandin D2 in lipopolysaccharide-stimulated rat peritoneal macrophages. Biochem Biophys Res Commun 230:110114.

60. Ikegami, R., Sugimoto, Y., Segi, E., Katsuyama, M., Karahashi, H., Amano, F., Maruyama, T., Yamane, H., "Tsuchiya, S., and Ichikawa, A. 2001. The expression of prostaglandin E receptors EP2 and EP4 and their different regulation by lipopolysaccharide in C3H/HeN peritoneal macrophages, J Immunol 166:4689-4696.

61. Shinomiya, S, Naraba, H, Ueno, A., Utsunomiya, I, Maruyama, T, Ohuchida, S., Ushikubi, F., Yukil, $K_{\text {, }}$ Narumiya, $S$, Sugimoto, $Y_{r}$ et al. 2001. Regulation of TNFalpha and interleukin10 production by prostaglandins $I(2)$ and $E(2)$ : studies with prostaglandin receptor-deficient mice and prostaglandin E-receptor subtype-selective synthetic agonists. Biochem Pharmacol 61:1153-1160.

62. Tischfield, J.A., Xia, Y.R., Shith, D.M., Klisak, I, Chen, J., Engle, S.J, Siakotos, A.N., Winstead, M.V. Seilhamer, J.j. Allamand, V, et al. 1996. Low-molecular-weight, calcium-dependent phospholipase $A_{2}$ genes are linked and map to homologous chromosome regions in mouse and human. Genomics 32:328-333.

63. Murakami, M. Kambe, T, Shimbara, S. Higashino, K., Hanasaki, K. Arita, H., Horiguchi, M., Arita, M., Arai, H., Inone, K., et al: 1999. Different functional aspects of the group II subfamily (Types IIA and V) and type $X$ secretory phospholipase A(2)s in regulating arachidonic acid release and prostaglandin generation. Implications of cyclooxygenase-2 induction and phospholipid scramblase-mediated cellular membrane perturbation. / Biol Chen 274:31435 31444

64. Murakami, M., Masuda, S., Shimbara, S, Bezzine, S.r Lazdunski, M., Lambeau, G. Gelb, M.H., Matsukura, S., Kokubu, F, Adachi, M. et al. 2003. Cellular arachidonate-releasing function 
of novel dasses of secretory phospholipase $A_{2}$ s (groups III and XII). J Biol Chem 278:1065710667.

65. Gesquiere, L, Cho, W., and Subbaiah, P.V. 2002. Rolle of group Ila and group V secretory phospholipases $\mathrm{A}(2)$ in the metabolism of lipoproteins. Substrate specificities of the enzymes and the regulation of their activities by sphingomyelin. Biochemistry 41:4911-4920.

66. Sawada, H., Murakami, M., Enomoto, A., Shimbara, S. and Kudo, I. 1999. Regulation of type V phospholipase $\mathrm{A}_{2}$ expression and function by proinflammatory stimuli. Eur / Biochem 263:826-835.

67. Wooton-Kee, C.R., Boyanovsky, B.B., Nasser, M.S., de Villiers, W.J, and Webb, N.R. 2004. Group V sPLA hydrolysis of low-density lipoprotein results in spontaneous particle aggregation and promotes macrophage foam cell formation. Arterioscler Thromb Vasc Biol 24:762767 .

68. Balsinde, J., Balboa, M.A, and Dennis, E.A. 1998. Functional coupling between secretory phospholipase $\mathrm{A}_{2}$ and cyclooxygenase-2 and its regulation by cytosolic group IV phospholipase A. Proc Natl Acad Sci U S A 95:7951-7956. 
$\ddots$
$\vdots$
$\vdots$
$\vdots$
$\vdots$ 
Chapter 7

General discussion 
Atherosclerosis is progressive disease, initiated through the accumulation of lowdensity lipoprotein (LDL) in the arterial wall (1). A crucial step is the oxidative and enzymatic modification of these LDL particles. Once modified, LDL is taken up by macrophages and promotes foam cell formation, a hallmark of atherosclerosis (2). Amongst the most potent enzymes capable to perform LDL modification are the phospholipases, which have been shown in atherosclerotic lesions and inflammatory diseases $(3,4)$. Several members of the phospholipases have been found in atherosclerotic lesions. This thesis is focused on the role of two members of the phospholipase $\mathrm{A}_{2}$ gene family: phospholipase $\mathrm{A}_{2}$ group IIA (sPLA $\amalg \mathrm{A}_{2}$ ) and group $X\left(s^{2} L A_{2} X\right)$.

\section{Phospholipase IIA and atherosclerosis}

sPLA IIA is associated with many inflammatory diseases, in particular coronary heart diseases (5). The enzyme is present in atherosclerotic lesions, but shows little activity on intact cell membranes $(6,7)$ and LDL particles (8). Nevertheless, the interaction between sPLA $I I A, L D L$, and extracellular matrix components can induce LDL aggregation and promote atherosclerotic lesion formation (9-11).

We have been able to establish the pro-atherosclerotic properties of sPLA IIA. We found a 2.5 fold increase in lesion size due to $S P L A_{2}$ IIA overexpression (chapter 3 ). However, the role of SPLA ${ }_{2}$ IIA in lesion progression is complex. Phospholipase IIA does not only enhance lipid retention and plaque formation in the vascular system, we also found increased collagen content in atherosclerotic lesions. We hypothesize that SI'L $A_{2}$ IIA modulates the extracellular matrix balance either through binding newly formed matrix components and subsequently reducing their degradation rate, or through inducing elevated matrix component production. In the latter case, phospholipid derived inflammatory mediators are likely involved. Primary candidate is the production of anti-inflammatory prostaglandin $\mathrm{D}_{2}\left(\mathrm{PGD}_{2}\right) . \mathrm{PGD}_{2}$ is involved in inflammatory resolution, which is associated with collagen deposition $(12,13)$. The role of sPLA IIA in lesion stability is supported with our findings in human atherosclerotic lesions. Ruptured lesions showed little sPLA $\mathrm{A}_{2}$ IIA expression compared to early and advanced lesions. We hypothesize that low levels of SPLA, IIA result in reduced collagen content and thus make these lesions prone to rupture. As such SPLA $A_{2}$ IIA (over)expression does not enhance lesion severity, despite its contribution to plaque size, and has an ambiguous role in atherosclerosis.

The limited catalytic activity of sPLA IIA on mammalian membranes suggests that this enzyme might have little impact on inflammation. However, sPLA IIA can bind to the phospholipase receptor, activate MAPK, which activates intracellular production of A.A and lysophospholipids by cytosolic PLA $\left(\mathrm{CPLA}_{2}\right)(14,15)$. As such, sPLA, IIA can indirectly induce the formation of inflammatory mediators, through a functional coupling between these phospholipases (16). Nevertheless, SPLA IIA does have a catalytic function as it shows potent activity on bacterial membranes, rich in phosphatidylglycol $(17,18)$. As such the primary function of sPLA $_{2}$ IIA might be situated in the field of bacterial host defense. Tear fluid (19) for example, contains large amounts of this enzyme. The fact that IIA is often related to acute infections (sepsis (4)) makes its anti-bacterial function quite plausible. The 
presence of SPLA, MA in atherosclerosis might very well be a side effect of its role in the innate inmune system. Pathways activated during bacterial infections are also present in atherosclerotic lesion formation. One of the prominent cell types involved is the macrophage, for which SPLA, IIA is an effective tool during host bacterial defense. An anti-bacterial response in atherosclerosis is not always without merits. Infections are involved in atherosclerosis and can induce exacerbation in plaque growth (20-23) and SPLA, $M A$ expression in atherosclerotic lesion is correlated with the presence of microbial pathogens (24).

\section{Phospholipase $A_{2}$ group $X$ and atherosclerosis}

In contrast to sPLA IIA, sI $\mathrm{A}_{2} X$ exhibits potent enzymatic activity on intact cell membranes $(6,25)$ and is in fact one of the most potent phospholipases in the human body with a catalytic efficiency comparable to cobra venom $\operatorname{sPLA}_{2}(6,26)$. Phospholipase group $X$ is present in many organs and tissues throughout the human body. Phospholipase group $X$ expression and regulation is not fully understood, but appears not to be altered during inflammation $(27,28)$. Its constitutive expression pattern indicates a primary function in delivering eicosanoid substrate to the cell. In our experiments with murine macrophages, we were unable to show changes in sPLA $A_{2}$ X expression after LPS induced inflammation (Ghesquiere et al. 2005, chapter 4). The involvement of sPLA $X$ in atherosclerosis has not been fully elucidated, however, sPLA $X$ is present in macrophage foam cells in the vessel wall of high fat-fed apolipoprotein $E$ knockout mice (29). We have shown sPLA, $X$ expression in macrophages. sPL $A_{2} X$ renders LDL particles pro-atherogenic as our results have shown (chapter 4$)$. Nevertheless, we have been unable to find differences in SPLA 2 X expression between early, advanced and ruptured human plaques (chapter 6). While the exact role of sPLA $A_{2} X$ is not fully elucidated, our results indicate that $s P L A_{2} X$ is an important enzyme for the delivery of eisosanoid substrate. More detailed studies on the expression of this enzyme are necessary.

The potent enzymatic activity of $\mathrm{PLLA}_{2} X$ combined with absence of extracellular matrix binding makes this enzyme an interesting tool to study the pure enzymatic component of phospholipase activity in atherosclerosis. sPLA, IIA, for example, shows little activity on intact cells and native LDL, but: is capable to modulate collagen deposition. It is not clear to which extent the enzymatic activity is responsible for the collagen increase and the retention of LDL. sPLA ${ }_{2}$ Could potentially help to distinguish the enzymatic property from other effects. A similar strategy would be to alter the enzymatic domain on sPLA IIA, by removing the HisAsp dyad in the enzymatic cavity. Making use of the natural occurring sPLA IIA knockout mouse strains, such as C57/B6, holds little chance for success as sPLA IIA functions can be taken over by the closely rellated $S P L A_{2}$ group $V(30)$. Phospholipase $A_{2}$ group V (sPLA, V) is, similar to sPLA, IIA, known to bind heparan sulfate proteoglycan (25), a component of the extracellular matrix. Additionally, sPLA 2 IIA expression in atherosclerotic lesion is correlated with the presence of microbial pathogens (24), with little expression in pathogen free mice. Even under optimal conditions, the natural knockout model is not an optimal model to study atherosclerosis and exhibits almost no abnormalities (31).

We choose to create a mouse model with macrophage specific sPLA $\chi$ X overexpres- 
sion with the macrophage specific CD68 promotor. Unfortunately, our attempts have been hampered by the difficulty to obtain viable mouse lines. A potentially more successful approach might be the use of a less potent variant of the CD68 promotor (32), or to use a longer sPLA $\mathrm{A}_{2} X \mathrm{CDNA}$ fragment, which is known to result in less potent sPLA $X$ production (33). Similarly, another promoter can be used as well; good candidates are the CD1L and the SR-A promotor. An additional option is to use an inducible promotor to drive sPLA $\mathrm{A}_{2}$ X expression, followed by bone marrow transplantation to limit sPLA $\mathrm{X}$ expression to the myeloid system.

\section{Phospholipases in the lung}

Fortunately, our $S P L A_{i} X$ model delivered a limited number of mice that lived long enough to study its phenotype. In the lungs (chapter 5) we observed macrophage infiltration, indications of surfactant accumulation, and thickening of the alveolar walls with reduction of the alveolar lumen. There were no signs of infection in these mice and the areas around the bronchioli and trachea remained unaffected. As such a macrophage specific $\mathrm{sPLA} \mathrm{A}_{2} \mathrm{X}$ overexpression model did inadvertently deliver a model for lung pathology. A stable surfactant balance requires phospholipase activity for clearance of surfactant (34). Lysosomal phospholipase $\mathrm{A}_{2}\left(\mathrm{LPLA}_{2}\right)$ is considered to be responsible for surfactant clearance, although LPLA ${ }_{2}$ knockout mice do not develop lung pathology (35). Redundant phospholipase activity in the lung delivered by sPLA $A_{2}$ group $V$ and $X$ shows to be sufficient to maintain adequate clearance (35). A phospholipase often associated with lung pathology is group IIA. During acute respiratory distress (ARD), a potentially lethal pulmonary condition related to various infectious diseases, $S P L A_{2}$ IIA production in the lung increases considerably (36). Nevertheless, it is more likely that sPLA, V is the primary phospholipase responsible for ARD symptoms (37). This is supported by the absence of lung pathology in both our macrophage specific sPLA IIA model and the general sPLA ${ }_{2}$ IIA model (38). Similar to sPLA, IIA, sPLA ${ }_{2} V$ is present in the lung and is up-regulated during inflammation $(30,39)$, but instead is a potent modifier of lung surfactant (37). We believe that a murine PLA $_{2} X$ overexpression model can contribute to a better understanding of the role of phospholipases in the lung. A valuable addition would be a mouse model for LPLA, overexpression. Eventually, one can consider using the LPLA 2 promotor to deliver alveolar macrophage specific expression of SPLA $_{2} X$.

\section{PAF-AH and atherosclerosis}

PAH $-A H$ removes oxidized phospholipids from membranes, including LDL particles $(40,41)$. Elevated plasma levels of PAF-AH are associated with coronary artery diseases (CAD), but it is not clear if this is cause or consequence (42). In our research, we have found a dramatic increase in PAH-AH expression in the ruptured lesions compared with the early lesions. Apparently, PAF-AH expression is associated with unstable plaques. The exact mechanism is unknown, but the preference of PAF-AH for oxidized phospholipids has the potential to release large amounts of oxidized free fatty acids in the atherosclerotic lesions, thus promoting inflammation and the production of oxidative molecules $(41,43)$. Our re- 
sults, in combination with the results published by other groups, show a potential active role of PAH-AH in atherosclerosis rather than being a mere risk marker. This creates an opportunity for therapeutic strategies focussed on the inhibition of PAH-AH activity. In our research group, we have been engineering a macrophage specific PAH-AH overexpression model. Unfortunately, our attempts have been unsuccessful so far, largely due to the low expression delivered by the selected promotor.

\section{Phospholipases and inflammation}

In vitro $s P L A_{2} X$ overexpression revealed anti-inflammatory activity in macrophages (chapter 4). As our results show, the pro-inflammatory TNF levels were significantly reduced as result of SPLA 2 overexpression, while the anti-inflammatory interleukine-10 ( $\mathrm{L} 10)$ response increased. This observation was accompanied by an increase in prostaglandin $\mathrm{E}_{2}\left(\mathrm{PGE}_{2}\right.$, and 15-Deoxy-Delta 12,14-prostaglandin $J_{2}\left(15 \mathrm{~d}-P G J_{2}\right)$ production, both known to reduce inflammatory response in macrophages. In particular the increase of the anti-inflammatory $15 \mathrm{~d}-\mathrm{PGJ}_{2}$ is interesting, as $15 \mathrm{~d}-\mathrm{PG} \mathrm{J}_{2}$ is nowadays recognized as a potent anti-inflammatory prostaglandin $(44,45)$. In the sPLA $X_{2}$ induced anti-inflammatory response, cyclooxygenase-2 (COX-2) plays an important role. $\mathrm{COX}-2$ is the rate limiting enzyme in the production of prostaglandins during inflammation $(46,47)$, which explains why in absence of inflammation, $S P L A_{2} X$ does not enhance the production of prostaglandins. Based on our results, we conclude that increased AA production by $s P L A_{2} X$ enhances an inflammatory feedback mechanism that reduces macrophage activation $(48,49)$. $\mathrm{PGE}_{2}$ and $\mathrm{PGD}_{2} / 15 \mathrm{~d}-\mathrm{PGI}_{2}$ knockout and overexpression mouse models would be valuable to investigate the role of phospholipase activity in atherosclerotic lesions, in particular the regulation of inflammation.

Our findings could have serious implications for the use of COX-2 inhibiting therapies in atherosclerosis. COX-2 specific inhibition has the potency to eliminate the anti-inflammatory effects of phospholipase activity, and could thus increase macrophage activation. In the light of the recent controversy around COX-2 selective inhibitors, a better understanding of the prostaglandin pathway activation is vital.

\section{Phospholipases during the course of atherosclerosis}

We investigated the role of several phospholipases in human atheroselerotic plaques and made interesting observations. Future research should include more genes and a larger research population. Excellent genes for inclusion are phospholipase group $\mathrm{V}$ and cytosolic phospholipase IVa ( $\left.\mathrm{CPLA}_{2} \mathrm{a}\right)$. The first because sPLA $\mathrm{V}$ is present in atherosclerotic lesions and has been shown to induce foam cell formation (50), the latter for its known modulation of inflammation through interactions with other phospholipases $(14,51)$. More enzymes involved with the eicosanoids production, such as prostaglandin $\mathrm{D}_{2}$ and 15-lipoxygenase, should be included in future investigations. 


\section{Therapeutic strategies}

The involvement of phospholipases in various inflammatory diseases, including atherosclerosis, makes them a potential target for therapeutic intervention. How' ever, the role of phospholipases is ambiguous. While some phospholipases are usable as marker for inflammatory processes, this does not always imply direct involvement. Care must be taken to distinguish cause and consequence.

It has repeatedly been shown that PLA IIA plasma levels increase during acute and chronic inflammation. Blocking the enzyme offers a credible therapeutic option, but $S P L A_{2}$ IIA has anti-bacterial properties and as such plays an important role in the innate immunity. Reducing the activity of sPLA, ILA might therefore have adverse effects during bacterial infections. Our results confirm that sPLA IIA plays a role in atherosclerosis and can enhance lesion formation. However, sPLA $_{2}$ IIA inhibition might reduce plaque stability and increase the risk to plaque rupture. In specific cases, such as acute respiratory distress (ARD), sPLA IIA inhibition might be beneficial. High levels of sPLA ${ }_{2}$ IIA in the lungs can exacerbate the symptoms.

High PAF-AH plasma levels are associated with increased risk for CAD. Additionally, our results show that the PAF-AH expression in ruptured lesions is strongly increased. As such, reducing PAF-AH levels in both the plasma and the atherosclerotic lesions might offers a good opportunity to prevent $C A D$ and plaque rupture. However, at the moment, it is unclear if PAF-AH increase is cause or consequence (42). As such, we recommend transgenic models with cell specific PAH-AH overexpression to further investigate the role of PAF-AH in atherosclerosis.

The biological effects of phospholipase activity are closely connected with the eicosanoid pathways. Recent discoveries have shown that both pro- and anti-inflammatory mediators are produced from the same precursor molecules. Developing successful phospholipase based therapies require selective, local inhibition of specific phospholipases, possibly in combination with monitoring and directing the related eicosanoid pathways.

At present, however, the therapeutic strategies involving "phospholipases" do not use the potential that is offered by these pathways. In part, this is due to limitations of our current knowledge. One of the challenges for the future is to get a better understanding of lipid interactions in complex diseases such as atherosclerosis. Technological advantages have made it possible to investigate which genes are involved during various stages of atherosclerosis. This work, and the work from other groups, showed that the expression of several phospholipases is regulated during the formation of atherosclerotic lesions.

The combination of in vitro work, animal models and population studies reveal the functions of enzymes, such as phospholipases. However, to fully understand plaque development it is equally important to understand the environment in which the products of the expressed genes operate. The activity of phospholipids, for example, depends on factors as phospholipid composition, interactions with charged compounds, and presence of oxidized lipid components. Additionally, phospholipase activity results in the production of a whole range eicosanoids, which interact with plaque components and modulates inflammation.

It would be of great value to track lipid pathways in the atherosclerotic plaque and 
make so called 'lipid-signatures'. Combining lipid data with gene expression patterns should allow to detecting subtle variations in gene expression that amplify atherosclerotic plaque development. With the link between the common lipid profiles and genetic expression patterns established, it becomes possible to develop new therapeutic strategies that channel lipid pathways to the most beneficial outcome.

\section{References}

1. Williams, KJ and Tabas, I. 1995. The response-to-retention hypothesis of early atherogenesis. Arterioscler Thromb Vasc Biol 15:551-561.

2. Goldstein, J.L., Ho, Y.K., Basu, S.K., and Brown, M.S. 1979. Binding site on macrophages that mediates uptake and degradation of acetylated low density lipoprotein, producing massive cholesterol deposition. Proc Natl Acad Sci US A 76.333-337.

3. Menschikowski, M., Kasper, M., Lattke, P., Schiering, A, Schiefer, S., Stockinger, H., and Jaross, W. 1995. Secretory group II phospholipase $A_{2}$ in human atherosclerotic plaques. Atherosclerosis $118173-181$.

4. Vadas, F., and Pruzanski, W. 1993. Induction of group Il phospholipase $A_{2}$ expression and pathogenesis of the sepsis syndrome. Cir Shock 39:160-167.

5. Rader, DJ. 2000. Inflammatory markers of coronary risk. N Engl J Med 343:1179-1182.

6. Bezzine, S, Koduri, RS, Valentin, E. Murakami, M., Kudo, I., Ghomashchi, F, Sadilek, M., Lambeau, $G$, and Gelb, MH. 2000. Exogenously added human group $X$ secreted phospholipase $A(2)$ but not the group $\mathrm{B}, \mathrm{LA}$, and $\mathrm{V}$ enzymes efficiently release arachidonic acid from adherent mammalian cells. I Biol Chem 2753179-3191.

7. Murakami, M., Koduri, R.S., Enomoto, A., Shimbara, S., Seka, M., Yoshihara, K., Singer, A., Valentin, E., Ghomashchi, F, Lambeau, G., et al. 2001. Distinct arachidonate-releasing functions of mammalian secreted phospholipase $\mathrm{A}_{2} \mathrm{~s}$ in human embryonic kidney 293 and rat mastocytoma RBL-2H3 cells through heparan sulfate shuttling and external plasma membrane mechanisms. / Biol Chem 276:10083-10096.

8. Sartipy, P., Camejo, G., Svensson, L., and Hurt-Camejo, E. 1999. Phospholipase A(2) modification of low density lipoproteins forms small high density particles with increased affinity for proteoglycans and glycosaminoglycans. I Biol Chem 274:25913-25920,

9. Flood, C., Gustafsson, M., Pitas, RE, Arnaboldi, L., Walzem, R.L., and Boren, J. 2004. Molecular mechanism for changes in proteoglycan binding on compositional changes of the core and the surface of low-density lipoprotein-containing human apolipoprotein B100. Arterioscler Thromb Wasc Biol 24:564-570.

10. Hurt-Camejo, E., Camejo, G. and Sartipy, P. 2000. Phospholipase $\mathrm{A}_{2}$ and small, dense lowdensity lipoprotein. Curr Opin Lipido! 11:465-471.

11. Kovanen, P.T., and Pentikainen, M.O. 1999. Decorin links low-density lipoproteins (LDL) to collagen: a novel mechanism for retention of LDL in the atherosderotic plaque. Tirends Cardio7asc Med 9:86-91.

12. Gilloy, D.W., Colville-Nash, P.R., Willis, D., Chivers, J., Paul-Clark, M.J., and Willoughby, D.A. 1999. Inducible cyclooxygenase may have anti-inflammatory properties. Nat Med 5:698-701.

13. Ianaro, A., Ialenti, A., Maffia, P., Pisano, B., and Di Rosa, M. 2001. Role of cydopentenone prostaglandins in rat carrageenin pleurisy. FEBS Lett 508:61-66.

14. Ballsinde, J., Balboa, M.A., and Dennis, E.A. 1998. Functional ooupling between secretory phospholipase $A_{2}$ and cyclooxygenase-2 and its regulation by cytosolic group IV phospholipase $\mathrm{A}_{2}$. Proc Nati Acad Sci U S A 95:7951-7956.

15. Hefner, Y., Borsch-Haubold, A.G., Murakami, M., Wilde, J.I, Pasquet, S., Schieltz, D., Gho- 
mashchi, F, Yates, J.R, 3rd, Armstrong, C. G. Paterson, A., at al 2000. Serine 727 phosphorylation and activation of cytosolic phospholipase $A_{2}$ by MNK1-related protein kinases. I Biol Chem 27537542-37551.

16. Anthonsen, M.W., Solhaug, A., and Johansen, B. 2001. Functional coupling between secretory and cytosolic phospholipase $A_{2}$ modulates tumor necrosis factor-alpha- and interleukin1beta-induced NF-kappa B activation. / Biol Chem 276:30527-30536.

17. Laine, VI., Grass, D.S, and Nevalainen, T.J. 1999. Protection by group II phospholipase A, against Staphylococcus aureus. / Irwwnol 162:7402-7408:

18. Weinraud, Y, Abad, C., Liang, N.S., Lowry, S.F, and Weiss, J. 1998. Mobilization of potent: plasma bactericidal activity during systemic bacterial challenge. Role of group IIA phospholipase $\mathrm{A}_{2}$. J Clin moest 102:633-638.

19. $Q u, X D$, and Lehrer, RI. 1998. Secretory phospholipase $A_{2}$ is the principal bactericide for staphylococci and other gram-positive bacteria in human tears. Infect immwn 66:2791-2797.

20. Gaydos, C.A., Summersgill, J.T., Sahney, N.N., Ramirez, J.A, and Quin, T.C. 1996. Replication of Chlamydia preumoniae in vitro in human macrophages, endothelial cells, and aortic artery smooth muscle cells. Infect Immun 64:1614-1620.

21. Chou, H.H., Yumoto, H., Davey, M., Takahashi, Y, Miyamoto, T., Gibson, F.C., 3rd, and Genco, C.A. 2005. Porphyromonas gingivalis fimbria-dependent activation of inflammatory genes in human aortic endothelial cells. Infect Immun 73:5367-5378.

22. Saijo, Y., Utsugi, M., Yoshioka, E, Horikawa, N., Sato, T., Gong, Y, and Kishi, R. 2005. Relationship of Helicobacter pylori infection to arterial stiffness in Japanese subjects. Hypertens Res 28:283-292.

23. Kaplan, M., Yavuz, S.S., Cinar, B., Koksal, V., Kut, MLS., Yapici, F., Geroekoglu, H., and Demirtas, M.M. 2005. Detection of Chlanydia pneumoniae and Helicobacter pylori in atherosclerotic plaques of carotid artery by polymerase chain reaction. Int I Infect Dis.

24. Menschikiowski, M., Rosner-Schiering, A, Eckey, R, Mueller, E., Koch, R, and Jaross, W. 2000. Expression of secretory group ILA phospholipase A(2) in relation to the presence of microbial agents, macrophage infiltrates, and transcripts of proinflammatory cytokines in human aortic tissues. Arterioscler Thromb Vase Biol 20:751-762.

25. Murakami, M., Shimbara, S, Kambe, T. Kuwata, H., Winstead, MV., Tischfield, J.A., and Kudo, 1. 1998. The functions of five distinct mammalian phospholipase $\mathrm{A}_{2} \mathrm{~S}$ in regulating arachidonic acid release. Type Illa and type $V$ secretory phospholipase $A_{2} S$ are functionally redundant and act in concert with cytosolic phospholipase $\mathrm{A}_{2}$.J Biol Chem 273:14411-14423.

26. van Eijk, J.H. Verhej, H.M., Dijkman, $\mathrm{R}_{\text {, }}$ and de Haas, G.H. 1983. Interaction of phospholipase $A_{2}$ from Naja melanolevca snake venom with monomeric substrate analogs. Activation of the enzyme by protein-protein or lipid-protein interactions? Eur / Biochem 132:183-188.

27. Hamaguchi, K., Kuwata, H, Yoshihara, K., Masuda, S, Shimbara, S., Oh-ishi, S., Murakami, M., and Kudo, I. 2003. Induction of distinct sets of secretory phospholipase A(2) in rodents during inflammation. Biochin Bioplyys Acta 1635:37-47.

28. Masuda, S., Murakami, M., Komiyama, K., Ishilhara, M., Ishikawa, Y., Ishii, T., and Kudo, I. 2005. Various secretory phospholipase $A_{2}$ enzymes are expressed in rheumatoid arthritis and augment prostaglandin production in cultured synovial cells. Febs ) 272:655-672.

29. Hanasaki, K., Yamada, K. Yamamoto, S., Ishimoto, Y., Saiga, A., Ono, T, Ikeda, M., Notoya, $\mathrm{M}_{,}$Kamitani, $S_{*}$ and Arita, H. 2002. Potent modification of low density lipoprotein by group $X$ secretory phospholipase $A_{2}$ is linked to macrophage foam cell formation. I Biol Chem 277:29116-29124.

30. Sawada, H., Murakami, M., Enomoto, A., Shimbara, S., and Kudo, I. 1999. Regulation of type $V$ phospholipase $A_{2}$ expression and function by proinflammatory stimuli. Eur J Biochen 263:826-835.

31. Kennedy, B.P., Payette, P., Mudgett, I., Vadas, P., Pruzanski, W., Kwan, M., Tang, C., Rancourt, D.E. and Cromlish, W.A. 1995. A natural disruption of the secretory group II phospholipase 
$\mathrm{A}_{2}$ gene in inbred mouse strains. J Biol Chem 270:22378-22385.

32. Gough, P., Gordon, S, and Greaves, D.R. 2001. The use of human CD68 transcriptional regulatory sequences to direct high-level expression of class A scavenger neceptor in macrophages in vitro and in vivo. Intmunology 103:351-361.

33. Cupillard, L. Koumanov, K, Mattei, M.G, Lazdunski, M, and Lambeau, G. 1997. Cloning, chromosomal mapping, and expression of a novel human secretory phospholipase $\mathrm{A}_{2}$. I Biol Chem 272:15745-15752.

34. Abe, A., Hiraoka, M., Wild, S., Wilcoxen, S.E., Paine, R., 3rd, and Shayman, J.A. 2004. Lysosomal phospholipase $A_{2}$ is selectively expressed in alveolar macrophages. I Biol Chent 279:42605-42611.

35. Fisher, A.B., Dodia, C., Feinstein, S.I. and Ho, X.S. 2005. Altered lung phospholipid metabolism in mice with targeted deletion of lysosomal-type phospholipase $\mathrm{A}_{2}$ / Lipid Res 46:12481256.

36. Arbibe, L, Koumanov, K., Vial, D., Rougeot, C, Faure, G., Havet, N., Longacre, S., Vargaftig, B.B., Bereziat, G., Voelker, D. R. et al. 1998. Generation of lyso-phospholipids from surfactant in acute lung injury is mediated by type-II phospholipase $\mathrm{A}_{2}$ and inhibited by a direct surfactant protein A-phospholipase $\mathrm{A}_{2}$ protein interaction. / Clin lmvest 102:1152-1160.

37. Touqui, $L_{y}$ and $W u, Y . Z$. 2003. Interaction of secreted phospholipase $A_{2}$ and pulmonary surfactant and its pathophysiological relevance in acute respiratory distress syndrome. Acta Pharmacol Sin 24:1292-1296.

38. Grass, D.S., Felkner, R.H. Chiang, M.Y., Wallace, R.E., Nevalainen, TJ., Bennett, C.F, and Swanson, M.E. 1996. Expression of human group II PL. $A_{2}$ in transgenic mice results in epidermal hyperplasia in the absence of inflammatory infiltrate. J Clin Invest 97:2233-2241.

39. Masuda, $S_{,}$Murakami, M., Mitsuishi, M., Komiyama, K., Ishikawa,, , Ishii, T, and Kudo, I. 2005. Expression of secretory phospholipase $A_{2}$ enzymes in lungs of humans with pneumonia and their potential prostaglandin-synthetic function in human lung-derived cells. Biochem 3 387:27-38.

40. Farr, R.S., Cox, C.P., Wardlow, M.L., and Jorgensen, R. 1980. Preliminary studies of an acid-labile factor (ALF) in human sera that inactivates platelet-activating factor (PAF). Clin Immunol Inmunopathol 15:318-330.

41. Min, J.H., Wilder, C., Aoki, J., Arai, H., Inoue, K, Paul, L, and Gelb, M.H. 2001. Platelet-activating factor acetylhydrolases: broad substrate specificity and lipoprotein binding does not modulate the catalytic properties of the plasma enzyme. Biockemistry 40:4539-4549.

42. Packard, C.J., O'Reilly, D.S., Caslake, M.J., MoMahon, A.D., Ford, I., Cooney, J., Macphee, C.H., Suckling, K.E., Krishna, $M_{z}$ Wilkinson, F.E., et al. 2000. Lipoprotein-associated phospholipase $\mathrm{A}_{2}$ as an independent predictor of coronary heart disease. West of Scotland Coronary Prevention Study Group. N Engl J Med 343:1148-1155.

43. Evangelou, A.M. 1994. Platelet-activating factor (PAF): implications for coronary heart and vascular diseases. Prostaglandins Letkikat Essent Fatty Acids 50:1-28.

44. Kawahito, Y., Kondo, M., Tsubouchi, Y., Hashiramoto, A., Bishop-Bailey, D., Inoue, K., Kohno, M., Yamada, R, Hla, T, and Sano, H. 2000. 15-deoxy-delta(12,14)-PG)(2) induces synoviocyte apoptosis and suppresses adjuvant-induced arthritis in rats. I Clin invest 106:189-197.

45. Harris, S.G., Padilla, J., Koumas, L., Ray, D. and Phipps, R.P. 2002. Prostaglandins as modulators of immunity. Trends Immunol 23:144-150.

46. Hinz, B., Kraus, V., Pahl, A., and Brune, K. 2000. Salicylate metabolites inhibit cyclooxygenase-2-dependent prostaglandin $\mathrm{E}(2)$ synthesis in murine macrophages. Biochew Biophys Res Cormun 274:197-202.

47. Harizi, $\mathrm{H}_{\text {, J Juan, }}$., Grosset, C., Rashedi, M., and Gualde, N. 2001. Dendritic cells issued in vitro from bone marrow produce PGE(2) that contributes to the immunornodulation induced by antigen-presenting cells. Cell Immunol 209:19-28.

48. Wooton-Kee, C.R., Boyanovsky, B.B., Nasser, M.S., de Villiers, W.J., and Webb, N.R. 2004. 
Group V SPLA hydrolysis of low-dentity lipoprotein results in spontaneous particle aggregation and promotes macrophage foam cell formation. Arterinscler Thromb Vasc Biol 24762767.

49. Balsinde, $J$, and Dennis, E.A. 1996. Distinct roles in signal transduction for each of the phospholipase $\mathrm{A}_{2}$ eruxymes present in P388D1 macrophages. J Biol Chem 271.6758-6765. 


\section{Summary}


Atherosclerosis is an inflammatory disease of the large arteries, characterized by the accumulation of modified low-density lipoproteins (LDL). Native LDL is not retained in the vessel wall, unless it is oxidatively and enzymatically modified. Amongst the most prominent enzymes responsible for LDL modification are the secreted phospholipases $\mathrm{A}_{2}$ (sPLA $)_{2}$, which hydrolyse phospholipids at their sn-2 position, releasing free fatty acids and lysophospholipids. As such, phospholipase activity can modify phospholipids in the LDL particles enhancing their pro-atherosclerotic properties. At the same time, the generated FFA and lysoPL products are converted into potent inflammatory mediators, which can also highly affect atherogenesis.

Several members of the phospholipases $A_{2}$ family have been shown in atherosclerotic lesions. In this study, the main focus was given to SPLA $_{2}$ group IIA (chapter

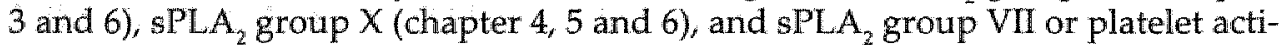
vating factor acetylhydrolase (PAF-AH) (chapter 6). Additionally we investigated enzymes crucial in the processing of the arachidonic acid, which is liberated as result of phospholipase activity (chapter 6 ).

To study the role of sPLA ${ }_{2}$ IIA in macrophages during atherogenesis, transgenic mice were generated using the human sPLA, IIA gene and the CD11b promoter (chapter 3). We performed bone marrow transplantations to LDLR deficient mice to study sPLA $\mathrm{A}_{2}$ IIA in an atherosclerotic susceptible mouse model. After 10 weeks on a high fat diet, the mice overexpressing sPLA, IIA in macrophages showed 2.3 fold larger lesions as compared to controls. Examination revealed that $\mathrm{sPLA}_{2}$ IIA expressing mice had increased collagen in their lesions, independent of lesion size. However, smooth muscle cells or fibroblasts in the lesions were not affected, neither did we find significant changes in T-cell quantities and cell turnover as result of sPLA IIA overexpression. Our data clearly show that macrophage SPLA $_{2}$ IIA promotes lesion growth, but at the same time enhances collagen production in the plaque and thus fibrotic cap development, which suggests improved plaque stability. Another indication that $\mathrm{SPLA}_{2}$ IIA contributes to plaque stabilisation was obtained in human atherosclerotic lesions (chapter 6), where sPLA, IIA expression was remarkably decreased in ruptures lesions when compared to advanced and early lesions.

In chapter 4 and 5 we studied the involvement of macrophage sPLA, $X$ in atherosclerosis and inflammation. sPLA $\mathrm{A}_{2} \mathrm{X}$ is much more active on cell membranes and LDL particles than SPLA ${ }_{2}$ IIA. We have been able to show sPLA $X$ expression in murine macrophages. To investigate the role of sPLA $X$ in inflammation and atherosclerosis, we generated a macrophage specific construct, in analogy with our SPLA $\mathrm{A}_{2}$ IIA construct used in chapter 2 . This time, however, we used the macrophage specific $C D 68$ promoter instead of the CD11b promoter.

First, we used the CD68 sPLA $X$ construct to transfect RAW264.7 cell lines and we obtained several stable cell lines expressing the sPLA $A_{2} X$ construct. Prior to performing experiments, phospholipase activity was measured to confirm the production of enzymatically active SPLA $X$. We found that sPLA $X$ overexpression in macrophages strongly increased foam cell formation upon incubation with native $L D L$, which indicates that $s P_{L} A_{2} X$ is capable to contribute to atherosclerotic lesion formation. The next step was to use these macrophage cell lines for 
activation experiments (chapter 4). Our results revealed a novel role for sPLA, $X$, as $\mathrm{PLA}_{2} X$ overexpression inhibited lipopolysaccharide-induced macrophageactivation, characterized by reduced cell adhesion, lower levels of TNF secretion and increased interleukin-10 production. These effects are likely mediated by increased prostaglandin $E_{2}$ and 15-deoxy- $\Delta 12,14$-prostaglandin $J_{2}$ production, as our results show. Our experiments show a potentially two-faced role for SPLA $\mathrm{X}_{2} \mathrm{X}$ in atherosclerosis, with promoting foam cell formation and at the same time reducing the inflammatory response in macrophages.

Besides in vitro experiments with sPLA $\mathrm{X}_{2}$ Xverexpression, we decided to examine the role of $s \mathrm{PLA}_{2} X$ in atherosclerosis formation with a transgenic mouse model. Unfortunately, it proved hard to establish viable mouse lines with the CD68 sPLA, $X$ construct, despite numerous attempts. Only a few transgenic mice were born, which either died within weeks after birth, or failed to transfer the sPLA $X$ gene to their offspring. Nevertheless, we took the opportunity to examine the transgenic mice we managed to obtain. In the mice that spontaneously died we observed severe lung pathology, with massive macrophage invasion and additional protein and lipid accumulation. The mice that failed to transfer the PLA $_{2} X$ gene showed much milder lung pathology, but also exhibited increased macrophage infiltration. We could not find signs of infections in our mice that could have produced this pathology.

While several phospholipase have been found in atherosclerotic lesions, such as sPLA IIA and SPLA ${ }_{2} X$, little is known about the role and expression of these phospholipases during plaque development. We therefore investigated the expression patterns of sPLA IIA, $_{\text {, } P L A}, X$, and PAF-AH in human atherosclerotic lesions. In our analysis we included enzymes involved in pathways closely connected to phospholipase activity, such as 5-lipoxygenase (5-LO), cyclooxygenase-2 (COX2) and prostaglandin $E_{2}$ synthase (mPGES) (chapter 6). Arterial plaque material from 13 patients was collected and classified into an early, advanced, and ruptured group. mRNA was isolated and the expression of selected genes was quantified by realtime PCR. Interestingly, our results showed a strong decrease in SPLA IIA expression in ruptured lesions, indicating a role for this enzyme in lesion stability. While not quantified, the early, and advanced lesions exhibiting high sPLA, IIA expression levels had a thick, fibrous cap and a stable phenotype. This is nicely in line with our results with sPLA IIA overexpression in mice (chapter 3), where we found increased collagen deposition due to $\mathrm{PLLA}_{2}$ IIA overexpression. Conversely, PAF-AH expression levels were increased in ruptured lesions. Considering the previously established correlation between plasma PAF-AH and coronary artery disease, our results suggest that intra-plaque PAF-AH similarly contributes to lesion destabilisation. Our results, in combination with the results published by other groups, show a potentially active role of $\mathrm{PAF}-\mathrm{AH}$ in atherosclerotic progression and rupture rather than being a mere risk marker. Interestingly, the expression of the $\mathrm{SLA}_{2} \times$ did not differ between the early, advanced, and ruptured lesions. This is similar to what we have found in chapter 4 , where we have shown that SPLA $X$ is not regulated by lipopolysaccharide (LPS) stimulation. There are strong indications that SPLA $\mathrm{X}_{2}$ is constitutively expressed under most circumstances, although differences in basic expression levels between individuals can be of importance. As 
such, sPLA $X$ expression patterns should be studied in larger population studies. Phospholipase activity results in the production of A.A, which can be transformed and metabolised into a whole myriad of anti- and pro-inflammatory eicosanoids. As such, it is pivotal to understand which pathways are activated during and after phospholipase activity in the atherosclerotic plaque. Therefore we included several key enzymes in our study, COX-2 and mPGES from the prostaglandin synthesis pathway, and 5-LO from the leukotriene pathway. Our results are very interesting, as we observed increased COX-2 expression in the ruptured lesions, which did not come with increased mPGES expression. This might indicate that prostaglandins other than prostaglandin $E_{2}$ are produced in ruptured lesions lesions. Because it is not clear to which extent this affects atherosclerosis and plaque stability, future research should expand to inclusion of other prostaglandin synthases, such as prostaglandin $I_{2}$ synthase (PGIS) and prostaglandin $D_{2}$ synthase (PGDS). The 5-LO expression levels in advanced and ruptured lesions were strongly increased, which confirms the involvement of leukotrienes in atherosclerotic plaque severity. This finding is supported by previous studies, were a correlation between lesion severity and 5-LO concentrations was found.

In conclusion: our results show that phospholipases, although they contribute to lesion growth, are not necessarily harmful due to their capacity to stabilize atherosclerotic lesions and reduce the detrimental inflammatory processes associated with atherosclerosis. 


\section{Samenvatting}


Atherosclerose, ook wel bekend als 'aderverkalking', is de onderliggende oorzaak van veel hart- en vaatziekten. Kenmerkend aan deze aandoening is de stapeling van vetten en cellen in de vaatwand. Het gevolg hiervan is dat het vat nauwer wordt, hetgeen de bloedstroom kan belemmeren. Nog problematischer wordt het als de plaque scheurt en vervolgens stolsels gevormd worden die verstoppingen in het vaatstelsel kunnen veroorzaken. Vaak gebeurt dat in de coronaire vaten, waardoor de bloedvoorziening van de hartspier in het gedrang komt, met een hartaanval" als gevolg.

Het onderzoek dat beschreven id in dit proefschrift richt zich op het ontstaan en de groei van atherosclerotische plaques. Het stapelen van vet, in de vorm van van LDL (low-density lipoproteins) in de vaatwand, en de opname ervan door macrofagen liggen aan de basis van plaquevorming. LDL deeltjes zijn verantwoordelijk voor vet- en cholesterol-transport van de organen naar de lever. Ze bestaan uit een eiwit, ingebed in een membraan van fosfolipiden, en zijn gevuld met cholesterol en lipiden. LDL deeltjes komen door diffusie in de valatwand terecht en worden vervolgens opgeruimd door macrofagen. Door oxidatie en enzymatische activiteit kan het LDL gaan binden aan moleculen in de vaatwand en hoopt het LDL op. Daarnaast wordt de opname en verwijdering door macrofagen verstoord, en raken de macrofagen gevuld met vetdeeltjes en veranderen ze in 'schuimcellen'. Dit vormt de aanzet tot de vorming van een atherosclerotische plaque.

De voornaamste enzymen die LDL modificeren en LDL stapeling in de vaatwand en de vorming van schuimcellen veroorzaken zijn de secretoire fosfolipasen. Deze enzymen breken fosfolipiden af die een hoofdbestanddeel vormen van celmembranen en LDL deeltjes. De hierbij vrijkomende wrije vetzuren (o.a. arachidonzuur) en lysofosfolipiden beinvloeden ontstekingsprocessen, die dan weer een rol spelen in de ontwikkeling van atherosclerose.

In dit proefschrift wordt vooral de aandacht gegeven aan secretoir fosfolipase$A_{2}$ groep IIA (sPLA ${ }_{2}$ IIA) (hoofdstuk 3 en 6) en group X (sPLA $A_{2}$ ) (hoofdstuk 4 , 5 en 6). In mindere mate komt ook group VII (hoofdstuk 6), ook wel bekend als (bloed)plaatjes activerende factor acetylhydrolase (PAF-AH) aan bod. Daarnaast hebben we in hoofdstuk 6 enzymen bestudeerd die arachidonzuur omzetten in ontstekingsmediatoren.

Om de rol van SPLA ${ }_{2}$ IIA in atherosclerose te onderzoeken (hoofdstuk 3 ) hebben we een transgene muis gemaakt met het sPLA $A_{2}$ IIA gen van de mens. Om de sPLA IIA productie te beperken tot de atherosclerotische plaques is het gen voorzien van een macrofaag specifieke promotor. Vervolgens is het beenmerg van deze muizen getransplanteerd naar een muismodel voor atherosclerose: de LDL receptor deficiënte muis. De muizen werden vervolgens 10 weken op een vetrijk dieet gezet. Na afloop stelden we vast dat de muizen die sPLA ${ }_{2}$ IA beenmerg hadden gekregen gemiddeld 2.3 maal grotere atherosclerotische lesies hadden dan muizen die gewoon beenmerg ontvangen hadden. Niet alleen waren de lesies groter, ze bevatte in verhouding veel meer collageen. Dit is interessant omdat collageen een plaque sterker en stabieler maakt, waardoor deze minder snel scheurt. In het aantal gladde spiercellen, fibroblasten, $T$-cellen en celdelingen waren er geen verschillen. De resultaten van dit experiment laten zien dat sPLA, IIA de groei van atherosclerotische plaques bevordert, maar deze eveneens stabieler maakt. Dat 


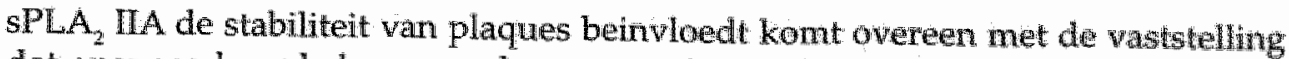
dat opengescheurde humane plaques aanzienlijk minder sPLA, UA tot expressie brachten dan wroege en gevorderde lesies en daardoot mogelijik minder stabiel waren (hoofdstuk 6).

In hoofdstuk 4 en 5 worden de resultaten behandeld van onze experimenten met $s P L A_{2} \chi$. Dit enzym is vele malen actiever op celmembranen en LDL darn sPLA $A_{2}$ IIA. sPLA $X$ komt voor in atherosclerotische plaques en macrofagen. Door $\mathrm{sPLA}_{2} \times$ mRNA aan te tonen lieten we zien dat sPLA $\mathrm{X}_{2}$ ook daadwerkelijk door macrofagen geproduceerd wordt. Om de rol van sPLA $X$ te kumnen onderzoeken werd het humane sPLA $A_{2} X$ gen voorzien van een macrofaag specifieke CD68 promotor en ingebracht in muismacrofaag cellijnen, zodat deze grote hoeveelheden sPLA $\mathrm{A}_{2} \mathrm{X}$ begonnen te produceren (hoofdstuk 4). Het eerste experiment met deze macrofagen bestond erin om LDL aan het kweekmedium toe te voegen. Hieruit bleek dat sPLA $\mathrm{A}_{2} \mathrm{X}$ schuimcelformatie sterk bevorderde en zo kan bijdragen aan de vorming van atherosclerotische plaques. De volgende stap was het bestuderen van de ontstekingseigenschappen van deze sPLA $\mathrm{X}_{2}$ macrofagen. Hiertoe werden de macrofagen gestimuleerd met lipopolysaccharide. De resultaten lieten zien dat sPLA $A_{2} X$ de onstekingreactie in macrofagen afremt. $Z$ o was het TNF niveau lager dan in normale macrofagen, terwijl de interleukine-10 concentratie verdubbelde. s.PL $\mathrm{A}_{2} \mathrm{X}$ bleek te zorgen voor een toename in de productie prostaglandin $\mathrm{E}_{2}$ en 15 -deoxy- $\Delta 12,14$-prostaglandin $J_{2}$ in geactiveerde macrofagen. De toename van deze ontstekingsremmende prostaglandines verklaart de ontstekingsremmende werking van SPLA $A_{2} X$. Onze in vitro proeven tonen aan dat $S P L A_{2} X$ atherosclerose kan bevorderen door schuimcelformatie, maar daarnaast de ontsteking in atherosclerotische plaques kan remmen.

De logische volgende stap was het maken van een transgene sPLA $X$ muis in analogie met onze sPLA 2 IIA muis (hoofdstuk 5). Dit bleek moeilijker dan verwacht. Er werden slechts 3 transgene muizen geboren, waarvan er 2 op jonge leeftijd stierven. De overlevende muis gaf het gen nauwelijks aan het nageslacht. De longen van een van de gestorven muizen bevatte veel macrofagen, waren sterk oedemateus en vertoonden lipide- en proteinstapeling. De transgene muizen die niet op jonge leeftijd stierven hadden een veel mildere vorm van longpathologie. We konden geen sporen van infectie vaststellen. Waarschijnijk verstoorde SPLA $_{2}$ $X$ de longsurfactant balans door afbraak van het surfactant. Dit veroorzaakte een ontstekingsreactie en stapeling van surfactant residuen. De conclusie is dat macrofaag specifieke sPLA $\mathrm{A}_{2} X$ overexpressie voor ernstige longproblemen kan zorgen via afbraak van surfactant.

Er is nog maar weinig bekend over het verband tussen de verschillende fosfolipasetypen en de ernst en samenstelling van een atherosclerotische plaque. Om dit beter in kaart te brengen hebben we de expressie van sPLA, IIA, sPLA, $X$ en PAF-AH in humaan plaque materiaal gemeten (hoofdstuk 6). Atherosclerotisch materiaal van 13 personen werd verzameld en geclassificeerd in vroege, gevorderde en gescheurdle plaques. Uit dit materiaal is RNA geisoleerd en is vervolgens de expressie van de genen gemeten met realtime PCR. Onze resultaten laten zien dat sPLA $\mathrm{A}_{2}$ IIA expressie sterk afneemt in gescheurde plaques, hetgeen aangeeft dat dit enzym een rol speelt in plaque stabiliteit. Bovendien bleek dat 
wroege en gevorderde plaques met een hoge sPLA, IIA expressie een stevigere structuur hadden. Het expressieniveau van PAF-AH daarentegen nam sterk toe in gescheurde plaques. De relatie tussen een hoge PAF-AH plasma waarden en coronair vaatlijden is al langer bekend, maar onze resultaten laten zien dat PAFAH productie in de atherosclerotische plaque negatieve gevolgen kan hebben. Het lijkt erop dat sPLA $\times$ productie niet beinvloed wordt door de samenstelling van de plaque, aangezien er geen verschillen vastgesteld werden in vroege, gevorderde en gescheurde plaques. Er zijn aanwijzingen dat sPLA, $X$ expressie per individu verschilt en zo een factor kan zijn in atherosclerose vorming. Hier is echter meer onderzoek voor nodig.

We hebben eveneens gekeken naar enzymen die het arachidonzuur, dat vrijkomt bij fosfolipase activiteit, omzetten in ontstekingsregulerende eicosanoïden. Cyclooxygenase-2 (COX-2) expressie was toegenomen in de gescheurde plaques, terwijl $\mathrm{PGE}_{2}$ synthase (mPGES) expressie niet verhoogd was. Dit is interessant, aangezien $\mathrm{COX}-2$ het substraat levert voor $\mathrm{PGE}_{2}$ productie en deze twee enzymen vaak tegelijkertijd actief zijn. Waarschijnlijk spelen andere prostaglandinesynthases een belangrijke rol in gescheurde plaques en kunnen deze bijdragen aan het scheuren van de plaque. De expressieniveau's van 5-lipoxygenase (5-LO) waren toegenomen in zowel de gevorderde lesies als ook in de gescheurde lesies. Deze bevinding bevestigt de relatie tussen de ernst van de atherosclerotische plaque en de concentratie 5-LO.

De resultaten in dit proefschrift laten zien dat fosfolipasen kunnen bijdragen aan de groei van atherosclerotische lesies, maar eveneens de ernst van deze lesies kunnen verminderen door stabilisatie en het remmen van de ontsteking. Daarnaast laten onze resultaten zien dat de rol van fosfolipasen in het lichaam niet los kunnen worden gezien van de eicosanoiid routes. 
. 


\section{Dankwoord Acknowledgements}


Promoveren doe je niet alleen. Daarom wil ik alle collega's, kennissen, vrienden en familie die me de afgelopen jaren gesteund hebben bedanken. De moeilijkheid van een dankwoord schrijven is niemand te vergeten. Onvermijdelijk heb ik dat toch gedaan en daarom bedankt aan allen die ik vergeten ben!

Marten, mijn promotor, graag wil ik je bedanken voor het vertrouwen dat je in mij hebt gehad. Misschien hebben we elkaar niet altijd even goed begrepen, maar dat ligt achter ons. De afgelopen periode heb ik steeds het gevoel gehad dat je achter mij stond. Dat heeft mij veel geholpen en mij de moed gegeven mijn promotie te voltooien. Dank je Marten!

Beste Menno, je wist altijd het beste uit mijn resultaten te halen. Iedere keer als ik dacht dat er niets wit leek te komen, zag jij er toch nog iets in dat als basis kon dienen voor nieuwe experimenten. Je enthousiasme en optimisme heeft mij uiteindelijk veel geholpen. Ook waardeer ik dat ik altijd je kamer kon binnenlopen, ook als het je niet uitkwam. Dank je Menno dat je mijn co-promotor was!

Er is de afgelopen jaren veel veranderd bij Moleculaire Genetica. Toen ik eind 2000 als AlO begon waren we maar met handvol mensen. We konden een lab gebruiken bij Moleculaire Celbiologie en we hadden een paar zitkamers aan de de andere kant van de gang. Bij 'even naar het lab lopen' lag de nadruk dan ook op het lopen. $\mathrm{Nu}$ is de groep aanzienlijk groter. Samen met mijn mede-sardientjes heb ik met plezier de AIO kamer gevuld. Graag wil ik hen persoonlijk bedanken.

Daphna, rustig, vriendelijk en hulpvaardig, kortom ik heb je ervaren als een fijne collega.

Beste Iris, de tijd dat we samen op een kamer zatten is al weer jaren geleden. Het was vast wennen om met een slakkenman opgescheept te zitten. Bloemen op jou ijsdoos en een slak op de mijne, zo wisten van wat van wie was. Dank je voor die fijne tijd.

Kristiaan, jij als echte Belg op ons lab. Je hebt nu versterking van Pieter gekregen, misschien dat Patrick daar zijn pijlen op gaat richten, alhoewel... Ik ga je hier niet de zatte vriend noemen, aangezien ik je zo nog niet heb meegemaakt, maar toch bedankt ons ermee bekend te maken.

Mathijs, we wisten elkaars rommel goed in evenwicht te houden. Zo ook op de labtafel. Soms maakte ik me ongerust als er weer eens een ongedefinieerde vloeistof de labtafelgrens overschreed, maar dat zijn nu zorgen voor Pieter. Af en toe begon je te lachen achter je computer, dan wisten we dat je weer een goede cartoon op je scherm had staan. Het was fijn je als collega te mogen hebben, en wie weet kom ik je nog wel eens in een bos tegen, met een hele resem scoutjes in je kielzog.

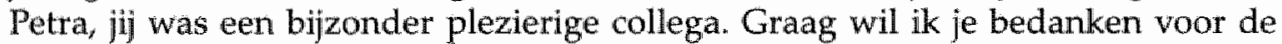
goede gesprekken die ik met je heb gehad, je vrolijkheid en natuurlijk ook voor mij goed op de hoogte te houden van het wel en wee van ex-studiegenootjes.

Pieter, er is te weinig tijd geweest om je goed te leren kennen, maar ik heb er alle vertrouwen dat je de Belgen eer aan zult doen. Maak je geen zorgen, dat kan ook zonder slakken, GSM's in de oven en experimenteren met droogijs.

Sander, jij mag niet ontbreken in dit dankwoord. Er hangen hier nog steeds satirische krantenknipsels op de deur, waarbij ik meteen ook aan je lach moet 
denken. Misschien een variant op Andy Warholds techniek: "I leave little notes, so they'll remember me"? In ieder geval bedankt voor alles.

En natuurlijk ook Yana, bedankt. Mijn Russisch is nog steeds niet voldoende om er ook maar iets van te verstaan. Gelukkig ben je ook het Engels en het Nederlands machtig, waardoor een goed gesprek bij tijd en stond toch mogelijk was.

Naast mijn kamergenoten wil ik ook graag de volgende mensen bedanken voor hun steun en gezelligheid.

Danielle, je verhaal over katten die de restjes eieren opaten na het slachten, ik moet er nog om lachen. Je directe en open stijl hebben me meermaals aangenaam verrast!

Frank, je hebt me altijd opgewekt gegroet als we elkaar tegenkwamen. Kleine boompjes en Ajax, daar associeer ik je mee. Ik vermoed dat de eerste je minder in de steek lieten dan de laatste.

Guillaume, de liefhebber van Oosters schoon, timmerman en bovenal fijne collega. Ik kon altijd bij je terecht, en heb daar ook regelmatig gebruik van gemaakt. Dank je voor je steun en luisterend oor!

Beste Inge, eerst student, daarna metgezel op het lab en nu mijn paranimf. Ik heb je vaak teleurgesteld als ik weer eens niet wist welke band het nummer op de radio aan het spelen was. Voor mij was het altijd een geruststelling wanneer je een proef voor me uitvoerde. Immuno's, facsen, het is allemaal in goede handen bij jou. Het was fijn en gezellig om met je te mogen samenwerken!

Marion, vaak hebben we samen boven muis en microscoop gehangen. Dat waren fijne momenten waar ik met plezier aan terugdenk.

Monique, je 'Limburgs' toverde meermaals een glimlach op mijn mond. Ook je meezingen met de radio was aangenaam om te horen. Je aanpak en stijl heb ik als zeer leerrijk ervaren. Proeven in je handen leggen is zoiets als geld in een kluis stoppen, je hoeft je er geen zorgen meer om te maken. Het was prettig om met je samen te werken.

Patrick, het was fijn om samen met je experimenten te doen. Je was nooit te beroerd om alles extra goed uit te leggen en altijd bereid om te helpen. Dat je af en toe wat steken onder water gaf heb ik er graag bijgenomen.

Will, bedankt voor de fijne tijd. Hopelijk hebben we wat te vieren op 16 mei 2007 ! Wilma, snel lopen over de gang met een bundel papieren onder de arm. Het is een van de eerste beelden die bij me opkomen als ik aan je denk. Graag wil ik je bedanken voor al je hulp.

Verder wil ik ook graag bedanken: Anne, Arjan, Bianca, Celine, Claudia, Debby, Elena, Ellen, Hanneke, Jan, Joost, Juliëtte, Le, Margot, Maurice, Mohammed, Nana, Olivier, Patrick J., Paula, Pierre \& Annie, Raymond, Ronald, Ronit, Rori, Roy, Sofia, Stefan, Stefanie, Susan, Ton, Vivian, Wiel, Willem, Wino, Yana en Yvonne.

Beste Jorg alias JorgOS, de vele avonden filmpjes kijken, robotten, fantaseren, plannen maken en beestjes kweken, ik hoop dat we dat nog lang kunnen doen. De afgelopen jaren zijn al die dingen een aangename afwisseling geweest op het labwerk. Hoewel, een lab thuis zouden we ook kunnen gebruiken, niet? Maarten, ik ben de tel kwijtgeraakt, maar de talrijke nerdetentjes voorzien van 
de nodige maatschappelijke discussies en geleuter waren momenten waar ik naar uitkeek. Misschien dat de lotgevallen van Monster, triops en Pic er af en toe te veel aan waren. Ik wil je graag bedanken voor de steun ik ik wan je heb gekregen.

Beste Peter, we kennen elkaar al lang en ik ben blij je nog met grote regelmaat te zlen. Het is dan ook een eer voor mij dat je toegestemd hebt mijn paranimf te worden. De vrijdagavonden in Diepenbeek met Daniela, Alexander en Amélie zijn altijd fijne momenten geweest. Ik hoop dat onze vriendschap nog lang mag duren!

Veerle alias Veke, er is aardig wat veranderd in jou en mijn leven, maar gelukkig heeft dit alles ons dichter bij elkaar gebracht. Je woont en werkt nu vlakbij en dat maakt het gemakkelijk om even langs te komen, iets waar ik de komende jaren ook nog graag gebruik van wil maken. Dank je Veerle en ook jij Koen voor alle steun! Klaas, broertje of is het broer? Een huis, nieuwe baan, een leuke vriendin die weldra je vrouw zal zijn, er is voor jou in al die jaren het een en het ander veranderd. Het doet me altijd plezier je te kunnen spreken. Bedankt, en ook jij Els voor alle steun! Lieve Wouter en Catrien, als ouders hebben jullie mij alle mogelijkheden en prikkels geboden die ik nodig heb gehad om te geraken waar ik nu ben. Jullie steun heeft altijd veel voor me betekend. Naar Martenslinde gaan betekent nog steeds een beetje thuiskomen voor me, en dat zal ook altijd zo blijven. Bedankt voor alles wat jullie me hebben gegeven!

Jildou, mijn liefste, ik wil je graag bedanken voor alles wat je me gegeven hebt de afgelopen jaren: steun, liefde, vertrouwen en begrip. Dat alles heeft mij enorm geholpen om mijn promotieonderzoek te voltooien. Ik hoop nog lang bij je te mogen blijven! 


\section{Curriculum vitae Publications}




\section{Curriculum vitae}

Stijn Ghesquiere was born in Leiden on September 1973. He grew up in Martenslinde, a small town in Belgium. There he spends most of his time looking at everything that swam, crawled or flied at the countryside.

After completing secondary school at the St. Lambertuscollege in Bilzen in 1992, he moved to Leuven to study Chemistry. In 1993 he went to Maastricht were he started to study Biological Health Sciences at Maastricht University. Additionally he started with the study Medicine at the same university in 1995. He completing his internship at the department of Clinical Genetics in 1999 and obtained his MSc degree in both Biological Health Sciences and Medicine.

After a short intermezzo, in which worked as editor at a medical website company, he decided to apply for $\mathrm{PhD}$ at the Faculty of Medicine at Maastricht University. At the Molecular Genetic Department in the lab of Martin Hofker he conducted research on the role of phospholipases in atherosclerosis. Through the use and development of transgenic mouse models, he tried to unravel the effect of phospholipase overexpression. In addition to this in vivo work, in vitro experiments and explorative studies with human material gave additional insights in the complex mechanism behind the development of atherosclerosis. While his understanding of the phospholipases and the onset of atherosclerosis grew considerable, he feels that only a few pieces of an immense puzzle have been discovered and put in the right place.

As a member of the Cardiovascular Research Institute Maastricht (CARIM) he obtained the CARIM certificate in 2004. In early 2006, he completes his PhD thesis and expects to finish the remaining experiments by the time he defends the thesis.

Parallel to his work at the university, he studied the biology of the Ampullariidae, better known as the apple snails. This resulted in the website Applesnail.net, which consumed much of his spare time. Despite receiving an offer for a $\mathrm{PhD}$ in the field of malacology at a lab in Chicago, he decided to keep it a hobby project. 


\section{Publications}

\section{Full papers}

Ghesquiere, S.A., Gijbels, M.J., Anthonsen, M., van Gorp, P.J., van der Made, I., Johansen, B., Hofker, M.H., and de Winther, M.P. 2004. Macrophage-specific overexpression of group IIa sPL $\mathrm{A}_{2}$ results in increased atherosclerotic lesion size and enhanced collagen deposition. J Lipid Res 46:201-210.

Ghesquiere SA, Hofker MH, de Winther MP.

The role of phospholipases in lipid modification and atherosclerosis. Cardiovasc Toxicol. 2005;5(2):161-82.

\section{Submitted}

Ghesquiere, S.A., van der Made, I., Vergouwe, M.N., Greaves, D.R., Hofker, M.H., and de Winther, M.P. 2006. Secretory Phospholipase $A_{2}$ group $X$ expression mediates foam cell formation and inhibits lipopolysaccharide induced activation of murine macrophages.

\section{Oral presentations}

ZonMW Genetica Retraite (Kerkrade, 2000).

Annual Meeting of the European Lipoprotein Club (Tutzing, Germany, 2004).

Dutch Atherosclerosis Society (DAS, Ermelo, The Netherlands, 2004). 